\title{
The dynamics of innovation and firm performance: an econometric panel data analysis
}

Citation for published version (APA):

Raymond, W. (2007). The dynamics of innovation and firm performance: an econometric panel data analysis. [Doctoral Thesis, Maastricht University]. Universiteit Maastricht.

https://doi.org/10.26481/dis.20070503wr

Document status and date:

Published: 01/01/2007

DOI:

10.26481/dis.20070503wr

Document Version:

Publisher's PDF, also known as Version of record

\section{Please check the document version of this publication:}

- A submitted manuscript is the version of the article upon submission and before peer-review. There can be important differences between the submitted version and the official published version of record.

People interested in the research are advised to contact the author for the final version of the publication, or visit the DOI to the publisher's website.

- The final author version and the galley proof are versions of the publication after peer review.

- The final published version features the final layout of the paper including the volume, issue and page numbers.

Link to publication

\footnotetext{
General rights rights.

- You may freely distribute the URL identifying the publication in the public portal. please follow below link for the End User Agreement:

www.umlib.nl/taverne-license

Take down policy

If you believe that this document breaches copyright please contact us at:

repository@maastrichtuniversity.nl

providing details and we will investigate your claim.
}

Copyright and moral rights for the publications made accessible in the public portal are retained by the authors and/or other copyright owners and it is a condition of accessing publications that users recognise and abide by the legal requirements associated with these

- Users may download and print one copy of any publication from the public portal for the purpose of private study or research.

- You may not further distribute the material or use it for any profit-making activity or commercial gain

If the publication is distributed under the terms of Article $25 \mathrm{fa}$ of the Dutch Copyright Act, indicated by the "Taverne" license above, 
The Dynamics of Innovation and Firm Performance An Econometric Panel Data Analysis

\author{
Proefschrift
}

ter verkrijging van de graad van doctor

aan de Universiteit Maastricht.

op gezag van Rector Magnificus,

Prof. mr. G.P.M.F. Mols

volgens het beshluit van liet College van Decemen.

in het openbatr te verdedigen

op donderdag 3 mei 2007 om 14.00 uur

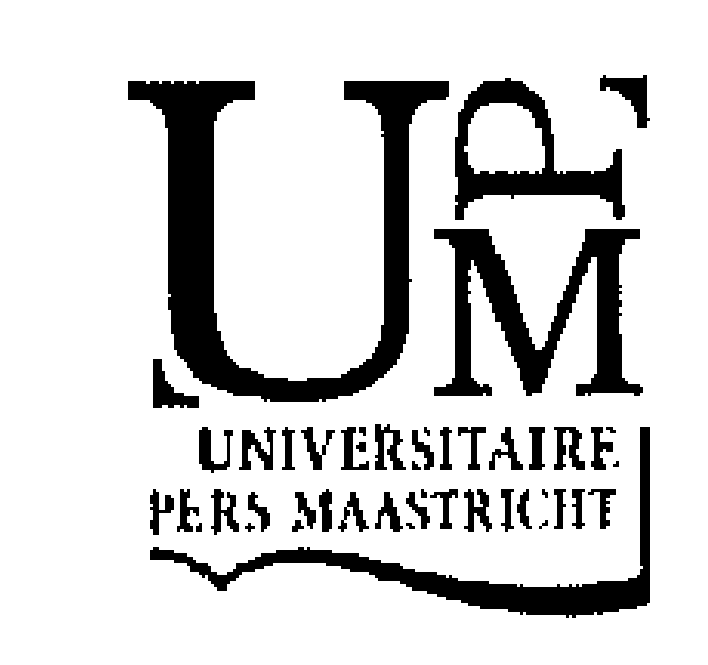


To gran Clarisse and papa Lyn 
This section is a given opportunity to thank all the people that have helped me out over the last four years in writing the thesis.

I ann deeply indebted to my supervisors Pierre Mohnen, Franz Palm and Sybrand Schim van der Loeff for their support, their advice and experience in guiding me through this research. I rcally enjoy working with them, as they are a great source of inspiration to my rescarch. I also thank them for spending time reading, correcting and re-reading my work.

I am also grateful to the reading committee Jacques Nairesse, Martin Carree and Denis Fougere for their time and comments. The empirical part of the thesis has been carried out at the Centre for Rescarch of Econonic Microclata at Statistics Netherlands. I wish to thank Statistics Netherlands, and in particular Bert Diederen, for helping me in accessing and using the Micronoom data set. Chapters 2, 3 and 4 have benefited from helpful comments by François Laisney. I thank him for this. A groat thank-you is given to Karin van den Boom, Haycleé Hallmanus and Yolanda Paulissen for their help regarding, among other things, how to deal with the administration. I also wish to thank Alexis Habiyaremye for his help regarding the Dutch summary of the thesis.

As they say in Latin, mens sana in copore sanum, achieving the thesis would not have been possible without my football club DBSV Red Socks; a special thanks to coach Jo Rousch and his wife Yvonne, and all the teammates. I also thank the old MERIT and the new UNUMERIT guys for their Friday cvening hangout and their Saturday football game.

Finally, I am indebted to my family and friends for thcir enduring support and encouragement, particularly Michel and Denise Blaess who have played a great role in the achicvement 
of the thesis. The use of words is just not enough to thank my wife Virginie, I will just say: "I LOVE YOU".

Wladimir Raymond

Maastricht, March 2007 
1 Introduction 1

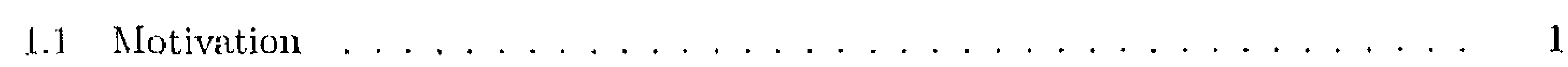

1.2 Literature . . . . . . . . . . . . . . . . . . . . 3

1.2.1 Theoretical explanations of the dynamies of innovation. . . . . . . 4

1.2.2 CIS-based empirical studies of innovation . . . . . . . . . . . 4

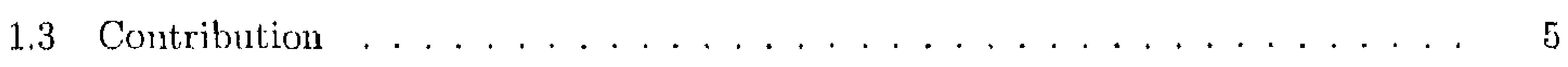

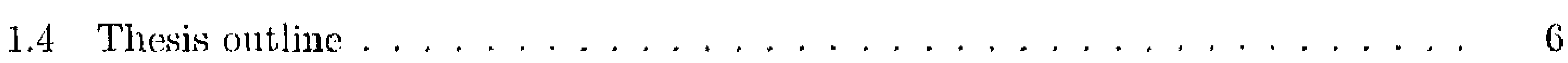

2 A classification of Dutch manufacturing based on a model of innovation 9

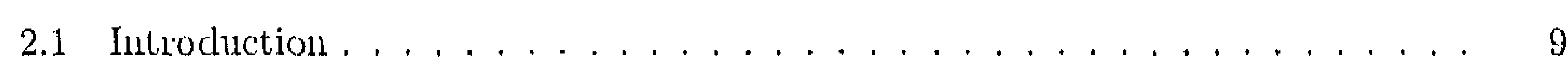

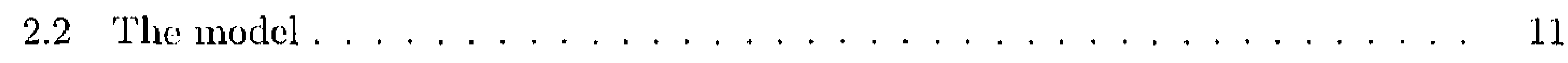

2.3 Data . . . . . . . . . . . . . . . . . . . . 14

2.4 A model-based industry classification . . . . . . . . . . . . . . . 17

2.5 Parameter estimates and imovation policy implications . . . . . . . . 20

2.5 .1 The selection equation . . . . . . . . . . . . . . . . 21

2.5 .2 The intensity equation . . . . . . . . . . . . . . 24

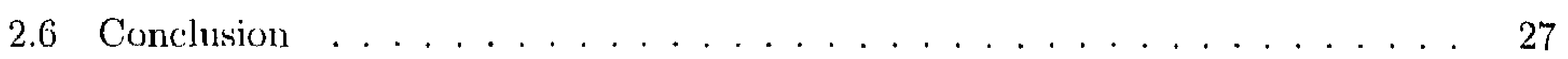

Appendix 2.A The likelihood function of the two-limit tobit model with sample

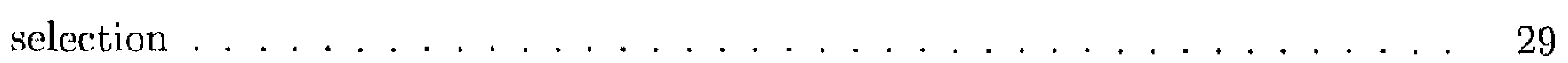

Appendix 2.B The distribution of the share of innovative sales . . . . . . . . . 31 
3 The behavior of the maximum likelihood estimator of dynamic panel data sample selection models

3.1 Introduction . . . . . . . . . . . . . . . . 33

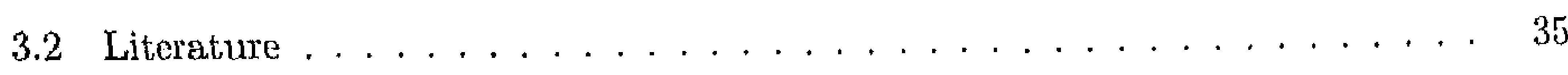

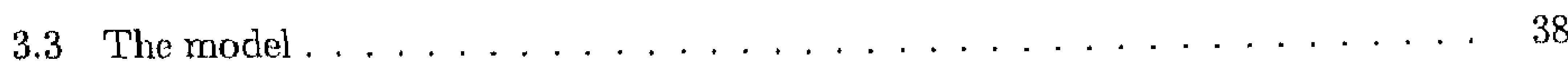

3.4 Maximum likelihood estimation . . . . . . . . . . . . . . . . 39

3.5 Monte Carlo study . . . . . . . . . . . . . . . . . . . . 44

3.5.1 The MLE behavior when the model is correctly specified . . . . . . . 45

3.5.2 The MLE behavior when the model is incorrectly specified . . . . 48

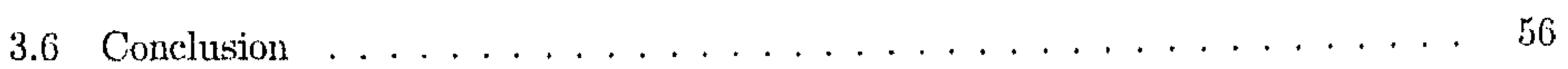

Appendix 3.A "Two-step" Gauss-Hermite quadrature . . . . . . . . . . . 58

Appendix 3.B Panel data models encompassed in the dynamic type 2 and type 3

tobit models . . . . . . . . . . . . . . . . . . . 6 61

4 Persistence of innovation in Dutch manufacturing: Is it spurious? 63

4.1 Introduction . . . . . . . . . . . . . . . . . . . . 63

4.2 Literature . . . . . . . . . . . . . . . . . . . 65

4.2 .1 The persistence of innovation . . . . . . . . . . 66 66

4.2.2 The dynamics of innovation output and firm performance . . . . . 67

4.3 Econometric model . . . . . . . . . . . . . . . . . . . 67

4.4 Maximum likelihood estimation . . . . . . . . . . . . . . . . . . . 70

4.5 Data . . . . . . . . . . . . . . . . . . . . 71

4.6 Results. . . . . . . . . . . . . . . . . . 73

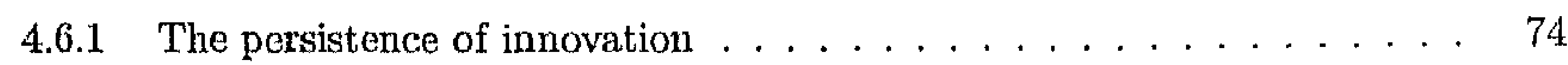

4.6 .2 The dynamics of innovation output . . . . . . . . . . . 76

4.6 .3 Robustness analysis . . . . . . . . . . . . . . . . . . 77

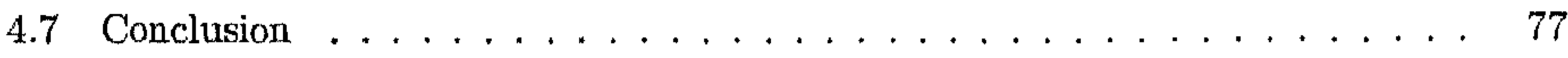

Appendix 4.A The results of the robustness analysis . . . . . . . . . . . 79

4.A.1 Dynamic probit: The persistence of innovation . . . . . . . . . 79

4.A.2 Dymamic linear regression: The dynamics of innovation output . . . 80

4.A.3 The persistence of engaging in $R \& D$ and the dynamics of $R \& D$ invest-

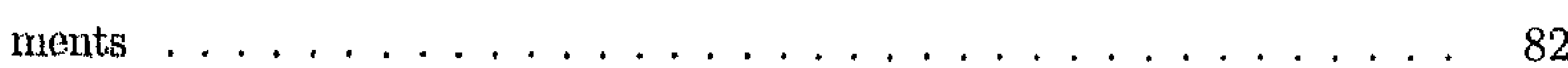

5 Modeling the initial conditions in dynamic panel data sample selection models 
5.1 Introduction . . . . . . . . . . . ......... 85

5.2 Modeling the initial conditions and estimation . . . . . . . . . . . . . 87

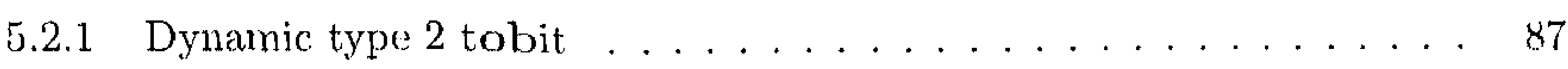

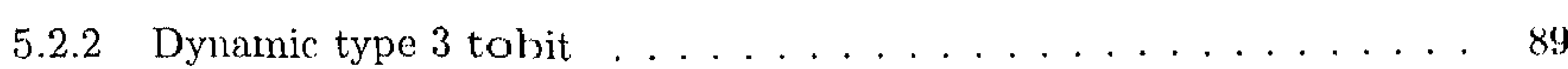

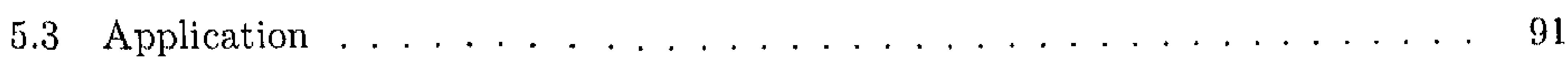

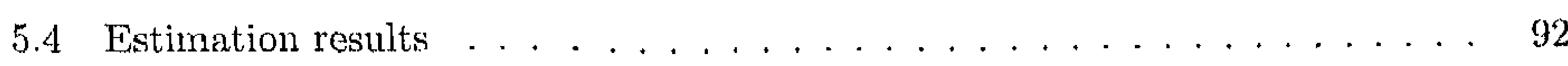

5.4.1 The sensitivity of the persistence of innovation to the treatment of the initial conditions . . . . . . . . . . . . . . . . 92

5.4 .2 The dynamics of incremental and radical innovations . . . . . . . . 93

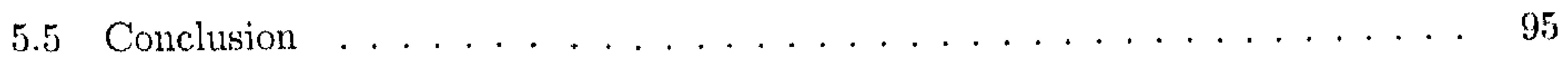

6 Joint modeling of the dynamics of innovation activities, R\&D investments $\begin{array}{ll}\text { and innovative sales } & \mathbf{9 7}\end{array}$

6.1 Introduction . . . . . . . . . . . . . . . . 97

6.2 A three-equation nonlincar dynamic model of innovation . . . . . . . . . 99

6.3 Maximum likclihood estimation . . . . . . . . . . . . . . 100

6.4 Data . . . . . . . . . . . . . . . . . . 103

6.4.1 The cross-sectional model specification . . . . . . . . . . 103

6.4 .2 The panel data model specification . . . . . . . . . . 105

6.5 Estimation results . . . . . . . . . . . . . . . . 107

6.6 Conclusion ............................... 115

Appendix 6.A The random-effects likelihood function of the three-equation tobit-

type model . . . . . . . . . . . . . . . . . . . 117

6.A.1 The likelihood function conditional on the individual effects . . . . 117

6.A.2 "Three-step" Gauss-Hermite quadrature . . . . . . . . . . . . 119

Appendix 6.B The dynamics of R\&D investments of innovative firms . . . . . 122

(1)

7.1 Summary ......................... 123

7.2 Limitations and further research $\ldots \ldots \ldots \ldots \ldots \ldots \ldots$

\section{Bibliography}

Author index

Samenvatting

Curriculum vitae 
2.1 Likelihood ratio test results for the two-limit tobit model urith sample selection: CIS 2, CIS 2.5, CIS 3 The Netherlands . . . . . . . . . . . . . . . 18

2.2 Descriptive statistics for the 3 categories, means and standard deviations in parentheses for continuous variables: CIS 2 CIS 2.5 CIS 3 The Netherlands 19

2.3 Maximum likelihood estimation results: CIS \& The Netherlands . . . . . 21

2.4 Maximum likelihood estimation results: CIS 2.5 The Netherlands . . . . . . 22

2.5 Maximum likelihood estimation results: CIS 3 The Netherlands . . . . . . . 23

2.6 Empirical findings from studies on the determinants of innovation in manufacturing using the Community Innovation Survey . . . . . . . . . 25

3.1 Studies on sample selection models with panel data $\ldots \ldots \ldots$. . . . . . 37

3.2 ML estimates based on 200 replications and 2 -point Gauss-Hermite quadrature: Data generating process . . . . . . . . . . . . . . . . 47

3.3 ML estimates based on 200 replications and 2-point Gauss-Hermite quadrature: No individual effects . . . . . . . . . . . . . . . . . . . . . . . . . 49

3.4 ML estimates based on 200 replications and 2-point Gauss-Hermite quadrature: Exogenous initial conditions . . . . . . . . . . . . . . . . 51

$3.5 M L$ estimates based on 200 replications and 2-point Gauss-Hermite quadrature: No selection bias correction . . . . . . . . . . . . . . . . . . . 52

3.6 ML eslimates based on 200 replications and 2-point Gauss-Hermite quadrature: Static model estimated under a dynamic data generating process . . . . . . . . 53 
3.7 ML estimates based on 200 replications and 2-point Gauss-Hermite quadrature: Dynamic model estimated under a static data generating process . . . . . . 55

3.8 Panel data models encompassed in the dynamic type 2 and type 3 tobit models 61

4.1 Empirical studies on the persistence of innovation ............ 68

4.2 Descriptive statistics . . . . . . . . . . . . . . . . 72

4.3 Transition probability: Persislence in innovation and innovation intensity . . 73

4.4 Dynamic type 2 tobit estimates with 5-point Gauss-Hermite quadrature: Inno-

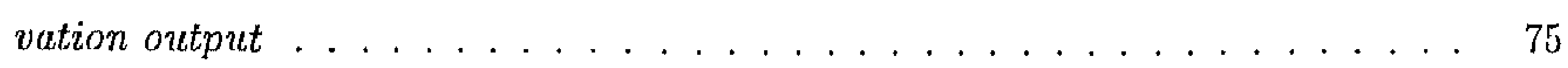

4.5 Dynamic probit estimates: The persistence of innovation . . . . . . . . 79

4.6 Dynamic linear regression estimates: The dynamics of innovation output . . 82

4.7 Dynamic type 2 tobit estimates with 5-point Gauss-Hermite quadrature: RBSD investments ........................ 83

5.1 Dynamic type 2 tobit estimates with 5-point Gauss-Hermite quadrature and the Heckman approach of handling the initial conditions: Innovation output . . . 93

5.2 Dynamic type 3 tobit estimates with 5-point Gauss-Hermite quadrature: Incremental and radical innovation output . . . . . . . . . . . . . . 94

6.1 Descriptive statistics per category of industries and CIS: Means and standard deviations in parentheses for continuous variables . . . . . . . . . . . . . 104

6.2 Descriptive statistics for the balanced panel . . . . . . . . . . . . . . 106

6.3 ML estimation results of the cross-sectional model: CIS \& The Netherlands . 107

6.4 ML estimation results of the cross-sectional model: CIS 2.5 The Netherlands 108

6.5 ML estimation results of the cross-sectional model: CIS 3 The Netherlands , 109

$6.6 M L$ estimation results of the dynamic panel data model . . . . . . . . . . 110

6.7 Empirical findings from studies on the interrelationship between innovation activities, innovation input and innovation output . . . . . . . . . . 114

6.8 ML estimation results of the dynamic linear regression model of $R \& D$ investments of innovative firms . . . . . . . . . . . . . . . . . 122 
List of Figures

2.1 The distribulion of the share of innovative sales of "normal"product innovators

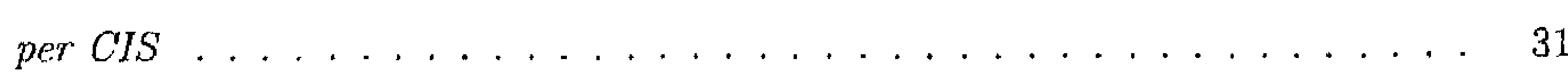

2.2 The distribution of the logit transform of the share of innovative sales of "normal"product innovators per CIS . . . . . . . . . . . . . . . 31 
CHAPTER 1

Introduction

\subsection{Motivation}

Technological innovation is recognized as being a key factor as both a creative force in the growth of enterprises and as a destructive force making those same enterprises prone to competition (Utterback, 1994). In the knowledge-based economy, innovation is also shown to play a positive role in firms' survival (Cefis and Marsili, 2005). New products and new processes keep being introduced into the market and force firms to adjust if they want to stay in the game. In order to stimulate economic growth, employment and envirommental sustainability, govermments are increasingly concerned about promoting firms' innovation but do not always have the right recipe to achieve their goal. It is hence very important to understand what makes firms innovative, how long it takes for innovation incentives to work out, how long it takes for R\&D, trial production and first product launchings to become successful, and finally how long it takes between first product appearances and improvements of firm economic performance. Among the difficulties encountered by policy-makers in the past is the measurement of innovation. Early studies frequently use R\&D activities (e.g. Hall and Hayashi, 1989) usually linked to productivity (e.g. Griliches and Mairesse, 1984; Mairesse and Sassenou, 1991), or patents (see Table 4.1) or both (e.g. Pakes and Griliches, 1984; Hall et al., 1986). In the 1980s scholars and statisticians in innovation felt growingly dissatisfied with the mere existence of $R \& D$ surveys or patent data to analyze innovation. Indeed, the 
use of the sole R\&D or patent data omits important aspects of the imovation process in that $R \& D$ is only one of various innovation inputs and some types of technology are not patentable. ${ }^{1}$ Hence, under the auspices of OECD, the Oslo manual was written to guide a new kind of survey, the innovation survey also known in Europe as the Community Innovation Survey (CIS). In this survey, respondents arc asked to give information about the input, the output and the behavioral and organizational dimensions of their innovations. On the input side, data on $R \& D$ expenditures and on other innovation expcnditures besides $R \& D$ (such as product design, trial production, training of employees, and market analysis) are collected. On the output side, various market-based innovation indicators (unlike patents) are available, namely the declaration of whether an enterprise has introduced a new product or process, the percentage of sales due to incrementally or significantly improved or new products, and the share in sales of imnovative products new to the entcrprise or new to the industry. On the other dimensions of innovation, we have binary data on whether $R \& D$ is done continuously and in cooperation with others, and categorical data on the sources of knowledge, the reasons for innovating, the perceived obstacles to innovation, and the perceived strength of various appropriability mechanisms.

Several waves of the CIS have been launched since the first edition of the Oslo manual in 1992 making the use of panel data possible when analyzing the innovation process. The purpose of this thesis is to study the dynamics of innovation in Dutch manufacturing using firm data from three waves of the CIS pertaining to the periods 1994-1996, 1996-1998, and 1998-2000. ${ }^{2}$ More specifically, the thesis seeks to answer questions related to the dynamics of imnovation hitherto rarely examined when using the CIS such as the persistence of immovation considered on both the input and the output side, the effect of past $R \& D$ investments on current $R \& D$ investments, the effect of past share in total sales of innovative sales on current share in total sales of innovative sales, and the role of firm hetcrogeneity in the innovation process. Hence, the hypotheses of "success breeds success" (Mansfield, 1968), "dynamic economies of scales" and existence of sunk costs in firms' innovation activities can be tested. The thesis also seeks to develop empirical models that can be applied to other types of

\footnotetext{
${ }^{1}$ The limitations of R\&D and patents are stressed in cletail in the studies by Kleinknechl ot al. (2002) and Griliches (1090) respectively.

${ }^{2}$ In The Netherlands, an additional survey pertaining to the period $1986-1988$ was conducicel prior to the first wave of the CIS (1990-1992). These two surveys could not be included in the thesis as they were conducted in a different mames. Furthermore, CIS 3.5 and CIS 4 pertaining to the periods 2000$)-2002$ and $2002-2004$ were not available at the time the research was being carried out.
} 
economic panel data that have similar characteristics to the CIS data, hence contributing to the growing econometric literature on (dynamic) panel data.

\subsection{Literature}

As stated earlier, it is of great concern for policy-makers to understand the driving forces behind imnovation and its socioeconomic consequences, hence the need for a model of the innovation process. A great deal of models that describe the imnovation process exist in the literature. They range from the "naive" linear models to more realistic and more complex nonlinear models. The former also known as pipeline or stage models describe the imnovation process as a series of stages assumed isolated from one another (Utterback, 1971), and the latter identify interrelationships between the various stages of the process (Kline and Rosenberg, 1986). Because of the complexity of the innovation process, no universal theoretical imnovation model exists in the literature as it should include a myriad of factors that enter the process (Forrest, 1991). However, any model that describes the innovation process should account for the following critical factors identified by Forrest. Firstly, the model should be nonlinear in that the various stages of the immovation process are interrelated, and dynamic in that the process evolves over time. For instance, Utterback and Abernathy (1975) develop a nonlinear dynamic model of process and product inuovation where the nature of the innovation process changes over time from new product development to process optimization and cost reduction. Secondly, the model should include both inputs and ontputs of innovation so as to determine the effectiveness of the immovation process. Thirdly, the model should be of use with both product and process innovations, and must account for the cffects of demand pull, technology push and "strategic alliances" (using Forrest's terms) on the inmovation process." Finally, firm heterogeneity should be accounted for due the dynamic feature of the imnovation process. Indeed, firms have different innovative behavior because of different experience acquired from past innovative behavior. We are able to test empirically the relevance of those factors to the innovation process by including, in the specification of the models considered in the thesis, the above-mentioned variables which are available in the CIS.

\footnotetext{
3 "Strategic alliances" include among others RSD cooperation with universilies and research institutes. See Forrest (1991) for more delails.
} 


\subsubsection{Theoretical explanations of the dynamics of innovation}

Since the main issue of the thesis is the dynamics of innovation, it is worthwhile to stress its theoretical explanations.

On the input side, the persistence of $R \& D$ activities is usually explained by the hypothesis of sunk costs. For instance, Scherer (1967) argues that R\&D is time dependent in that it is a heuristic process that involves significant uncertainties about feasible solutions. The knowledge accumulation theory (see for instance Hall and Hayashi, 1989; Klette, 1996) predicts that there is complementarity between current $R \& D$ effort and already acquired knowledge, hence R\&D is a cumulative dynamic process. On the output side, Flaig and Stadler (1994) develop a stochastic dynamic optimization model where firms maximize their present value of profits over an infinite time horizon by choosing an optimal path of innovation activity. They allow for dynamic: spillover effects and past innovation success, which reflects Mansfield's "success breeds success", i.e. past inuovation success increases technological opportunities making future innovation success more likely. Finally, Stein (1997) develops a theoretical competition model that explains the dynamics of innovation by the learning-by-doing hypothesis.

\subsubsection{CIS-based empirical studies of innovation}

Due to the richness of the CIS in terms of innovation indicators, CIS-based empirical studies give a broader description of innovation than studies based on the sole traditional R\&D and patent data. For instance, Brouwer and Kleinknecht (1996) model the decision to engage in $R \& D$ and the impact on the amount of R\&D investments, and the effect of R\&D investments on the probability to innovate and the share of innovative sales. ${ }^{4}$ Crépon et al. (1998, CDM) study in a unified framework the decision to engage in R\&D activities and the impact on the amount of $R \& D$ investments, the effect of $R \& D$ investments on the share of imnovative sales, and the effect of the share of innovative sales on productivity. Janz and Peters (2002) and Lööf and Heshmati (2002a) study variants of the CDM model and consider both the share in sales of innovative products new to the enterprise (incremental innovative sales) and new to the market (radical innovative sales). Janz and Peters find that the larger the firm the larger the probability to introduce incremental innovations while firm size does not increase the probability to introduce radical innovations. Lööf and Heshmati's results suggest that innovation investments play a role only in incremental innovations which have a larger effect

\footnotetext{
'See also Mairesse and Molnu'n (2(4)1).
} 
on firm productivity than radical innovations. Klomp and van Leeuwen (2001) depart from the CDM model using Kline and Rosenberg's (1986) chain-link model as the base framework and study the input and output stages of the innovation process linked with firm sales and employment growth. Unlike the CDM model, they allow for feedback effects of sales growth on innovation input and output.

In spite of their richmess in explaining the innovation process, those studies fail to account for two important features of the process identified by Forrest, namely dynamics and firm heterogeneity. ${ }^{5}$ With the exception of Mairesse and Mohnen (2001), all the studies listed in Tables 2.6 and 6.7 assume similar innovative behavior across industries in that the parameters of the model are equal across industries. Furthermore, with the exception of van Leeuwen (2002) who considers a dynamic model of innovation, all those studies are static and fail to answer questions such as the persistence of innovation, ${ }^{6}$ the dynamics of R\&D investments and innovation output. The thesis makes a step in that direction.

\subsection{Contribution}

As stated earlier, the thesis sceks to study the dynamics of immovation, hitherto rarely examined when using the CIS, using dynamic panel data econometric techniques, hence contributing to both the empirical literature on innovation and the econometric literature on (dynamic) panel data.

The thesis contributes to the empirical literature on innovation in a number of ways. Firstly, it analyzes the persistence of innovation using other output measures than patents (see Table 4.1). Secondly, unlike the empirical studies listed in Tables 2.6 and 6.7, three waves of the CIS, pertaining to the Dutch manufacturing sector, are used for the first time to link the persistence of immovation (qualitative) to the dynamics of firms' $R \& D$ investments and technological performance (quantitative). The incidence and the intensity of imnovation are jointly estimated allowing for a correlation between the processes governing the introduction of new or significantly improved products and/or processes, and the generation of innovative sales (cf. Chapter 4), or the processes governing the engagement in innovation activitics, R\&D investments, and the gencration of innovative sales (cf. Chapter 6). Finally, the thesis

\footnotetext{
SSoe Tables 2.6 and 6.7 .

${ }^{6}$ Two other CIS-based empirical studies that investigate the persistence of innovation are Duguet and Monjon (2002) and Peters (2005). However, only the incidence of imnovalion is explained in those studies (See Cliapter 4).
} 
always accounts for observed and unobserved firm heterogeneity in the imnovation process.

As for the contribution to the econometric literature, the thesis provides a practical method to the problem of the maximum likelihood estimation of the parameters of panel data sample selection models in which random individual effects (possibly correlated with the explanatory variables) and the lagged dependent variable are included in the selection equation as woll as in the regression equation. The selection rule may be either of the binary or of the consoring type, the most two considered in the literature (see Table 3.1). To handle the initial conditions problem, Wooldridge's (2005) (cf. Chapter 3) and Heckman's (1981b) (cf. Chapter 5) solutions to this problem in single equation dynamic nonlinear panel data models are extended to models with two equations. "Two-step" Gauss-Hermite quadrature is used to evaluate the resulting double integral. In short, the thesis proposes a simple method to implement the maximum likelihood estimator of dynamic panel data extensions of the type 2 and type 3 tobit models, according to Amemiya's (1984) terminology. Furthermore, the thesis reports on a Monte Carlo investigation into the behavior in finite samples of the proposed method that is extended to dynamic panel data sample selection models with two regression equations and a sclection equation (cf. Chapter 6). In this latter case, "three-stcp" Gauss-Hermite quadrature is used to cvaluate the resulting triple integral.

\subsection{Thesis outline}

Chapter 2 studies the degree of homogeneity of innovative behavior in order to determine empirically an industry categorization of Dutch manufacturing that can be used for policy purposes. For each of the eleven Dutch manufacturing industries defined at two-digit level, we estimate a two-linit tobit model with sample selection that explains the decision by enterprises to imnovate and, for innovators, the intensity of innovation as measured by the share of innovative sales. By estimating the model separately for each industry, possible differences in innovative behavior across industries are accounted for. Furthermore, within industries, we account for unobserved heterogeneity by treating "differently" non-innovators, process-only innovators, product innovators and "large" product innovators. The hypothesis of homogeneity of innovative behavior across industries is tested using a likelihood ratio (LR.) test that reveals three types of categories of industries in Dutch manufacturing, namely high-tech, low-tech and the wood industry that scems to be different from the remaining 
industries.

Chapter 3 investigates by means of Monte Carlo simulation the behavior of the maximum likelihood estimator of dynanic panel data extensions of the type 2 and type 3 tobit models with unobserved individual effects (possibly correlated with the explanatory variables) in each equation. The individual effects are assumed to be random following a normal distribution, and are "integrated out" from the joint density function for the data and individual cffects. The initial conditions problem is solved using Wooldridge's (2005) "simple solutions" that consist in writing the individual effects, in each period, as linear functions of the strictly exogenous explanatory variables and the initial conditions. The resulting likelihood functions involve a two-dimensional indefinite integral that is evaluated using two successive GaussHermite approximations. In the Monte Carlo experiments, the "two-step" Gauss-Hermite quadrature works well for a number of integration points as small as two. Hence, the maximum likelihood estimation of the parametors in a random-effects dynarric sample selection model is feasible and could conceivably be incorporated as a command in a general use software package such as Stata.

In Chaptcr 4, we apply the dynamic type 2 tobit studied in Chapter 3 to a model of innovation that investigates the persistence of innovation and the dynamics of the sharc of innovative sales in Dutch manufacturing. We find that the persistence of innovation is spurious in the sense that, when unobserved individual effects and the initial conditions are properly handled, the persistence of innovation vanishes. More specifically, being successful in past innovation activities does not increase the probability of being successful in current innovation activities. However, past share of innovative sales does condition, albeit to a small extent, current share of immovative sales.

Chapter 5 considers an alternative way of handling the initial conditions problem, which consists in specifying a model for the initial conditions given the individual effects and the strictly exogenous explanatory variables. This model is often assumed to be similar to the underlying model of the remaining process (Heckman, 1981b). We then apply the Heckman approach to estimating the dymamic type 2 tobit model specified as in Chapter 4 , hence studying the sensitivity of the persistence of innovation to the treatment of the initial conditions. We find that the lack of persistence is robust to the (proper) treatment of the initial conditions. We also investigate jointly the dynamics of incremental and radical innovations using a dynamic type 3 tobit using both the Heckman and the Wooldridge treatment of the 
initial conditions. We find that the two approaches yield sinilar results in terms of the coefficients of the strictly exogenous variables whilc some differences arise in the coefficients of the lagged dependent variables and the individual effects.

In Chapter 6 we extend the model of Chapter 4 by adding a third equation of R\&D investments. More specifically, we jointly investigate the dyuamics of the decision to engage in innovation activities, that of $R \& D$ intensity and the share of innovative sales. The model is a dynamic panel data version of the first- and second-stage of the CDM model with individual effects in each equation. We use the same estimation method as in Chapter 3 extended to a sample selection model with two regression equations and a selection equation. "Three-step" Gauss-Hermite quadrature is now required to evaluatc the likelihood function. The results suggest the presence of dynamics in the innovation process. Furthermore, the decision to engage in innovation activities, R\&D intensity and the share of innovative sales are correlated at least through the individual effects, and unobserved firm heterogeneity plays an important role in the innovation process.

Finally, Chapter 7 summarizes the main findings of the thesis and stresses the limitations and recommendations for future research. 


\subsection{Introduction}

In order to encourage $\mathrm{R} \& \mathrm{D}$ or innovation, governments are interested in supporting firms that are expected to bchave in a manner conducive to its policy objectives. It is necessary, therefore, to be able to identify categories of such firms towards which the support may be targeted, lest individual firms from a multitude of heterogeneous firms have to be selected. From an efficiency standpoint, those categories should be homogeneous in the sense that, within a category, the proportion of target firms should be as large as possible. The objective of this chapter is to study the degree of homogeneity of innovative behavior in order to determine empirically an industry categorization of Dutch manufacturing that can be used for policy purposes.

The most widely used categorization of industries is the Organization for Economic Cooperation and Development (OECD, 1999) industry classification. There are actually two OECD industry classifications. The first one uses only the direct $R \& D$ intensity expressed as the ratio of R\&D expenditures over either gross output or value-added and distinguishes three categories of industries, namely the high-technology, the medium-technology, and the low-technology industries. ${ }^{1}$ The second indicator uses the overall R\&D intensity, which is de-

${ }^{1}$ Hatzichronoglon (1997) points out that using value-added an the one hand and gross ontput on the other 
fined as the ratio of $\mathrm{R} \& \mathrm{D}$ expenditures plus technology embodied in intermediate and capital goods over gross output. The revised classification, which is currently used, consists of four categories of industries: the high-technology, the medium-high-technology, the medium-lowtechmology and the low-technology industries. ${ }^{2}$ The important point, however, is that the OECD taxonomy is based on a single innovation input indicator, namely the R\&D intensity. This is too narrow. There are many other innovation policy instruments besides R\&D support. For instance, a few of the wide-ranging policy reforms suggested by the OECD (1998) are "improving the efficiency and the leverage of industrial R\&D support", or "strengthening technology diffusion mechanisms by encouraging more competition in product markets".

At least two other well-known classification schemes exist in the literature. One is the famous Pavitt (1984) taxonomy of innovating firms based on similarities and differences among sectors with respect to the sources, nature and impact of innovations, and the characteristics of innovating firms. Pavitt's classification consists of three categories, namely the "supplier-dominated", the "production intensive" and the "science-based" categories. The middle category consists of two sub-categorics: "scale intensive" and "specialized-suppliers". The other approach followed by Hollenstein (1996) and Baldwin and Gellatly (2000) is based on a principal components analysis accounting for a number of innovation indicators, such as worker skills and technology use, that are commonly used to classify industries. Their framework constitutes a multidimensional approach to industry classification. They state that existing industry taxonomies have a unidimensional characteristic and are therefore too narrow and incomplete.

In line with the approaches in the previous paragraph we also take a multidimensional view towards industry categorization. The main contribution of our study is to test an industry categorization based on an econometric model that explains innovation behavior. A category is called homogeneous if the parameters of the model for each industry in that category are identical. The model describes the decision to immovate and its impact on the share of innovative sales. This type of model has been used in many other studies. It is estimated for each two-digit industry using the standard industrial classification (SBI) and for categories formed by grouping industries, and then it is tested whether industries included in a category are similar in terms of innovative behavior. Firm-level data are used stemming

lakds to different classifications.

${ }^{2}$ Industries that belong to these categories are described in details in OECD (1999). 
from three Dutch Community Innovation Surveys (CIS) pertaining to the periods 1994-96, 1996-98 and 1998-2000, merged with production survey data. A comparison of the modelbased categorization with other typologies concludes the chapter.

The chapter is organized as follows. The model and the likelihood ratio (LR) test are explained in Section 2.2. In Section 2.3 we describe the data sources, the variables constructed from the data samples, and some descriptive statistics. Empirical results for the model and the industry classification resulting from the LR test, and its policy implications are presented and discussed in Section 2.5. In Section 2.6 we summarize and conclude.

\subsection{The model}

The model we consider in this study explains the decision by Dutch manufacturing enterprises to innovate and, for imnovators, the intensity of imnovation as measured by the share of immovative sales. Modeling the determinants of imnovation strongly depends on the design of the CIS. In the CIS a technological product and process (TPP) innovator is defined as an enterprise that has implemented new or improved products, and/or new or improved processes during the period under review. We have more information about TPP innovators than about non-TPP innovators. Our model therefore consists of two equations, a selection equation that discriminates between TPP innovators and non-innovators, and a regression equation explaining the share of innovative sales for innovators. Formally, our model can be written as

$$
\begin{aligned}
& y_{1}^{*}=\beta_{1}^{\prime} \mathbf{x}_{1}+\epsilon_{1}, \\
& y_{2}^{*}=\beta_{2}^{\prime} \mathbf{x}_{2}+\epsilon_{2},
\end{aligned}
$$

where the dependent variable is defined as

$$
y_{2}=\left\{\begin{array}{l}
0 \text { if } y_{1}^{*} \leq 0 \text { (non-innovators) } \\
c_{1} \text { if } y_{1}^{*}>0 \text { and } y_{2}^{*} \leq c_{1} \text { (process-only immovators) } \\
y_{2}^{*} \text { if } y_{1}^{*}>0 \text { and } c_{1}<y_{2}^{*} \leq c_{2} \text { ("normal" product imovators) } \\
c_{2} \text { if } y_{1}^{*}>0 \text { and } y_{2}^{*}>c_{2} \text { ("large" product innovators). }
\end{array}\right.
$$


As it stands in equations (2.1), (2.2) and (2.3), our model is a combination of the two-limit tobit model and the generalized tobit model. ${ }^{3}$ More specifically, it is a two-limit tobit model with sample selection. It is different from the former in that it consists of two decisions (two latent variables), and from the latter in that it has two additional thresholds $c_{1}$ and $c_{2}$.

The latent variable $y_{1}^{*}$ captures the potential post-innovation return to imnovation for all enterprises. It is a function of explanatory variables included in the vector $\mathbf{x}_{1}$. When $y_{1}^{*}$ is sufficiently large, i.e. the expected return to innovation is high cnough, an enterprise has enough incentive to innovate, then the observed $y_{1}$ equals one, meaning that the enterprise is a TPP innovator. Moreover $\epsilon_{1}$ is the error term that captures the effects unaccounted for by the model, and $\beta_{1}$ is the vector of parameters to be estimated." The second equation pertains only to TPP innovating firms. The dependent variable is the share of innovative sales in total sales $y_{2}$. It is expressed as the ratio of sales from new or improved products over total sales. This figure is directly reported by the surveyed enterprises. As the original share of innovative sales lies within the unit interval, we take the logit transformation that may take on any real value. In addition, the logit transform makes the distribution of the share of innovative sales more symmetric than the original distribution of the share of innovative sales. ${ }^{7} \beta_{2}$ is the vector of parameters to be estimated, and $\epsilon_{2}$ is the error term capturing the effects influencing the share of innovative sales unaccounted for by the model.

\section{The thresholds $c_{1}$ and $c_{2}$}

TPP innovators comprise product-only imnovators, process-only innovators, and productand-process innovators. As there is no quantitative measure for a process innovation in the CIS, process-only innovators have a zero share of innovative sales during the period under review. Therefore, the logit transform of the share of innovative sales camnot be applied to process-only innovators. Mairesse and Mohnen (2001) choose to substitute, for the zero shares of process-only immovators, the smallest positive value of the original share of imnovative sales, namcly 0.01. Klomp and van Lecuwen (2001) use a similar approach where the smallest positive value of the share of innovative sales is 0.001 . In our model, we choose to censor the zero values for process-only immovators, by fixing a threshold $c_{1}$ to 0.001 and treat all the zero

\footnotetext{
"The two-limit tobit model is described in denils in Maddala (198:3) and Thomats (2000)). A variant. of this model is the so-called model of friction used by Rosett (1959).

"In order to simplify the notation, the enterprise and industry subscripts have been dropped.
seee Appendix 2.B.
} 
values as values that belong to the censored region. ${ }^{6}$ The difference between our approach and that of Mairesse and Mohnen (2001), and Klomp and van Leeuwen (2001) is that, for observations with share of innovative sales below the smallest obscrved positive value, the probability that the share is below this value has been used rather than the value of the density function evaluated at this value. The same holds for the category of "large" product innovators, i.e. enterprises whose sales are almost exclusively innovative sales. By fixing the threshold $c_{2}$ to 0.95 , which is the value of the largest observed share less than one, values equal to unity are censored. Again, the probability that the share is above 0.95 has been used rather than the value of the density function evaluated at a value close to 1 .

A further reason to introduce the thresholds $c_{1}$ and $c_{2}$ is that, according to the Oslo manual (OECD, 1997), process-only innovators are to be treated differently from product imovators and non-innovators. They are not to be treated as non-innovators, given that they have implemented new or improved processes. Actually, they produce unchanged products with changed methods, as opposed to non-imovators that produce unchanged products with unchanged methods. They are different from product-innovators in the sense that they have not implemented new or improved products (during the period under review), but they might do so in the future. Finally, the category of "large" product innovators, as measured by the share of innovative sales, mostly consists of firms that got established during the period stiudied by the imnovation survey. Again, according to the Oslo manual (1997), these firms are to be treated differently, as they may be different from the remaining firms in terms of innovation activities, objectives and characteristics.

\section{Estimation}

In order to estimate the model, for each industry, the error terms are assumed to follow a bivariate normal distribution with zero mean and covariance matrix $\Sigma$ with the error variance of the selection equation being normalized to one. The model is estimated by the method of maximum likelihood. Furthermore, we assume the vectors of disturbances to be independent across industries such that, the log-likelihood function for the Dutch manufacturing sector is the sum of the log-likelihood functions for each industry in this sector. The disturbance covariance matrix $\Sigma$ is allowed to be different across industries. ${ }^{7}$

\footnotetext{
${ }^{6}$ For the estimation, logit transforms of the thresholds $a_{1}$ and $c_{2}$ have been used.

${ }^{7}$ The likelihood function of the two-limit tobit model with sample selection is given in Raymond ot al. (2004), and derived in Appendix 2.A.
} 


\section{A likelihood ratio (LR) test for homogeneity among industries}

The empirical studies on the detcrminants of innovation mentioned earlicr implicitly assume that all industries in manufacturing lave the same innovative behavior (in terms of the parameters of the model) and different intercepts. The only exception is the study by Mairesse and Mohnen (2001) that allows firms in the high-R\&D industries to have a differcnt innovative behavior than firms in the low-R\&D industries. In our study, we account for possible differences in innovative behavior across industries by estimating our model for each of the eleven two-digit Dutch manufacturing industries. We shall be referring to this as the unrestricted model. Let a category, for instance, consist of $k$ industries. The mull hypothesis is that the $p$ parameters of the model, i.e. the slope parameters, the two intercepts and the two parameters of $\Sigma$, for each of the $k$ industries are equal versus the alternative that at least for one industry a parameter is different from the corresponding parameters of the $k-1$ other industries. The resulting test statistic must be compared to the critical value for a $\chi^{2}$ distribution with $(k-1) p$ degrees of freedom. In the case that we allow the two intercepts in the $k$ industries to differ, the number of degrees of freedom is $(k-1)(p-2)$.

\section{$2.3 \quad$ Data}

The clata used to implement the model are collected by the Centraal Bureau voor de Statistiek (CBS). They stem from three waves of the Dutch Community Innovation Survey, CIS 2, 2.5 and 3, merged with data from Production Survey (PS). Only enterprises in Dutch manufacturing (SBI 15-37) are included in the analysis. The population of interest consists of enterprises with at least ten omployees and positive sales at the end of the period covered by the innovation survey.

The CIS data are collected at the enterprise level. A combination of a census and a stratified random sampling is used. A census is used for the population of large enterprises, while a stratified random sampling is used for small- and medium-size enterprises. The size of an enterprise is measured by the number of employees, and the stratum variables are the economic activity and the size of an enterprise, where the economic activity is given by the Dutch standard industrial classification (SBI 1993). The cut-off point used by CBS to choose between a census and a sampling is 100 employees.

Like in the CIS, the statistical unit of analysis within the Production Survey is the enter- 
prise. A ccnsus is also used for large enterprises, and a stratified random sampling for smalland medium-size enterprises. The stratum variables and the cut-off points are the same as in the CIS. However, unlike the CIS, non-financial activities are not covered by the PS, implying that enterprises in the institutions of finance, insurance and pension funds (SBI 65-67) are not surveyed. The PS data included in this study replace the CIS equivalents and pertain to the periods 1996, 1998 and 2000. The corresponding CIS data have been removed from the CIS data base.

We now explain the construction of the variables included in this analysis.

\section{Innovation dummy}

In the innovation survey, an enterprise is asked (1) whether it has implemented at lcast one new or improved product, (2) whether it has implemented at least one new or improved process, and (3) whether it has ongoing or abandoned innovative projects during the period under review. TPP innovators are those enterprises that have responded positively to either (1) or (2) or both.

\section{Intensity of innovation}

The CIS questionnaire provides information regarding the share of innovative sales in total sales. This is the measure for the success of product innovation used in this study. A logit transformation of this measure is used for reasons mentioned earlier in the analysis. A non-TPP innovator has automatically a zero imnovation output intensity. Because there is no quantitative measure of the success of process imnovations in the innovation survey, some TPP innovators also have a zero innovation output intensity. They are called process-only innovators. ${ }^{8}$

\section{Size}

The size of an enterprisc used in this study is measured by the number of employees. This variable stems from the PS and is log-transformed.

\section{Relative size}

This variable is defined as the ratio of the sales of an enterprise over the total sales of the industry that it belongs to. A log-transformation of this ratio is used.

\footnotetext{
${ }^{\gamma}$ In fact enterprises that report to have implemented at least one new or improved product but report a zero value for the share of innovative sales in total sales are considered as non-product imovators in the analysis.
} 
Because of the way the innovation survey is designed, very few explanatory variables are available for innovators and non-innovators. Size and relative size are the only two variables that are available for all enterprises." This is the reason why, except for industry dummies, these are the only two variables that have been included in the vector $\mathbf{x}_{1}$ in equation (2.1) The vector $x_{2}$ in equation (2.2) comprises, besides industry dummies, the variables size, demand pull, technology push, subsidies, cooperation, R\&D intensity, continuous R\&D and non-R\&D performer.

\section{Demand pull}

In the CIS questionnaire, an enterprise is asked about the importance of the objectives of innovation, "open-up new markets", "extend product range" and "replace products phased out", on the basis of a 0-3 Likert scale. A dummy variable proxying demand pull equals one for an enterprise if at least one of the above objectives of innovation is given the highest mark (i.e. very important), and zero otherwise.

\section{Technology push}

Other imnovation indicators available in the CIS are the sources of imnovation. They may be internal (from the enterprise or other enterprises within the enterprise group), from the market (e.g. clients or customers), from public or private institutions (e.g. universities) or from other locations. Technology push is proxied by a dummy variable constructed from the indicators stating the importance of the sources of innovation from public or private institutions. This proxy takes on the value one if at least one of these institutions are deemed to be important or very important to an enterprise (i.e. at least one of the sources of innovation stemming from public or private institutes is given the values 2 or 3 ), and zero otherwise.

\section{Subsidies}

If an enterprise answers that it has been granted at least a subsidy during the period under review, the variable subsidies takes on the value one and zero otherwise.

\section{Innovation cooperation}

The dummy variable innovation cooperation takes on the value one if the enterprise reports that it undertook its innovative activities in cooperation of any kind and zero otherwise.

\footnotetext{
${ }^{9}$ In the innovation survey enterprises report whether they belong to a group or not. This potentially important information was, however, not available in the clatia provided by CBS.
} 


\section{R\&D intensity}

$R \& D$ intensity is the ratio of total (intramural and extramural) $R \& D$ expenditures (from the CIS) over total sales. The logarithmic transform of this variable is used when the variable takes on a positive value.

\section{Continuous R\&D}

The dummy variable continuous $R \& D$ takes on the value one if the cnterprise reports that it performed intramural R\&D continuously during the period under review and zero otherwise.

\section{Non-R\&D performer}

The dummy variable non-R\&D performer takes on the value one if the enterprise had no (intramural or extramural) R\&D expenditures during the period under review and zero otherwise. ${ }^{11}$

\subsection{A model-based industry classification}

Our industry taxonomy stems from likelihood ratio tests performed on our model. Table 2.1 reports the relevant statistics to perform the likelihood ratio test. The umrestricted model consists of eleven sub-models, where the log-likelihood is the sum of the eleven loglikelihoods of the sub-models. The restricted model assumes that the parametcrs arc identical for industries within the categories referred to as high-tech, low-tech and wood, respectively (allowing for different industry dummies), and allows differences across categories. The results of Table 2.1 show that the restricted model, i.c. the classification into thrce categories, is not rejected at the conventional $5 \%$ level of significance with a $p$-value ranging from almost $20 \%$ to almost $30 \%$. When the industry of wood is classified into either the low-tech category or the high-tech category, the restricted model is rejected with $p$-values below $1 \%$.

Hence, an analysis of the innovative behavior of the enterprises in the Dutch manufacturing sector during 1994-2000 reveals that this sector can be classified into three categories. The categories consist of the industries of i) chemicals, electrical, machinery and equipment

\footnotetext{
${ }^{10}$ In addition to the variable R\&D intensity, the dumny variable non-R\&D performer is included in the analysis to 'ompensate' for the fact that the $\log$ (musform of the original R\&D intensity is set up to zero for observations with original R\&D intensity egual to zero.
} 
(M\&E), plastic and vchicle (that we refer to as ligh-tech), ii) food, metals, non-metallic products, textiles, and products not elsewhere classified (that we refer to as low-tech); and iii) wood that secms to be different from the remaining industries in Dutch manufacturing. All the industries in each category have the same inmovative behavior in the sense that, the parameters of the model for the industries in that category are identical with the exception of the intercepts.

Table 2.1: Likelihood ratio test results for the two-limit tobit model with sample selection: CIS 2, CIS 2.5, CIS \& The Netherlands

\begin{tabular}{|c|c|c|c|c|}
\hline Indusitry & \#parameters & $\operatorname{CIS~} 2$ & $\operatorname{CIS~} 2.5$ & $\operatorname{CIS} 3$ \\
\hline & & \multicolumn{3}{|c|}{ log-likelihood } \\
\hline Chemicals (SBI $23-2-24$ ) & $1-1$ & $-18: .376$ & -.465 .442 & $-190,16 j$ \\
\hline Elertrical (SBI 30-33) & 11 & $-5,579.374$ & -528.182 & -359.803 \\
\hline Machinery \& equipment (SBI 29) & 14 & -761.739 & -808.456 & $-(883.550$ \\
\hline Pletstic (SBI 25) & 11 & -3.44 .978 & $-333-1.675$ & -257.036 \\
\hline Vehicle (SBI 34-35) & 14 & -429.351 & -3666.979 & -217.786 \\
\hline Food (SBI 15-16) & 14 & -845.271 & -7333.758 & -581.581 \\
\hline Metals (SBI 27-28) & 1.1 & -892.066 .4 & -907.108 & -878.32 .5 \\
\hline Nom-metallic (SBI $2(6)$ & 11 & -285.001 & $-257.90 ; 3$ & -1666.512 \\
\hline NEC (SBI 36-37) & 14 & -374.76 .1 & -346.728 & $-4(3 \times .+195)$ \\
\hline Textile (SBI 17-19) & 1.4 & $-4(1) .923$ & -281.351 & $-1(33.174$ \\
\hline Wood (SBI 20-22) & 1.4 & -1001.419 & -1028.358 & .813 .283 \\
\hline Unrestricted model & 15.54 & $-(0.105 .260)$ & $-(j 1.18 .940$ & -5079.706 \\
\hline High-tech (SBI 23-25, 29,30-35) & 22 & -2625.407 & -2529.387 & -2038.133 \\
\hline Low-tech (SBI 15-19, 26-28, 36-37) & 22 & -2831.791 & -2642.834 & -2280.811 \\
\hline Wood (SBI 20-22) & 14 & -1001.419 & -1028.358 & -813.283 \\
\hline \multirow[t]{2}{*}{ Restricted model } & 58 & -0458.617 & -6200.579 & -5132.227 \\
\hline & & \multicolumn{3}{|c|}{ p-values } \\
\hline Test restricted-unrestricterl & & 0.214 & 0.287 & 0.248 \\
\hline
\end{tabular}

We also test for homogeneity of the innovative behavior of the three categories across the three waves of innovation survey. Pooling the data of the three waves for each catcgory, we are able to jointly test for equality of the parameters of the model for each category across waves, allowing for different industry and time intercepts. Assuming that the vector of disturbances are independent over time, we find that the innovative behavior of the three categories in CIS 2 is similar to that in CIS 2.5 , with a $\chi^{2}(36)=46.72$ and a $p$-value $=0.109$; while the innovative behavior of the three categories in CIS 3 is different from that in CIS 2.5, with a $\chi^{2}(36)=64.72$ and a $p$-value $=0.002$.

In Table 2.2 the descriptive statistics are shown for the three categories based on the testing procedure described above. The difference in the percentage of innovators and the 


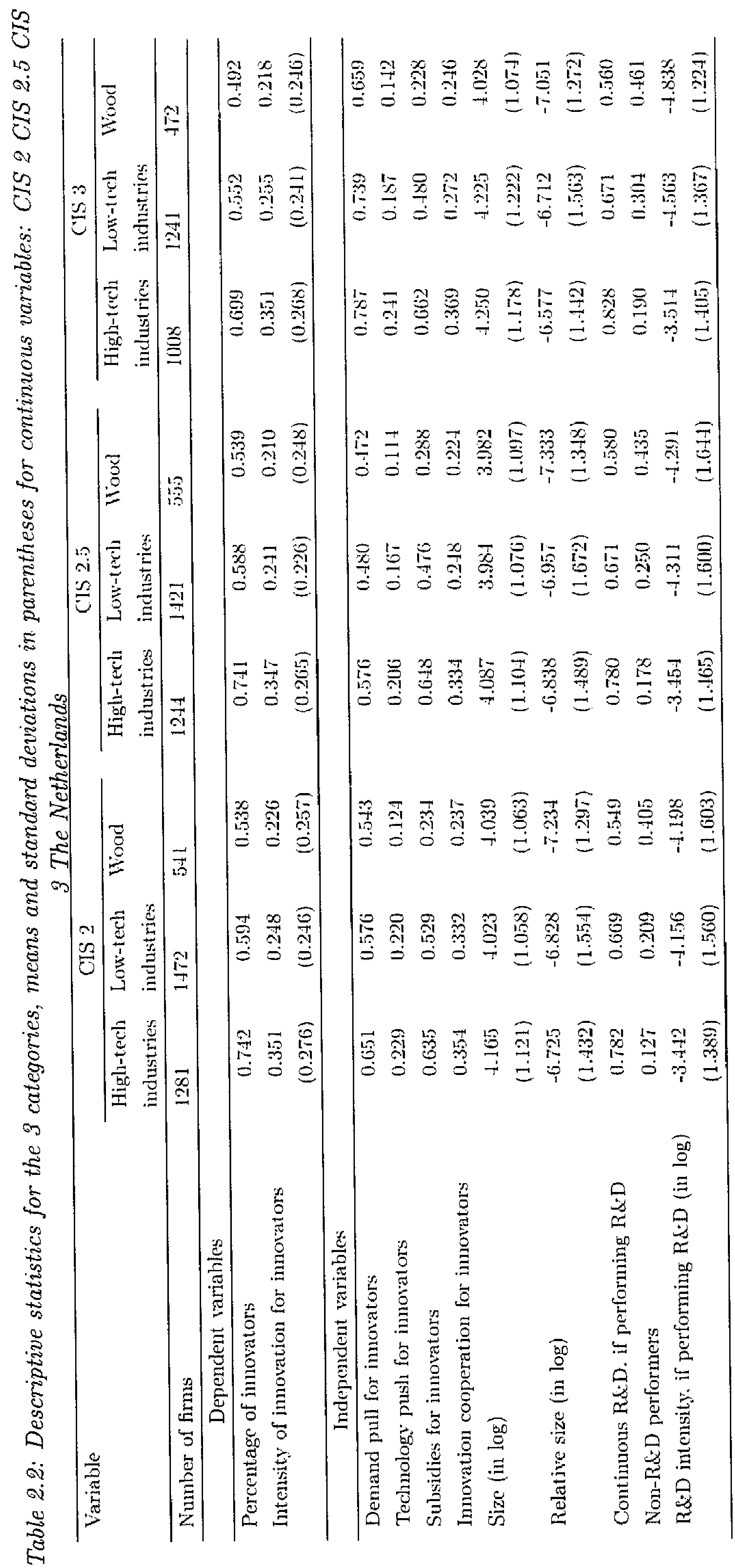


average intensities of innovation for immovators show up very clearly. Firms that belong to the high-tech category have on average larger intensities of imovation and larger $R \& D$ intensities, receive innovation subsidies more often and innovate more frequently than firms in the low-tech category and in the wood industry. The first category of firms also perform R\&D more frequently and more often on a continuous basis. For the three CIS, the enterprises in the wood industry seem to be rather different from the enterprises in the manufacturing industries. These differences are particularly pronounced for the dependent variables, the R\&D variables and the dummy for subsidies. One explanation for this is that the wood industry consists of a high percentage of process-only innovators. The percentage of TPP imovators in the wood industry that are granted a subsidy is roughly 30 per cent while this percentage is more than 50 per cent in total manufacturing (figures not shown in the tables). We can also note that in the wood industry, the percentage of R\&D performers annong TPP innovators, the percentage of continuous $R \& D$ performers among $R \& D$ performers, and the average $R \& D$ intensities are rather different from the equivalent figures for the other two categories. However, firms in the three categories on avcrage do not differ significantly in terms of size and relative size.

Across the three waves of the CIS the characteristics and the activities of the enterprises in Dutch manufacturing are rather similar. The only variables that vary from one wave to another are demand pull, size and relative size as measured by the market share. The values of these variables show a decrease from CIS 2 to CIS 2.5 and an increase in CIS 3 .

\subsection{Parameter estimates and innovation policy implications}

In order to derive possible innovation policies, we shall discuss the estimated coefficients of the explanatory variables which are to be understood as innovation policy instruments. In the wood industry, the reference group is an enterprise that performs $R \& D$ occasionally, having no imnovation cooperation of any kind, for which neither demand pull nor technology push are important, and not being granted innovation subsidies. In the high-tech and low-tech categories, the reference group is an enterprise having the same characteristics as above, and that belongs to the industries of chemicals products and products not elscwhere classified respectively. 
Table 2.3: Maximum likelihood estimation results: CIS 2 The Netherlands

\begin{tabular}{|c|c|c|c|c|c|c|}
\hline Variable & Cocefficiont & (Sld. Err.) & Cocificient & (Stcl. Err.) & Coufficient & (Std. Err.) \\
\hline & \multicolumn{6}{|c|}{ Int ('nsity of innovation } \\
\hline & \multicolumn{2}{|c|}{ High-tech } & \multicolumn{2}{|c|}{ Low-tech } & \multicolumn{2}{|c|}{ Wood } \\
\hline Size (in log $)$ & $-0.195^{* *}$ & $(0.071)$ & $-0.691^{* *}$ & $(0.116)$ & $-1.19 .4^{* *}$ & $(0,2 \times 9)$ \\
\hline Demamal pull & $0.2000^{\dagger}$ & $(0.137)$ & $0.7 .49^{* * *}$ & $(0.178)$ & $1.083^{* *}$ & $(0.3955)$ \\
\hline lochnology push & -0.074 & $(0.162)$ & -0.089 & $(0.220)$ & -0.343 & $(0.611)$ \\
\hline Innovation cooperation & $0.261^{\dagger}$ & $(0.150)$ & 0.275 & $(0.200)$ & $0.992^{*}$ & $(0.505)$ \\
\hline Non-R\&D performers & -0.467 & $(0.311)$ & $-1.3 .344^{* *}$ & $(0.371)$ & -0.275 & $(0.817)$ \\
\hline Contimous IRA:D & $0.8330^{* *}$ & $(0.176)$ & $0.5000^{*}$ & $(0.210)$ & 0.448 & $(0.517)$ \\
\hline RXD D intensity (in $\mathrm{log}$ ) & $0.11 \mathrm{i} 5^{*+4}$ & $(0.052)$ & $0.170^{* * *}$ & $(0.065)$ & -0.040 & $(0.162)$ \\
\hline Subsiclies & $0.451^{*: *}$ & $(0.15-1)$ & $0.140^{\circ}$ & $(0.203)$ & 0.729 & $(0.512)$ \\
\hline Liectrical & $0.811^{* * *}$ & $(0.220)$ & - & - & - & - \\
\hline $\operatorname{M\& E}$ & $0.831^{* *}$ & $(0.204)$ & - & - & - & - \\
\hline l'lelstic & $0.475^{\dagger}$ & $(0.249)$ & - & - & - & - \\
\hline Velideles & $1.141^{* \cdot k}$ & $(0.250)$ & - & - & - & - \\
\hline Food & - & - & -0.376 & $(0.348)$ & - & - \\
\hline Metals & + & - & -0.081 & $(0.339)$ & - & - \\
\hline Non-metallic: & - & - & -0.559 & $(0.433)$ & - & - \\
\hline Textile: & - & - & 0.314 & $(0.304)$ & - & - \\
\hline Intcrectet & -0.740 & $(0.452)$ & $2.805^{* k}$ & $(0.608)$ & $4.560^{* *}$ & $(1.341)$ \\
\hline \multirow[t]{2}{*}{$\sigma$} & $2.190^{* *}$ & $(0.080)$ & $3.404^{* *}$ & $(0.134)$ & $5.571^{* *}$ & $(0.390)$ \\
\hline & \multicolumn{6}{|c|}{ Probability to innovale? } \\
\hline Size (in $\log )$ & 0.070 & $(0.086)$ & $0.2099^{* * *}$ & $(0.059)$ & 0.092 & $(0.111)$ \\
\hline Rolative size (in log) & $\cdot 0.207^{* *}$ & $(0.067)$ & $0.105^{* * *}$ & $(0.0 .10)$ & 0.071 & $(0.087)$ \\
\hline Electrinal & $-0.371^{* *}$ & $(0.141)$ & - & - & - & - \\
\hline$M \& E$ & $-0.393^{* *}$ & $(0.145)$ & - & - & - & - \\
\hline Plitstic & $-0.580^{* *}$ & $(0.207)$ & - & - & - & - \\
\hline Velichess & $-0.717^{* *}$ & $(0.153)$ & - & - & - & - \\
\hline Food & - & - & $0.249^{\dagger}$ & $(0.146)$ & - & - \\
\hline Metinls & - & - & 0.131 & $(0.121)$ & - & - \\
\hline Non-metallic & - & - & 0.119 & $(0.137)$ & - & - \\
\hline Texlile? & - & - & -0.1443 & $(0.118)$ & - & - \\
\hline Intercept & $2.195^{*}$ & $(0.857)$ & 0.012 & $(0.448)$ & 0.221 & $(1.051)$ \\
\hline$\rho$ & $-0.668^{* *}$ & $(0.071)$ & $-0.881^{* *}$ & $(0.023)$ & $-0.0000^{* *}$ & $(0.013)$ \\
\hline Number of firms & \multicolumn{2}{|c|}{1281} & \multicolumn{2}{|c|}{1472} & \multicolumn{2}{|c|}{541} \\
\hline Log-likelihood & \multicolumn{2}{|c|}{$-2(j 25.407$} & \multicolumn{2}{|c|}{-2831.791} & \multicolumn{2}{|c|}{-1001.419} \\
\hline
\end{tabular}

\subsubsection{The selection equation}

\section{Size and Relative size}

According to the Sclumpeterian tradition, the size and relative size of an enterprisc influence positively the decision by this enterprise to engage in imovation activities, e.g. $R \& D$, as well as the probability to be a product innovator. It is often argued that larger firms have better access to finance. Therefore, they are more likely to engage in risky projects, 
and benefit from economies of scale. All empirical studies in Table 2.6 find such an evidence. Either size or relative size (or both) positively and significantly affects the probability to innovate in our high-tech and low-tech categories. The effect of size is less evident for the wood industry (only for CIS 2.5 there is a significant effect of size). Sizc and relative size are always significant in the low-tech industry.

Table 2.4: Maximum likelihood estimation results: CIS 2.5 The Netherlands

\begin{tabular}{|c|c|c|c|c|c|c|}
\hline Variablo & Coefficiont & (Std. Err.) & Coefficient & (Std. Err.) & Coefficient & (Stcl. Err.) \\
\hline & \multicolumn{6}{|c|}{ Intensity of innovalion } \\
\hline & \multicolumn{2}{|c|}{ High-terdh } & \multicolumn{2}{|c|}{ Low-tech } & \multicolumn{2}{|c|}{ Wood } \\
\hline Size (in $\log )$ & $-0.214^{* *}$ & $(0.071)$ & $-0.785^{* *}$ & $(0.109)$ & -0.410 & $(0.259)$ \\
\hline Demand pull & $0.741^{* *}$ & $(0.131)$ & $0.571^{* *}$ & $(0.160)$ & $1.102^{* *}$ & $(0.369)$ \\
\hline Techuology push & 0.038 & $(0.161)$ & 0.316 & $(0.229)$ & 0.767 & $(0.650)$ \\
\hline Innovalion cooperation & $0.277^{\dagger}$ & $(0.144)$ & $0.418^{*}$ & $(0.201)$ & 0.298 & $(0.485)$ \\
\hline Non-R\&D performers & -0.419 & $(0.280)$ & $-0.5055^{\dagger}$ & $(0.312)$ & 0.540 & $(0.758)$ \\
\hline (ontinuous R\&I) & $0.813^{* *}$ & $(0.176)$ & $0.8 .34^{* *}$ & $(0.20: 3)$ & 0.012 & $(0.515)$ \\
\hline$R \& D$ intensity (in log) & $0.126^{*}$ & $(0.051)$ & $0.148^{* *}$ & $(0.0 .57)$ & $-(0.092$ & $(0.1410)$ \\
\hline Sutbsidies & $0.442^{* *}$ & $(0.154)$ & $0.305^{\dagger}$ & $(0.182)$ & 0.407 & $\left(0.4666^{\circ}\right)$ \\
\hline Electrical & 0.220 & $(0.231)$ & - & - & - & - \\
\hline M\&:E & $0.381^{\dagger}$ & $(0.211)$ & - & - & - & - \\
\hline Plast ir & 0.087 & $(0.256)$ & - & - & - & - \\
\hline Veliteles & $0.724^{* * *}$ & $(0.258)$ & - & - & - & - \\
\hline Food & - & - & -0.521 & $(0.345)$ & - & - \\
\hline Netals & - & - & $-0.547^{\dagger}$ & $(0.327)$ & - & - \\
\hline Non-metallic & - & - & $-0.873^{*}$ & $(0.428)$ & - & - \\
\hline Textile & - & - & -0.4 .38 & $(0.415)$ & - & - \\
\hline Intercept & -0.561 & $(0.425)$ & $3.211^{* *}$ & $(0.559)$ & 0.935 & $(1.307)$ \\
\hline \multirow[t]{2}{*}{$\sigma$} & $2.304^{* *}$ & $(0.076)$ & $3.315^{* *}$ & $(0.121)$ & $5.548^{* *}$ & $(0.379)$ \\
\hline & \multicolumn{6}{|c|}{ Probability to innovate } \\
\hline Sizo (in log) & 0.005 & $(0.078)$ & $0.204^{* *}$ & $(0.061)$ & $0.272^{* *}$ & $(0.101)$ \\
\hline R(native size (in log) & $0.240^{* *}$ & $(0.059)$ & $0.135^{* *}$ & $(0.041)$ & $-0.09: 3$ & $(0.075)$ \\
\hline Elect rical & -0.102 & $(0.129)$ & - & - & - & - \\
\hline M\&E & -0.198 & $(0.122)$ & - & - & - & - \\
\hline Plastic & $-0.4 .47^{*}$ & $(0.178)$ & - & - & - & - \\
\hline Ventides & $-\left(0.444^{* *}\right.$ & (0.136) & - & - & - & - \\
\hline Foorl & - & - & 0.220 & $(0.150)$ & - & - \\
\hline Méals & - & - & 0.166 & $(0.127)$ & - & - \\
\hline Non-metallic & - & - & -0.060 & $(0.140)$ & - & - \\
\hline Textile & - & - & -0.193 & $(0.132)$ & - & - \\
\hline Lntercept & $2.198^{* *}$ & $(0.746)$ & 0.253 & $(0.462)$ & $-1.685)^{\dagger}$ & $(0.922)$ \\
\hline$\rho$ & $-0.831^{* *}$ & $(0.033)$ & $-0.931^{* *}$ & $(0.013)$ & $-0.9633^{* *}$ & $(0.012)$ \\
\hline Number of firus & \multicolumn{2}{|c|}{1244} & \multicolumn{2}{|c|}{1.421} & \multicolumn{2}{|c|}{555} \\
\hline Log-likeliluood & \multicolumn{2}{|c|}{-2529.387} & \multicolumn{2}{|c|}{-2642.834} & \multicolumn{2}{|c|}{-1028.358} \\
\hline
\end{tabular}


Crépon et al. (1996) point out that controlling for technological opportunities and appropriability may render the size or relative size effect on the probability to innovate insignificant. In our case technological opportunities and appropriability are captured by industry dummies, in the sense that it is easier to innovate in some industries than in othors and that the way of appropriability of innovation differs with different industries. A case in point may be our finding of no significant effects of size and relative size for the wood industry,

Table 2.5: Maximum likclihood estimation results: CIS 3 The Netherlands

\begin{tabular}{|c|c|c|c|c|c|c|}
\hline Variable & Coetficient & (Stcl. Err.) & Corefficient & (Stul. Err.) & Cocfficient & (Stcl. Err.) \\
\hline & \multicolumn{6}{|c|}{ Intensity of innovation } \\
\hline & \multicolumn{2}{|c|}{ High-tecll } & \multicolumn{2}{|c|}{ Low-techl } & \multicolumn{2}{|c|}{ Wood } \\
\hline Size $($ in $\log )$ & $-0.343^{* *}$ & $\overline{(0.082)}$ & $-0.655^{4^{* *}}$ & $(0.117)$ & $-1.040^{* *}$ & $(0.310)$ \\
\hline Demand pull & $0.537^{*}$ & $(0.198)$ & $1.400^{* *}$ & $(0.235)$ & $2.036^{* *}$ & $(0.434)$ \\
\hline Tex-lnolugy push & -0.177 & $(0.199)$ & 0.378 & $(0.261)$ & 0.698 & $(0.629)$ \\
\hline Innovation cooperation & $0.504^{* * *}$ & $(0.182)$ & $0.4244^{\dagger}$ & $(0.233)$ & 0.512 & $(0.542)$ \\
\hline Non-R\&D performers & $-1.16(5)^{* * *}$ & $(0.439)$ & $-1.640^{* *}$ & $(0.557)$ & $-2.454^{\dagger}$ & $(1.368)$ \\
\hline Continuons R\&D) & 0.053 & $(0.252)$ & 0.060 & $(0.2699)$ & -0.183 & $(0.61(j)$ \\
\hline R\&D inlensity (in log) & $0.2200^{* *}$ & $(0.070)$ & $0.263^{* * *}$ & $(0.092)$ & 0.303 & $(0.240)$ \\
\hline Subsidies & $0.360^{\dagger}$ & $(0.196)$ & 0.115 & $(0.222)$ & -0.004 & $(0.5 ; 38)$ \\
\hline Electrical & $0.810^{* * *}$ & $(0.277)$ & - & - & - & - \\
\hline$M \& E$ & $0.857^{* *}$ & $(0.239)$ & - & - & - & - \\
\hline Plastiv: & 0.226 & $(0.301)$ & - & - & - & - \\
\hline Velicles & $1.205^{* *}$ & $(0.322)$ & - & - & - & - \\
\hline Food & - & - & -0.437 & $(0.376)$ & - & - \\
\hline Motals & - & - & -0.415 & $(0.353)$ & - & - \\
\hline Non-metallic & - & - & -0.832 & $(0.531)$ & - & - \\
\hline Textile & - & - & -0.2699 & $(0.539)$ & - & - \\
\hline Intereept & 0.808 & $(0.602)$ & $3.457^{* *}$ & $(0.816)$ & $5.891 * *$ & $(1.879)$ \\
\hline \multirow[t]{2}{*}{$\sigma$} & $2.463^{* *}$ & $(0.103)$ & $3.718^{* *}$ & $(0.169)$ & $5.724^{* *}$ & $(0.475)$ \\
\hline & \multicolumn{6}{|c|}{ Probability to inmovate } \\
\hline Siza (in log) & $0.324^{* *}$ & $(0.072)$ & $0.165^{* *}$ & $(0.044)$ & $0.040^{\circ}$ & $(0.088)$ \\
\hline Relative size (in $\log$ ) & -0.022 & $(0.059)$ & $0.075^{*}$ & $(0.037)$ & 0.076 & $(0.068)$ \\
\hline Electrical & -0.170 & $(0.146)$ & - & - & - & - \\
\hline $\operatorname{MSE}$ & $-0.2233^{\dagger}$ & $(0.121)$ & - & - & - & - \\
\hline Plantic & -0.124 & $(0.186)$ & - & - & - & - \\
\hline Vehicles & $-0.415^{* *}$ & $(0.150)$ & - & - & - & - \\
\hline Fond & - & - & 0.086 & $(0.112)$ & - & - \\
\hline Metals & - & - & 0.111 & $(0.101)$ & - & - \\
\hline Non-metallic: & - & - & -0.150 & $(0.156)$ & - & - \\
\hline Textile & - & - & -0.151 & $(0.161)$ & - & - \\
\hline Intercept & -0.803 & $(0.711)$ & -0.115 & $(0.417)$ & 0.306 & $(0.794)$ \\
\hline$\rho$ & $-0.781^{* *}$ & $(0.048)$ & $-0.911^{* *}$ & $(0.019)$ & $-0.964^{* *}$ & $(0.014)$ \\
\hline Number of firms & \multicolumn{2}{|c|}{1008} & \multicolumn{2}{|c|}{1241} & \multicolumn{2}{|c|}{472} \\
\hline Log-likclihood & \multicolumn{2}{|c|}{-2038.133} & \multicolumn{2}{|c|}{-2280.811} & \multicolumn{2}{|c|}{-813.283} \\
\hline
\end{tabular}


that in this interpretation is homogeneous with respect to technological opportumities and appropriability.

\subsubsection{The intensity equation}

Size

The literature on the determinants of innovation reveals that there is mixed evidence with regard to the effect of size on the share of innovative sales in total sales given that a firm is an innovator. Our finding is in accordance with Brouwer and Kleinknecht (1996) and Janz et al. (2004), i.e., for the three CIS and for each category (except for the wood industry in CIS $2.5)$, smaller enterprises are more innovation intensive than their larger counterparts. While size is good for getting firms onto the innovation bandwagon, at least in low-tech industries, it does not lead to large shares of innovative sales. This holds for all categories.

\section{Demand pull}

On the basis of the Schmookler tradition, many empirical studies on the determinants of innovation include the variable demand pull as an explanatory variable of innovation. Regardless of the proxy used for demand pull, a majority of these studies find a positive impact on innovation output intensity. Our finding is in accordance with these studies. In other words, for each category and during the three periods under review, the variable demand pull has a positive impart on the share of innovative sales.

\section{Technology push}

Schumpeter's tradition reveals that technology push enhances innovation. However, many empirical studies find no evidence with regard to the positive effect of technology push on innovation. Our finding is in accordance with these studies, i.e., technology push does not seem to play a role in the innovation output intensity. It is often argued that, when controlling for technological opportunities, appropriability and demand conditions, as we do using industry dunmies, pro-Schumpeterian results turn out non-significant (Crépon et al., 1996).

\section{Cooperation}

Unlike the previous empirical studies in Table 2.6, we find some evidence with regard to the role of cooperation in innovation output intensity. In some cases, cooperating innovators 


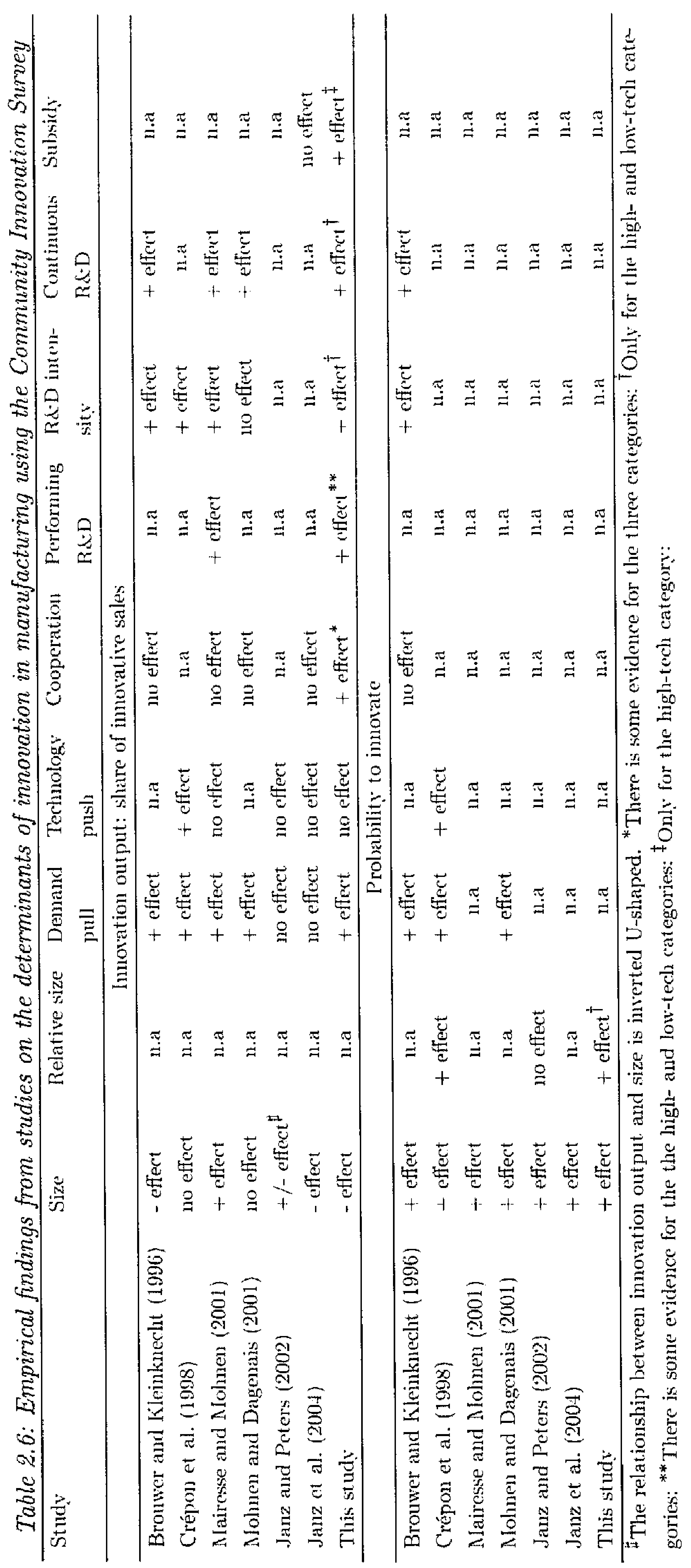


seem to be more successful than non-cooperating innovators with the same characteristics. This is particularly so for the high-tech category in the three waves of the CIS. However, generally speaking the estimates of the effect of cooperation are not very precise. Based on the argument that developing innovation in cooperation is relevant mostly to firms lacking knowledge ("weak" innovators) we would expect cooperation to be particularly important for the low-tech or the wood industry compared to high-tech industry. "This is not borne out by our results.

\section{R\&D}

It is often argued that experience and knowledge accumulated from past $R \& D$ positively influences innovation output. The three variables pertaining to $R \& D$ usually have a positive and significant effect on innovation output intensity in previous studies. There is some evidence that, among the innovators in the low-tech and high-tech categories, non-R\&D performers are less successful than R\&D performers with the same characteristics. This dummy variable hardly matters for the wood industry. Furthermore, except for CIS 3 , in both the high-tech and low-tech categories, innovators that perform R\&D on a continuous basis are more successful than those that perform $R \& D$ occasionally with the same characteristics. Again, there is no apparent effect of performing R\&D continuously in the wood industry. Finally, $R \& D$ intensity, as measured by total $R \& D$ expenditures over total sales, always plays a positive and significant role in the innovation output intensity for the ligh-tech and for the low-tech categories. This variable never matters for the wood industry. To stimulate innovation, $R \& D$, in particular continuous $R \& D$, should be encouraged in the high-tech and low-tech industries. The evidence for the wood industry is less persuasive in favor of this policy instrument.

\section{Subsidy}

We expect cnterprises that receive subsidies to be more innovative, on the grounds that they do more R\&D which may also be expected to positively affect innovation output. In the three waves of the CIS, imnovators in the high-tech category that are granted subsidies are more successful than those that are not granted subsidies with the same characteristics. In the low-tech category and in the wood industry, innovation subsidies do not seem to make

\footnotetext{
"See Brouwer and Kleiuknecht (1996) for details.
} 
a difference. The results suggest a positive correlation between subsidies and innovation in high-tech industries. It may be, however, that subsidies are given primarily to firms in high-tech industries because they are known to be innovative (Lach, 2002).

\subsection{Conclusion}

The contribution of our study is to set up an industry categorization of Dutch manufacturing that is based on a model of economic behavior. We have considered a model of the determinants of innovation that explains the decisions by business enterprises to innovate, and the impact of these decisions on the share of innovative sales in total sales. We have estimated a two-limit tobit model with sample selection for each industry and performed likelihood ratio tests to classify industries into categories. Each category consists of industries for which the parameters of the model are identical. Our taxonomy suggests that industries in the Dutch manufacturing sector can be classified into three categories, namely the high-tech category, the low-tech category, and the wood industry. The high-tech category consists of the chemicals, electrical, M\&E, plastic and vehicle industries. The food, metals, non-metallic products, textiles, and products not elsewhere classified (NEC) industries form the low-tech category. Our empirically-based industry categorization of Dutch manufacturing holds for the three Dutch Community Innovation Surveys.

Two main differences between our categorization and the OECD taxonomy are to be noted. The first one is that we place the plastic industry in the high-tech category, while it belongs to the low-tech category of the OECD taxonomy. The second one is that the wood industry cannot be classified into either the high- and low-tech category because the hypothesis that it has the same innovative behavior as the other industries in Dutch manufacturing had to be rejected. However, our classification could have been more different from the OECD classification had we used a finer industrial aggregation. The Pavitt and PCA thxonomy approaches circumvent this problem, but they are based on descriptive statistics and hence suffer from the absence of an empirical model. The OECD classification relies only on aggregate $R \& D$ within an industry. It can therefore lead to inefficient imnovation policies because it ignores differences between enterprises within an industry. The PCA approach is firm-based but it relies on clustering of enterprises on the basis of a set of characteristics without modeling the interactions between these characteristics. The Pavitt classification is constructed 
on a priori knowledge and assumptions about industry characteristics and interrelationships rather than on empirical findings regarding their innovative behavior. To illustrate our point, consider the effect of size. We have found that size is conducive to becoming an innovator but not necessarily to increasing the share of inmovative sales. Thereforc, a policy suggested on the basis of our categorization would be to stimulate non-innovating enterprises, for example by letting them grow, but not to favor large enterprises that are innovators. One shortcoming of our data is that we have little information about non-innovators.

Although our classification is rather robust, it is not to be seen as the ultimate one. The classification may be sensitive to the choice of the model and to the choice of the explanatory variables used in the model. Therefore, before being considered as definitive, our classification should be tested using other models of innovation. We have considered a static model estimated for three cross-sectional data sets. We have also assumed that R\&D is determined exogenously, and the observed innovation input (R\&D) and output (innovative sales) are measured at the same period of time, namely at the end of the period under review. But, more and more recent empirical studies assume that there is a decision to engage in $R \& D$, hence endogenize R\&D. These studies are the variants of the Crépon-Duguet-Mairesse (CDM, 1998) model. However, as far as we know, all these studies endogenize R\&D in a static framework. ${ }^{12}$ We believe that there may be a time lag between innovation input (e.g. R\&D) and innovation output as measured by the share of innovative sales. A natural way to extend our model is to consider a dynamic panel data framework.

Finally, we have found some homogeneity in the innovative behavior across certain industries in the Dutch manufacturing sector. But, within the categories of industries it is likely that heterogeneity among firms exists that we have not captured. ${ }^{13}$ The argument of Baldwin and Gellatly (2000) that high-tech firms may be found in low-tech industries and vice versa is still valid. It would be worthwhile in future research to account for unobservable heterogeneity by considering, for instance, a model with panel data and individual effects.

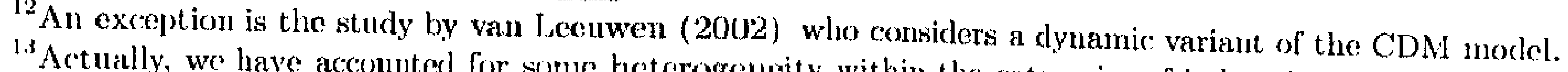
forently", in the estination of the model, hetogenenty within the catchoriss of industries by treating "dif"large" product innovators. However, this is done in a non-standard way insovators, prodnct innovators and inclividual effects.
} 


\section{Appendix 2.A The likelihood function of the two-limit tobit model with sample selection}

Consider the model given in equations (2.1), (2.2) and (2.3). Suppose that the error terms $\epsilon_{1}$ and $\epsilon_{2}$ are jointly and normally distributed with mean zero and covariance matrix $\Sigma=$ $\left(\begin{array}{cc}1 & \rho \sigma \\ \rho \sigma & \sigma^{2}\end{array}\right)$. The likelihood function can be written as

$$
\begin{aligned}
L= & \prod_{0} P\left(y_{1}^{*} \leq 0\right) \prod_{c_{1}} P\left(y_{1}^{*}>0 ; y_{2}^{*} \leq c_{1}\right) \\
& \prod_{y_{2}^{*}} f\left(y_{2} \mid y_{1}^{*}>0 ; c_{1}<y_{2} \leq c_{2}\right) P\left(c_{1}<y_{2} \leq c_{2} \mid y_{1}^{*}>0\right) P\left(y_{1}^{*}>0\right) \\
& \prod_{r^{2}} P\left(y_{1}^{*}>0 ; y_{2}^{*}>c_{2}\right),
\end{aligned}
$$

where $\prod_{0}, \prod_{c_{1}}, \prod_{y_{2}^{*}}$ and $\prod_{c^{2}}$ denote the products over non-innovators, process-only innovators, product innovators and "large" product innovators respectively. The contribution of a non-innovator to the likelihood function (first expression) is written as $\Phi_{1}\left(-\beta_{1}^{\prime} \mathbf{x}_{1}\right)$, where $\Phi_{1}$ is the univariate standard normal cumulative distribution function. The contribution of a process-only innovator (second expression) involves the calculation of a double integral, i.c. $\int_{-\beta_{1}^{\prime} \mathbf{x}_{1}}^{\infty} \int_{-\infty}^{\frac{\sigma_{1}-\beta_{2}^{\prime} x_{2}}{\sigma}} \phi_{2}\left(\epsilon_{1}, \frac{\epsilon_{2}}{\sigma}, \rho\right) d \varepsilon_{1} d \frac{\epsilon_{2}}{\sigma}$, where $\phi_{2}$ is the bivariate standard normal density function. This latter expression can be written as $\Phi_{1}\left(\frac{c_{1}-\beta_{2}^{\prime} \mathbf{x}_{2}}{\sigma}\right)-\Phi_{2}\left(-\beta_{1}^{\prime} \mathbf{x}_{1}, \frac{c_{1}-\beta_{2}^{\prime} \mathbf{x}_{2}}{\sigma}, \rho\right)$, where $\Phi_{2}$ is the bivariate standard normal cumulative distribution function. The third expression, corresponding to a not too "large" product innovator, is calculated as $\frac{f\left(y_{2} \mid y_{1}^{*}>0\right)}{P\left(c_{1}<y_{2} \leq c_{2} \mid y_{1}^{*}>0\right)} P\left(c_{1}<\right.$ $\left.y_{2} \leq c_{2} \mid y_{1}^{*}>0\right) P\left(y_{1}^{*}>0\right)$ so that it becomes

$$
\underset{y_{2}^{*}}{L}=f\left(y_{2} \mid y_{1}^{*}>0\right) P\left(y_{1}^{*}>0\right)
$$

From the definition of a truncated distribution, we derive $\underset{y_{2}^{*}}{L}$ as $\int_{0}^{\infty} f\left(y_{2}, y_{1}^{*}\right) d y_{1}^{*}$, where $f$ is the bivariate normal density function. In order to make the computation easier, we write the bivariate density as a conditional multiplied with a marginal density so that

$$
\int_{0}^{\infty} f\left(y_{2}, y_{1}^{*}\right) d y_{1}^{*}=f\left(y_{2}\right) \int_{0}^{\infty} f\left(y_{1}^{*} \mid y_{2}\right) d y_{1}^{*}
$$


Proposition 1 If $y$ is normally distributed with mean $\mu$ and variance $\sigma^{2}$, then $\int_{0}^{\infty} f(y) d y=$ $\Phi\left(\frac{n}{\sigma}\right)$.

Proof. The density function of $y$ is $\frac{1}{\sigma \sqrt{2 \pi}} \exp \left[-\frac{1}{2}\left(\frac{y-\mu}{\sigma}\right)^{2}\right]$ so that

$$
\int_{0}^{\infty} f(y) d y=\frac{1}{\sigma} \int_{0}^{\infty} \phi_{1}\left(\frac{y-\mu}{\sigma}\right) d y=\frac{1}{\sigma \sqrt{2 \pi}} \int_{0}^{\infty} \exp \left[-\frac{1}{2}\left(\frac{y-\mu}{\sigma}\right)^{2}\right] d y
$$

Let $z=\frac{y-\mu}{\sigma}$ such that $d y=\sigma d z$, then

$$
\int_{0}^{\infty} f(y) d y=\frac{1}{\sigma} \int_{\frac{-\mu}{\sigma}}^{\infty} \phi_{1}(z) \sigma d z
$$

Using the property of symmetry of the normal distribution, the integral (2.7) is finally written as:

$$
\int_{0}^{\infty} f(y) d y=\int_{-\infty}^{\frac{\mu}{\sigma}} \phi_{1}(z) d z=\Phi_{1}\left(\frac{\mu}{\sigma}\right)
$$

Applying the results of Proposition 1 to the conditional distribution of $y_{1}^{*} \mid y_{2}$ that is normal with mean $\mu_{y_{1}^{*} \mid y_{2}}$ and variance $\sigma_{y_{1}^{*} \mid y_{2}}^{2}$, we finally obtain the contribution to the likelihood function of one product innovator as $L=\frac{1}{\sigma_{2}^{*}} \phi_{1}\left(\frac{y_{2}-\beta_{2}^{\prime} x_{2}}{\sigma_{2}}\right) \Phi_{1}\left(\frac{\mu_{y_{1}^{*}} \mid y_{2}}{\sigma_{y_{1}^{*} \mid y_{2}}}\right) \cdot 14$

Finally, the contribution of a "large" product innovator (fourth expression in (2.4)) also involves a double integral $\int_{-; r_{1}^{\prime} \mathbf{x}_{1}}^{\infty} \int_{\frac{\varepsilon_{2}-i_{2}^{\prime} \mathbf{x}_{2}}{\sigma}}^{\infty} \phi_{2}\left(\epsilon_{1}, \frac{\epsilon_{2}}{\sigma}, \rho\right) d \varepsilon_{1} d \frac{\epsilon_{2}}{\sigma}$ which equals $1-\Phi_{1}\left(-\beta_{1}^{\prime} \mathbf{x}_{1}\right)-$ $\Phi_{1}\left(\frac{\alpha_{2-1}^{\prime} x_{2} x_{2}}{\sigma}\right)+\Phi_{2}\left(-\beta_{1}^{\prime} \mathbf{x}_{1}, \frac{\sigma_{2}-\beta_{2}^{\prime} x_{2}}{\sigma}, \rho\right)$.

\footnotetext{
${ }^{14}$ If $\left(y_{1}, y_{2}\right)^{\prime}$ follows a bivariate normal distribution with mean $\left(h_{1}, \mu_{2}\right)^{\prime}$ and covariance matrix $\Sigma=$ $\left(\begin{array}{cc}\sigma_{1}^{2} & \rho \sigma_{1} \sigma_{2} \\ \rho \sigma_{1} \sigma_{2} & \sigma_{2}^{2}\end{array}\right)$. then the conditional distribution of $h / y_{2}$ is normal the mean and variance of which are respectively

anul

$$
\mu_{y_{1} \mid y_{2}}=\mu_{1}+\frac{\rho \sigma_{1} \sigma_{2}}{\sigma_{2}^{2}}\left(y_{2}-\mu_{2}\right)
$$$$
\sigma_{y_{1} y_{2}}^{2}=\sigma_{1}^{2}-\frac{p^{2} \sigma_{1}^{2} \sigma_{2}^{2}}{\sigma_{2}^{2}}=\sigma_{1}^{2}\left(1-\rho^{2}\right)
$$ 


\section{Appendix 2.B The distribution of the share of innovative sales}

Figure 2.1: The distribution of the share of innovative sales of "normal"product innovators per CIS

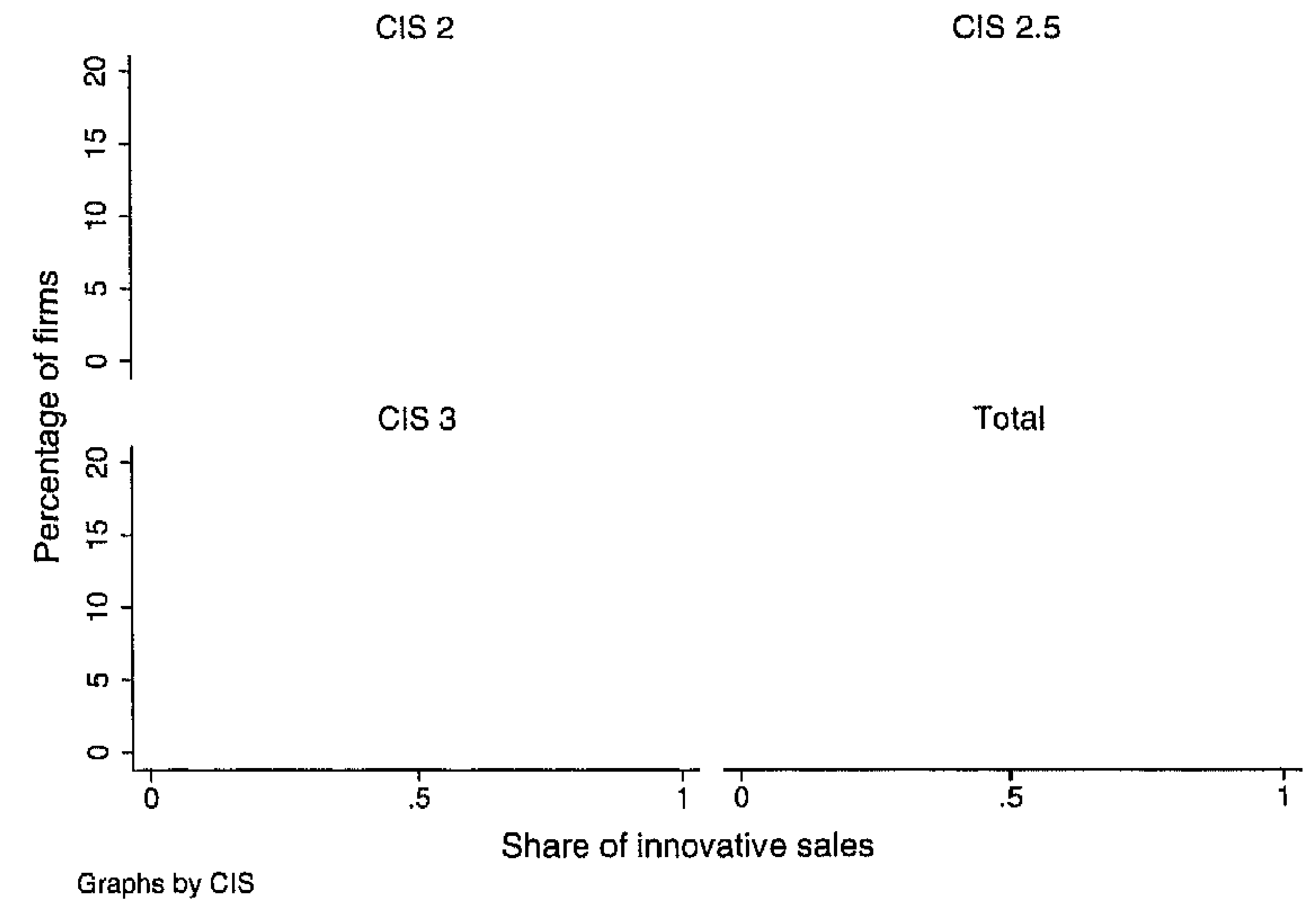

Figure 2.2: The distribution of the logit transform of the share of innovative sales of "normal" product innovators per CIS

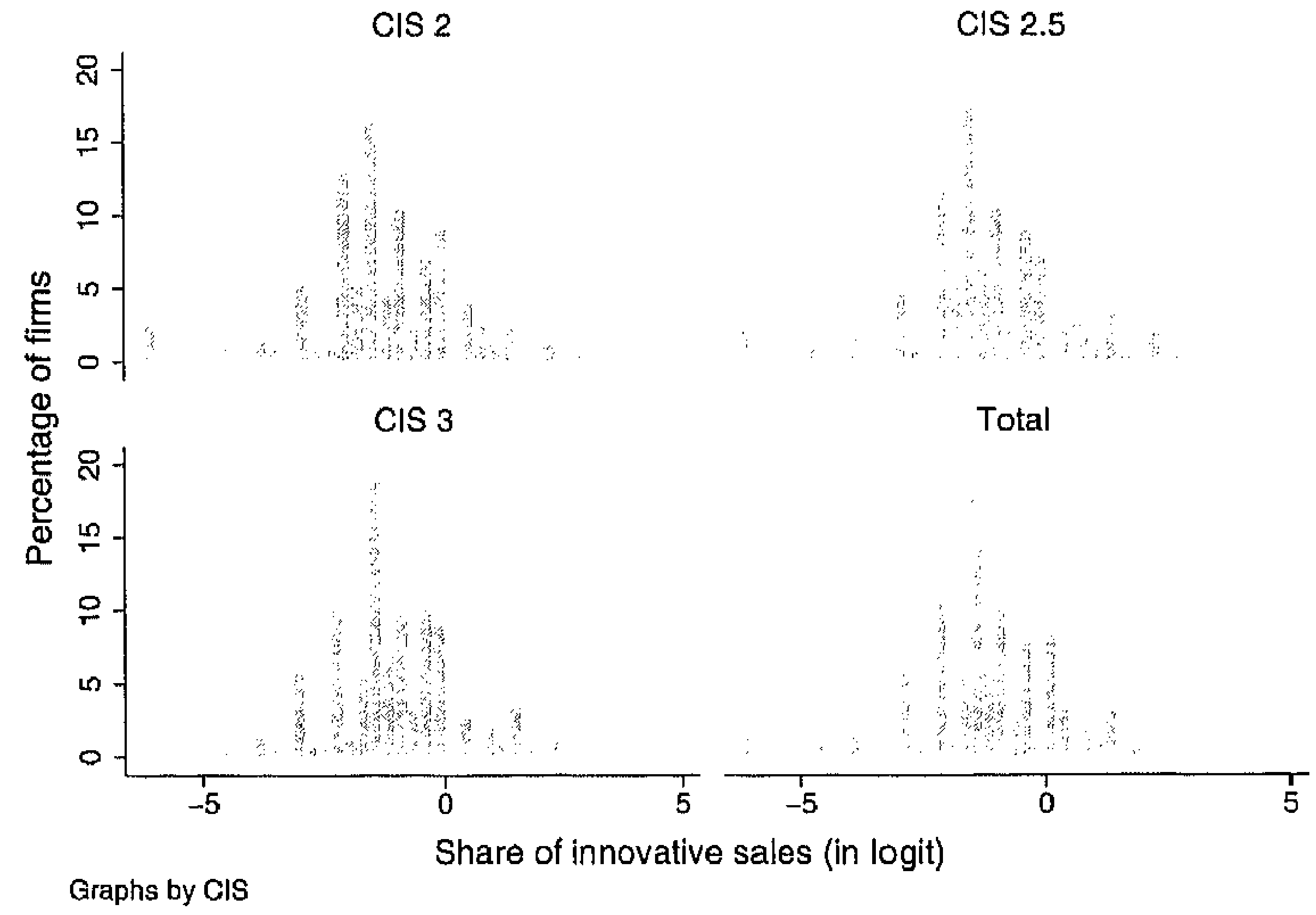


CHAPTER 3

\section{The behavior of the maximum likelihood estimator of dynamic panel}

\section{data sample selection models}

\subsection{Introduction}

The ongoing development of the relevant econometric methodology for panel data has increased the choice for the applied researcher as to which model to choose in any given situation. Whereas this choice should be driven by the question which underlying assumptions are appropriate in the case at hand, optimality properties of the estimators are typically known only for large sample sizes. In order to have some guidance in the choice process it is important to know the implications, in terms of ease of computation and the robustness to deviations of the assumptions, of employing a particular method. In this chapter the behavior is investigated by means of Monte Carlo simulation of the maximum likelihood (ML) estimator in a general model that encompasses a wide set of models that have been considered in the literature. The generic form of the model consists of a regression equation, henceforth referred to as the equation of interest, and a selection equation. Both equations contain a lagged dependent variable and unobserved individual effects possibly correlated with the explanatory variables. The selection rule may be of the binary type or of the censoring type. ${ }^{1}$ In terms of the Amemiya (1984) typology, the models considered in this paper are the dynamic

\footnotetext{
Following the literature the term censoring nodel will be used throughout the chapter although it. would, line with Wooldridge (2005), be preferable to speak of comer solution models since the lagged dependent variable considered in this paper is the observed - rather than the latent - variable.
} 
parel data extensions of the type 2 and type 3 tobit models. Variants of these types of models have been widely used, mostly in labor economics but also in other areas (sce Section 3.2).

This study contributes to the existing literature in two ways. Firstly, a practical method is provided to the problem of the maximum likelihood estimation of the parameters of a panel sample selection model in which random individual effects and the lagged dependent variable are included in the equation of interest as well as in the selection equation. The selection rule may be either of the binary or of the censoring type. ${ }^{2}$ To handle the initial conditions problem. Wooldridge's (2005) solution to this problem in single equation dynamic nonlinear panel data models is extended to models containing more than one equation. Gaussian quadrature is used to evaluate the resulting multiple integral. Secondly, the paper reports on a Monte Carlo investigation into the behavior in finite samples of the proposed method. It is shown that using Wooldridge's solution to deal with the dependence between the initial conditions and the individual effects is successful in recovering the parameters of a process that generates the data according to a stationary process. It is also shown that incorrectly ignoring the individual effects, or the dependence between the initial conditions and the individual effects results in an overestimation of the coefficients of the lagged dependent variable in both equations. The likelihood functions of the dynamic panel data extensions of the type 2 and type 3 tobit models involve a two-dimensional indefinite integral. For the likelihood functions generated in the Monte Carlo experiments, Gaussian quadrature, implemented as two successive Gauss-Hermite approximations, works well for a number of evaluation points as small as two. ${ }^{3}$ Evidently, when using real data more than two evaluation points may be necessary to attain the required numerical accuracy. Nevertheless, the Monte Carlo results indicate that $\mathrm{ML}$ estimation of the parameters in a random-effects dynamic sample selection model is feasible and could conceivably be incorporated as a command in a general use software package such as Stata.

The remainder of the chapter is organized as follows. We discuss the most cited studies on panel data sample selection models in Section 3.2. Section 3.3 describes the model and Sertion 3.4 describes its maximum likelihood estimation. The small sample behavior of the estimator is studied in a Monte Carlo study in Section 3.5, and Section 3.6 concludes. The

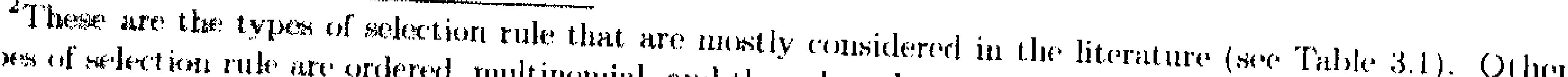

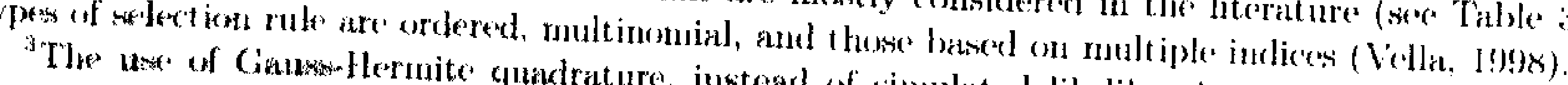
Gitulkey ard Marphy (1903) that, for the instead of simulated likelihood, is motivated by the finding of

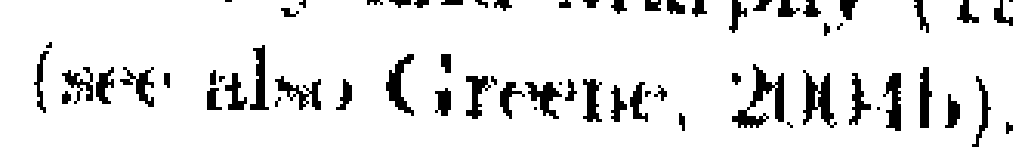


Gauss-Hermite quadrature is explained in Appendix 3.A.

\section{$3.2 \quad$ Literature}

Most of the studies on panel data sample selection models are static and of the type 2 or type 3 tobit (see the upper part of Table 3.1), which are estimated either by ML or two-step least squares (Heckman, 1979).

For instance, Hausman and Wise (1979) define a two-period model of attrition and estimate by ML the impact of attrition on earnings. Attrition is defined as the inability to observe the dependent variable of the equation of interest in the second period. ${ }^{4}$ Ridder (1990) generalizes the model of Hausman and Wise (1979) to allow for more than two periods and attrition to occur also in the first period. Hence Ridder's model can be used as a standard attrition or sample selection model. Nijman and Verbeek (1992) apply this model to study the effect of nonresponse on Dutch households' consumption. Verbeek (1990) assumes random and fixed individual effects in the selection and regression equations respectively, and estimates by ML a transformed model with a selection equation written in levels and a within-transformed equation of interest. Verbeek's model is criticized by Zabel (1992) who considers random individual effects correlated with the explanatory variables in both the selection equation and the equation of interest and estimates the resulting model by ML. As mentioned earlier, all these studies are of limited use to the applied researcher who wants to implement the ML estimator as they present only the general expression of the likelihood function which involves a multiple integral that is yet to be calculated. Our study makes a step in this direction.

The two-step Heckman type estimator consists, in a first step, in estimating the selection equation and constructing an estimate of a selection correction term that is included as a regressor in the equation of interest which, in a second step, is estimated using ordinary least squares (OLS) regression. Wooldridge (1995) estimates an augmented equation of interest written in levels by pooled OLS where estimates of the selection correction terms are obtained, in a first step, using a probit model for each period. Kyriazidou (1997) and Honoré and Kyriazidou (2000a) propose to estimate, by kernel-weighted least squares, a pairwise differenced equation of interest for individuals that are selected into the sample and have "the

\footnotetext{
${ }^{1}$ Attrition in the first period is usually referred to as sample selection.
} 
same" selection equation index in two different periods. Under a conditional exchangeability assumption, the sample selection is time-invariant for such individuals so that differencing the equation of interest over time wipes out. not only the individual effects, but also the sample selection effect. In order to construct the kernel weights, the parameters of the selection equation are estimated, in a first step, using conditional logit or smoothed conditional maximum score. Rochina-Barrachina (1999) applies OLS to a pairwise differenced equation of interest augmented with two selection correction terms for indivicluals that are selected into the sample in two different periods. Estimates of these selection correction terms are obtained, in a first step, using a bivariate probit for each combination of time periods. The studies cited so far consider sample selection models with a binary selection rule (type 2 tobit).

Heckman and MaCurdy (1980) estimate by ML a fixed-effects type 3 tobit and apply it to a wage equation with a labor supply (the number of hours worked) equation as the selection equation. Ai and Chen (1992) and Honoré and Kyriazidou (2000a) estimate the same model using symmetrically trimmed least squares (STLS), and Wooldridge (1995) uses the same estimator as the one mentioned above where estimates of the selection correction terms are now obtained, in a first step, using a tobit model for each period. A Monte Carlo study comparing the estimators of Wooldridge (1995), Honoré and Kyriazidou (2000a)and a semiparametric first-difference estimator is provided by Lec (2001).

So far, all the mentioned studies on panel data sample selection models assume strict exogeneity of the explanatory variables in the equation of interest. Models with censored endogenous explanatory variables are studied by Vella and Verbeek (1999) and Askildsen et al. (2003), while Dustmann and Rochina-Barrachina. (2000) and Semykina and Wooldridge (2005) study models with continuous endogenous explanatory variables. Vella and Verbeek (1999) estimate by OLS with selection bias correction (SBC) a wage equation where labor supply enters the set of explanatory variables, and where estimates of the sclection correction terms are obtained, in a first step, using a dynamic tobit model of labor supply. Askildsen et al. (2003) estimate the wage elasticity of labor supply for Norwegian nurses using an instrumental variable (IV) version of the Kyriazidou (1997) method. Dustmann and RochinaBarrachina (2000) and Semykina and Wooldridge (2005) estimate the effect of experience, which is assumed to be endogenous, on wages. The former study extends the Wooldridge (1995), Kyriazidou (1997) and Rochina-Barrachina (1999) estimators in order to account for 


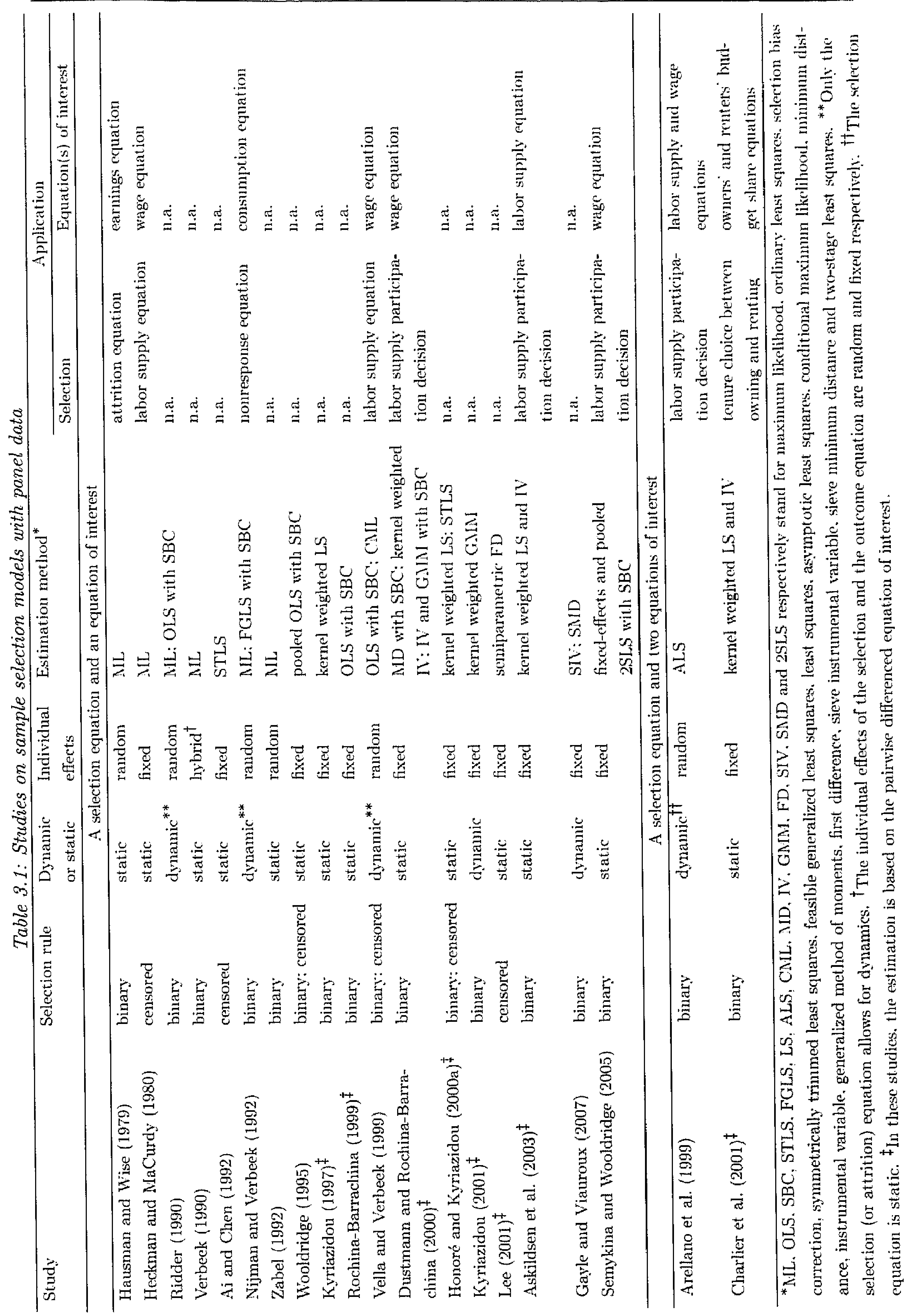


endogeneity in the explanatory variables, while the latter uses a pooled and a fixed-effects two-stage least squares estimator with SBC. Finally, sample selection models that allow for dynamics in both the selection equation and the equation of interest are studicd by Kyriazidou (2001) who uses a two-step kernel weighted general method of moments (GMM) estimator, and Gayle and Viauroux (2007) who use a sieve instrumental variable (SIV) and minimum distance (SMD) estimator.

Two rather different sample selection models are studied by Arellano et al. (1999) and Charlier et al. (2001). The former estimate a simultaneous equation second-order autoregressive model of labor supply and wages with selection using asymptotic least squares (ALS). The latter estinate a type 5 tobit, also known as endogenous switching regression, that explains the effect of Dutch households' tenure choice between owning and renting on owners' and renters' budget shares using kernel weighted IV.

\subsection{The model}

The dynamic pancl data sample selection model studied in this chapter consists of two latent dependent variables $d_{i t}^{*}$ and $y_{i t}^{*}$ written as

$$
\begin{aligned}
& d_{i t}^{*}=\rho d_{i, t-1}+\delta^{\prime} \mathbf{w}_{i t}+\eta_{i}+\epsilon_{1 i t}, \\
& y_{i t}^{*}=\gamma y_{i, t-1}+\beta^{\prime} \mathbf{x}_{i t}+\alpha_{i}+\epsilon_{2 i t},
\end{aligned}
$$

with observed counterparts $d_{i t}$ and $y_{i t}$, and $i=1, \ldots N ; t=1, \ldots T$. Equation (3.1) is the selection equation that determines whether individual $i$ is included in the sample on which the estimation of the equation of interest (eq. (3.2)) is based at period $t$. It is a function of past selection outcome $\left(d_{i, l-1}\right)$, strictly exogenous explanatory variables $\left(\mathbf{w}_{i l}\right)$, time-invariant unobserved individual effects $\left(\eta_{i}\right)$ and other time-variant unobserved variables $\left(\epsilon_{1 i t}\right)$. The scalar $\rho$ and the vector $\delta^{\prime}$ capture respectively the effects of past selection outcome and the explanatory variables on the current sclection process, and are to be estimated. The equation of interest depends on its past outcome $\left(y_{i, t-1}\right)$, strictly exogenous explanatory variables $\left(\mathbf{x}_{i t}\right)$, time-invariant unobserved individual effects $\left(\alpha_{i}\right)$ and other time-variant unobserved variables 
$\left(\epsilon_{2 i t}\right)$, and is observed only when $d_{i t}^{*}$ is positive, i.e.

$$
y_{i t}=\mathbf{1}\left[d_{i t}^{*}>0\right] y_{i t}^{*}
$$

where $1[. .$.$] is the indicator function with value one if the expression between square brackets$ is true, and zero otherwisc. The scalar $\gamma$ and the vector $\beta^{\prime}$ capture respectively the effects of past outcome and explanatory variables on current outcome, and are to be estimated. Since a fully parametric approach is considered in this study, there is no exchusion restriction in the vector of explanatory variables. In other words, $\mathbf{w}_{i t}$ and $\mathbf{x}_{i t}$ may be the same, totally different or may have common explanatory variables.

Two types of selection rule are considered in this study, namely binary and censored. When the selection rule is binary, only the sign of the current selection process is observed and the current selection outcome is defined as

$$
d_{i t}=1\left[d_{i t}^{*}>0\right]
$$

while in the censored case, not only the sign but also the actual value of the current selection process is observed whenever it is positive and the current selection outcome is defined as

$$
d_{i t}=1\left[d_{i l}^{*}>0\right] d_{i t}^{*}
$$

Amemiya (1984) refers to the model described in equations (3.1), (3.2), (3.3) and (3.4) as type 2 tobit, and the one described in equations (3.1), (3.2), (3.3) and (3.5) as type 3 tobit. We now turn to the estimation technique.

\subsection{Maximum likelihood estimation}

Two difficulties arise when estimating dynanic panel data sample selection models, namely the presence of unobserved individual effects and the treatment of the initial observations."

One way of handling the presence of unobserved individual effects is to create a dummy variable for each individual $i$ and estimate the corresponding parameters $\eta_{i}$ and $\alpha_{i}$, together

\footnotetext{
${ }^{5}$ This study describes the difficulties that arise when estimating dynamic nonlincar panel data models and suggests solutions to them in a fully paranetric framework. Details on how to handle the presence of unobserved individual effects and lagged clependent variables as regressors in a semiparametric framowork are given in Arcllano and Honoré (2001).
} 
with the other parameters of the model, by maximum likelihood assuming a joint distribution for the error terms $\epsilon_{1 i t}$ and $\epsilon_{2 i t}$. This approach is referred to as fixed-effects and has two shortcomings when the considered panel consists of a large $N$ and a small $T$. The first one lies in the difficulty of computing the maxinum likelihood estimator of the coefficients of possibly thousands of dummy variables. This computational problem can be overcome, for instance, by a two-step "zigzag" kind of likelihood maximization (Heckman and MaCurdy, 1980) or by "brute force" maximization (Greene, 2004a). These two computational methods cannot, however, solve the second problem of "incidental parameters" of the fixed-effects approach, namely the inconsistency of the maximum likelihood estimator of $\eta_{i}$ and $\alpha_{i}$ when the number of periods $T$ is small (Neyman and Scott, 1948). Unlike in the linear model, the inconsistency of the estimator of the individual effects carrics over to the estimator of the slope parameters. Hence, the individual effects have to be conditioned out of the likelihood function so that the remaining parameters of the model can be consistently estimated by maximum likelihood. The resulting estinutor is known as the conditional maximum likelihood estimator and is studied, for instance, by Chamberlain (1980) and Magnac (2004). The conditional likelihood approach is, however, restrictive for two reasons. First, there are very few nonlinear panel data models for which conditioning the individual effects out of the likelihood function is possible. They are surveyed in the study by Lancaster (2000). Secondly, the approach works only under the assumption of strict exogeneity of the explanatory variables, which rules out the inclusion of lagged dependent variables as explanatory variables. The above-mentioned shortcomings of the fixed-effects approach may justify the use of a random-effects approach, where $\eta_{i}$ and $\alpha_{i}$ are assumed to have a joint distribution.

A computational (and methodological) difficulty that arises in the random-effects approach is the so-called initial conditions problem. Two assumptions are often made on the initial conditions in the literature, namely they are exogenous or the process is in equilibrium. Neither assumption is satisfactory Hsiao (2003). Two approaches of handling the initial conditions problem are proposed by Heckman (1981b) and Wooldridge (2005). The first approach specifies a model for the initial conditions given the individual effects and the strictly exogenous explanatory variables. In empirical work, this model is often assumed to be similar to the model underlying the remaining process. For instance, if the underlying model is a dynamic panel data probit, the model at the initial period is assumed to be standard probit. 
A likelihood function that is marginal to both tho individual ffects and the initial conditions ran be derived and maximized using standard numerical procelures. The weond apporow spreifice the distribution of the individual effects conditional on the initial conditions and

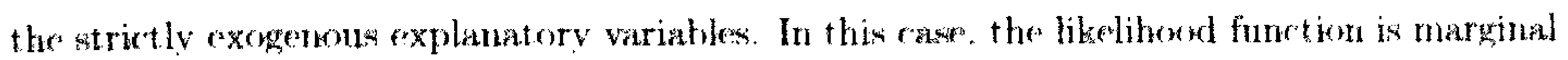
te the individual effects but conditional on the initial ronditions. Ituder the assumption of correct specification of the distribution of the errors beth appreaches yeld consigtent estimates of the paraneters of the model. The Heckman approach is fairly difficute to implement "vall more wo when the model comsists of more than cone equation. The" Wooldridge approarh. on the other hand. is easy to implement and flexible in the sense that it applies to a wide range of nonlinear dynamic panel data models. Furthermore. the likelihod function derived in this approach has the same strueture for both the dynamie and the statio versions of the nomlinear model. This study extends this latter approach to models containing nore than one equation. The appronch is described as follows.

The individual offects are assumed, in each period. to be linear in the strictly exogenous explanatory variables and the initial conditions, i.e.

$$
\eta_{n}=b_{0}^{*}+b_{1}^{*} d_{30}+\mathbf{b}_{2}^{\prime s} \mathbf{w}_{i}+a_{1}
$$

and

$$
\alpha_{1}=b_{0}^{r}+b_{1}^{r} y_{10}+b_{2}^{r} \mathbf{x}_{1}+a_{21}
$$

where $\mathbf{w}_{t}^{\prime}=\left(\mathbf{w}_{i 1}^{\prime}, \ldots, \mathbf{w}_{i T}^{\prime}\right), \mathbf{x}_{1}^{\prime}=\left(\mathbf{x}_{11}^{\prime}, \ldots, \mathbf{x}_{i T}^{\prime}\right), b_{0}^{*}, b_{1}^{*}, \mathbf{b}_{2}^{\prime *}, b_{0}^{r}, b_{1}^{r}$ and $\mathbf{b}_{2}^{\prime r}$ are to be estimated. and $a_{1}$, and $a_{2,}$ are independent of $\left(d_{x(1} . w_{1}\right)$ and $\left(y_{11}, \mathbf{x}_{2}\right)$ respectively. ${ }^{6}$ The scalars $b_{1}^{4}$ and $b_{1}^{r}$ capture the dependence of the individual effects on the initial conditions. The vectors $\left(\epsilon_{1,}, \epsilon_{2 t}\right)^{\prime}$ and $\left(a_{1 t}, a_{2 s}\right)^{\prime}$ are assumed independent of each other. and independently and identically distributed over time and across individuals following a normal distribution with mean zero and covariance matrix

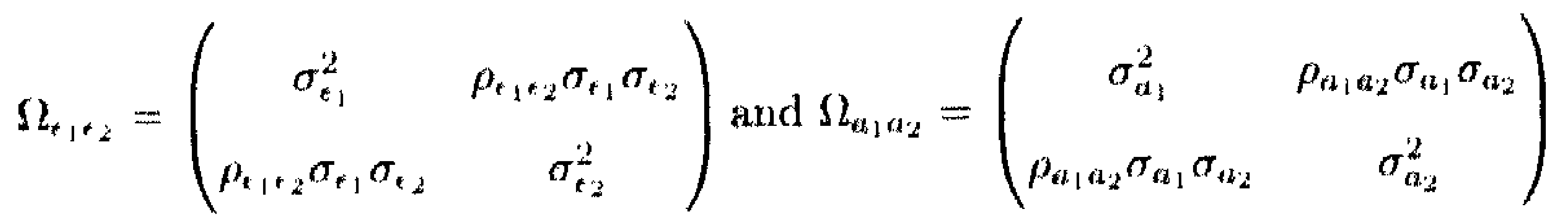

respetively. The parameters of the covariance matrices are also to be extimated. Hence, the:

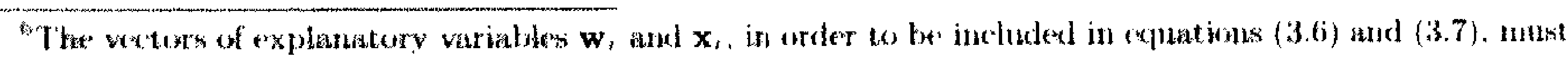

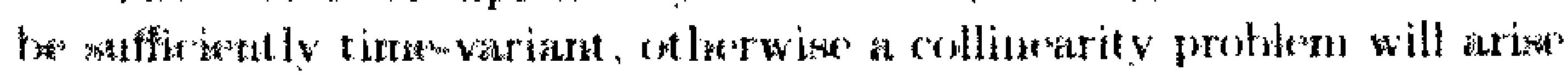


likelihood function of individual $i$, starting from $t=1$ and conditional on the regressors and the initial conditions. is written as

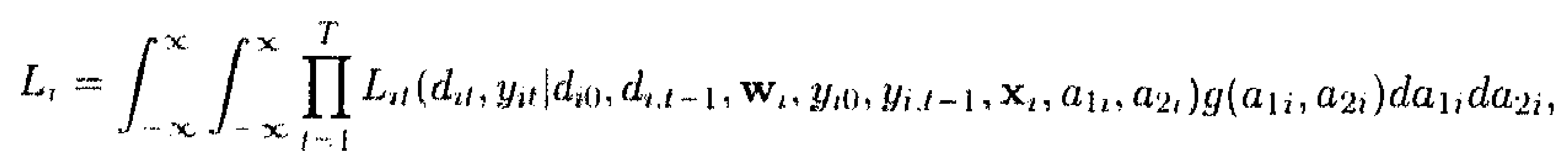

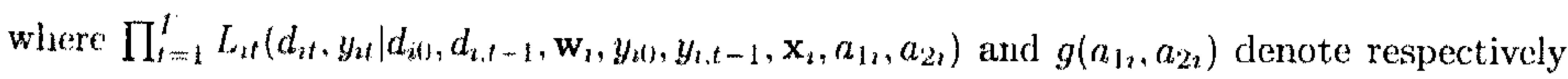
the likelihood function of individual $i$ conditional on the individual effects, and the bivariate normal density function of $\left(a_{1 i}, a_{22}\right)$. Define

$$
A_{t t}=\rho d_{1, t-1}+\delta^{\prime} \mathbf{w}_{3 t}+b_{0}^{s}+b_{1}^{s} d_{i t)}+\mathbf{b}_{2}^{\prime s} \mathbf{w}_{l}
$$

and

$$
B_{a t}=\gamma \mu_{l . t-1}+\beta^{\prime} \mathbf{x}_{l t}+b_{0}^{r}+b_{1}^{r} y_{t l}+\mathbf{b}_{2}^{\prime \prime} \mathbf{x}_{t},
$$

the individual likelihood function conditional on the individual effects is written as

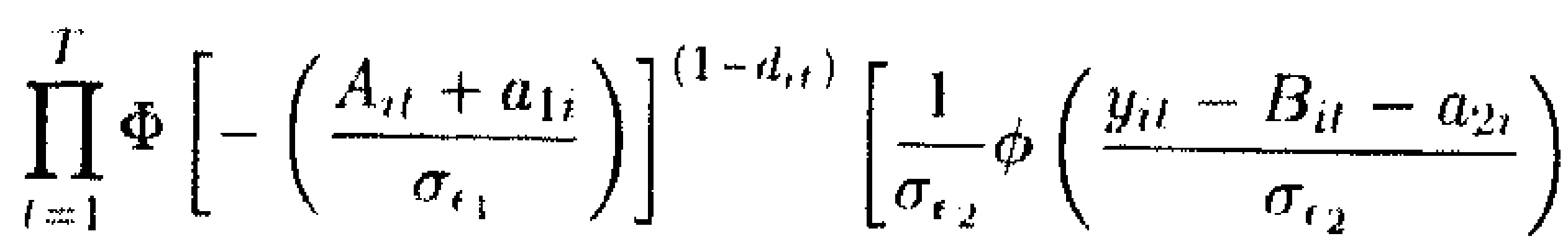

$$
\begin{aligned}
& \left.\times \Phi\left(\frac{A_{i t}+a_{1 t}+\rho_{t 1 \epsilon_{2}} \frac{a_{\tau_{1}}}{\sigma_{22}}\left(y_{1 t}-B_{i t}-a_{2 t}\right)}{\sigma_{\ell 1} \sqrt{1-\rho_{t_{1+2}}^{2}}}\right)^{f_{t t}}\right],
\end{aligned}
$$

when the selection rule is binary and

$$
\begin{aligned}
& \prod_{t=1}^{T} \Phi\left[-\left(\frac{A_{2 t}+a_{1 t}}{\sigma_{t 1}}\right)\right]^{\left(1-s_{z t}\right)}\left[\frac{1}{\sigma_{t ; 2}} \phi\left(\frac{y_{i t}-B_{i t}-a_{2 i}}{\sigma_{\epsilon \cdot 2}}\right)\right.
\end{aligned}
$$

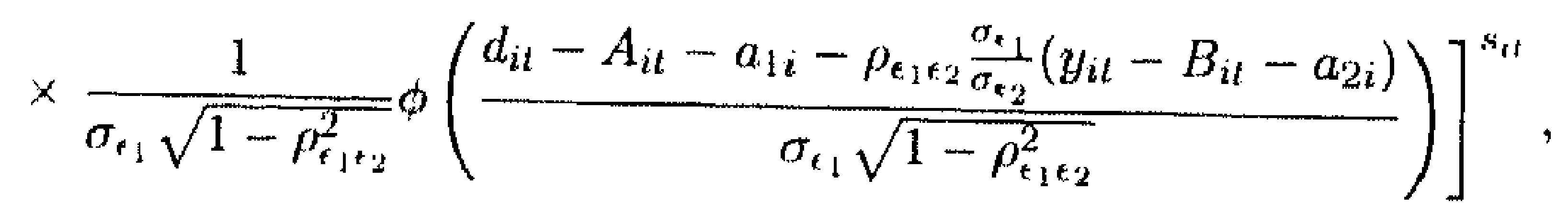

when the selection rule is censored. ${ }^{7}$ In equations (3.12) and (3.13), $\phi$ and $\Phi$ denote respectively the univariate standard normal density and cumulative distribution functions, $s_{i l}$ is defined in the type 3 tobit as

$$
s_{i t}=1\left[d_{i t}^{*}>0\right]^{*}
$$

\footnotetext{
The individual likelihos function conditional on the individual effects is the product over time of indi-

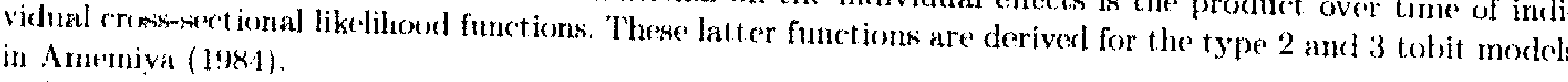

"In the type 2 tobit model, explations (3.4) and (3.14) are equivalent so that $x_{t}=d_{a t}$, anel $\sigma_{t}$, camot be idertitient and is net 610 in erpation $(3.12)$.
} 


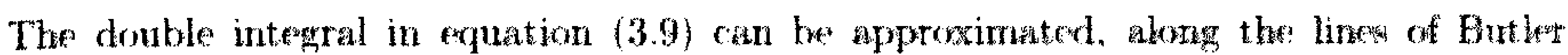
and Noffit (1982). by "two-step" Ganss-Hernite quadrature (sfo Appendix "3.A) so that th" random-effects individual likelihood functions of the type 2 and type 3 tobit madel becone respetively

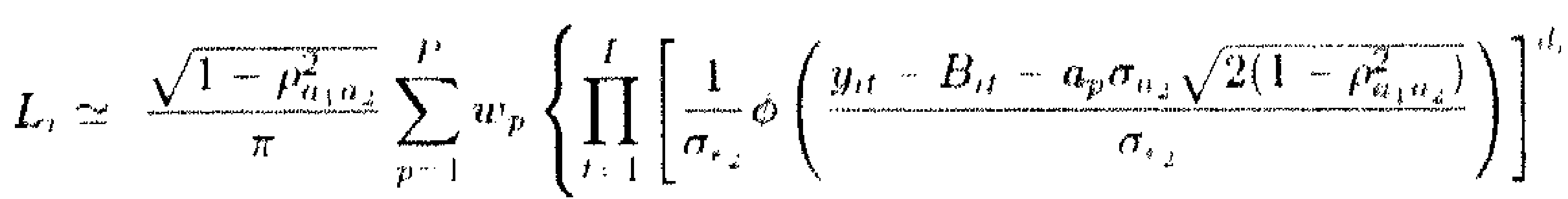

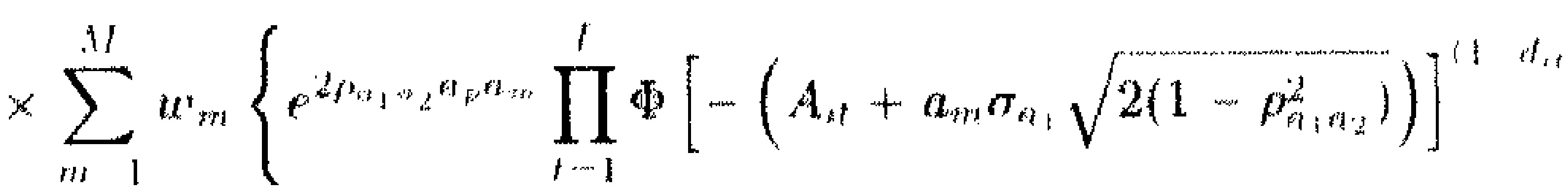

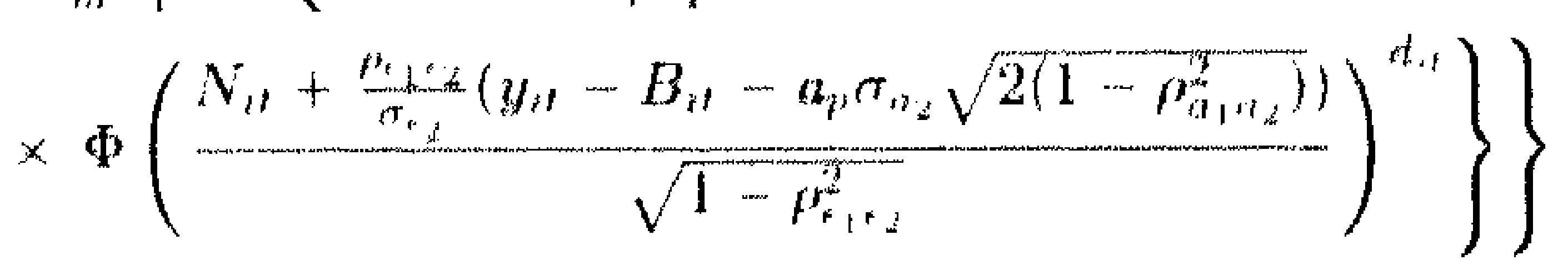

and

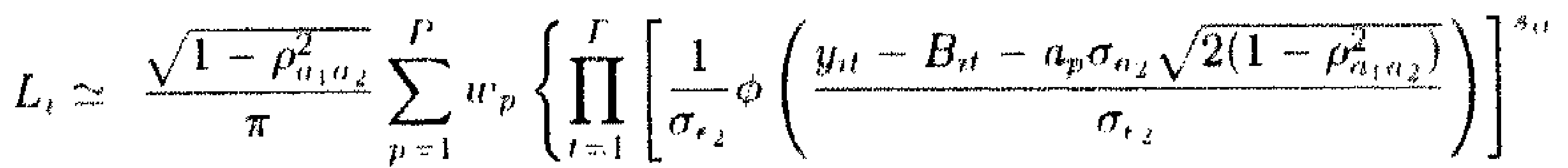

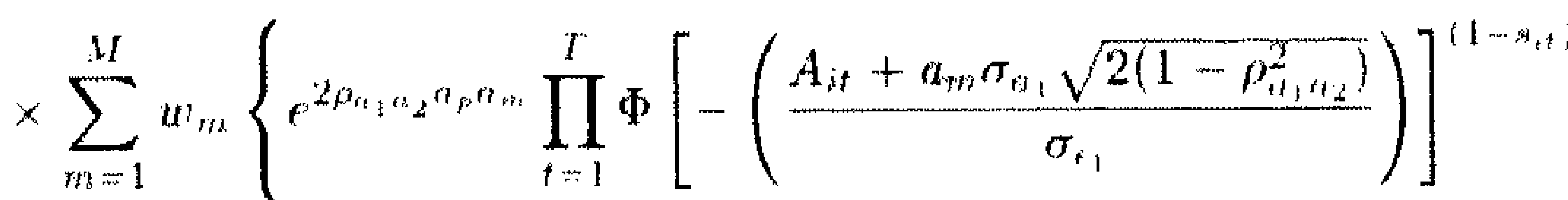

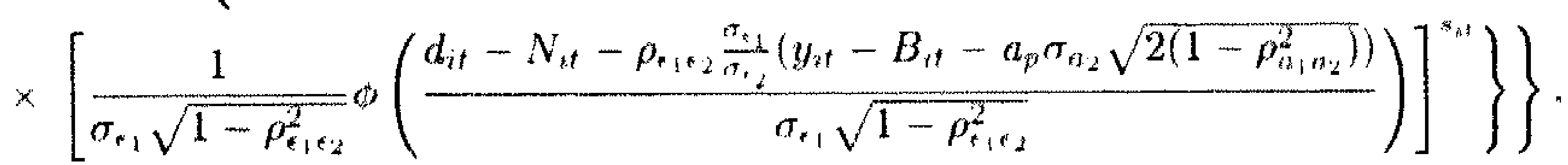

where $w_{m}, w_{p} . a_{m}$ and $a_{p}$ are respectively the woights and abscissas of the first- and secondstep Gaus-Hermite quadrature with $M$ and $P$ being the first and second-step total number of integration points, and $N_{t}$ is written as

$$
N_{i t}=A_{i t}+a_{n t} \sigma_{a_{1}} \sqrt{2\left(1-\rho_{a_{1+2}}^{2}\right)}
$$

The product over $i$ of the approximate likelihood functions ( 3.15$)$ and (3.16) can be maximized using standard numerical procedures to obtain estimates of the parameters of the dynamic type 2 and type 3 tobit models.

Our approach luandles the estimation, by maximum likelihood, of a wide range of linear and nonlinear panel data models. Indeed, equations (3.15) and (3.16) encompass the likelihood functions of the models which are obtained by restrieting the values of certain parameters of the dynamic sample selection models (so "Table 3.8 of Appendix 3.B). For instance, if $\rho_{a_{1} a_{2}}=\rho_{c_{1} e_{2}}=0$ and the remuining parameters are unrestricted, the likelihood 
functions are the product of the likelihood functions of a dynamic random-effects probit and a dynamic random-effects linear regression (eq. (3.15)), and that of the likelihood functions of a dynamic random-effects type 1 tobit and a dynamic random-effects linear regression (eq. (3.16)). In other words, when there is no selection bias, estimating a dynamic type 2 (type 3 ) tohit amounts to estimating separately a dynamic probit (typo 1 tobit) and a dynamic linear regression. The parameter restrictions listed in Table 3.8 can be tested using a standard likrlihood ratio or Wald test.

We now present Monte Carlo simulations to study the small sample behavior of the maximum likelihood estimator of the type 2 and type 3 tobit models.

\subsection{Monte Carlo study}

The data arc generated according to the following "true" model

$$
\begin{aligned}
& d_{i t}^{*}=\rho d_{t, t-1}+\delta w_{i t}+\eta_{t}+\epsilon_{1 i t}, \\
& y_{i t}^{*}=\gamma y_{t, t-1}+\beta x_{1 t}+\alpha_{2}+\epsilon_{2 i t},
\end{aligned}
$$

where $u_{z t}$ and $x_{n t}$ are generated according to the standard normal distribution and are independent of each other, $\left(\epsilon_{1 i t}, \epsilon_{2 i t}\right)$ is generated according to the bivariate normal distribution with mean zero and covariance matrix defined as in equation (3.8) (first matrix). The individual effects $\left(\eta_{i}, \alpha_{i}\right)$ are generated independently of $\left(\epsilon_{1 i t}, \epsilon_{2 i t}\right)$ according to the bivariate normal distribution with mean $\left(d_{30}, y_{10}\right)$ and covariance matrix defined as in equation (3.8) (second matrix). The dependent variables of the equation of interest and the selection rules are defined as in equations (3.3-3.5), i.e., both the type 2 and type 3 tobit are considered.

The true parameter values are $\delta=\beta=1, \sigma_{a_{1}}=\sigma_{a_{2}}=\sigma_{\epsilon_{2}}=0.5, \sigma_{\epsilon_{1}}=1, \rho_{t_{1} a_{2}}=0.5$, $\rho_{f_{1}+2}=0.8$, and two sets of values are chosen for $\rho$ and $\gamma$, namely $\rho=\gamma=0$ when the model is static, and $\rho=\gamma=0.5$ when the model is dymamic.

Given these values of the parameters, sample selection is not constant over time, i.e. the selection ontcome $d_{i t}$ (or $s_{i t}$ ) has a rather high within standard deviation (around 0.40) for the (dynamic and static) type 2 and type 3 tobit. Furthermore, the censoring rate over the whole period, for both models, is approximately $40 \%$ and $50 \%$ in the dynamic and the static settings respectively. Finally, the correlation between the individual effects and the initial 
conditions for the type 2 and type 3 tobit is 0.70 and 0.80 in the selection equation, and 0.80 for both models in the equation of interest.

To summarize, the data generating process (DGP) at the initial period is standard type 2 (type 3 ) tobit while the remaining period DGP is dynamic type 2 (type 3 ) tobit with endogenous initial conditions correlated with the individual effects, and accounting for selection bias correction (SBC). The static DGP is obtained by setting the true values of $\rho, \gamma$ to 0 .

The estimation results of $\rho, \gamma, \delta, \beta, \sigma_{a_{1}}, \sigma_{a_{2}{ }_{2}}, \rho_{a_{1} a_{2} 2}$ and $\rho_{\epsilon_{1} \epsilon_{2}}$ based on 200 replications are shown in Tables 3.2-3.7 for the following sample sizes: $N=500$ and $T=4, N=500$ and $T=$ 7 , and $N=800$ and $T=4$. We report the mean and standard deviation over the replications of these estimates." In each replication, the estimation is based on $T-1$ periods, the first one being the initial period. We study the small sample behavior of the maximum likelihood estimator (MLE) of the above-mentioned parameters when the model is both correctly and incorrectly specified. More specifically, when the DGP is dynamic, misspecification includes a dynamic model with no individual effects but SBC; with individual effects, exogenous initial conditions and SBC; with individual effects, endogenous initial conditions but no SBC; and a static model with individual effects and SBC. When the DGP is static, misspecification includes a static model with no individual effects but SBC; with individual effects but no SBC; and a dynamic model with no individual effects but SBC, and with individual effects and endogenous initial conditions correlated with the individual effects and SBC.

We now discuss the Monte Carlo results.

\subsubsection{The MLE behavior when the model is correctly specified}

The mean and standard deviation of the MLE of $\rho, \gamma, \delta, \beta, \sigma_{a_{1}}, \sigma_{a_{2}}, \rho_{a_{1} a_{2}}$ and $\rho_{\mathrm{f}_{1} c_{2}}$, when the model is correctly specified, are reported in Table 3.2 .

The MLE of $\delta$ and $\beta$ in both the dynamic and static type 2 and type 3 tobit is biased towards zero. The bias does not exceed $2 \%$ and $0.7 \%$ for $\delta$ and $\beta$ in the type 2 tobit, and $3.5 \%$ and $0.8 \%$ in the type 3 tobit. There is no clear pattern of bias reduction as either $T$ or $N$ increases. In all cases but the dynamic type 2 tobit with $N=800$ and $T=4$, the estimate of $\beta$ is on average closer to the true value than that of $\delta$. In both the type 2 and type 3 tobit, the estimates of $\delta$ and $\beta$ are closer to the true values in the static case than in the dynamic case, except in the dynamic type 2 tobit with $N=800$ and $T=4$ where the pattern shows up

\footnotetext{
${ }^{3}$ We do not report the estimale results of $\sigma_{t,}$ (for the type 3 tobit), $\sigma_{i, 2}$, and the additional parameters of equations (3.6) and $(3.7)$.
} 
the other way round in the estimate of $\delta$. From this, we can conclude that it is more difficult to estimate accurately the coefficients of the strictly exogenous explanatory variables in both the selection equation and the equation of interest of dynamic panel data sample selection models than those of their static counterparts.

The MLE of $\rho$ and $\gamma$ is also biased towards zero in both the dynamic type 2 and type 3 totit. The bias does not exceed $2 \%$ and $4.7 \%$ for $\rho$ and $\gamma$ in the type 2 tobit, and $3.5 \%$ and $4.2 \%$ in the type 3 tobit. Like $\delta$ and $\beta$, there is no clear pattern of bias reduction as either $T$ or $N$ increases, and the MLE bias of $\rho$ and $\gamma$ is overall larger than that of $\delta$ and $\beta$. As a result, we can state that it is more difficult to estimate accurately the coefficients of the lagged dependent variables than those of the strictly exogenous variables in both the selection equation and the equation of interest of dynamic panel data sample selection models.

In both models. $\sigma_{a_{1}}$ and $\sigma_{a_{2}}$ are much less accurately estimated than $\rho, \gamma, \delta$ and $\beta$, even though their bias remains touards zero. For both models, the bias is smaller in the static case than in the dynamic case. In all cases but, for $\sigma_{a_{1}}$ when $N=500$ and $T=7$, the bias is smaller in the type 2 tobit than in the type 3 tobit. The two models exhibit different patterns in the bias reduction as $T$ increases. Indeed, the type 2 tobit shows an increase in the MLE bias of $\sigma_{a_{1}}$ and $\sigma_{a_{2}}$ that is more pronounced for $\sigma_{a_{1}}$ than it is for $\sigma_{a_{2}}$. The increase in the MLE bias of $\sigma_{a_{1}}$, as $T$ increases, confirms the results by Rabe-Hesketh et al. (2005) that show that the MLE of the standard deviation of the individual effects in random-effects probit models is biased away from zero for large cluster size $T$, with a bias that ranges from $19 \%$ for $T$ as small as 10 to $178 \%$ for $T$ as large as 500 . The type 3 tobit on the other hand shows a decrease in the bias of the MLE of $\sigma_{a_{1}}$ and $\sigma_{a_{2}}$ that is more pronounced for $\sigma_{a_{1}}$ than it is for $\sigma_{a_{2}}$. As $N$ increases, the bias reduction pattern is not clear cut, especially in the type 3 tobit.

Finally, in both models, the MLE of $\rho_{u_{1} a_{2}}$ is biased away from zero with a bias of about $25 \%$, while that of $\rho_{r_{1} t_{2}}$ is biased away from zero in the type 2 tobit and towards zero in the type 3 tobit. This bias decreases only slightly as $T$ increases, while there is no clear pattern of reduction as $N$ increases.

To summarize, we can state that, when the model is correctly specified, the MLE bias of the parameters of panel data sample selection models is very small for a sample size as large as the one considered in the Monte Carlo study. The "two-step" Gauss-Hermite quadrature used to approximate the likelihood function works very well, even for a number of integration 


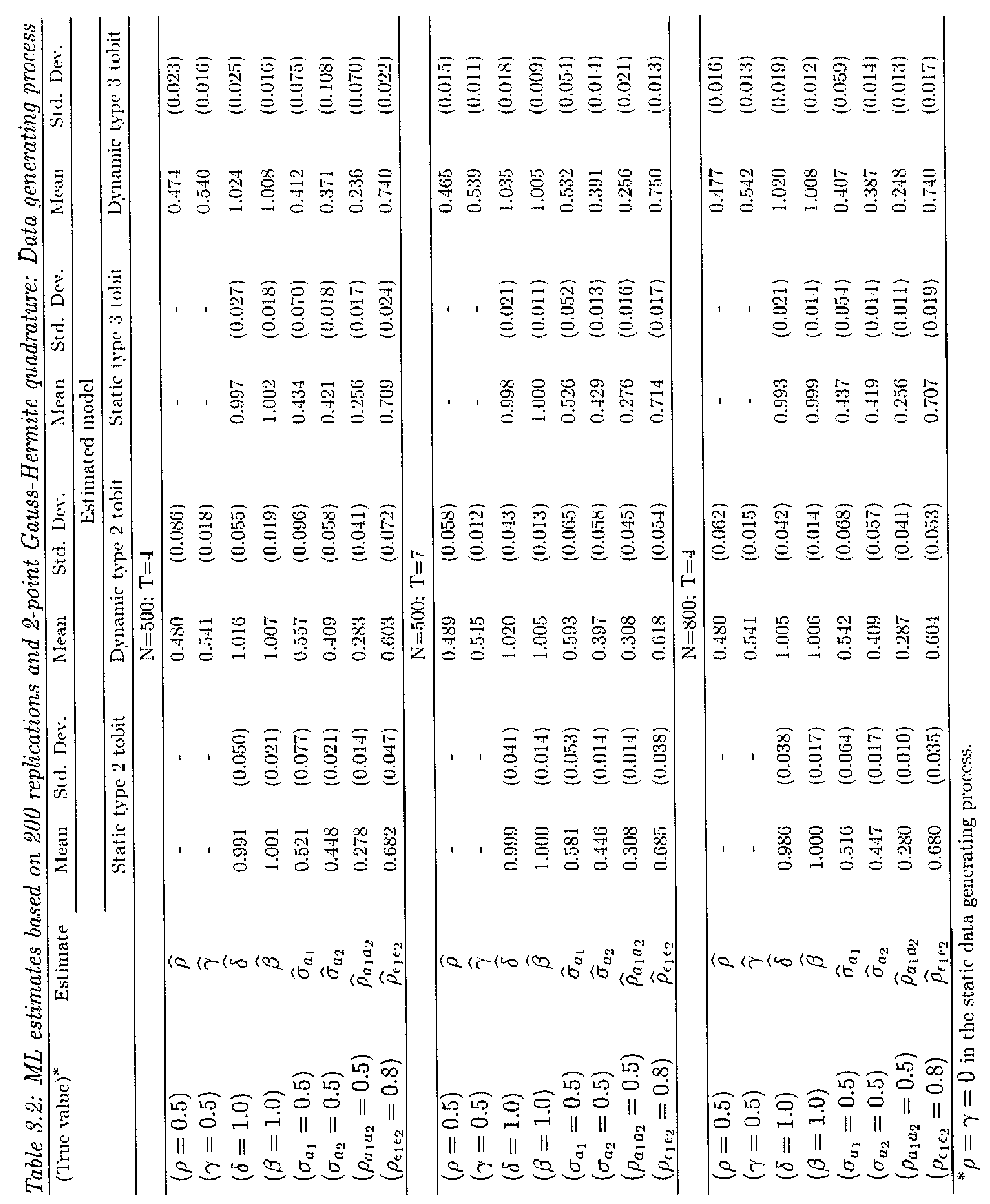


prints. in each step. as small as 2. However. the standard deviations of the individual effects and the sample selection terms are less accurately estimated than the remaining parameters of Tabbe 3.2. Accuracy in the estimates can be gained by either increasing the nutnber of integration points or using adaptive Gauss-Hermite quadrature in the spirit of Rabe-Hesketh et al. $(2005))^{10}$

We now discuss the behavior of the MLE when the model is incorrectly specified.

\subsubsection{The MLE behavior when the model is incorrectly specified}

The mean and standard deviation of the MLE of $\rho, \gamma, \delta, \beta, \sigma_{a_{1}}, \sigma_{a_{2}}, \rho_{a_{1} a_{2}}$ and $\rho_{\mathrm{t}_{1+2}}$, when the model is incorrectly specified, are reported in Tables 3.3-3.7. More specifically, we study the finite sample bias of the MLE when we fail to account for individual effects, when we assume exogenous initial conditions and when we fail to correct for selection bias. We also study the case where a static model is stimated under a dynamic DGP and vice verst.

\section{No individual effects}

Table 3.3 reports the mean and standard deviation of the MLE of $\rho, \gamma, \delta, \beta$ and $\rho_{\mathrm{t}_{1} \epsilon_{2}}$ when the individual effects, while being present in the DGP, are ignored in the estimation of the model, i.e. $\sigma_{s_{1}}, \sigma_{a_{1} z_{2}}$ and $\rho_{a_{1} a_{2}}$ are all assumed to be zero.

The MLE of 3 remains biased towards zero in all cases. In other words, the MLE bias of the coefficient of the strictly exogenous explanatory variable in the equation of interest is unaffected if we fail to account for individual effects. This result holds regardless of the type of the selection rule, and regardless of whether the model is dynamic or static. The MLE of $\delta$ also remains biased touards zero in the type 3 tobit and in the static type 2 tobit with a larger bias than that of $\beta$. In the dynamic type 2 tobit, however, the MLE of $\delta$ is biased away from zero with a bias that is always larger than $15 \%$. Hence, unlike $\beta$, when we fail to account for individual effects, the MLE behavior of the coefficient of the strictly exogenous explanatory variable in the selection equation differs according to the type of the selection rule and according to whether the model is dynamic or static.

In the dynamic version of the model, the MLE of $\rho$ and $\gamma$ is biased away from zero and upwards in all cases, with a bias that gets as large as $61 \%$ in the type 2 tobit, and $55 \%$ in the

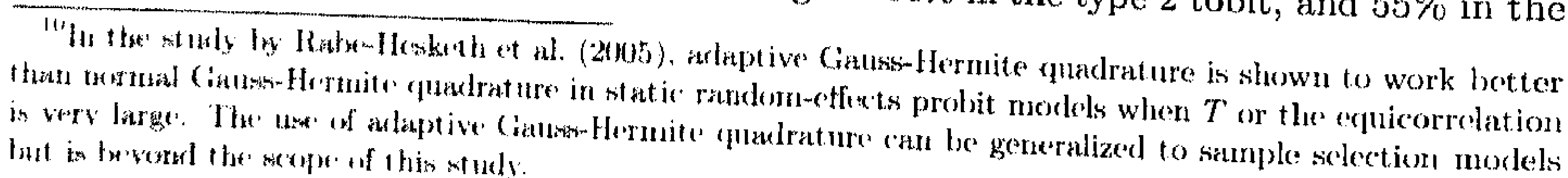




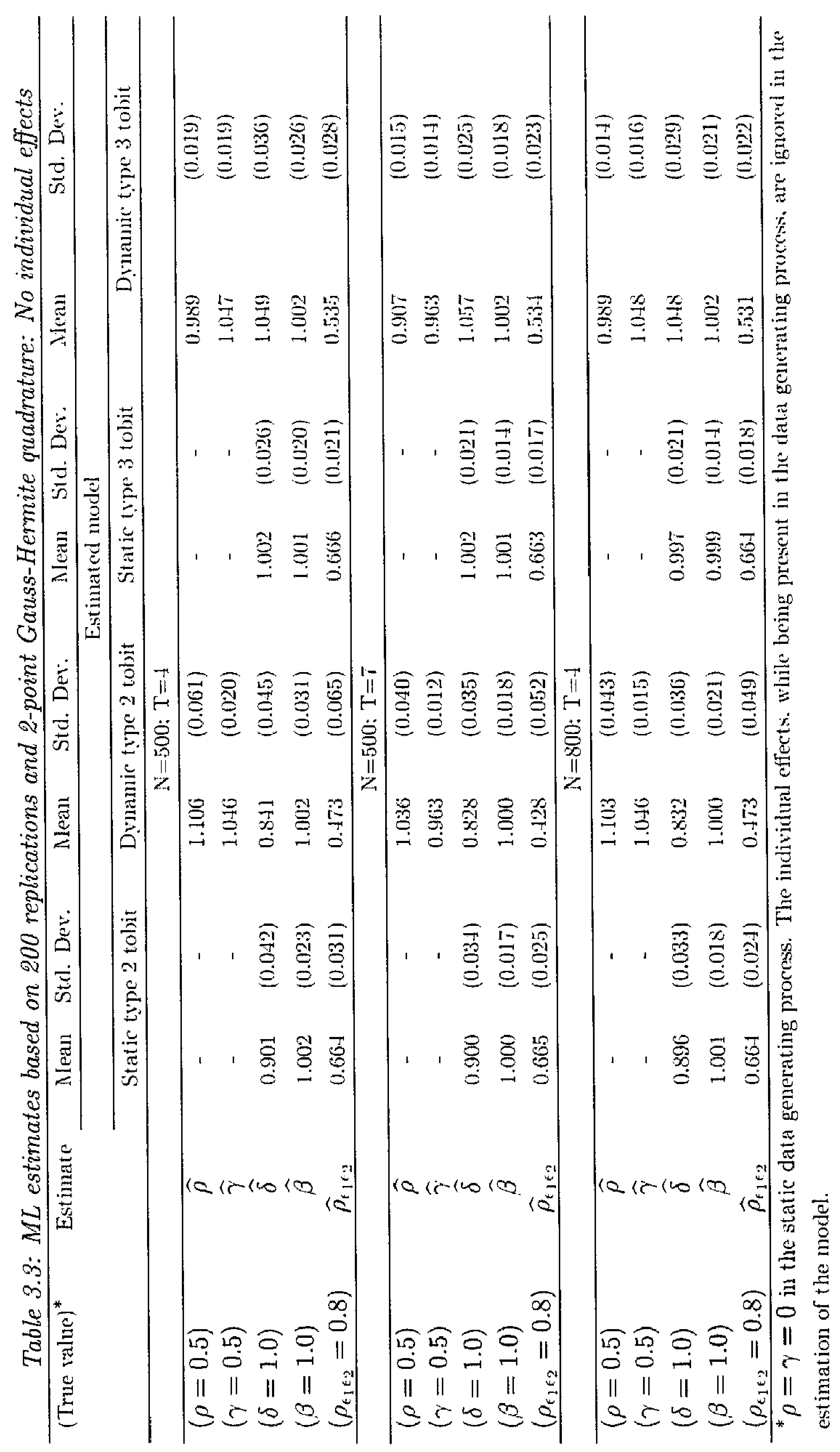


type 3 tot.ut. This biam is reduced fairly substantially (by about $9 \%$ ) as $T$ increases but remains wery high. and is unchanged as $N$ increases. In other words, when estimating the dynamic wersing of tho model and failing to arcount for individual effects, the coefficients of the lagged deprendot explanatory variables. in both the selection equation and the equation of interest, are watestimated. In the dynamic panel data discrete choice model, this phenomenon is knewan ats spurtots state dependenep (Herkman. 1981a). i.e. too much credit is attributed to

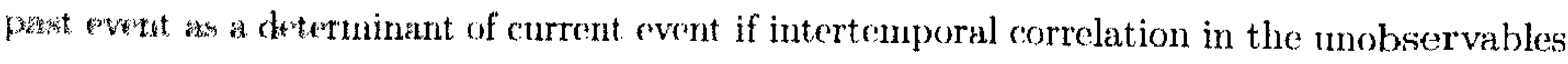
is rut acconnted for.

Finally, the MLE of $p_{3+2}$ is biased away from zoro with a bias of about $25 \%$ in the static

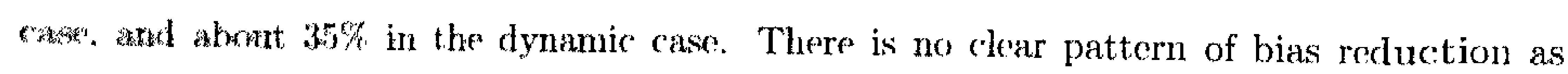
enther $T$ or $N$ increases.

\section{Exogenous initial conditions}

Tabla 3.4 reports the mean and standard deviation of the MLE of $\rho, \gamma, \delta, \beta, \sigma_{a_{1}}, \sigma_{a_{2}}, \rho_{a_{1} a_{2}}$ and $\rho_{e n}$ when the initial conditions, while being endogenous and correlated with the individual effects in the DGP, are assumed to be exogenous, i.e., $b_{1}^{*}$ and $b_{1}^{r}$ are assumed to be zero.

In bath the type 2 and type 3 tobit, the MLE bias of $\delta$ and $\beta$ increases by about $6 \%$ with respect to the case of the DGP but remains fairly small, less than $9 \%$ in the type 2 tobit, and las than $11 \%$ in the type 3 tobit. As for the MLE of $\rho$ and $\gamma$, their bias remains sibustantially large compared to the case where the individual effects are ignored. Accounting for individual effects but assuming exogenous initial conditions also results in a spurious stata dependence situation." Hence, we can state that, in order for the coefficients of the lagext doperydent explanatory variables to be accurately estimated, the correlation between the initial conditions and the individual effects must be taken into account: controlling for incividual effects only is not sufficient. As $T$ increases, the MLE bias of $\rho$ and $\gamma$, in both the type 2 and type 3 tobit, decreases by about $10 \%$ but remains substantially large, while, as $N$ increaseses, the bias remains the same. Finally, the MLE bias of $\rho_{a_{1} a_{2}}$ and $\rho_{t_{1}+2}$ is higher than in the DGP case, and that of $\sigma_{a_{1}}$ and $\sigma_{a_{2}}$ is comparable to that of the same parameters in the DGP catse.

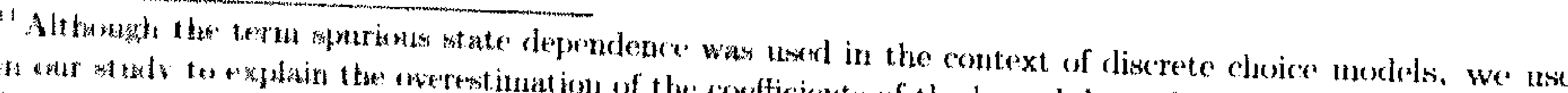

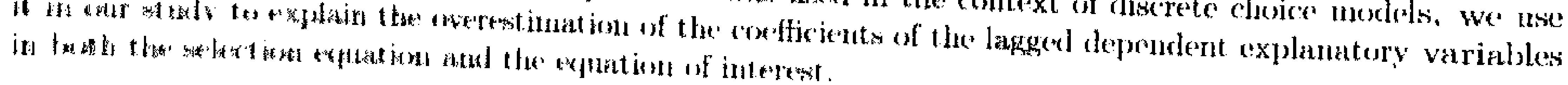


Table 3.4: ML estimates based on 200 replications and 2-point Gauss-Hermite quadrature:

\begin{tabular}{|c|c|c|c|c|c|}
\hline \multirow{3}{*}{ (True value) $^{*}$} & \multirow{3}{*}{ Estimate } & Nean & Sid. Dev. & Motul & Sta. Dev. \\
\hline & & \multicolumn{4}{|c|}{ Estimaterl model } \\
\hline & & \multicolumn{2}{|c|}{ Dynamic: type ? tobit } & \multicolumn{2}{|c|}{ Dymamic type 3 tobit } \\
\hline & & \multicolumn{2}{|c|}{$\mathrm{N}=500: T=4$} & & \\
\hline$(\rho=0.5)$ & $\widehat{p}$ & 1.115 & $(0.069)$ & 0.924 & $(0.020)$ \\
\hline$(\gamma=0.5)$ & $\widehat{\gamma}$ & 0.067 & $(0.026)$ & 0.973 & $(0.024)$ \\
\hline$(\delta=1,0)$ & $\delta$ & 0.923 & $(0.051)$ & $1.080^{\circ}$ & $(0.0355)$ \\
\hline$(\beta=1.0)$ & $\widehat{\beta}$ & 1.062 & $(0.030)$ & 1.071 & $(0.025)$ \\
\hline$\left(\sigma_{a_{1}}=0.5\right)$ & $\widehat{\sigma}_{a_{1}}$ & 0.571 & $(0.080)$ & 0.583 & $(0.078)$ \\
\hline$\left(\sigma_{a_{2}}=0.5\right)$ & $\widehat{\sigma}_{a \cdot 2}$ & 0.458 & $(0.175)$ & 0.182 & $(0.177)$ \\
\hline$\left(\rho_{a_{1} a_{2}}=0.5\right)$ & $\hat{\rho}_{a_{1} a_{2}}$ & 0.229 & $(0,088)$ & 0.214 & $(0.080)$ \\
\hline$\left(\rho_{t_{1} \leftarrow 2}=0.8\right)$ & $\hat{\rho}_{t+2+2}$ & 0.411 & $(0.0955)$ & 0.560 & $(0.034-4)$ \\
\hline \multicolumn{6}{|c|}{$\mathrm{N}=5000: \mathrm{T}=7$} \\
\hline$(\rho=0.5)$ & $\widehat{\rho}$ & 1.0330 & $(0.045)$ & 0.829 & $(0.017)$ \\
\hline$(\gamma=0.5)$ & $\widehat{\gamma}$ & 0.8663 & $(0.016)$ & 0.869 & $(0.019)$ \\
\hline$(\delta=1.0)$ & $\widehat{\delta}$ & 0.915 & $(0.0: 10)$ & 1.102 & $(0.024)$ \\
\hline$(\beta=1.0)$ & $\widehat{\beta}$ & 1.048 & $(0.017)$ & 1.0 .51 & $(0.016)$ \\
\hline$\left(\sigma_{n_{1}}=0.5\right)$ & $\widehat{\sigma}_{a_{1}}$ & 0.6332 & $(0.0 .58)$ & 0.718 & $(0.075)$ \\
\hline$\left(\sigma_{a_{2} 2}=0.5\right)$ & $\widehat{\sigma}_{a_{2}}$ & 0.5332 & $(0.076)$ & 0.538 & $(0.159)$ \\
\hline$\left(\rho_{a_{1} a_{2}}=0.5\right)$ & $\hat{\rho}_{a_{1} a_{2}}$ & 0.266 & $(0.0411)$ & 0.240 & $(0.073)$ \\
\hline$\left(\rho_{\mathrm{c}_{1} \mathrm{C}_{2}}=0.8\right)$ & $\hat{\rho}_{f_{1} f_{2}}$ & 0.403 & $(0.080)$ & 0.586 & $(0.027)$ \\
\hline \multicolumn{6}{|c|}{$\mathrm{N}=800 ; \mathrm{T}=-1$} \\
\hline$(\rho=0.5)$ & $\widehat{\rho}$ & 1.113 & $(0.480)$ & $0.92+t$ & $(0.017)$ \\
\hline$(\gamma=0.5)$ & $\widehat{\gamma}$ & 0.968 & $(0.019)$ & 0.974 & $(0.020)$ \\
\hline$(\delta=1.0)$ & $\delta$ & 0.914 & $(0.039)$ & 1.085 & $(0.029)$ \\
\hline$(\beta=1.0)$ & $\beta$ & 1.060 & $(0.020)$ & 1.071 & $(0.019)$ \\
\hline$\left(\sigma_{a_{1}}=0.5\right)$ & $\widehat{\sigma}_{a_{1}}$ & 0.563 & $(0.057)$ & 0.587 & $(0.058)$ \\
\hline$\left(\sigma_{u_{2}}=0.5\right)$ & $\widehat{\sigma}_{a_{2}}$ & 0.187 & $(0.027)$ & 0.503 & $(0.102)$ \\
\hline$\left(\rho_{a_{1} a_{2}}=0.5\right)$ & $\widehat{\rho}_{a_{1} a_{2}}$ & 0.247 & $(0.012)$ & 0.224 & $(0.046)$ \\
\hline$\left(\rho_{\varepsilon_{1} k_{2}}=0.8\right)$ & $\hat{p}_{+1 \leqslant 2}$ & 0.406 & $(0.069)$ & 0.557 & $(0.025)$ \\
\hline
\end{tabular}

\section{No selection bias correction}

The mean and standard deviation of the MLE of $\rho, \gamma, \delta, \beta, \sigma_{a_{1}}$ and $\sigma_{a_{2}}$ are reported in Table 3.5 when we do not correct for the selection bias, i.e., we assume $\rho_{a_{1} a_{2}}$ and $\rho_{\mathrm{f}_{1} \epsilon_{2}}$ to be zero.

In both the type 2 and type 3 tobit and regardless of whether the model is dymamic or static, the MLE bias of the coefficients of the lagged dependent and strictly exogenous explanatory variables is unaffected. This result always holds for $\delta$ and $\beta$ when the strictly exogenous explanatory variables in the selection equation and in the equation of interest are not at all or only slightly correlated. When they are highly correlated, Monte Carlo results 


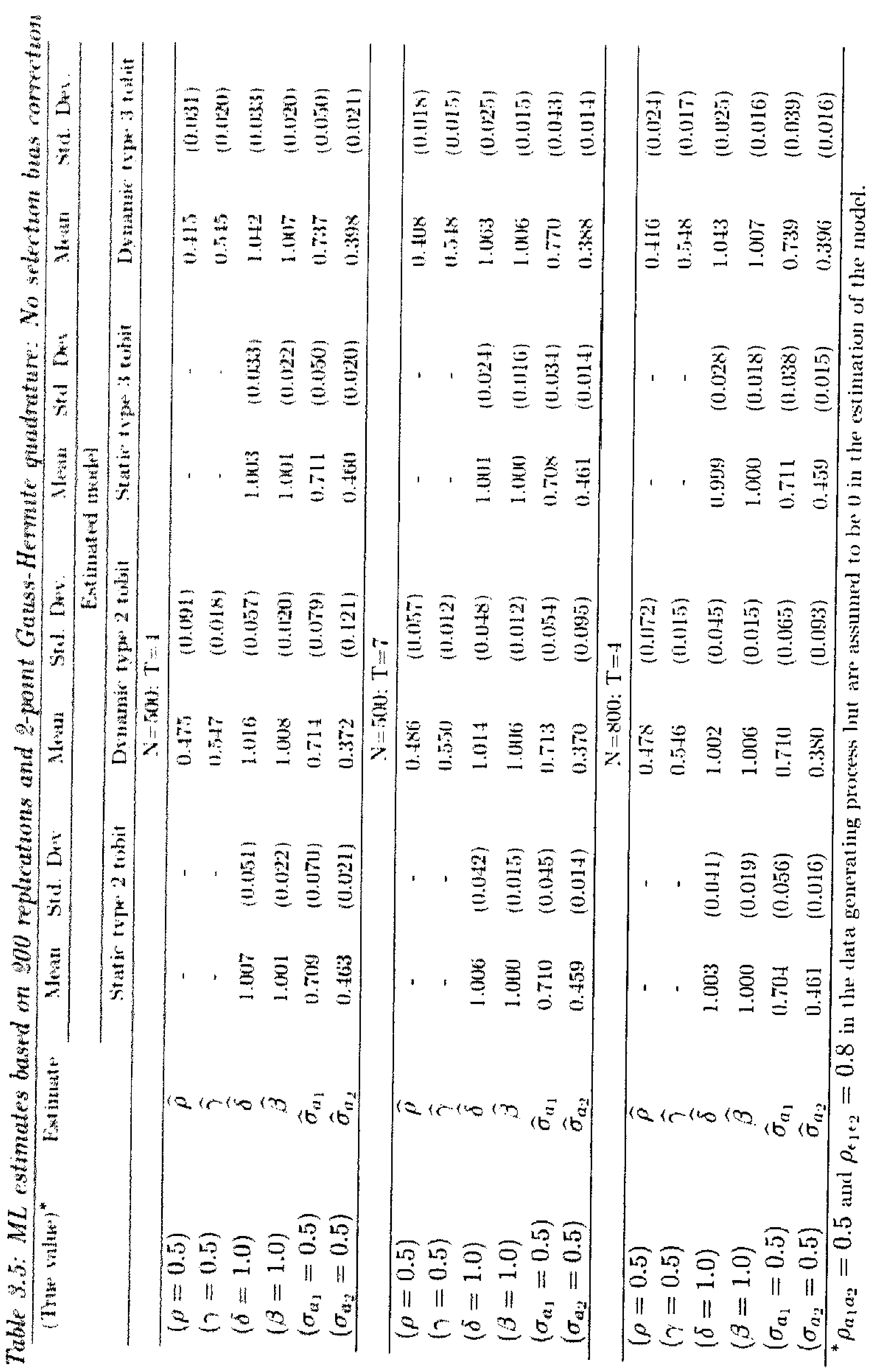


not reported here show that the MLE of the coefficients in the equation of interest are biased downwards while that of the coefficients in the selection equation remains unaffected. The most notable change occurs in the MLE of $\sigma_{a_{1}}$ which, in all cases, becomes biased away from zero, while that of $\sigma_{a_{2}}$ remains, in all cases but in the dynamic type 2 tobit, biased towards zero.

\section{Static model estimated under a dynamic DGP}

The MLE of $\delta, \beta, \sigma_{a_{1}}, \sigma_{a_{2},}, \rho_{a_{1} a_{2}}$ and $\rho_{\mathrm{f}_{1} c_{2}}$ are reported in Table 3.6 when a static model is estimated under a dynamic DGP, i.e., $\rho$ and $\gamma$ are assumed to be zero.

Table 3.6: $M L$ estimates based on 200 replications and 2-point Gauss-Hermite quadrature:

\begin{tabular}{|c|c|c|c|c|c|}
\hline \multirow[t]{3}{*}{ (True value) $^{*}$} & \multirow[t]{3}{*}{ Estimate } & Menn & Sicl. Dov. & Mean & Stu. Dev. \\
\hline & & \multicolumn{4}{|c|}{ Estimated model } \\
\hline & & \multicolumn{2}{|c|}{ Shatic type 2 lollit } & \multicolumn{2}{|c|}{ Static type 3 tobit } \\
\hline & & \multicolumn{2}{|c|}{$\mathrm{N}=500 ; \mathrm{T}=4$} & & \\
\hline$(\delta=1.0)$ & $\widehat{\delta}$ & $0.6 \mathrm{i} 82$ & $(0.047)$ & 1.338 & $(0.072)$ \\
\hline$(\beta=1.0)$ & $\widehat{\beta}$ & 0.909 & $(0.057)$ & 0.919 & $(0.060)$ \\
\hline$\left(\sigma_{a 1}=0.5\right)$ & $\widehat{\sigma}_{a_{1}}$ & 0.762 & $(0.102)$ & 2.075 & $(0.193)$ \\
\hline$\left(\sigma_{a_{2}}=0.5\right)$ & $\widehat{\sigma}_{a_{2}}$ & 1.408 & $(0.075)$ & 1.410 & $(0.079)$ \\
\hline$\left(\rho_{a_{1} a_{2}}=0.5\right)$ & $\hat{\rho}_{a_{1} a_{2}}$ & 0.248 & $(0.016)$ & 0.237 & $(0.018)$ \\
\hline$\left(\rho_{\mathrm{C}_{1} \epsilon_{2}}=0.8\right)$ & $\widehat{\rho}_{\epsilon_{1} \epsilon_{2}}$ & 0.345 & $(0.115)$ & 0.365 & $(0.077)$ \\
\hline \multicolumn{6}{|c|}{$\mathrm{N}=500: \mathrm{T}=7$} \\
\hline$(\delta=1.0)$ & $\widehat{\delta}$ & 0.688 & $(0.041)$ & 1.381 & $(0.057)$ \\
\hline$(\beta=1.0)$ & $\widehat{\beta}$ & 0.921 & $(0.038)$ & 0.931 & $(0.041)$ \\
\hline$\left(\sigma_{a_{1}}=0.5\right)$ & $\widehat{\sigma}_{a_{1}}$ & 0.865 & $(0.077)$ & 2.509 & $(0.106)$ \\
\hline$\left(\sigma_{a_{2}}=0.5\right)$ & $\widehat{\sigma}_{a_{2}}$ & 1.541 & $(0.068)$ & 1.583 & $(0.078)$ \\
\hline$\left(\rho_{a_{1} a_{2}}=0.5\right)$ & $\widehat{\rho}_{a_{1} a_{2}}$ & 0.279 & $(0.019)$ & 0.260 & $(0.018)$ \\
\hline$\left(\rho_{c_{1} \epsilon_{2}}=0.8\right)$ & $\widehat{\rho}_{t_{1} \in 2}$ & 0.389 & $(0.133)$ & 0.423 & $(0.073)$ \\
\hline \multicolumn{6}{|c|}{$\mathrm{N}=800: \mathrm{T}=4$} \\
\hline$(\delta=1.0)$ & $\widehat{\delta}$ & 0.679 & $(0.0 .34)$ & 1.347 & $(0.054)$ \\
\hline$(\beta=1.0)$ & $\widehat{\beta}$ & 0.908 & $(0.044)$ & 0.915 & $(0.047)$ \\
\hline$\left(\sigma_{a_{1}}=0.5\right)$ & $\widehat{\sigma}_{a_{1}}$ & 0.752 & $(0.086)$ & 2.079 & $(0.142)$ \\
\hline$\left(\sigma_{a_{2}}=0.5\right)$ & $\widehat{\sigma}_{a_{2}}$ & 1.4102 & $(0.057)$ & 1.403 & $(0.056)$ \\
\hline$\left(\rho_{a_{1} a_{2}}=0.5\right)$ & $\widehat{\rho}_{a_{1} a_{2}}$ & 0.249 & $(0.013)$ & 0.236 & $(0.015)$ \\
\hline$\left(\rho_{\epsilon_{1} \varepsilon^{2}}=0.8\right)$ & $\widehat{\rho}_{\epsilon_{1} \in 2}$ & 0.338 & $(0.105)$ & 0.365 & $(0.063)$ \\
\hline
\end{tabular}

In both the type 2 and type 3 tobit, the MLE of $\delta$ is biased away from zero, with a bias that is no less than $30 \%$, while the MLE of $\beta$ remains biased towards zero but with a larger bias than in the DGP case. Furthermore, the standard deviations of the individual effects are 
cowerestimated and their MLE brias gets as large as $200 \%$ for $\sigma_{a_{1}}$, and $100 \%$ for $\sigma_{n_{2}}$. In other wordis, when past event is a detorminant of current event and is left out of the explanatory variathes. tow mon credit is attributed to the individual effects as a determinant of current event. This is the reverse phenomenon of the spurious state dependence. Finally, $\rho_{a_{1} n_{2}}$ and $\rho_{1 .}$ are biased anday from zero with a bias of approximately $25 \%$ and $45 \%$ respectively.

\section{Dynamic model estimated under a static DGP}

We estimate two types of dynamic models under a static DGP. The first one ignores the individual effects, and the second one accounts for individual effects that are correlated with endogenonts initial conditions. In other words, the first type assumes $\sigma_{a_{1}}, \sigma_{a_{2}}$ and $\rho_{a_{1} a_{2}}$ to be all zero while the second one makes no restriction assumptions on the parameters of the mordel. The mean and standard deviation of the MLE of $\rho, \gamma, \delta, \beta, \sigma_{a_{1}}, \sigma_{a_{2}}, \rho_{a_{1} a_{2}}$ and $\rho_{\varepsilon_{1} r_{2}}$ are reported in Table 3.7 .

In both cases. the MLE of $\delta$ and $\beta$ are biased towards zero in the type 2 and type 3 tobit. However. the bias for $\delta$ is larger when we do not account for the individual effects than when we account for them. The most notable difference between the two cases lies in the estimates of the coefficients of the lagged dependent explanatory variables. They are positive, around 0.10 for $\rho$ and 0.15 for $\gamma$, and significantly different from zero when we do not account for the individual effects. In other words, ignoring the individual effects results in attributing credit to past event as a determinant of current event while the former does not condition at all the latter. This is an extreme case of the spurious state dependence mentioned earlier. When we accourt for individual effects that are correlated with endogenous initial conditions, these estimates become very close to zero, their true value, and the standard deviations of the individual effects are biased towards zero. Hence, when estimating a dynamic panel data model. regardless of whether the DGP is dynamic or static, the issues of properly accounting for the individuat effects and treating the initial conditions must be taken care of. As for $\rho_{a_{1} n_{2}}$, it is biased away from zaro in both the type 2 and type 3 tobit. whilo $\rho_{t, \epsilon_{2}}$ is biased away from zoro in the type 2 tobit, and in the typo 3 tobit with no individual effects. When individual effects that are correlated with endogenous initial conditions are accounted for, $\rho_{e 1 .}$ is biased towards zero in the type 3 tobit. 


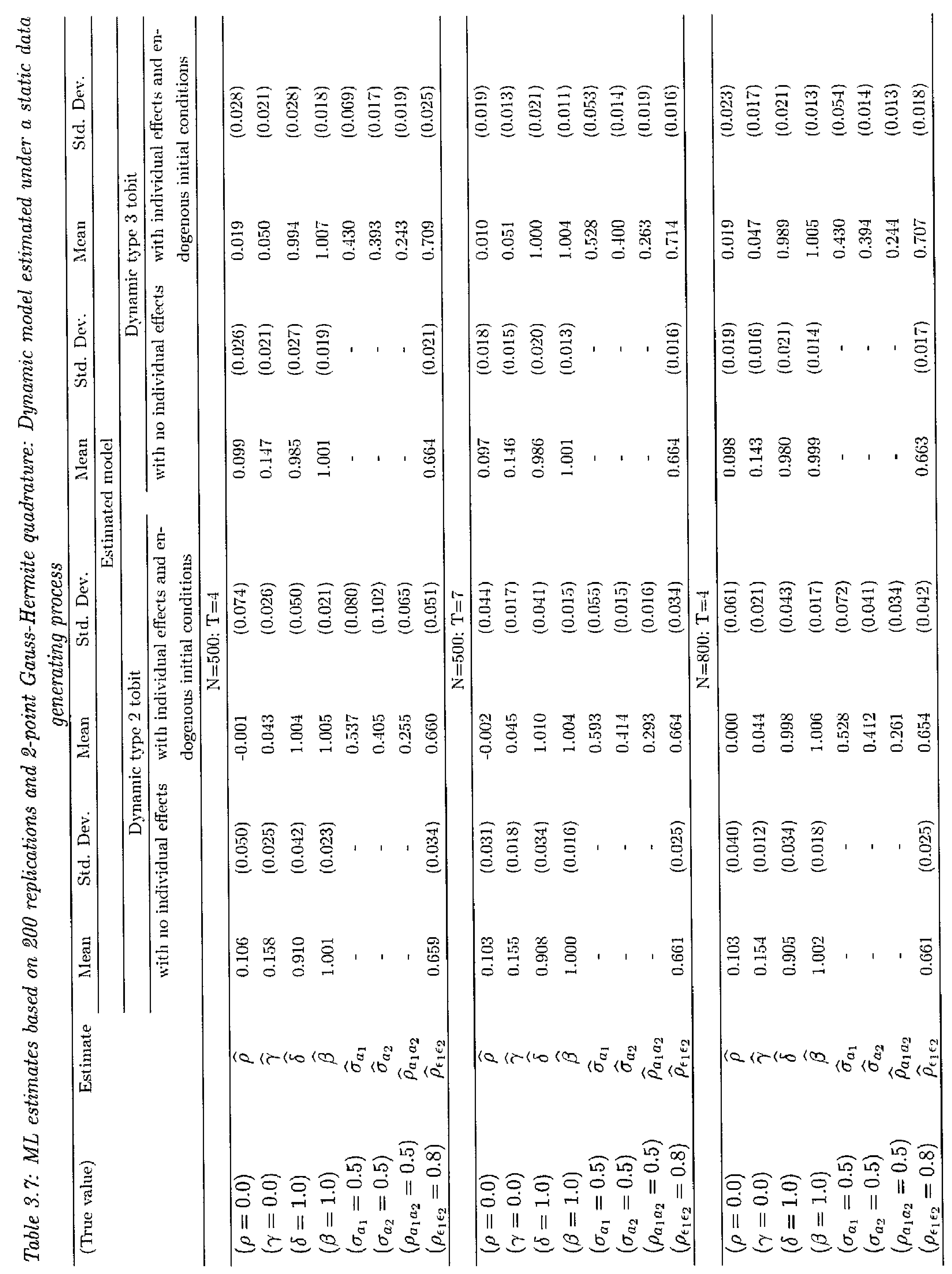




\subsection{Conclusion}

We have propered a simple method to implement the maximum likelihood estimator of $d y$. namic panel data sample selection models. The method consists in writing the likelihood function conditional on the individual effects which are then "integrated out" with respect to their joint normal distribution. Wo have handled the double integral involved in the likelihowd function using "two-step" Gaus-Hermite quadrature, and solved the initial conditions problem using the approach of Wooldridge (2005). The resulting likelihood function encompawwes a wide range of likelihood functions of panel data models whose estimation can be achieved by simply making restriction assumptions on the parancters of the dynamic panel data sample selertion model. These assumptions can be tested using a standard likelihood ratio or Wald test.

In order to assess the quality of the Gauss-Hermite quadrature, and hence that of the maximum likelihood estimator, we have conducted a Monte Carlo study and obtained the following results. First, under the data generating process, the maximum likelihood estimator works very well, even for a number of integration points, in each step of the Gauss-Hermite quadrature. as small as 2. The estimator bias of the coefficients of the lagged dependent and strictly exogenous explanatory variables, as well as that of the standard deviations of the individual effects is very small for a sample size as large as the one considered in the Monte Carlo study. The sample selection terms, however, are less accurately estimated when the mumber of integration points is very small. Secondly, too much credit is attributed to the lagged dependent variables as a determinant of the current dependent variables when either the individual effects or the correlation between the initial outcome and the individual effects are wot taken into account. Thirdly, the selection bias really matters when the explanatory variables in the selection equation and the equation of interest are highly correlated, otherwise it can be safely ignored. Fourthly, when the lagged dependent variables condition the current dependent variables and are left out of the explanatory variables, too much credit is attributed to the individual effects as a determinant of the current dependent variables. Finally, when estimating a dynamic panel data model, regardlos of whether the true model is dynamic or static, the individual effects and the correlation between the initial ontcome and the individual effects must be taken into account, otherwise a situation of spurious state dependence will arise "ven under its extreme form. In this latter case, credit is attributed to the lagged 
dependent variables as a determinant of the current dependent variables while the former do not condition at all the latter.

Our approach can be, in a straightforward manner, extended to estimate by maximum likelihood panel data sample selection models with more than two equations, that include a lagged dependent explanatory variable and individual effects in cach equation. For instance, our approach can handle the estimation of dynamic panel data type 4 and type 5 tobit models with individual effects. 


\section{Appendix 3.A "Two-step" Gauss-Hermite quadrature}

Consider the dynamie pand data type 2 tobit model defined by entuations (3.1-3.1) and (3.63.7), and consider expressions (3.10) and (3.11). Assume that the veretors (el, 1.21$)^{\prime}$ and $\left(a_{1 i}, a_{2 i}\right)^{\prime}$ are independent of cach other, and independently and ident ically dist ributed over time and across individuals following a nomal distribution with mon and and comianes matrix given in expuation (3.8). The likelihood function of individual $i$, starting from $t=1$ and conditional on the regressors and the initial conditions, is whtained hy "int regrating enet" the individual effects (equation (3.9)). The likelihood limedion of individual i comdilional on the individual effects is written in ecpution (3.12) with $\sigma_{1}$, boing nomalizol to 1 for identification reasons. The expression of the bivariate normal distribution af an, and $a_{2} ;$ is written as

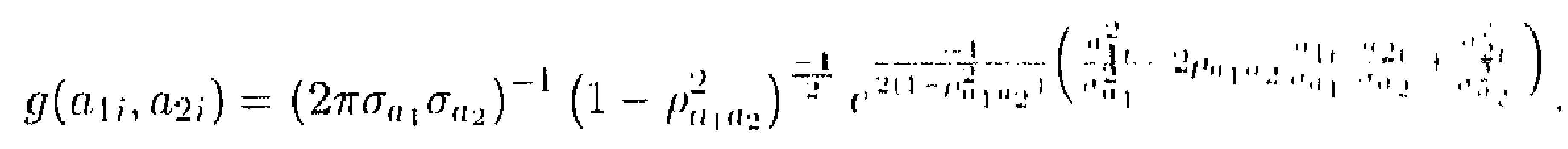

Hence, equation (3.9) can be written as

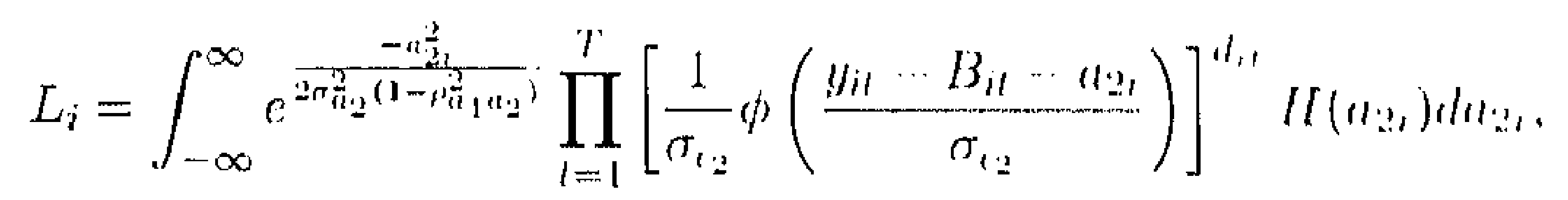

where $H\left(a_{2 i}\right)$ is written as

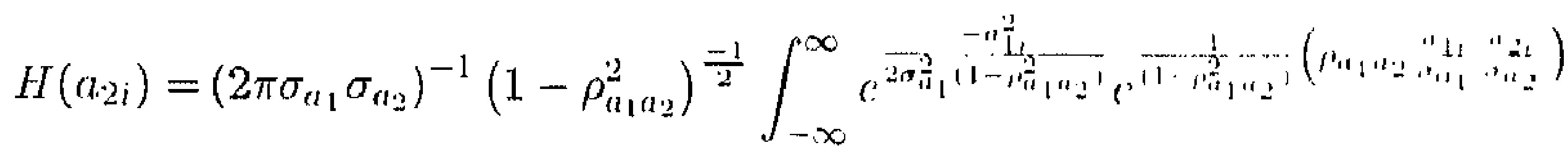

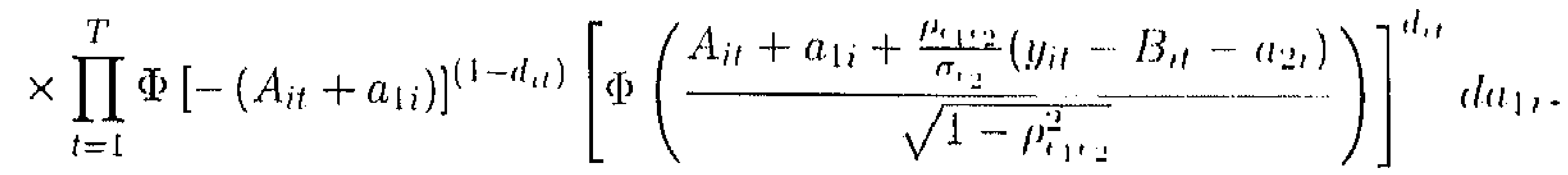

Equation (3.21) can be approximated using "two-step" Gauss-Hemile (nualrature which stalies that

$$
\int_{-\infty}^{\infty} e^{-z^{2}} f(z) d z \simeq \sum_{m=1}^{M} w_{m} f\left(a_{m}\right)
$$

where $w_{m}$ and $a_{m}$ are respectively the weights and abscissas of the Gaulss-Hormite culadrature, the tables of which are formulated in mathematical textbooks (e.g. Abramovitz and Stegun, 1964), and $M$ is the total number of integration points. The larger $M /$, the more ancurate 
the Gauss-Hermite quadrature. The "two-step" Gauss-Hermite quadrature consists, in the first step, in approximating equation (3.22) using equation (3.23). In the sccond step, a second approximation is applied to equation (3.21) where $H\left(a_{2 i}\right)$ is replaced by its first-step Gauss-Hermite approximation. The approach is described as follows.

Consider the variable change $z_{1 i}=\frac{a_{1}}{\sigma_{a_{1}} \sqrt{2\left(1-\rho_{\left.a_{1} a_{2}\right)}^{2}\right)}}$ so that $d a_{1 i}=d z_{1 i} \sigma_{a_{1}} \sqrt{2\left(1-\rho_{a_{1} a_{2}}^{2}\right)}$. Equation (3.22) is then written as

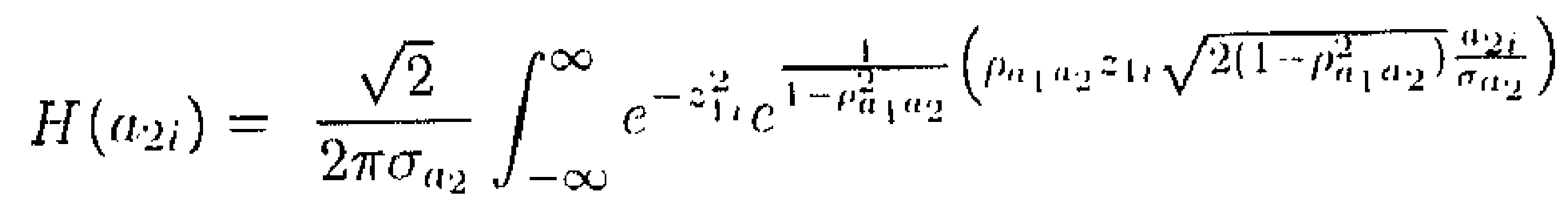

$$
\begin{aligned}
& \times \prod_{l=1}^{T} \Phi\left[-\left(A_{i t}+z_{l i} \sigma_{a_{1}} \sqrt{2\left(1-\rho_{a_{1} n_{2}}^{2}\right)}\right)\right]^{\left(1-d_{l l}\right)}
\end{aligned}
$$

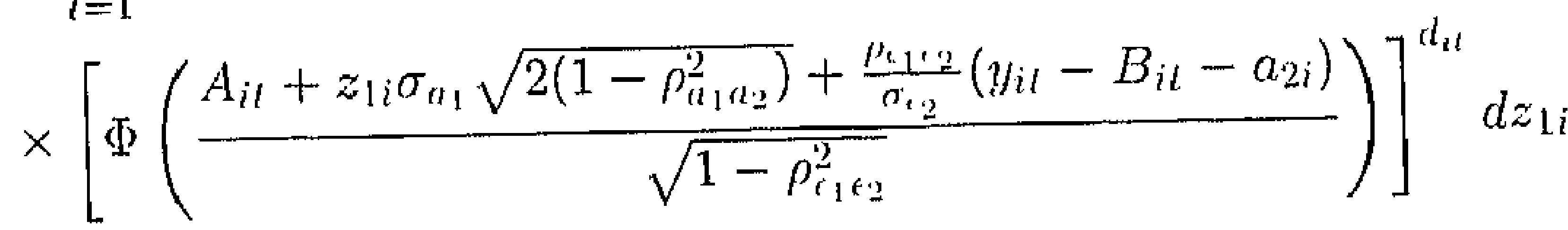

and can be approximated using equation (3.23) by

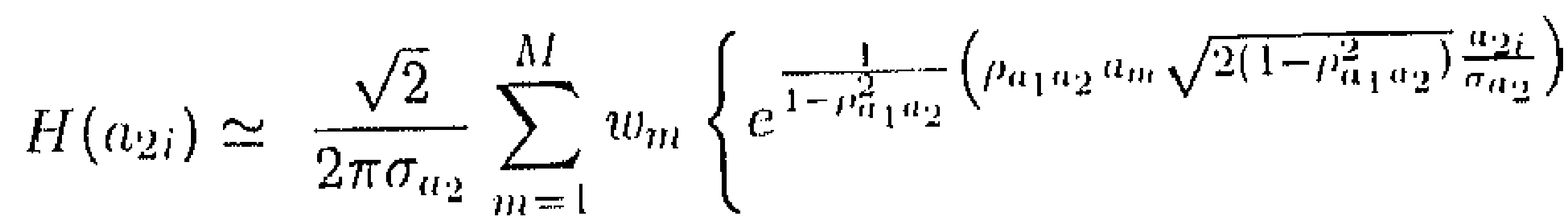

$$
\begin{aligned}
& \times \prod_{l=1}^{T} \Phi\left[-\left(A_{i l}+a_{m} \sigma_{u_{1}} \sqrt{2\left(1-\rho_{a_{1} a_{2}}^{2}\right)}\right)\right]^{\left(1-d_{u l}\right)} \\
& \left.\times\left[\Phi\left(\frac{A_{i l}+a_{m} \sigma_{i 1} \sqrt{2\left(1-\rho_{u 1 a_{2}}^{2}\right)}+\frac{\mu_{i, c_{2}}}{\sigma_{+2}}\left(y_{i t}-B_{i l}-a_{2 i}\right)}{\sqrt{1-\rho_{t+12}^{2}}}\right)\right]^{d_{t 1}}\right\},
\end{aligned}
$$

where $w_{m}$ and $a_{m}$ are the weights and abscissas of the first-step Gauss-Hermite quadrature with $M$ being the total number of integration points.

Consider the second variable change $z_{2 i}=\frac{a_{2_{1}}}{\sigma_{a_{2} 2} \sqrt{2\left(1-\rho_{\left.u_{1} u_{2}\right)}^{2}\right)}}$ so that $d a_{2 i}=d z_{2 i} \sigma_{a_{2}} \sqrt{2\left(1-\rho_{a_{1} a_{2}}^{2}\right)}$.

Replacing equation (3.25) into equation (3.21) yields

$$
\begin{aligned}
& L_{i} \simeq \frac{\sqrt{1-\rho_{a_{1} a_{2}}^{2}}}{\pi} \int_{-\infty}^{\infty} e^{-z_{2 i}^{2}} \prod_{t=1}^{T}\left[\frac{1}{\sigma_{\mathrm{t}_{2}}} \phi\left(\frac{y_{i l}-B_{i l}-z_{2 i} \sigma_{a_{2}} \sqrt{2\left(1-\rho_{a_{1} a_{2}}^{2}\right)}}{\sigma_{t \cdot 2}}\right)\right]^{d_{i t}} \\
& \times \sum_{m=1}^{M} w_{m}\left\{e^{2 \rho \rho_{a_{1} a_{2}} z_{2 l} a_{m}} \prod_{t=1}^{T} \Phi\left[-\left(A_{i t}+a_{m} \sigma_{a_{1}} \sqrt{2\left(1-\rho_{a_{1} a_{2}}^{2}\right)}\right)\right]^{\left(1-d_{i t}\right)}\right. \\
& \left.\times\left[\Phi\left(\frac{A_{i l}+a_{m} \sigma_{a_{1}} \sqrt{2\left(1-\rho_{u_{1} a_{2}}^{2}\right)}+\frac{\rho_{c_{1} c_{2}}}{\sigma_{c_{2}}}\left(y_{i l}-B_{i l}-z_{2 i} \sigma_{a_{2}} \sqrt{2\left(1-\rho_{a_{1} l_{2}}^{2}\right)}\right)}{\sqrt{1-\rho_{\epsilon_{1} l_{2}}^{2}}}\right)\right]^{d_{i t}}\right\} d z_{2 i}
\end{aligned}
$$


which can be approximated using again equation (3.23) by

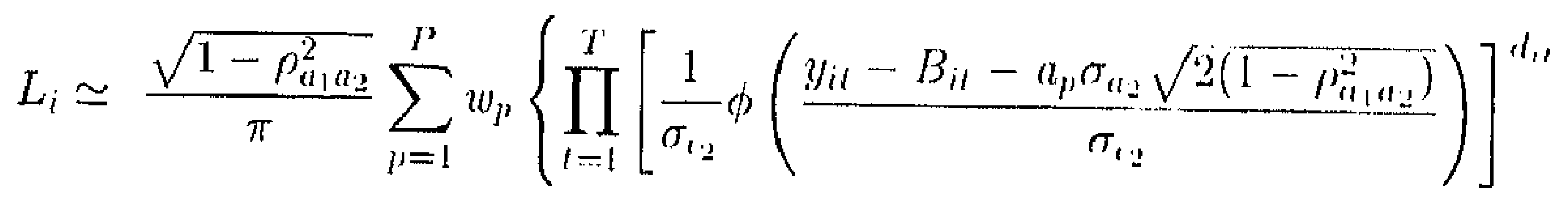

$$
\begin{aligned}
& \times \sum_{m=1}^{M} w_{m}\left\{e^{2 p_{u_{1} u_{2} a_{2} a_{p} a_{m}}} \prod_{l=1}^{T} \Phi\left[-\left(A_{i l}+a_{m} \sigma_{u_{1}} \sqrt{2\left(1-\rho_{u_{1} n_{2}}^{2}\right)}\right)\right]^{\left(1--l_{i t}\right)}\right.
\end{aligned}
$$

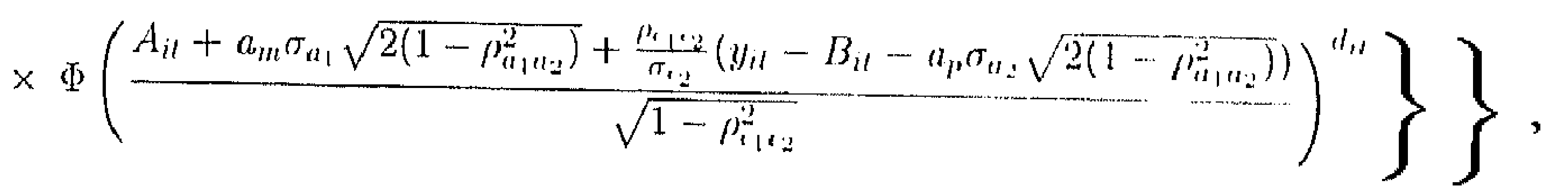

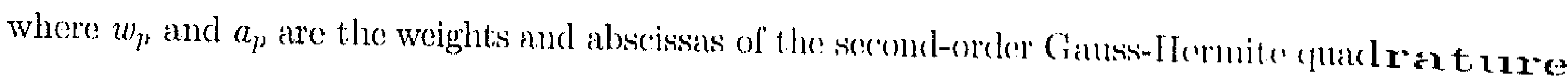
with $P$ being the total mumber of integration points.

Using equations (3.9), (3.13), (3.14) and (3.20), the randonn-dfects individual likelibood function of the type 3 tobit can be derived similarly to yield cepuation (3.16). 


\section{Appendix 3.B Panel data models encompassed in the dynamic}

\section{type 2 and type 3 tobit models}

Trble 3.8: Panel data models encompassed in the dynamic type 2 and type 3 tobit models

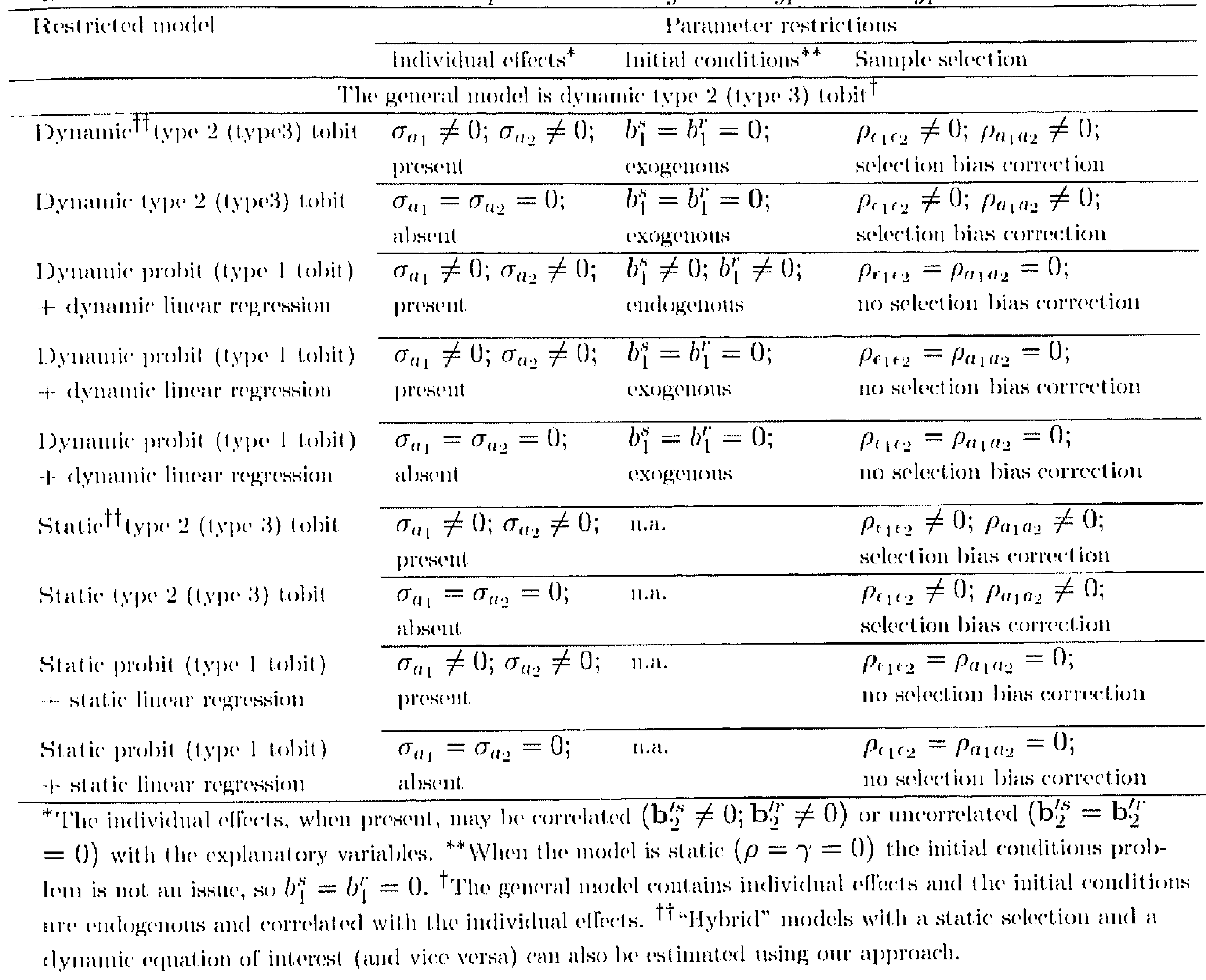




\section{CHAPTER 4}

\section{Persistence of innovation in Dutch manufacturing: Is it spurious?}

\subsection{Introduction}

This chapter exanines, at the firm level, the clynamics of the innovation process in Dutch manulancturing using three waves of the Community Innovation Survey (henceforth CIS) pertaining to the periods 1994-1996, 1996-1998 and 1998-2000. Nore specifically, we atcempt to mnswer two (pucstions. First, cloes being successful in past imnovation activities increase the probability of being successful in current imnovation activities? Secondly, does past imnovation output, as moasured by the share in total sales of innovative sales, ${ }^{1}$ generate current innovation output?

The first research question relates to the literature on the persistence of innovation which, at the micro level, plays an important role in the context of cndogenous growth models (Romer, 1990; Aghion and Howitt, 1992). It also helps to understand industrial economics phenomena such as the persistence of profitability (Roberts, 2001) and total factor productivity (TFP) growth (Geroski, 1989). Several theoretical explanations of the persistence of innovation (at the firm level) exist in the literature. In one approach the persistence of innovation is explained by the existence of sunk costs: in order to build and maintain an R\&D department, R\&D expenditures are regular. In the linear model of innovation, as opposed. to the chain-link model, a direct relationship between a firm's R\&D expenditures and its

\footnotetext{
'This chenpter considers products that are new to the fim, not necessinrily new to the market.
} 
innovations is postulated such that the persistence of innovation coincides with that of $R \& D$ expenditures. A second explanation of the persistence of innovation pertains to the financial constraints that a firm may face in funding $R \& D$ activities, which makes it dependent on retained earnings as a source of funds. Innovations that have met a commercial success in the past generate profits that may be invested in current innovation activities and hence "success breeds success" (Mansfield, 1968). Finally an explanation of the persistence of innovation is given by the learning-by-doing model. It predicts that the production of innovations is subject to dynamic economies of scale. In other words, knowledge that has been used to produce past innovations can be used, assuming that the depreciation rate of innovative abilities is small, to produce current and even future innovations. In Schumpeterian terms, the three theoretical explanations of the persistence of innovation can be referred to as "creative accumulation", as opposed to "creative destruction", where the latter term is used to explain the absence of persistence in innovation activities.

The dynamics of innovation output, investigated by the second research question, plays a crucial role in understanding the dynamics of firms' technological performance (e.g. innovative sales) and economic performance (e.g. profits). Since the empirical work by Crépon et al. (1998), a great number of empirical studies focus on the relationship betwecn innovation output and firm performance, the latter variable being measured, for instance, by sales per employee, value-added per employee, export per employee, growth rates of sales, total employment growth and so on. The main finding of these studies is that, regardless of how performance is measured, innovation output positively and significantly affects firm performance, with the exception of the study by Klomp and van Leeuwen (2001) that finds a negative but insignificant effect of innovation output on employment growth. ${ }^{2}$ For instance, innovation output has a positive and significant effect on value-added per employee of French firms (Crépon et al., 1998), sales per employee of German firms (Janz ct al., 2004), sales growtl of Dutch firms (Klomp and van Leeuwen, 2001), and labor productivity (valuc-added per employee) growth of Swedish firms (Lööf and Heshmati, 2002a). Lööf and Heshmati (2002b) perform a sensitivity analysis using, besides the previously-mentioned ones, three additional measures of firm performance, namely, sales margin, profit before and after depreciation (in level and growth rates), and find the same pattern of positive and significant

\footnotetext{
${ }^{2}$ The relationship between innovation and employment is not a clear-cut one. Empirical studies identify both a positive and a negative effect of the former on the latter. The sign of the relationship depends, e.g., on the type of the data, the time-period and the level of analysis (firm versus industry level) (Piantai, 2004).
} 
effect of innovation output on firm performance. Because of this close relationship between innovation output and firm performance, the dynamics of the former is expected to explain that of the latter. In other words, our second research question can help us address the issue of the persistence of firm performance (Cefis, 2003b; Cefis and Ciccarelli, 2005).

This study contributes to the empirical literature on innovation in a number of ways. Firstly, it analyzes persistence using other output measures than patents. Secondly, unlike the aforementioned empirical studies on firm performance, three waves of the CIS, pertaining to the Dutch manufacturing scctor, are used for the first time to link the persistence of innovation (qualitative) to the dynamics of firms' technological performance (quantitative). We estimate a dynamic panel data type 2 tobit model accounting for unobserved individual effects and handling the initial conditions problem encountered when estimating dynamic panel data models. The incidence and the intensity of innovation are jointly estimated allowing for a correlation between the processes governing the introduction of new or significantly improved products and/or processes, and the generation of innovative sales. We use estimation techniques suggested by Wooldridge (2005), and extended in Chapter 3 , and find that being successful in past innovation activities does not increase the probability of being successful in current innovation activities, and that past innovation output does condition, albeit to a small extent, current innovation output.

Section 4.2 summarizes the findings of the empirical literature on the persistence of innovation and firm performance. Section 4.3 presents the model that is estimated in Section 4.4. We describe the data used to implement the model in Section 4.5, present and discuss estimation results in Section 4.6, and conclude in Section 4.7.

\subsection{Literature}

This section summarizes the findings of the empirical literature on the persistence of innovation. Two types of studies are identified according to whether patent or other data are used (see Table 4.1). We explain the importance of the type of data that are used to measure innovation activities when persistence is analyzed. We also describe the findings of the rather few empirical studies on the relationship between the persistence of imnovation output and that of firm performance. 


\subsubsection{The persistence of innovation}

The studies on the persistence of innovation are motivated by testing the Schumpeter Mark I and II hypotheses. In other words, authors seek to know whether innovation activities are subject to "crcative destruction" or "creative accumulation". The hypotheses of whether innovation activities are subject to "dynamic economies of scales" or whether "success breeds success" are also tested in these studies. Finally, industry and country differences in the persistence of innovation are investigated.

\section{Patent data}

Innovation activities are captured in these studies by the number of patents that are either applied for or granted by the European Patent office (henceforth EPO) or the United States Patents and Trademarks Office (henceforth US PTO). Table 4.1 shows that, with the exception of Crépon and Duguet (1997), all the studies on the persistence of imnovation that use patent data conclude more or less alike regardless of the methodology: there is no clear-cut evidence of strong persistence in innovation activities. In fact, those studies share a common drawback, namely, the type of data used to analyze persistence. The limitations of patent data are well-known (Griliches, 1990), and the inability to obtain unequivocal empirical results using such data is therefore not surprising. Indeed, in order for a firm to be properly accounted for in a patent data set, it has to be the first to apply for a patent. Hence, when analyzing the persistence of innovation using patent data, one is unwittingly analyzing the persistence of "winning the patent race", which is unlikely to be strong (Duguet and Monjon, 2002). As a result, other types of data should be used to investigate the persistence of innovation activities.

\section{Major inmovation, R\&D, CIS and other innovation survey data}

Major innovation, R\&D, CIS and other innovation survey data are also used to analyze the persistence of innovation activities. The first type of data yields results that are similar to those of studies using patent data. Duguet and Monjon (2002) point out that persistence is also likely to be low when using major innovation data. Indeed, since a major innovation is one that meets a commercial success, innovators arc likely to be imnovation or commercial leaders, which is unlikely to persist over a long period of time. Thus, major innovation data are as demanding as patent data when analyzing the persistence of innovation. On the other 
hand, R\&D and CIS data are seen as less demanding as persistence can be analyzed at the firm level without mentioning the patenting or market leadership status of the firm. In this case, regardless of the methodology, persistence in innovation activities is found to be high, whether input measures (Máñez Castillejo et al., 2004; Peters, 2005) or output measures (Duguet and Monjon, 2002) of innovation are used. Using data stemming from an innovation survey similar to the CIS and collected by the IFO-Institute in Munich, Flaig and Stadler (1994) also find high persistence in realizing product and/or process innovations.

\subsubsection{The dynamics of innovation output and firm performance}

All the empirical studies mentioned in Section 4.1 on the relationship between innovation output and firm performance are cross-sectional, whereas this one is based on panel data. 3 Hence, they cannot analyze the dynamics of the innovation process and that of firm performance. Little is known about the relationship between the dynamics of innovation and that of firm performance. Two instances of studies that investigate this relationship are Cefis (2003b) and Cefis and Ciccarelli (2005). Both studies use patent data and find that persistent innovators have profits that are and remain higher than those of non-persistent innovators, hence the persistence of innovation and that of firm performance are closely related to each other.

Our study attempts to give a first insight into the dynamics of the innovation process in Dutch manufacturing using three waves of the CIS. We consider a model of innovative behavior in a "true" dynamic panel data framework, i.e. accounting for unobserved individual effects and handling the initial conditions problem. We estimate a dynamic panel data type 2 tobit model, according to Amemiya's (1984) terminology, which encompasses the crosssectional type 2 tobit model studied, for instance, by Brouwer and Kleinknecht (1996) and Mairesse and Mohnen (2001).

\subsection{Econometric model}

The model explains the achievement by Dutch manufacturing enterprises of technological product and/or process (TPP) innovations and the impact of these innovations on the share

\footnotetext{
${ }^{3}$ To the best of our knowledge, van Leenwen's (2002) stucly is the only one that analyres the dynamics of innovation input (R\&D expenditures/total sales) and output (innovative sales/total sales), and links innovation outpul to firm performance. However, lis analysis is not done in a "true" panel datn franework in that individual effects are not accominted for.
} 


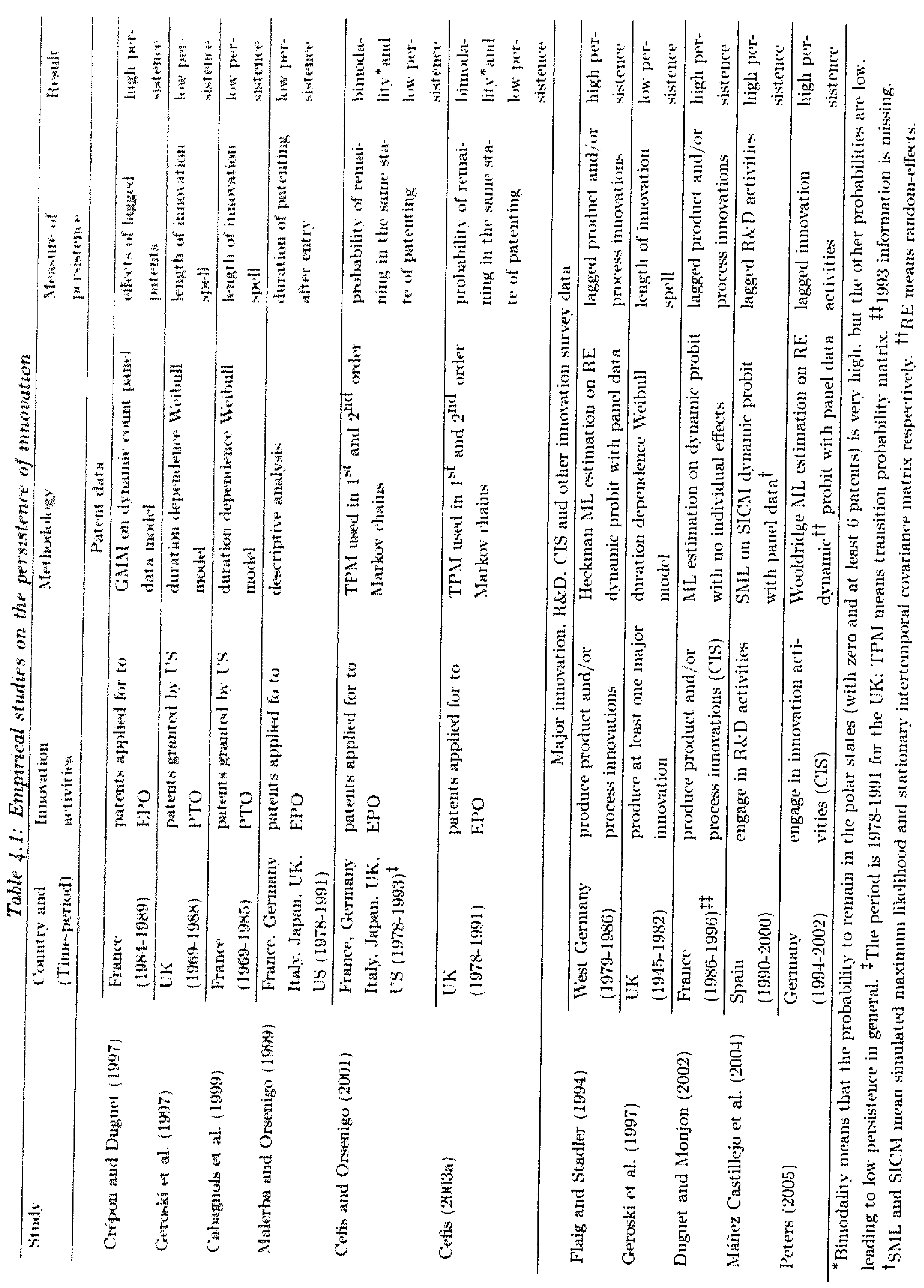


of innovative sales. Formally, it is written as

$$
\begin{aligned}
& d_{i l}=1\left[\rho d_{i, t-1}+\delta^{\prime} \mathbf{w}_{i t}+\eta_{i}+\epsilon_{1 i t}>0\right] \\
& y_{i t}= \begin{cases}\gamma y_{i, t-1}+\beta^{\prime} \mathbf{x}_{i t}+\alpha_{i}+\epsilon_{2 i t} & \text { if } d_{i t}=1, \\
0 & \text { if } d_{i t}=0,\end{cases}
\end{aligned}
$$

with $t=1, \ldots T ; i=1, \ldots N$.

Equation (4.1) models the current decision of enterprise $i$ to innovate as a latent function of its past innovation achievement $\left(d_{i, t-1}\right)$, its observable characteristics $\left(\mathbf{w}_{i f}\right)^{4}$, time-invariant unobserved individual effects $\left(\eta_{i}\right)$ and other time-variant unobserved variables $\left(\epsilon_{1 i t}\right)$ uncorrelated with $\mathbf{w}_{i t}$. The expression in square brackets represents the incentive to innovate. If the incentive is sufficiently high, enterprise $i$ is a TPP innovator in which case $d_{i t}$ is observed to be 1. The scalar $\rho$ and the vector $\delta^{\prime}$ capture respectively the effects of past innovation achievement and firm characteristics on current innovation achicvement, and are to be estimated. A positive and statistically significant estimate of $\rho$ identifies the presence of persistence in innovation which may occur for two reasons: because of state dependence or because of unobserved effects or left-out variables that are correlated over time (through serially-correlated errors or individual effects). Heckman (1981a; 1981c) refers to the first phenomenon as true state dependence and the second one as spurious state dependence. True state dependence states that past innovation achievement increases positively and significantly the probability of current innovation achievement (true persistence). ${ }^{5}$ In order to distinguish it from spurious state dependence, unobserved effects that are correlated over time and the initial conditions must be properly accounted for when estimating eq. (4.1).

Equation (4.2) models the current share of innovative sales $\left(y_{i t}\right)$ of innovator $i\left(d_{i t}=1\right)$ as being determined by its past share of innovative sales $\left(y_{i, t-1}\right)$, its characteristics $\left(\mathbf{x}_{i t}\right)$, time-invariant unobserved individual effects $\left(\alpha_{i}\right)$ and other time-variant unobserved variables $\left(\epsilon_{2 i t}\right)$ uncorrelated with $\mathbf{x}_{i t}$. This share is zero if enterprise $i$ is not an innovator, and the full set of regressors included into $\mathbf{x}_{i l}$ are only available when enterprise $i$ is an imovator. The scalar $\gamma$ and the vector $\beta^{\prime}$ capture respectively the effects of past share of innovative sales and firm characteristics on current share of innovative sales, and are to be estimated.

\footnotetext{
${ }^{4} \mathbf{w}_{\text {it }}$ could also include market specific characteristics if they were observables.

"When the term persistence is used in this study wilhout any further explanation, it is to be understood as true persistence which occurs in the case of true state dependence.
} 
Equations (4.1) and (4.2) are jointly estimated allowing for a correlation between the processes governing the introduction of TPP innovations and the generation of innovative sales.

We now turn to the estimation technique.

\subsection{Maximum likelihood estimation}

This section explains how to estimate the dynamic panel data type 2 tobit model accounting for individual effects and handling the initial conditions problem. It is shown in the econometric literature that the coefficient associated with the lagged dependent variable can be overestimated if these two problems are not properly accounted for. Estimation techmiques that properly handle these problems are known in the econometric literature (Heckman, 1981b; Wooldridge, 2005).

Kyriazidou (2001) suggests a "semi-parametric fixed-effects" approach, i.e., the individual effects $\eta_{i}$ and $\alpha_{2}$ are assumed to be fixed, and derives moment restrictions (along the lines of Ahn and Schmidt (1995)) that are exploited to construct two-step GMM-type estimators. In the first step, the parameters of eq. (4.1) are consistently estimated, e.g., by methods suggested by Honore and Kyriazidou (2000b). In the second step, these estimates are used to construct kernel weights that are larger for individuals whose sample selection effect is small. Under appropriate assumptions, the derived kernel-weighted GMM estimators are shown to be consistent and asymptotically normal. These estimators, however, cannot be applied in this study because of data limitations. First, the fixed-effects approach requires data that show a lot of variation over time (within variation), otherwise they are wiped out when time-differencing. This is hardly the case in our data since most of the variables are qualitative, and the continuous ones exhibit little within variation. For instance, the approach does not identify the effects of industry dummies which are assumed to capture technological opportunities. Sccondly, the estimators are effective when the number of time periods is fairly large $(T \geq 4)$, which is not the case in our study either. Indeed, the moment equations require time-differencing resulting in a loss of information in the data, and the remaining information must be sufficient to estimate the model, which is not feasible when $T$ is too
small.

In urder to cope with the limitations of our data, we consider a random-effects approach 
and make distributional assumptions on the individual effects. We use estimation techniques suggested by Wooldridge (2005), and extended in Chapter 3. More specifically, we estimate the model by maximum likelihood using "two-stcp" Gauss-Hermite quadrature to evaluate the likelihood function. "' The same number of integration points $(P=M=5)$ is used in this study, although $P$ need not be equal to $M$. Equations (4.1) and (4.2) are correlated through the individual effects $\left(\rho_{a_{1} a_{2}} \neq 0\right)$ and the idiosyncratic errors $\left(\rho_{\epsilon_{1}+2} \neq 0\right)$, and the "total" correlation between the two equations is calculated as

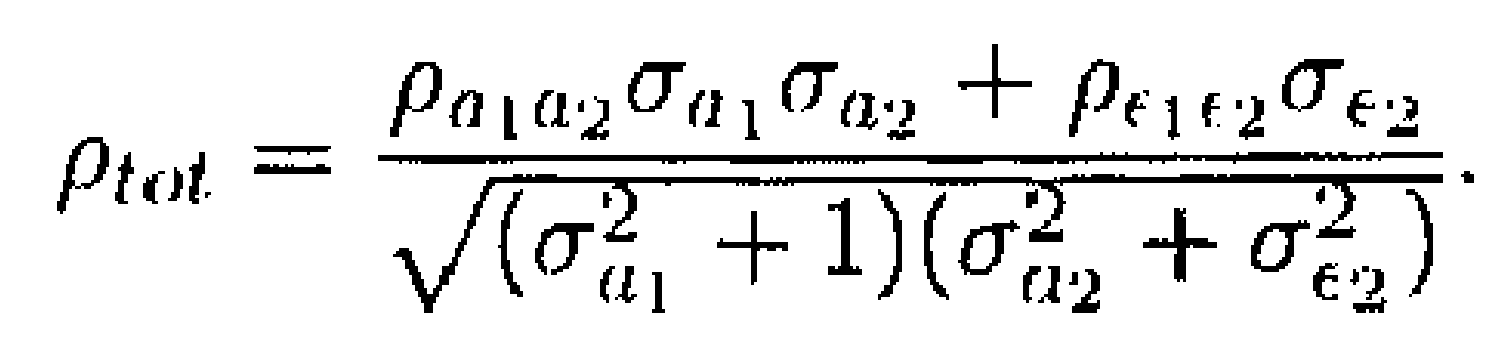

\subsection{Data}

To implement the model, we use the same data as in Chapter 2 collected by the Centraal Bureau voor de Statistick (CBS). They stem from three waves of the Dutch Community Innovation Survey, CIS 2 (1994-1996), CIS 2.5 (1996-1998) and CIS 3 (1998-2000), merged with data from the Production Survey (PS). Only enterprises in Dutch manufacturing (SBI 15-37) are included in the analysis. The population of interest consists of enterprises with at least ten employees and positive sales at the end of the period covered by the innovation survey, We consider enterprises that existed in 1994, survived (at least) until 2000 and took part in the three innovation surveys, resulting in a balanced panel of 861 enterprises.

Descriptive statistics and the definition of the variables are shown in Table 4.2. The dependent variable in equation (4.1) is binary indicating whether enterprise $i$ is a TPP innovator. $71 \%$ of such enterprises exist in our panel. Besides being a past TPP innovator, the probability of being a current TPP innovator is explained by lagged size and relative size, ${ }^{7}$ and industry dummies (according to SBI) that capture technological opportunities and appropriability, the measurements of which are available for both TPP and non-TPP innovators. The dependent variable in equation (4.2) is the ratio of sales from new or improved prod-

\footnotetext{
6ro approach considered in equations (3.6) and (3.7) allows the individual effects to be correlated with the regressors. However, because of the lack of variation over tims (within variation) in our data, a more restricted approach is considered in this analysis where the individual effects are assumed to be correlated only with the initial conditions.

${ }^{7}$ In the innovation survey, firms are asked whether they have product and/or process innovations, or incomplete and abandoned innovation activities during the whole period under study, while size and sales are measured only at the end of the period. Hence, all the cross-sectional studies on the determinants of innovalion have this unsatisfactory feature of explaining the probability of being a TPP innovator or being innovative (during the whole period) by size or relative size (at the end of the period). Taking lagged size or relative size as an explanatory variable in the pancl data context overcomes this problem.
} 
Table 4.2: Descriptive statistics

\begin{tabular}{|c|c|c|c|c|c|}
\hline Variable & Description & $\begin{array}{l}\text { Overall } \\
\text { Meraul }\end{array}$ & $\begin{array}{l}\text { Overall } \\
\text { Stcl. Deve }\end{array}$ & $\begin{array}{l}\text { Between } \\
\text { Strl. Dev. }\end{array}$ & $\begin{array}{l}\text { Within } \\
\text { Stcl. Dev. }\end{array}$ \\
\hline & \multicolumn{5}{|c|}{ Dependent variabless } \\
\hline TPP' innovator & $\begin{array}{l}1 \text { if product and /or } \\
\text { process inmovater }\end{array}$ & 0.714 & 0.152 & 0.350 & 0.287 \\
\hline $\begin{array}{l}\text { Intensity of } \\
\text { intorvation }\end{array}$ & $\begin{array}{l}\text { innovative sales/total sales. } \\
\text { for 'TPP innovators }\end{array}$ & 0.290 & 0.258 & 0.21 .8 & 0.147 \\
\hline & \multicolumn{5}{|c|}{ Explanatory variables } \\
\hline Demand pull & $\begin{array}{l}1 \text { if product-oriented imnova- } \\
\text { tion olnjectives are very } \\
\text { important, for TPP innovalors }\end{array}$ & 0.640 & 0.480 & 0.370 & 0.337 \\
\hline Techunolugy push & $\begin{array}{l}1 \text { if innovation sources are } \\
\text { from universities or other } \\
\text { institutes, for TPP innovators }\end{array}$ & 0.213 & 0.410 & 0.298 & 0.271 \\
\hline $\begin{array}{l}\text { Imovation } \\
\text { cooperation }\end{array}$ & $\begin{array}{l}1 \text { if there is any type of coope- } \\
\text { ration, for TPP immovat ors }\end{array}$ & 0.349 & 0.477 & 0.379 & 0.293 \\
\hline $\begin{array}{l}\text { Nun-Rd D } \\
\text { performors }\end{array}$ & $\begin{array}{l}1 \text { if not performing } R \& D \text {, } \\
\text { for TPP innovators }\end{array}$ & 0.196 & 0.397 & 0.380 & 0.214 \\
\hline $\begin{array}{l}\text { Cont inmous R\&D } \\
\text { performers }\end{array}$ & $\begin{array}{l}1 \text { if performing continuous } \\
\text { R\&D, for R\&D performers }\end{array}$ & 0.754 & 0.431 & 0.399 & 0.217 \\
\hline Subsidies & $\begin{array}{l}1 \text { if being subsidized at least } \\
\text { once, for TPP innovators }\end{array}$ & 0.577 & 0.494 & 0.424 & 0.284 \\
\hline R\&D inlernity ${ }^{* *}$ & $\begin{array}{l}\text { R\&D expenditures/lotal sales, } \\
\text { for R\&D performers }\end{array}$ & 0.046 & 0.078 & 0.064 & 0.037 \\
\hline Size $^{\dagger}$ & number of employees & 209.962 & 539.248 & 534.722 & 71.292 \\
\hline Relative size ${ }^{t \dagger}$ & total sales/sales of industry & 0.006 & 0.020 & 0.020 & 0.004 \\
\hline Number of observations & & 2583 & & & \\
\hline
\end{tabular}

try) are used in the estimation.

ucts (innovative sales) over total sales. This variable is logit-transformed in order to make it lie within the set of real numbers. ${ }^{8}$ The average share of innovative sales is rather small $(29 \%)$ in our panel. Besides lagged size, the current share of innovative sales is explained by past share of innovative sales and dummy variables capturing clemand pull, technology push, innovation cooperation, non-R\&D performers, continuous R\&D performers, subsidies, and lagged $R \& D$ intensity. The characteristics of TPP innovators and R\&D performers are as follows. Product-oriented innovation objectives are deemed important to $64 \%$ of TPP innovators, only $21 \%$ of them use innovation sources from public or private institutions (e.g. universities). ${ }^{9}$ About $35 \%$ of TPP innovators have some kind of cooperation, $58 \%$ reccive at

\footnotetext{
"The share of innovative sales takes on the values 0 for process-only innovators, and 1 for innovators that are newly estal)lished. They are replaced respectively by 0.0001 and 0.9999 in the logit transfornation.

"More detailed explanations about the construction of the variables are given in Section 2,3 of Chapter 2.
} 
least one subsidy and $80 \%$ are $\mathrm{R} \& \mathrm{D}$ performers who spend on average $5 \%$ of their total sales in $R \& D$, and of which $75 \%$ perform R\&D continuously.

As mentioned earlier, most of the variables are qualitative and show little variation over time. The few continuous variables typically vary more "between" enterprises than "within" enterprises over time. This is in part due to the rather small number of time periods $(T=3)$ of the panel.

Table 4.3: Transition probability: Persistence in innovation and innovation intensity

\begin{tabular}{|c|c|c|c|c|c|c|c|}
\hline \multirow[b]{2}{*}{ CIS 2} & \multicolumn{3}{|c|}{ CIS 3} & \multirow[b]{2}{*}{ CLS 2.5} & \multicolumn{3}{|c|}{ CIS 3} \\
\hline & Non-TPP (\%) & $\operatorname{TPP}(\%)$ & Total & & Non-TPP (1/1) & TPP (\%) & Total \\
\hline Non-TPP & 63.16 & 36.84 & 228 & Non-'TPl' & 64.50 & 35.50 & 231 \\
\hline ТРР & 21.04 & 78.36 & 633 & TIP' & 20.95 & $70.05)$ & 6330 \\
\hline \multirow[t]{2}{*}{ Total } & 281 & 580 & 861 & Total & 281 & 580 & 861 \\
\hline & \multicolumn{3}{|c|}{ Innov. intens. in CIS 3} & & \multicolumn{3}{|c|}{ Innov. int culs. in CIS 3} \\
\hline $\operatorname{CIS} 2$ & <avg. (\%) & $>$ avg. $(\%)$ & Total & $\operatorname{CIS} 2.5$ & $<a v g .(\%)$ & $>$ avg. $(\%)$ & Total \\
\hline$<$ average & 73.81 & 26.19 & 565 & $<$ average & 73.01 & 26.99 & 552 \\
\hline$>$ average & 28.38 & 71.62 & 296 & $>$ average & 31.72 & 68.28 & 309 \\
\hline Total & 501 & 360 & 861 & Total & 501 & 360 & 861 \\
\hline
\end{tabular}

Table 4.3 reports transition probabilities for innovation activities. $63 \%$ of non-TPP innovators and $78 \%$ of TPP innovators in CIS 2 remain in their initial state in CIS 3 . The same holds for the two sub-periods. As regards imnovation intensity, $73 \%$ of the innovators with below average intensity in CIS 2 remain below average in CIS 2.5 and CIS 3 , and about $70 \%$ are always above average. The general pattern in the figures of Table 4.3 is that innovation activities are persistent which may occur, as mentioned earlier, for two reasons namely true and spurious state dependence. In order to distinguish the former from the latter, we estimate eqs. (4.1) and (4.2) using estimation techniques described in subsection 3.4 of Chapter 3.

We now present the estimation results.

\subsection{Results}

By simultaneous estimation of equations (4.1) and (4.2) an answer is sought to the two research questions taken jointly. As product-life cycle and $R \& D$ intensity vary across industries, the persistence of innovation and $R \& D$ intensity may be expected to be industry-specific (Malerba and Orsenigo, 1999; Cefis and Orsenigo, 2001). In first instance, a test was performed on the equality of the industry persistence parameters (coefficients of the lagged 
dependent variables) and industry intercepts. The joint null hypothesis that the industry persistence parameters and the industry intercepts are equal could not be rejected. In Table 4.4 the results are presented of the model in which the industry persistence parameters and industry intercepts are restricted to be equal. In order to show the importance of accounting for individual efferts and handling the initial conditions problem, we present the estimation results of the dynamic type 2 tobit model without accounting for individual effects in the second pair of columms in Table 4.4, and those of the same model in which individual effects have been taken into account but the initial conditions have been assumed exogenous in the third pair of cohmms. These results are to be contrasted with the estimates in the fourth pair of columns resulting from estimation of the dynamic type 2 tobit model in which both individual effects have been taken into account and the initial conditions have been treated as endogenous. The estimation results on the persistence of innovation, i.e., the estimates of the parameters in equation (4.1), are presented in the upper part of Table 4.4 and discussed in subsection 4.6.1. The estimation results on the dynamics of innovation output, i.e., the estimates of the parameters in equation (4.2), are presented in the middle part of Table 4.4 and discussed in subsection 4.6.2. Finally, the outcomes of some sensitivity analyses are reported on in subsection 4.6.3.

\subsubsection{The persistence of innovation}

\section{No individual effects and individual effects with exogenous initial conditions}

The estimation results of the dynamic type 2 tobit model assuming the absence of individual effects and, alternatively, accounting for individual effects and assuming the initial conditions to be exogenous are very similar. ${ }^{10}$ The persistence parameter is positive and highly significant and lagged size affects positively and significantly the probability to innovate. As mentioned earlier, the persistence of innovation may be spurious. The existence of true persistence in innovation may be ascertained by verifying that, after accounting for individual effects and propery handling the initial conditions problem, the effect of the lagged dependent variable is, economically and statistically, relevant.

\section{Individual effects and endogenous initial conditions}

\footnotetext{
"Lxogenous initial conditions imply that bei

des not affect the probmbility to innovate later on.
} 


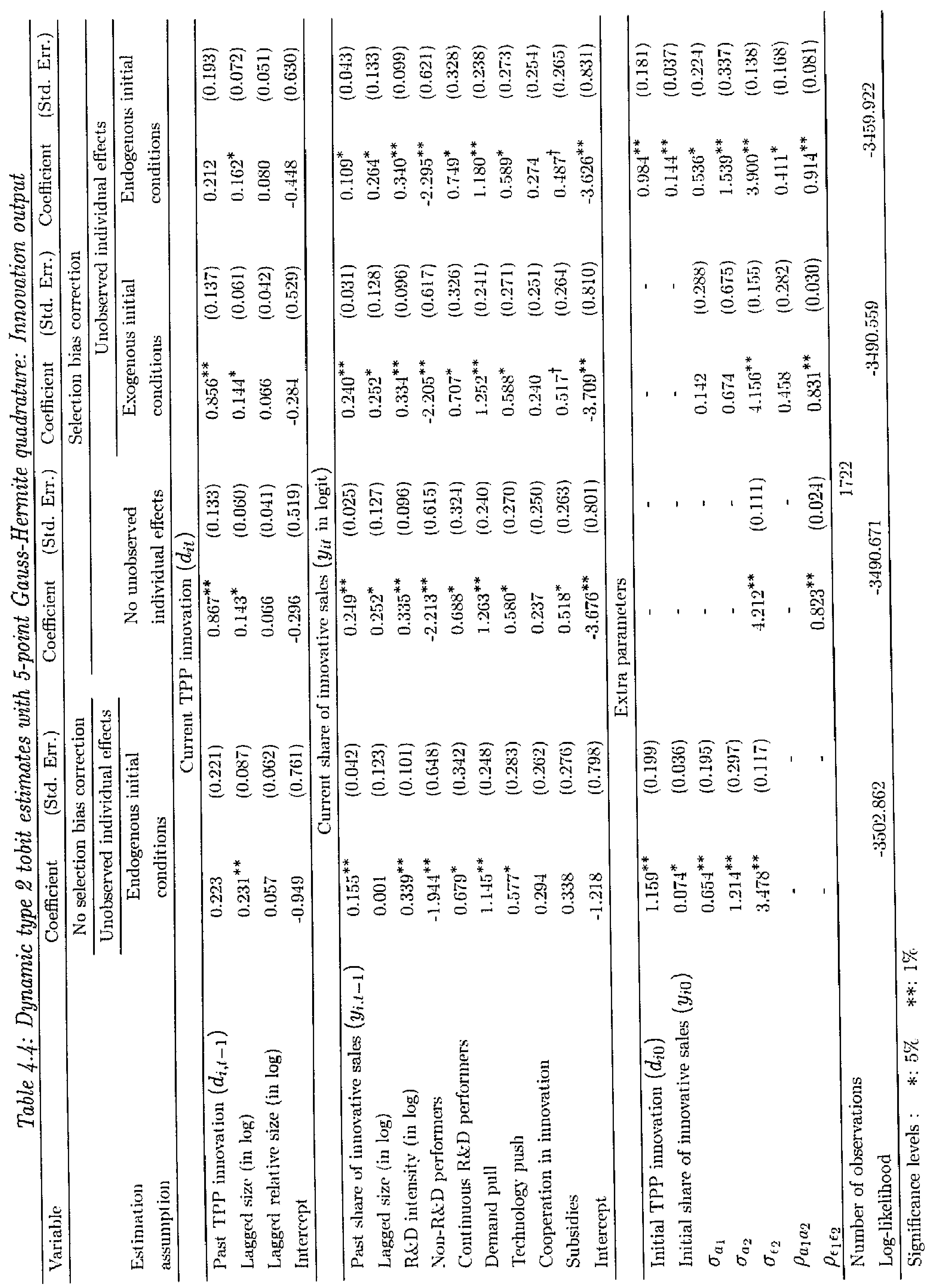


Once the two typical problems of individual effects and initial conditions are properly handled. the hypothesis that the persistence parameter. i.e., the cocfficient of the lagged dependent variable, is equal to zero can no longer be rejected. This result contrasts with that of Duguet and Monjon (2002) who find strong persistence in achieving TPP innovations in French manufacturing. However. they do not account for individual effects, and their finding of persistence may well be dur to spurious state dependence. Furthermore, lagged size positively and significantly affects the probability to innovate.

\subsubsection{The dynamics of innovation output}

\section{No individual effects and individual effects with exogenous initial conditions}

The estimates of the parameters of equation (4.2) are also similar in the dynamic type 2 tobit model without individual effects and in the model with individual effects and exogenous initial conditions. The persistence parameter is positive and highly significant. Furthermore, lagged size, $R \& D$ intensity, performing $R \& D$ on a continuous basis, demand pull, technology push and subsidies positively affect the current share of innovative sales and, ceteris paribus, non-R\&D performers are less successful than R\&D performers.

\section{Individual effects and endogenous initial conditions}

The results suggest that, even after accounting for individual effects and handling the initial conditions problem, the persistence parameter remains significant at $5 \%$ level of significance, suggesting that past innovation output generates in part current innovation output. As for the other regressors, the results mentioned above romain valid.

Both the model that assumes the absence of individual effects and the one that accounts for individual effects but assumes exogenous initial conditions are rejected using a likelihood ratio test at $1 \%$ level of significance. Hence, the full model is the preferred one where cquations (4.1) and (4.2) are jointly estimated allowing for a correlation between the processcs governing the introduction of TPP innovations and the generation of innovative sales. Both cross-equation individual effects and cross-equation idiosyncratic parts are found to be correlated and the "total" correlation (eq. (4.3)) between the two equations is calculated ex post to be 0.821 . 


\subsubsection{Robustness analysis}

When no correlation is assumed between the decision to be a TPP innovator and the share of innovative sales, consistent and efficient estimators of the parameters of the type 2 tobit model may be obtained by separately estimating equations (4.1) and (4.2), which is cquivalent to setting both $\rho_{a_{1} a_{2}}$ and $\rho_{i_{1} c_{2}}$ to zero. ${ }^{11}$ When estimating equations (4.1) and (4.2) scparately, estimation techniques by Heckman (1981b) (eq. (4.1)) and Anderson and Hsiao (1981; 1982) (eq. (4.2)) can also be used. ${ }^{12}$ The estimation results from separate estimations reveal the same pattern: similar to the results in Table 4.4, persistence in achieving TPP innovations vanishes when individual effects and the initial conditions are dealt with, while inertia shows up in the share of imnovative sales. Hence, the lack of persistence in achieving TPP immovations is a rather robust result.

Also the sensitivity of the model to using $R \& D$ input rather than output measures has been investigated. The dynamic type 2 tobit has been estimated using the incidence of engaging in R\&D activities rather than that of being a TPP innovator as dependent variable in equation (4.1) and using $R \& D$ intensity rather than the share of innovative sales as dependent variable in equation (4.2). ${ }^{13}$ The results of this analysis show the same pattern as that of Table 4.4, with the exception of the probit persistence parameter that remains significant also in the preferred model accounting for individual effects and the endogencity of the initial conditions. More specifically, the magnitude of the persistence parameters in both equations lessens when accounting for individual effects and assuming endogenous initial conditions. In this analysis the full model is also shown to be the preferred one: the restrictions imposed in the model without individual effects on the one hand, and those imposed in the model with individual effects and exogenous initial conditions, on the other hand, are - as in Table 4.4 - rejected using a likelihood ratio test.

\subsection{Conclusion}

This study gives first insights into the persistence of imnovation and the dynamics of innovation output in Dutch manufacturing using three waves of the CIS. We answer the questions jointly by estimating a dymanic type 2 tobit and find that there is no evidence of persistence

\footnotetext{
"See the first pair of columms in Table 4.4.

${ }^{12} \mathrm{Se}$ sub-apperedices $4 . \mathrm{A} .1$ and $4 . \mathrm{A} .2$ respectively.

${ }^{13}$ See sub-appendix 4.A.3.
} 
in achieving TPP innovations, while past shares of innovative sales condition, albeit to a small extent, current shares of innovative sales. The lack of persistence of innovation contrasts with the results by Flaig and Stadler (1994) and Duguet and Monjon (2002) who find evidence of strong persistence of innovation in West German and French manufacturing respectively. Hence, unlike these studies, our results do not support the "success breeds success" hypothesis. Once the individual effects and the initial conditions are allowed for, they seem to take over the role of persistence. This phenomenon is even more plausible when the panel is short because, the shorter the panel the higher the correlation between the initial conditions $\left(d_{i 0}\right)$ and the lagged dependent variable $\left(d_{a, t-1}\right)$. The fact that the same phenomenon does not take place in the regression equation (eq. (4.2)) indicates that the lack of persistence found cannot be attributed only to the shortness of the panel. This issue remains a topic of future research. The results on the sensitivity of the model to using $R \& D$ input rather than output measures indicate that there is evidence of persistence in engaging in $R \& D$ activities and in the share of $R \& D$ expenditures in total sales. The former result is in accordance with Máñez Castillejo et al. (2004) who find evidence of persistence by Spanish manufacturing firms in engaging in R\&D activities, and Peters (2005) who finds persistence by German manufacturing and services firms in engaging in innovation activities. Hence, the hypothesis of existence of sunk costs in firms' R\&D activities is supported by our results. They suggest that there is evidence of true persistence of innovation when considered on the input side and spurious persistence when taken on the output side. The idea is that persistent $R \& D$ performers may not be guaranteed to persistently achieve TPP innovations.

The main caveat of this study is the data we use to implement the model. First, the panel is rather short $(T=3)$ which may explain in part the lack of true persistence in achieving TPP innovations. Secondly, there is one-year overlap betwcen two consecutive waves of the Dutch CIS. Hence, to the extent that respondents answer this survey consistently, the overlap would tend to bias the results towards persistence in being a TPP imnovator. As no evidence of persistence is found in the preferred model, it may be concluded that the effect of the overlapping year is not important. 


\section{Appendix 4.A The results of the robustness analysis}

When estimating equations (4.1) and (4.2) separately, estimation techniques by Feckman (1981b) (eq. (4.1)) and Anderson and Hsiao (1981; 1982) (eq. (4.2)) can also be used. They are described as follows.

\section{A.1 Dynamic probit: The persistence of innovation}

Heckman (1981b) suggests that the initial conditions be approximated by a probit model

$$
d_{i 0}=1\left[\delta_{0}^{\prime} \mathbf{w}_{i 0}+\lambda \eta_{i}+\epsilon_{1 i 0}>0\right]
$$

where the vector $\delta_{0}^{\prime}$ and the scalar $\lambda$ are to be estimated. $\delta_{0}^{\prime} \mathbf{w}_{i 0}$ and $\lambda$ capture respectively the mean of the process at the initial period and the dependence of the initial conditions on the individual effects, $\epsilon_{1 i}$ is the idiosyncratic error at the initial period. If we denote the error term in equation (4.4) by $\varsigma_{i 0}=\lambda \eta_{i}+\epsilon_{1 i 0}$, the correlation between the initial conditions and the individual effects is shown to be $\rho_{\zeta \eta}=\frac{\lambda \sigma_{\eta}}{\sqrt{\lambda^{2} \sigma_{\eta}^{2}+1}}$, where $\sqrt{\lambda^{2} \sigma_{\eta}^{2}+1}$ is the standard deviation of the error term of the probit model at the initial period.

Table 4.5: Dynamic probit estimates: The persistence of innovation

\begin{tabular}{|c|c|c|c|c|c|c|}
\hline Variable & Coefficient & (Stcl. Err.) & Coefficient & (Sicl. Err.) & Cocflicient & (Stcl. Err.) \\
\hline & & & \multicolumn{4}{|c|}{ Unobserved individual effects } \\
\hline $\begin{array}{l}\text { Estimation } \\
\text { method } \\
\end{array}$ & \multicolumn{2}{|c|}{$\begin{array}{l}\text { No unobserved } \\
\text { indlividual effects }\end{array}$} & \multicolumn{2}{|c|}{$\begin{array}{l}\text { Exogenous initial } \\
\text { conditions }\end{array}$} & \multicolumn{2}{|c|}{$\begin{array}{l}\text { Endogenous initial } \\
\text { conditions }\end{array}$} \\
\hline \multicolumn{7}{|c|}{ Current TPP innovation $\left(d_{i t}\right)$} \\
\hline Past TPP innovation & $1.044^{* * *}$ & $(0.074)$ & $1.015^{* *}$ & $(0.075)$ & 0.256 & $(0.174)$ \\
\hline Lagged size (in log) & $0.154^{*}$ & $(0.061)$ & $0.164^{* *}$ & $(0.063)$ & $0.280^{* * *}$ & $(0.087)$ \\
\hline Lagged rel. size (in log) & $0.081^{\dagger}$ & $(0.045)$ & $0.081^{\dagger}$ & $(0.047)$ & 0.091 & $(0.059)$ \\
\hline Intercept & -0.497 & $(0.539)$ & $-(0.540$ & $(0.552)$ & -0.134 & $(0.711)$ \\
\hline \multicolumn{7}{|c|}{ Extra parancters } \\
\hline Inilial size (in $\log$ ) & - & - & - & - & $0.07^{2}$ & $(0.121)$ \\
\hline Initial rel. size (in $\log$ ) & - & - & - & - & $0.169^{\dagger}$ & $(0.088)$ \\
\hline Int.ercept & - & - & - & - & $1.742^{\dagger}$ & $(1.056)$ \\
\hline$\sigma_{\eta}$ & - & - & $0.173^{* *}$ & $(0.007)$ & $0.885^{* *}$ & $(0.171)$ \\
\hline$\rho_{\varsigma \eta}$ & - & - & $=$ & $\Xi$ & $0.769^{* *}$ & $(0.052)$ \\
\hline Number of observations & \multicolumn{6}{|c|}{1722} \\
\hline Log-likelilıod & \multicolumn{2}{|c|}{-881.888} & -850 & .232 & \multicolumn{2}{|c|}{-1355.599} \\
\hline
\end{tabular}

Once the initial conditions problem is liandled, the model as specified in equations (4.1) and (4.4) can be estimated by maximum likelihood. The likelihood function of individual $i$, 


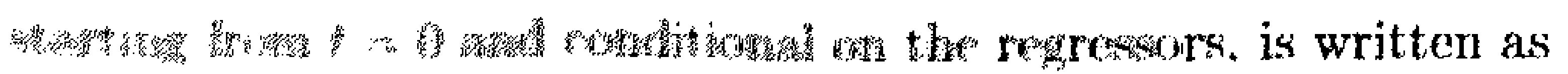

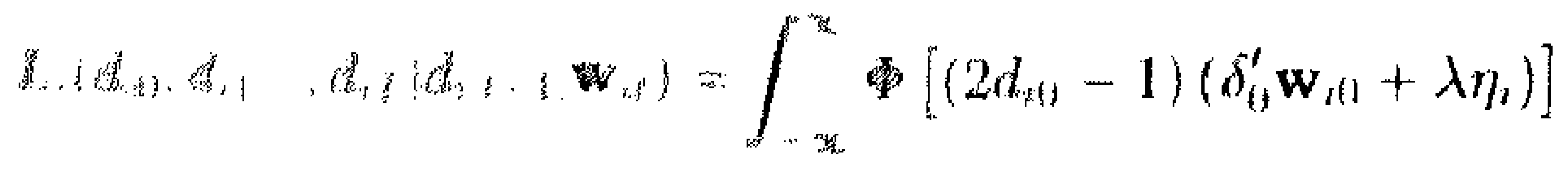

$$
\begin{aligned}
& \prod_{i=1}^{l}\left[\left(2 d_{\eta 1}-1\right)\left(\rho d_{l, l-1}+\delta^{\prime} \mathbf{w}_{l t}+\eta_{i}\right)\right] \frac{1}{\sigma_{\eta}} \phi\left(\frac{\eta_{i}}{\sigma_{\eta}}\right) d \eta_{i},
\end{aligned}
$$

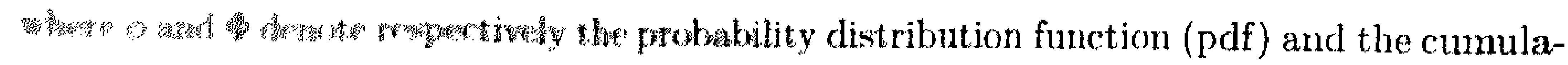

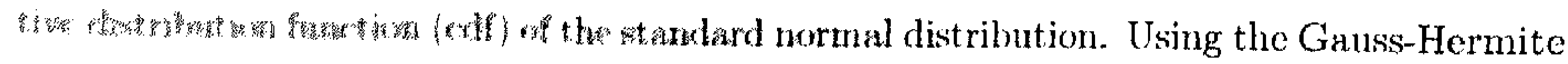

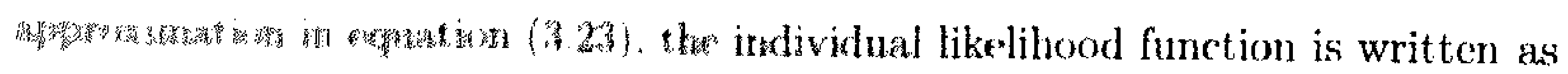

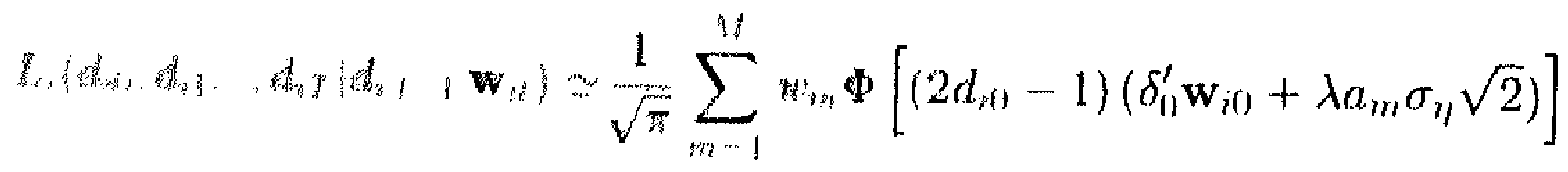

$$
\begin{aligned}
& * \prod_{i m 1}^{T} \Phi\left[\left(2 d_{2 l}-1\right)\left(\rho d_{l, t-1}+\delta^{\prime} \mathbf{w}_{i l}+a_{m} \sigma_{\eta} \sqrt{2}\right)\right] \text {. }
\end{aligned}
$$

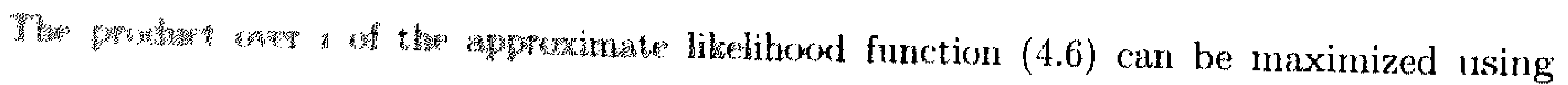

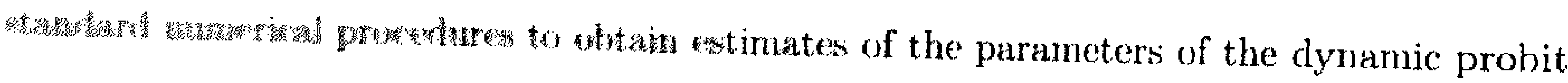

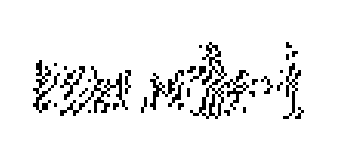

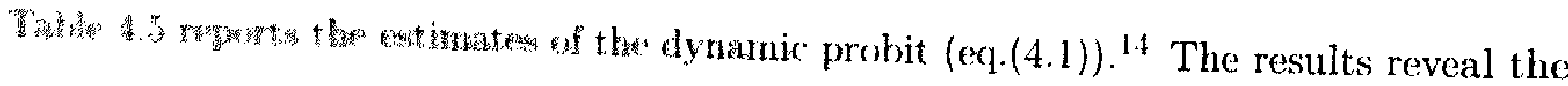

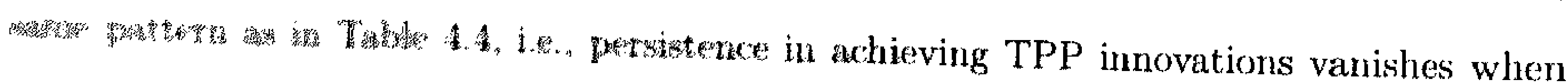

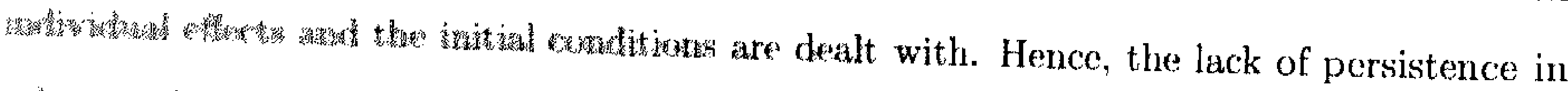

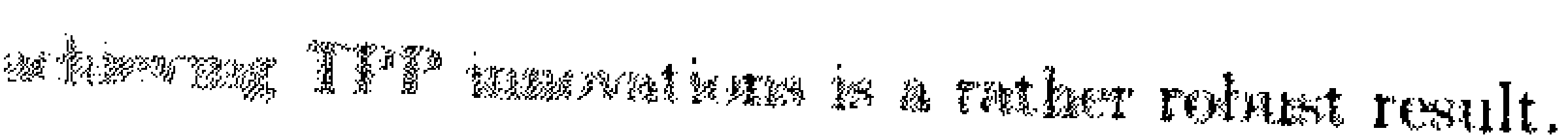

\section{A.2 Dyname linear regression: The dynamics of innovation output}

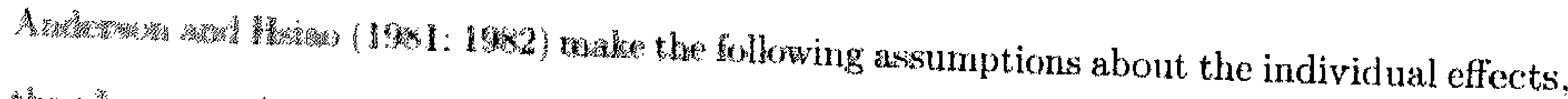

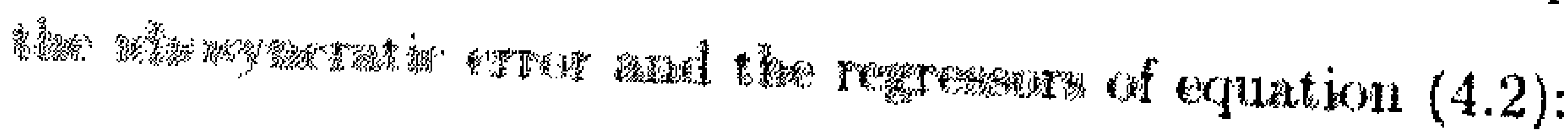

$$
\begin{aligned}
& E a_{i}=E E_{2 u t}=E a_{b} f_{2 u t}=0, E \alpha_{i} x_{z t}^{\prime}=0^{\prime},
\end{aligned}
$$

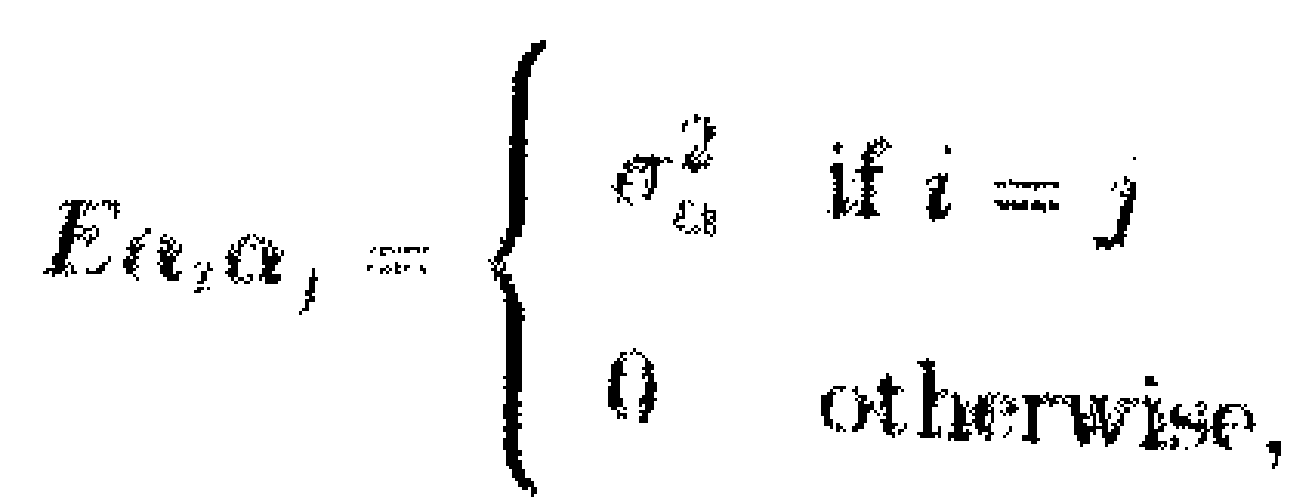

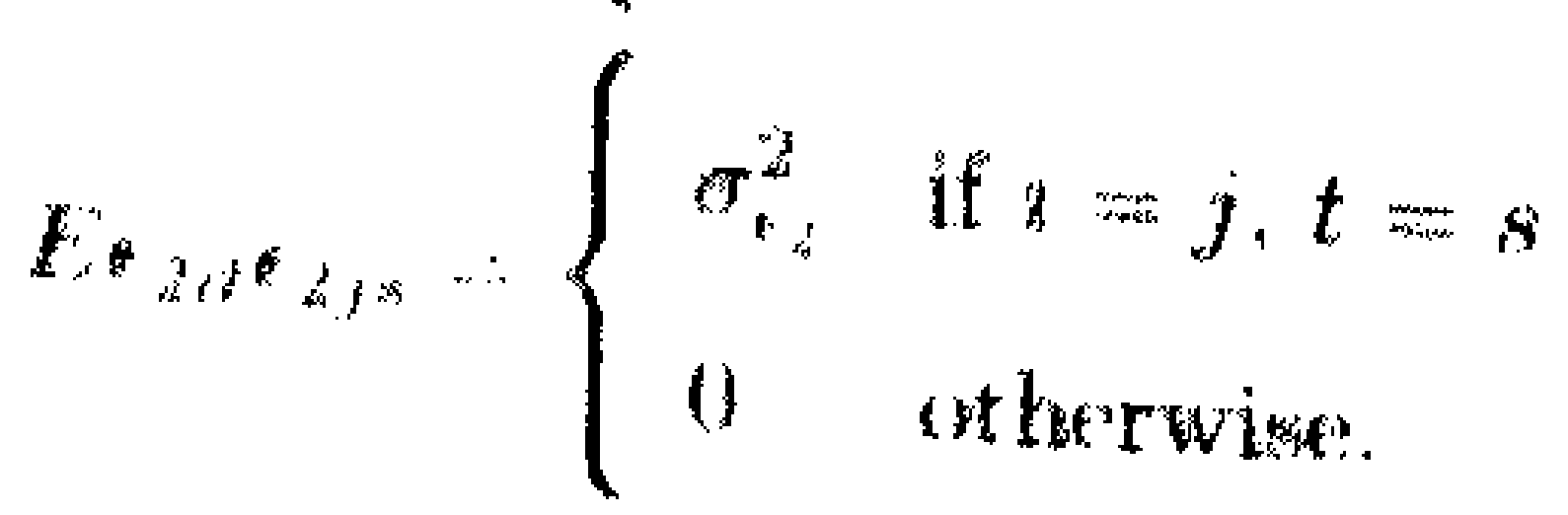

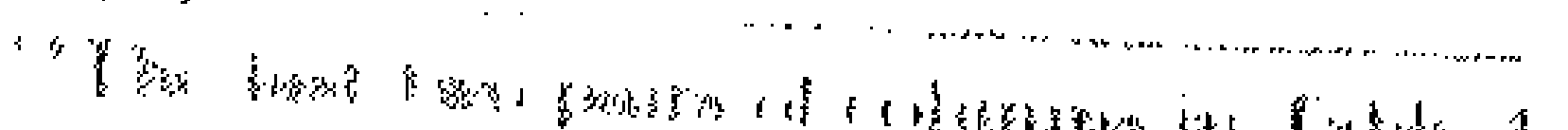

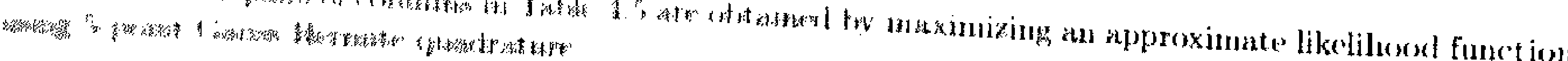


Like in the dynamic probit, the initial conditions problem is also of great issue in the dynamic: linear regression model. The idea is the same as before, i.c., a relationship that models the dependence of the initial conditions on the individual effects must be specified. Anderson and Hsiao $(1981 ; 1982)$ distinguish various cases depending on different assumptions made on the initial conditions. The most relevant case to our study is the one where the initial conditions are assumed to be random with mean $\mu_{y_{i 1}}$ and standard deviation $\sigma_{y_{i \mu}}$. Formally,

$$
y_{i 0}=\mu_{y_{11}}+\nu_{i}
$$

where $\nu_{i}$ is randomly distributed with mean zero and standard deviation $\sigma_{y_{(1)}}$. Furthermore, the initial outcome is assumed to be correlated with the individual effects. The intuition is that, the initial outcome affects all future outcomes through its correlation with the individual effects. Denoting by $\tau \sigma_{y_{21}}^{2}$ the covariance between the initial outcome and the individual effects, the correlation between them is shown to be $\rho_{y / n n_{t}}=\frac{\tau \sigma_{y_{i 11}}}{\sigma_{t_{1}}}$. Under the assumption of normal distributions of $\epsilon_{2 i t}, \alpha_{i}$ and $\nu_{i}$, the likclihood function of individual $i$, starting from $t=0$ and conditional on the regressors, is written as

$$
\begin{aligned}
& L_{i}\left(y_{i 0}, y_{i 1 \ldots,} y_{i T} \mid y_{i, t-1, \mathbf{x}_{i t}}\right)=(2 \pi)^{-\frac{T}{2}}\left(\sigma_{\epsilon_{2 \ell t}}^{2}\right)^{-\frac{\left(T^{2}-1\right)}{2}}\left(\sigma_{\epsilon_{2 \ell t}}^{2}+T c\right)^{-\frac{1}{2}} \\
& \times \exp \left\{-\frac{1}{2 \sigma_{\epsilon_{2 t}}^{2}} \sum_{t=1}^{T}\left[y_{i t}-\gamma y_{i, t-1}-\beta^{\prime} \mathbf{x}_{i t}-\tau\left(y_{i 0}-\mu_{y_{i 0}}\right)\right]^{2}\right. \\
& \left.+\frac{c}{2 \sigma_{\epsilon_{2, t}}^{2}\left(\sigma_{t_{2 t} t}^{2}+T c\right)}\left[\sum_{t=1}^{T}\left[y_{i t}-\gamma y_{i, t-1}-\beta^{\prime} \mathbf{x}_{i t}-\tau\left(y_{i t)}-\mu_{y_{t}}\right)\right]\right]^{2}\right\} \\
& \times\left(2 \pi \sigma_{y_{i 1}}^{2}\right)^{-\frac{1}{2}} \exp \left\{-\frac{1}{2} \frac{\left(y_{i 0}-\mu_{\left.y_{i 1}\right)}\right)^{2}}{\sigma_{y_{t 1}}^{2}}\right\} \text {, }
\end{aligned}
$$

where $c=\sigma_{r}^{2}-\tau^{2} \sigma_{y_{10}}^{2}$. The likelihood function in equation (4.9) is the product of the joint density of the outcomes, starting from $t=1$ conditional on the initial outcome, and the marginal density of the initial outcome. The product over $i$ of the likelihood function (4.9) can be maximized using standard numerical procedures to obtain estimates of the parameters of the dynamic linear regression model.

Table 4.6 reports the estimates of the dynamic linear regression (eq.(4.2)). The results reveal the same pattern as in Table 4.4, i.e., inertia shows up in the share of innovative sales of TPP innovators, even after accounting for individual effects correlated with endogenous 
initial conditions.

Table 4.6: Dynamic linear regression estimates: The dynamics of innovation output

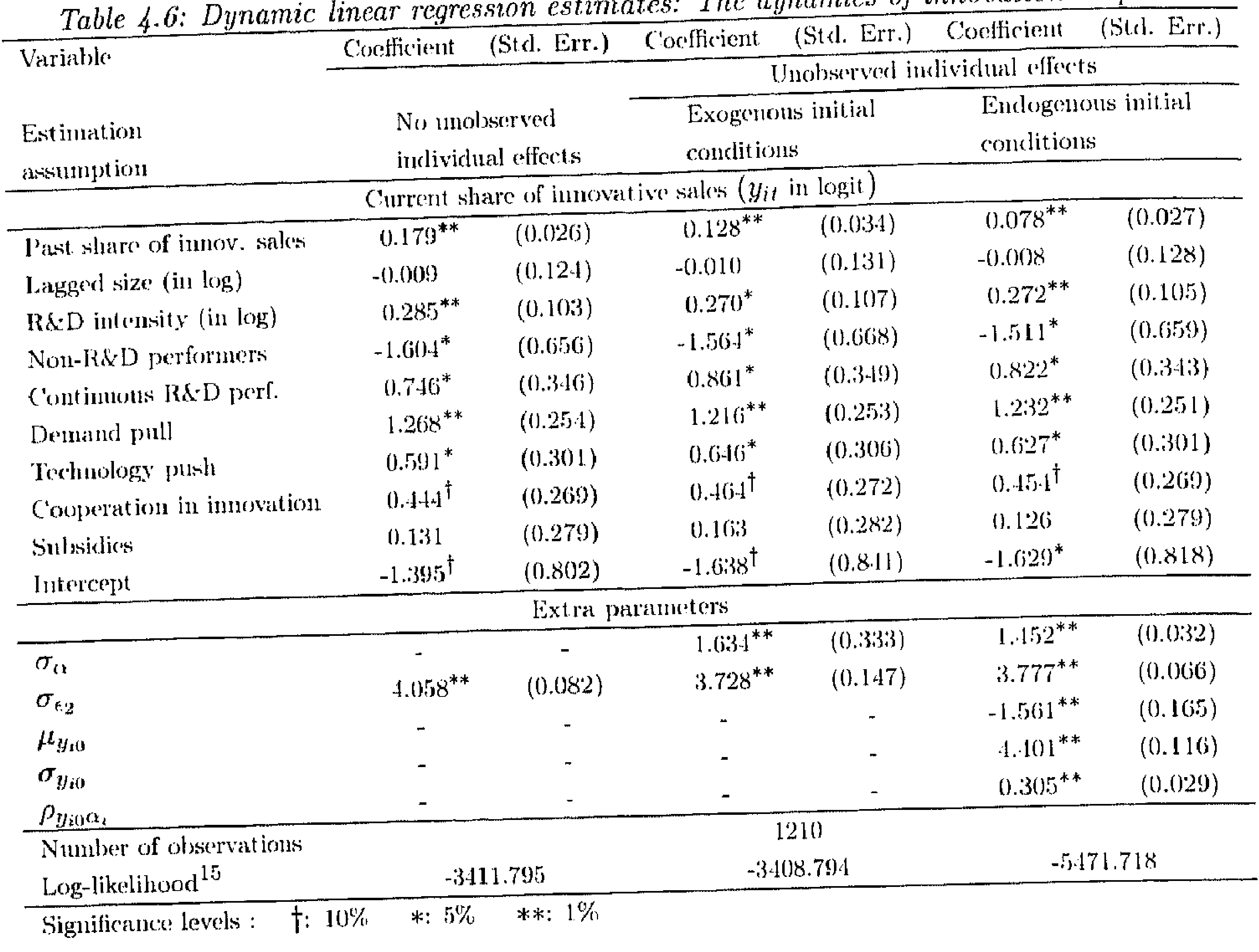

\section{A.3 The persistence of engaging in $R \& D$ and the dynamics of $R \& D$}

\section{investments}

In order to investigate the sensitivity of the model to using $R \& D$ input rather than output measures, we estimate the dynamic type 2 tobit using the incidence of engaging in $R \& D$ activities rather than that of being a TPP innovator as dependent variable in equation (4.1) and using R\&D intensity rather than the share of innovative sales as dcpendent variable in equation (4.2).

Table 4.7 reports the estimation results of the dynamic type 2 tobit that reveal the same pattern as that of Table 4.4, with the notable exception of the probit persistencc parameter that remains significant also in the preferred model accounting for individual effects and

\footnotetext{
${ }^{15}$ Unlike in Table 4.4, the models in the tirst and second pair of columms of Tables 4.5 and 4.6 are not nested in the model in the third pair of columns. Hence the log-likelihood of the first two models cannot be compared to that of the third model. The morlel in the first pair of columus is, however, nested in the one in the second pair of columns.
} 
4.A. The results of the robustness analysis

Table 4.7: Dynamic type 2 tobit estimates with 5-point Gauss-Hermite quadrature: R\&D

\begin{tabular}{|c|c|c|c|c|c|c|}
\hline \multirow[t]{2}{*}{ Variable } & Confficient. & (Std. Err.) & Coetficient & (Strl. Err.) & Conefficient & (Std. Err.) \\
\hline & & & \multicolumn{4}{|c|}{ Unobserved indivichual esterts } \\
\hline $\begin{array}{l}\text { Estimation } \\
\text { assimmption }\end{array}$ & \multicolumn{2}{|c|}{$\begin{array}{l}\text { No unobserved } \\
\text { individual effects }\end{array}$} & \multicolumn{2}{|c|}{$\begin{array}{l}\text { Exogenous initial } \\
\text { conditions }\end{array}$} & \multicolumn{2}{|c|}{$\begin{array}{l}\text { Endugenous initial } \\
\text { conditions }\end{array}$} \\
\hline \multicolumn{7}{|c|}{ Engaging in current $\mathrm{R} \& \mathrm{D}$ activit les $\left(d_{i f}\right)$} \\
\hline Past $R \& D$ activitics & $1.503^{* *}$ & $(0.120)$ & $1.419^{* *}$ & $(0.126)$ & $0.580^{* *}$ & $(10.1+1 \times)$ \\
\hline Lingged size (in log) & 0.072 & $(0.081)$ & 0.084 & $(0.0 \times 5)$ & 0.078 & $(0.11: 3)$ \\
\hline Langged rel. size (in log) & 0.071 & $(0.055)$ & $0.00(5)$ & $(0.059)$ & 0.0 .96 & $(11.078)$ \\
\hline Intercept & -0.198 & $(0.674)$ & $-1) .1 \times 0$ & $(0.716)$ & -0.167 & $(0.93 \times)$ \\
\hline \multicolumn{7}{|c|}{ Current R\&D intentsity $\left(y_{i t}\right.$ in log $)$} \\
\hline Past R\&D intensity & $0.429^{* *}$ & $\left(0.11^{2} 1\right)$ & $0.3699^{* *}$ & $(0.029)$ & $0.0777^{* *}$ & $(0 .(1) 21)$ \\
\hline Size (iı $\log )$ & -0.059 & $(0.040)$ & -0.001 & $(0.042)$ & -0.070 & $(0.040)$ \\
\hline Demand pull & $0.264^{* *}$ & $(0.080)$ & $0.261^{* *}$ & $(0.079)$ & $0.2233^{* *}$ & $(0.072)$ \\
\hline Techuology push & $0.210^{*}$ & $(0.087)$ & $0.225^{*}$ & $(0.0 \times(x)$ & $0.196^{*}$ & $(0.0 \times 5)$ \\
\hline Innovation cooperation & 0.114 & $(0.6) 8.3)$ & 0.118 & $(0.0 \times 3)$ & 0.111 & $(0.079)$ \\
\hline Subsidies & $0.452^{* *}$ & $(0.08(i)$ & $0.455^{* *}$ & $(0 .(1 \times 7)$ & $0.3665^{* *}$ & $(0.0 \times 3)$ \\
\hline Intercept & $-2.5900^{* *}$ & $(0.228)$ & $-2.804^{* *}$ & $(0.25 .5)$ & $-2.520^{* *}$ & $(0.260)$ \\
\hline \multicolumn{7}{|c|}{ Extra purameters } \\
\hline Initial R\&D aclivitius & - & - & - & - & $1.293^{* *}$ & $(0.233)$ \\
\hline Initial R\&D intensity & - & - & - & - & $0.3266^{* *}$ & $(0.024)$ \\
\hline$\sigma_{a_{1}}$ & - & - & $0.241^{\dagger}$ & $(0.137 \pi)$ & $0.811^{* *}$ & $(0.1711)$ \\
\hline$\sigma_{a_{2}}$ & - & - & $0.52 .3^{* *}$ & $(0.089)$ & $0.8: 32^{* *}$ & $(0.048)$ \\
\hline$\sigma_{\ell 2}$ & $1.182^{* *}$ & $(0.034)$ & $1.0366^{* *}$ & $(0.055)$ & $0.817^{* *}$ & $(0.0344)$ \\
\hline$\rho_{a_{1} a_{2}}$ & - & - & $-0.510^{* *}$ & $(0.151)$ & $0.369^{* *}$ & $(0.125)$ \\
\hline$\rho_{\mathrm{e}_{1} \mathrm{f}_{2}}$ & $0.617^{* *}$ & $(0.061)$ & $0.6600^{* *}$ & $(0.085)$ & $0.581^{* *}$ & $(0.126)$ \\
\hline Number of observations & \multicolumn{6}{|c|}{1087} \\
\hline Log-likelihood & \multicolumn{2}{|c|}{-1781.256} & \multicolumn{2}{|c|}{-1774.923} & \multicolumn{2}{|c|}{-1731.572} \\
\hline
\end{tabular}

the endogeneity of the initial conditions. Furthermore, the magnitude of the persistence parameters in both equations lessens when accounting for individual effects and assuming endogenous initial conditions. 
CHAPTER 5

Modeling the initial conditions in dynamic panel data sample

selection models

\subsection{Introduction}

When dealing with dynamic panel data models, a computational and methodological difficulty that arises, besides the unobserved individual effects, is the so-called initial conditions problem. In a random-effects approach, Anderson and Hsiao (1981; 1982) show that the consistency of the maximum likelihood estimator (MLE) of the dynamic linear regression depends on the treatment of the initial conditions. In nonlinear dynamic panel data models, the initial conditions problem is more difficult to solve, and the literature identifies various ways of treating the initial conditions.

A first approach is to assume that the initial conditions are exogenous. For instance, Nijinan and Verbeek (1992) estimate the effect of nonresponse on Dutch households' consumption, where the nonresponse equation is modeled as a dynamic probit and the initial nonresponse is assumed to be exogenous. This treatment of the initial conditions is unsatisfactory because it assumes no correlation between the initial conditions and the unobserved individual effects.

A better approach is to allow for endogenous initial conditions correlated with the unobserved individual effects by specifying a distribution for the initial conditions conditional on the individual effects and the strictly exogenous explanatory variables. The difficulty of 
this approach lies in the specification of this distribution. Some authors claim that the distribution of the initial conditions represent a steady-state distribution that is shown, in the literature, to exist in very special cases (Wooldridge, 2005). Heckman (1981b) circumvents this problem by "approximating" the initial conditions of a dynamic panel data probit, given the individual effects and the strictly exogenous regressors, by a simple probit. Although Heekman's solution to the initial conditions problem is shown to perform fairly well in Monte Carlo results for a dynamic panel data discrete choice model, very few empirical studies adopt his approach. Two exceptions are Vella and Verbeek (1998) who estimate a dynamic (probit) model of mionism and the effects of unions on wage, and Vella and Verbeck (1999) who estimate a dynamic (tobit) model of weekly hours worked and their impact on hourly wage rate. The former approximate the model of the initial conditions by a standard probit, while the lattor use a standard tobit for the initial conditions.

Finally, an alternative solution to handling the initial conditions is advocated by Pickles and Davies (1991) and more recently by Wooldridge (2005). It consists in specifying a distribution for the individual effects conditional on the initial conditions. In the former study a dynamic panel data probit model is considered where the distribution of the individual effects consists of two different sets of parameters according to whether the initial conditions take on the value zero or one. The latter study considers any nonlinear dynamic panel data model with one equation, and the distribution of the individual effects given the initial conditions consists of one set of parameters. More and more recent empirical studies adopt the Wooldridge approach because of its flexibility, i.e., it applies in the same manner to a broad range of nonlinear dynamic panel data models. For instance, Kaiser and Kongsted (2004) estimate a dynamic panel data logit to study the persistence of West German firms' exporting behavior, Contoyannis et al. (2004) estimate a dynamic panel data ordered probit to study the dynamics of British houselolds' health, and Peters (2005) estimates a dynamic panel data probit to study the persistence of engaging in innovative activities in the German manufacturing and services sectors. All these studies consider a single equation nonlinear dynamic model, and the Wooldridge approach is extended in Chapter 3 to nonlinear dynanic models with two equations.

The contribution of this chapter is to extend the Heckman approach of treating the initial conditions to dynamic panel data sample selection models. Since it is shown that the treatment of the initial conditions affects the estimates of nonlinear dynamic panel data 
models (sce Chapter 3 and Fotouhi, 2005) we investigate the sensitivity of the persistence of innovation to the treatment of the initial conditions. We estimate a dynamic type 2 tobit with the same specification as in Chapter 4 using the Heckman approach of treating the initial conditions and find that the lack of persistence is robust to the (proper) treatment of the initial conditions. Furthermore, we study the dynamics of incremental and radical innovations by estimating a dynamic type 3 tobit using both the Heckman and the Wooldridge approach of handling the initial conditions. We find that the two approaches yield similar results in terms of the coefficients of the strictly exogenous variables while some differences arise in the coefficients of the lagged dependent variables and the individual effects.

Scction 5.2 describes the Heckman approach in the context of dynamic panel data sample selection models and the resulting maximum likelihood estimation. Section 5.3 presents an economic application, Section 5.4 discusses the estimation results, and Section 5.5 concludes.

\subsection{Modeling the initial conditions and estimation}

The Heckman approach consists in specifying a model for the initial conditions given the individual effects and the strictly exogenous explanatory variables. This model is often assumed to be similar to the underlying model of the remaining process. For instance, if the process under study is dynamic probit, the model of the initial conditions given the individual effects and the strictly exogenous regressors is assumed to be standard probit. The model of the initial conditions uses pre-sample information that affects the initial outcome of the process and takes account of the correlation between the initial conditions and the indiviclual effects. We use this approach of handling the initial conditions problem to estimate the dynamic type 2 and type 3 tobit described in Chapter 3.

\subsubsection{Dynamic type 2 tobit}

Consider the dynamic type 2 tobit model defined in equations $(3.1),(3.2),(3.3)$ and (3.4) of Chapter 3. Modeling the initial conditions consists in writing the latent variables at the initial period as

$$
\begin{aligned}
& d_{i 0}^{*}=\delta_{0}^{\prime} \mathbf{w}_{i 0}+\lambda_{1} \eta_{i}+\epsilon_{1 i 0}, \\
& y_{i 0}^{*}=\beta_{0}^{\prime} \mathbf{x}_{i 0}+\lambda_{2} \alpha_{i}+\epsilon_{2 i 0},
\end{aligned}
$$


where $\lambda_{1}$ and $\lambda_{2}$ capture the dependence of the initial conditions on the individual effects in the selection equation and in the equation of interest respectively, and $\delta_{0}^{\prime}$ and $\beta_{0}^{\prime}$, as well as $\lambda_{1}$ and $\lambda_{2}$, are to be estimated. Assuming a type 2 tobit model for the initial conditions given the individual effects and the strictly exogenous regressors yield

$$
d_{i 0}=1\left[d_{i 0}^{*}>0\right]
$$

for the observed dependent variable of the selection equation and

$$
y_{i 0}=1\left[d_{i 0}^{*}>0\right] y_{i 0}^{*}
$$

for the observed dependent variable of the equation of interest.

The vectors $\left(\epsilon_{1 i t}, \epsilon_{2 i l}\right)^{\prime}$ and $\left(\eta_{i}, \alpha_{i}\right)^{\prime}$ are assumed independent of each other, and independently and identically distributed over time and across individuals following a normal distribution with mean zero and covariance matrix

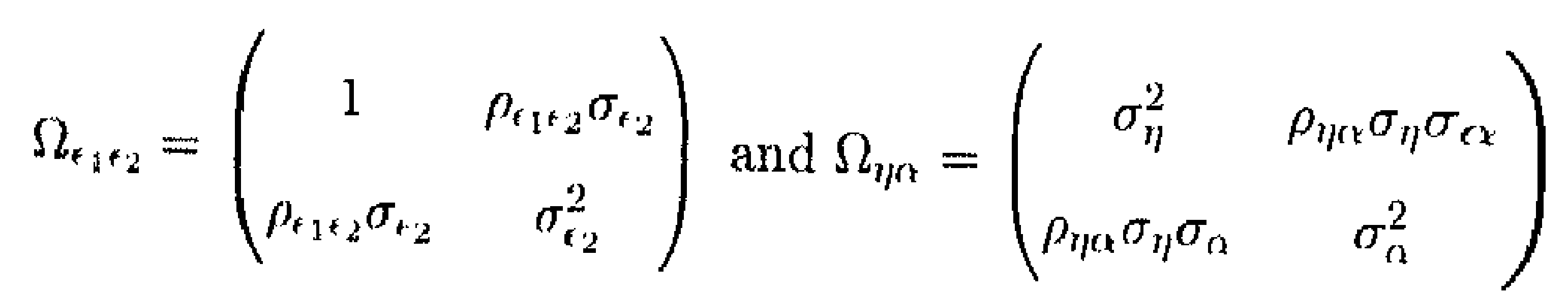

respectively. Let us denote by $\varsigma_{1 i 0}=\lambda_{1} \eta_{i}+\epsilon_{1 i 0}$ the error term of the initial conditions in the selection equation, and $\varsigma_{2 i 0}=\lambda_{2} \alpha_{i}+\epsilon_{220}$ that of the initial conditions in the equation of interest. The correlation between the initial conditions and the individual effects is slown to be $\rho_{1 \eta}=\frac{\lambda_{1} \sigma_{3}}{\sqrt{\lambda_{1}^{2} \sigma_{\eta}^{2}+1}}$ in the selection equation and $\rho_{\varsigma_{2} n}=\frac{\lambda_{2} \sigma_{\alpha}}{\sqrt{\lambda_{2}^{2} \sigma_{n}^{2}+\sigma_{\kappa_{2}}^{2}}}$ in the equation of interest. where $\sqrt{\lambda_{1}^{2} \sigma_{\eta}^{2}+1}$ is the standard deviation of the crror term of the initial conditions in the selection equation and $\sqrt{\lambda_{2}^{2} \sigma_{a}^{2}+\sigma_{t 2}^{2}}$ is that of the initial conditions in the equation of interest. We can then derive the likelihood function of individual $i$, starting from $t=0$ and conditional on the regressors as

$L_{i}=\int_{-\infty}^{\infty} \int_{-\infty}^{\infty} L_{i l 1}\left(\ldots \mid \ldots, \eta_{\eta}, \alpha_{l}\right) \prod_{i=1}^{T} L_{i l}\left(y_{i l}, d_{l l} \mid d_{i 1}, d_{i, l-1}, \mathbf{w}_{i l}, y_{i 0}, y_{i, l-1}, \mathbf{x}_{i l}, \eta_{i}, \alpha_{i}\right) g\left(\eta_{i}, \alpha_{i}\right) d \eta_{i} d \alpha_{i}$ where $\prod_{t \cdots 1}^{T} L_{t t}\left(y_{t t}, d_{t i} \mid d_{2(1)}, d_{t, t-1}, \mathbf{w}_{i t}, y_{t 1}, y_{l, t-1}, \mathbf{x}_{l l}, \eta_{l}, \alpha_{i}\right)$ denotes the likelihood function of individual $i$ ronditional on the individual effects, $L_{i 0}\left(\ldots \mid \ldots, \eta_{i}, \alpha_{i}\right)$ is the likelihood function of the initial conditions given the individual effects and the strictly exogenous regressors at the 
initial period, and $g\left(\eta_{i}, \alpha_{i}\right)$ is the bivariate normal density function of $\left(\eta_{i}, \alpha_{i}\right)$. The expression of the individual likelihood function conditional on the individual effects is given in equation (3.12) of Chapter 3 for the type 2 tobit, and the conditional likelihood function of the initial conditions is written as

$$
\begin{aligned}
& L_{i 0}\left(\ldots \mid \ldots, \eta_{i}, \alpha_{i}\right)=\Phi\left[-\left(\delta_{0}^{\prime} \mathbf{w}_{i 0}+\lambda_{1} \eta_{i}\right)\right]^{\left(1-d_{i 11}\right)}\left[\frac{1}{\sigma_{t_{2}}} \phi\left(\frac{y_{i 0}-\beta_{0}^{\prime} \mathbf{x}_{i 0}+\lambda_{2} \alpha_{i}}{\sigma_{\epsilon_{2}}}\right)\right. \\
& \left.\times \Phi\left(\frac{\delta_{0}^{\prime} \mathbf{w}_{i 0}+\lambda_{1} \eta_{i}+\frac{\mu_{i+12}}{\sigma_{i 2}}\left(y_{i 0}-\beta_{0}^{\prime} \mathbf{x}_{i 0}+\lambda_{2} \alpha_{i}\right)}{\sqrt{1-\rho_{\epsilon_{1+2}}^{2}}}\right)\right]^{\gamma_{111}} \text {. }
\end{aligned}
$$

Hence, using the results of Appendix 3.A, the individual likelihood function, starting from $t=0$ and conditional on the regressors can be approximated using "two-step" Gauss-Hormite quadrature by

$$
\begin{aligned}
& L_{i} \simeq \frac{\sqrt{1-\rho_{i n}^{2}}}{\pi} \sum_{p=1}^{p} w_{p}\left\{\left[\frac{1}{\sigma_{\epsilon 2}} \phi\left(\frac{y_{i 0}-\beta_{0}^{\prime} \mathbf{x}_{i 0}+\lambda_{2} a_{p} \sigma_{r 2} \sqrt{2\left(1-\rho_{i, k}^{2}\right)}}{\sigma_{\epsilon_{2}}}\right)\right]^{d_{t(1)}}\right. \\
& \times \prod_{l=1}^{T}\left[\frac{1}{\sigma_{\tau_{2}}} \phi\left(\frac{y_{i t}-B_{i t}-a_{p} \sigma_{\alpha} \sqrt{2\left(1-\rho_{\eta \alpha \Omega}^{2}\right)}}{\sigma_{t \cdot 2}}\right)\right]^{d_{i t}} \\
& \times \sum_{m=1}^{M} w_{m}\left\{e^{2 \rho_{\eta r} a_{m} a_{m}} \Phi\left[-\left(\delta_{0}^{\prime} \mathbf{w}_{i 0}+\lambda_{1} a_{m} \sigma_{\eta} \sqrt{2\left(1-\rho_{\eta n}^{2}\right)}\right)\right]^{\left(1-d_{i(1)}\right)}\right.
\end{aligned}
$$

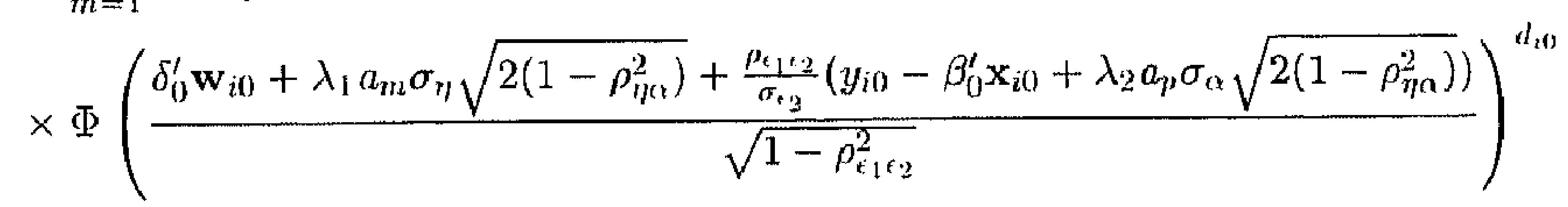

$$
\begin{aligned}
& \times \prod_{t=1}^{T} \Phi\left[-\left(A_{i t}+a_{m} \sigma_{\eta} \sqrt{2\left(1-\rho_{\eta(k)}^{2}\right)}\right)\right]^{\left(1-d_{i t}\right)}
\end{aligned}
$$

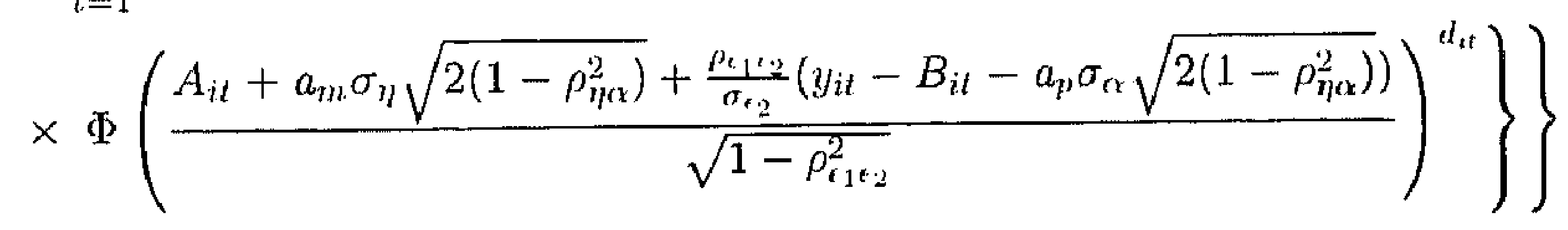

whose product over $i$ can be maximized using standard numerical procedures to obtain estimates of the parameters of the dynamic type 2 tobit.

\subsubsection{Dynamic type 3 tobit}

When the underlying model of the process is dynamic type 3 tobit, as defined in equations (3.1), (3.2), (3.3) and (3.5) of Chapter 3 , the model of the initial conditions is assumed to be type 3 tobit. The latent variables at the initial period are written as in equations (5.1) and 
(5.2), and their observed counterparts are given by

$$
d_{i 0}=\mathbf{1}\left[d_{i 0}^{*}>0\right] d_{i 0}^{*}
$$

and equation (5.4) respectively. In this case, the likelihood function of the initial conditions given the individual effects and the initial strictly exogenous explanatory variables is written ats

$$
\begin{aligned}
& L_{t+1}\left(\ldots, \ldots . \eta_{k}, \alpha_{2}\right)=\Phi\left[-\left(\frac{\delta_{i j}^{\prime} \mathbf{w}_{i 0}+\lambda_{1} \eta_{i}}{\sigma_{t_{1}}}\right)\right]^{\left(1-s_{t 3}\right)}\left[\frac{1}{\sigma_{t_{2}}} \phi\left(\frac{y_{i 0}-\beta_{0}^{\prime} \mathbf{x}_{i 0}+\lambda_{2} \alpha_{i}}{\sigma_{t_{2}}}\right)\right.
\end{aligned}
$$

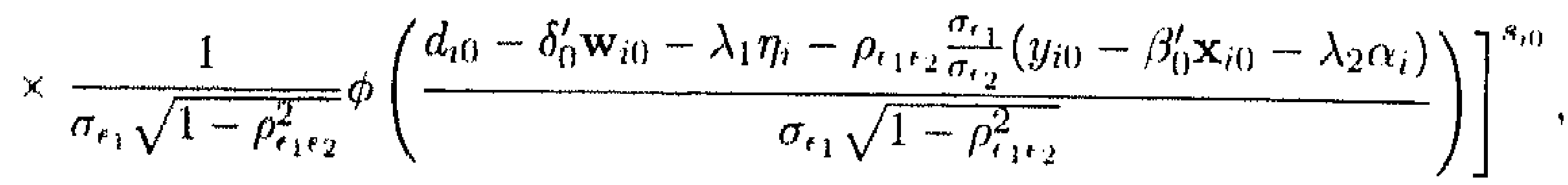

where $s_{i 0}$ is given by

$$
s_{i 0}=1\left[d_{i 0}^{*}>0\right]{ }^{\perp}
$$

Using again the results of Appendix 3.A, the approximated individual likelihood function, starting from $t=0$ and conditional on the regressors is given by

$$
\begin{aligned}
& L_{\imath} \simeq \frac{\sqrt{1-\rho_{p r}^{2}}}{\pi} \sum_{p=1}^{p} w_{p}\left\{\left[\frac{1}{\sigma_{\epsilon_{2}}} \phi\left(\frac{y_{i 0}-\beta_{0}^{\prime} \mathbf{x}_{t(1)}+\lambda_{2} a_{p} \sigma_{\kappa x} \sqrt{2\left(1-\rho_{t t_{k}}^{2}\right)}}{\sigma_{\epsilon_{2}}}\right)\right]^{s_{i 0}}\right. \\
& \times \prod_{t=1}^{T}\left[\frac{1}{\sigma_{t_{2}}} \phi\left(\frac{y_{i t}-B_{i t}-a_{p} \sigma_{\alpha} \sqrt{2\left(1-\rho_{\eta \alpha}^{2}\right)}}{\sigma_{\tau_{2}}}\right)\right]^{s_{i t}}
\end{aligned}
$$

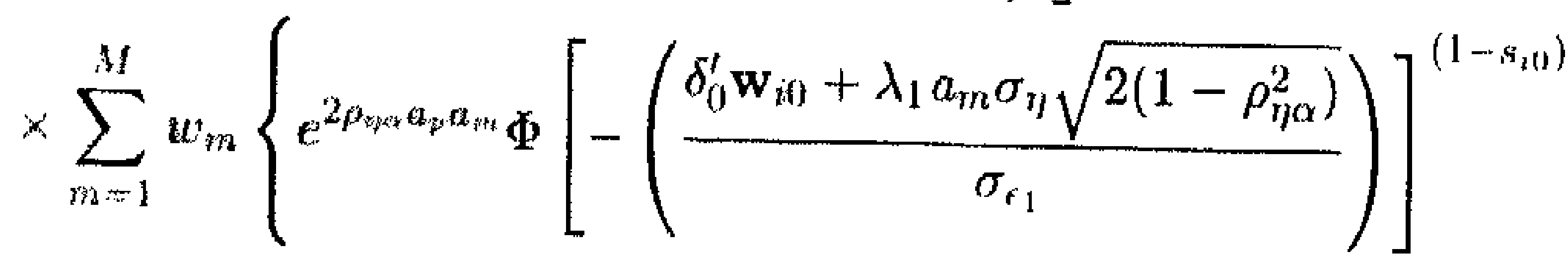

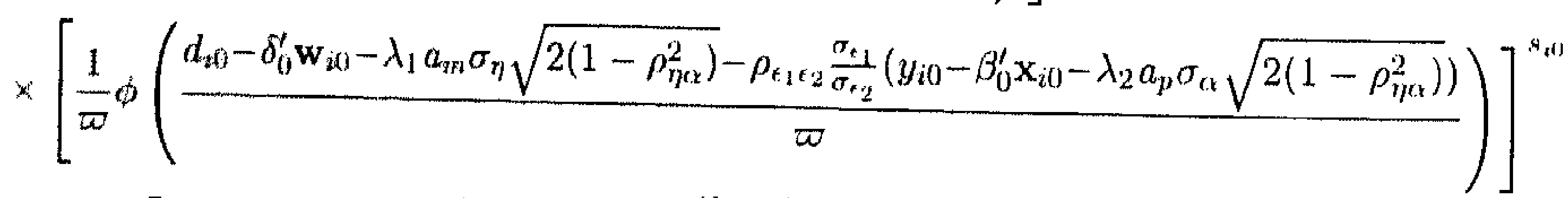

$$
\begin{aligned}
& \times \prod_{t=1}^{T} \Phi\left[-\left(\frac{A_{2 t}+a_{r_{2}} \sigma_{\eta} \sqrt{2\left(1-\rho_{\eta / 2}^{2}\right)}}{\sigma_{t_{1}}}\right)\right]^{\left(1-s_{t t}\right)}
\end{aligned}
$$

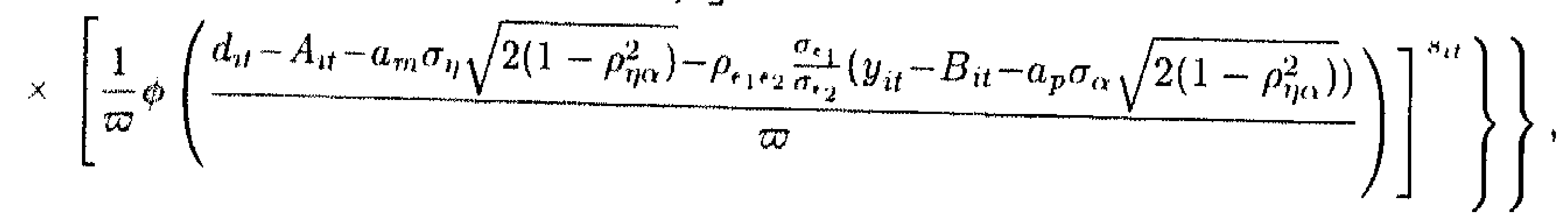

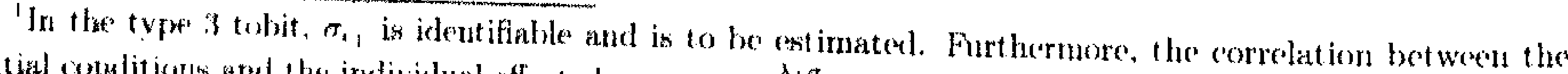

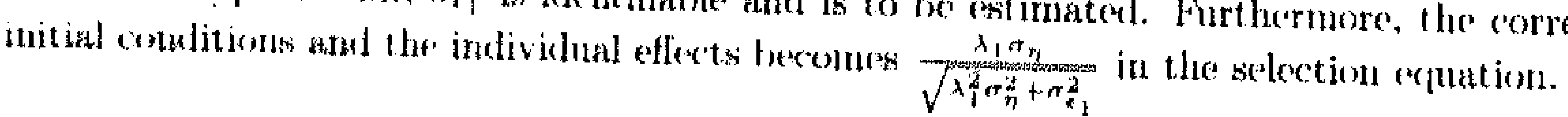


where $\varpi=\sigma_{\epsilon_{1}} \sqrt{1-\rho_{\epsilon_{1} \epsilon_{2}}^{2}}$. The product over $i$ of equation (5.10) can be maximized using standard numerical procedures to obtain estimates of the parameters of the dynamic type 3 tobit.

\subsection{Application}

We investigate the sensitivity of the persistence of innovation to the treatment of the initial conditions. More specifically, we estimate a dynamic type 2 tobit with the same specification as in Chapter 4 using the Heckman approach of treating the initial conditions. In other words, we model the initial conditions as a type 2 tobit explaining the initial decision to be a TPP innovator and, for initial innovators, the initial share of innovative sales. The initial decision to be a TPP innovator and the initial share of innovative sales are explained by the same initial strictly exogenous regressors as for the remaining process.

We also study the dynamics of incremental and radical innovations by estimating a dynamic type 3 tobit using both the Heckman and the Wooldridge approach of handling the initial conditions. Innovation surveys distinguish two types of product innovations, those new to the firm (incremental) and those new to the market (radical). The importance of each type of product innovation is measured by the share in total sales of innovative sales. But from the way the questionnaire of the survey is formulated, we only observe the latter if we observe the former. Equation (3.1) of Chapter 3 determines whether enterprise $i$ is an incremental product innovator at period $t\left(d_{i t}^{*}>0\right)$. In this case, the actual share of sales of incremental product innovations (eq. (3.5)) is positive, and the share of sales of radical product innovations (eq. (3.3)) and the full set of regressors included in the vector $\mathbf{x}_{i t}$ are observed. When enterprise $i$ is not an incremental product innovator, the shares of sales of incremental $\left(d_{i l}\right)$ and radical $\left(y_{i t}\right)$ product innovations are equal to zero, and only the set of regressors included in the vector $\mathbf{w}_{i t}$ is observed. The average share of sales of radical innovations is very small (6.5\%) in our panel. Like that of incremental innovations, the share of sales of radical innovations is logit-transformed in the estimation of the model. ${ }^{2}$ The specification of the model is similar to that of Section 4.5, except that the share of incremental innovative sales is the dependent variable of the selection equation, and the share of radical imnovative sales is the dependent variable of the regression equation. In the Heckman approach, we

\footnotetext{
${ }^{2}$ The share of sales of radical product innovations takes on the values 0 for some incrometial product innovators. They are replaced by 0.0001 in the logit transformation.
} 
model the initial conditions as a type 3 tobit explaining the initial share of incremental and, for incremental innovators, the initial share of radical innovative sales.

\subsection{Estimation results}

We discuss the results of the sensitivity of the persistence of innovation to the treatment of the initial conditions in subsection 5.4.1 and those of the dynamics of incremental and radical innovations in subsection 5.4.2.

\subsubsection{The sensitivity of the persistence of innovation to the treatment of the initial conditions}

Table 5.1 reports the estimation results of the dynamic type 2 tobit where we correct for sample selection bias and allow for unobserved individual effects correlated with endogenous initial conditions specified as a type 2 tobit. The results suggest a similar pattern to that of Table 4.4. More specifically, there is no evidence of true persistence of innovation while past share of innovative sales of innovators conditions, albeit to small extent, current share of imnovative sales. To the extent that innovation is not persistent, we interpret the latter result as a rather lengthy enjoyment by innovators of their old innovations. The probability to innovate is positively and significantly affected by lagged size, while lagged relative size hardly plays a role. The share of immovative sales of innovators is positively and significantly affected by lagged size, R\&D intensity, performing R\&D continuously, demand pull, technology push, subsidies while, ceteris paribus, non-R\&D performers are less successful than R\&D performers. Unobserved heterogeneity plays a highly significant role in both the probability to innovate and the share of innovative sales as suggested by the highly significantly estimated standard deviations of the individual effects. Furthermore, in both equations, the correlation between the initial conditions and the individual effects is statistically and significantly estimated to be 0.591 and 0.506 respectively. Hence, the assumptions of absence of unobserved individual effects and exogenous initial conditions can be rejected using a likelihood ratio at $1 \%$ level of significance, which corroborates the results of Section 4.6. Finally, like in Section 4.6, crossequation individual effects and cross-equation idiosyncratic parts are found to be correlated, indicating the presence of sample selection.

\footnotetext{
"In order 10 save space, the parameter estimates of the model of the initial conditions are not reported. They ran he obtained upon recjuest.
} 
Table 5.1: Dynamic type 2 tobit estimates with 5-point Gauss-Hermite quadrature and the

\begin{tabular}{|c|c|c|}
\hline Varialle & Coefficicint & (Std. I.rr.) \\
\hline Estimation assumption & \multicolumn{2}{|c|}{$\begin{array}{l}\text { Sillection bias correction with } \\
\text { unolserved individual effects } \\
\text { and endogenous initial condi- } \\
\text { tions }\end{array}$} \\
\hline \multicolumn{3}{|c|}{ Current TPP innovation $\left(d_{i t}\right)$} \\
\hline Past TPP innoval ion $\left(d_{i, t-1}\right)$ & 0.263 & (0.160) \\
\hline Lingged size (in log) & $0.154^{*}$ & $(0.078)$ \\
\hline Latgged relative size (in log) & $0.0093^{\dagger}$ & $(0.1154)$ \\
\hline Intercept & 0.477 & $(0.672)$ \\
\hline \multicolumn{3}{|c|}{ Current share of imnovative sales ( $y_{i t}$ in logit) } \\
\hline Past share of innovat ive sales $\left(y_{i, t-1}\right)$ & $0.123^{* *}$ & $(0.037)$ \\
\hline Lagged size (in log) & $0.306^{*}$ & $(0.138)$ \\
\hline R\&D intensity (iulog) & $0.371^{* *}$ & $(0.098)$ \\
\hline Non-R\&D performers & $-2.373^{* *}$ & $(0.615)$ \\
\hline Continuous R\&D performers & $0.854^{* *}$ & $(0.321)$ \\
\hline Demand pull & $1.202^{* *}$ & $(0.237)$ \\
\hline Technology push & $0.590^{*}$ & $(0.271)$ \\
\hline Cooporation in innovation & 0.304 & $(0.253)$ \\
\hline Subsidies & $0.532^{*}$ & $(0.26 .1)$ \\
\hline Intercept & $-4.256^{* *}$ & $(0.848)$ \\
\hline \multicolumn{3}{|c|}{ Extra parameters } \\
\hline$\sigma_{\eta}$ & $0.768^{* * *}$ & $(0.0833)$ \\
\hline$\sigma_{n}$ & $1.727^{* *}$ & $(0.259)$ \\
\hline$\sigma_{\epsilon_{2}}$ & $4.0002^{* *}$ & $(0.10: 3)$ \\
\hline$\rho_{T / \Omega}$ & $0.516^{* *}$ & $(0.06-1)$ \\
\hline$\rho_{\epsilon_{1} \epsilon_{2}{ }^{4}}$ & \multicolumn{2}{|c|}{0.950} \\
\hline$\rho_{\varsigma 1 \eta}$ & $0.591^{* *}$ & $(0.062)$ \\
\hline$P_{\mathrm{S}_{2} \mathrm{O}}$ & $0.506^{* *}$ & $(0.044)$ \\
\hline Number of ohservations & \multicolumn{2}{|c|}{1722} \\
\hline Log-likelilıod & \multicolumn{2}{|c|}{$-55,71.588$} \\
\hline
\end{tabular}

\subsubsection{The dynamics of incremental and radical innovations}

Table 5.2 reports the estimation results of the dynamic type 3 tobit where we correct for sample selection bias and allow for unobserved individual effects correlated with endogenous initial conditions. In the first pair of columns, the initial conditions problem is solved according to the Heckman approach, i.e., a type 3 tobit model is specified for the initial conditions given the individual effects and the strictly exogenous regressors. In the second pair of columns, we handle the initial conditions problem using the Wooldridge approach, i.e., the individual effects are specified as a linear function of the initial conditions and the

\footnotetext{
The estimate value of $\rho_{\varepsilon_{1} \epsilon_{2}}$ tended to approach 1 . Hencer $\rho_{e_{1} / 2}$ has been fixed to 0.950 .
} 
Thase 5.2: Dymamar type 3 tobit estimates with 5-point Gauss-Hermite quadrature:

\begin{tabular}{|c|c|c|c|c|}
\hline 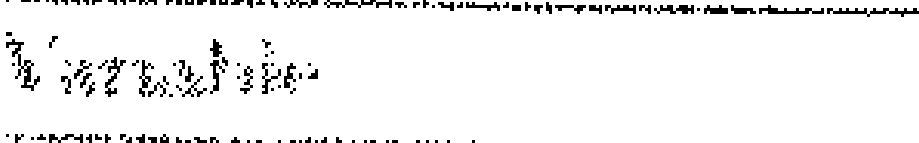 & Corfficient & (Sid. Err.) & Coefficient & (Stcl. Err.) \\
\hline 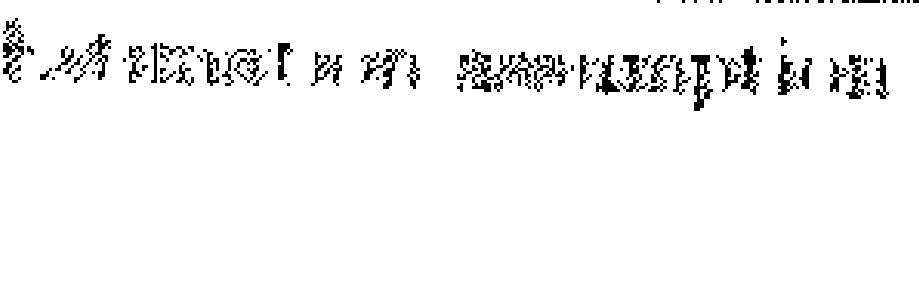 & $\begin{array}{l}\text { Selection bi } \\
\text { dfeerls and }\end{array}$ & $\begin{array}{l}\text { correction } \\
\text { ulogenous }\end{array}$ & $\begin{array}{l}\text { th mobser } \\
\text { ial condition }\end{array}$ & line \\
\hline
\end{tabular}

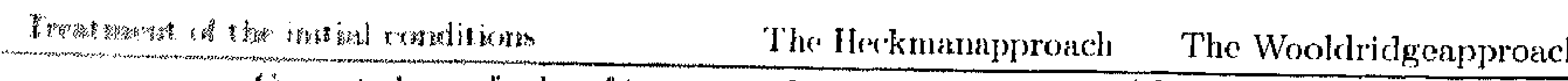

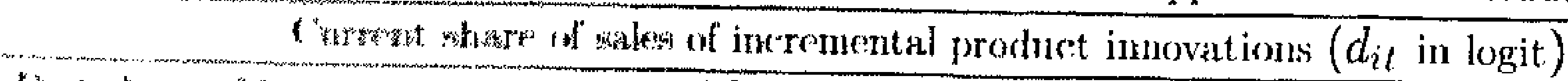

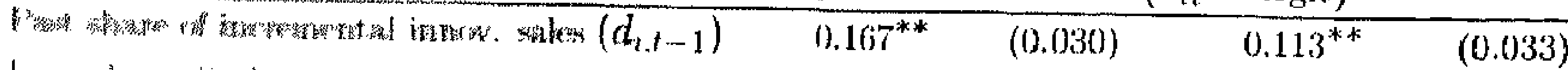

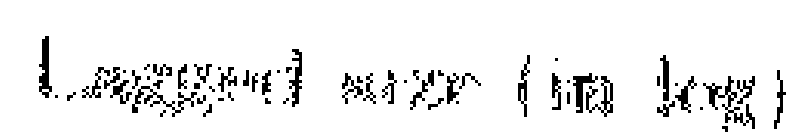

$0.3323^{*} \quad(0.157) \quad 0.354^{*} \quad(0.159)$

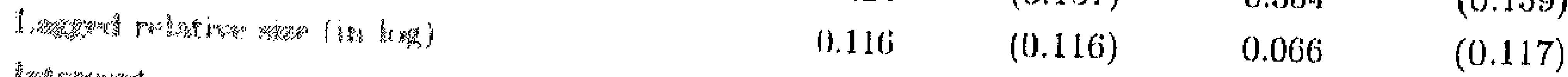

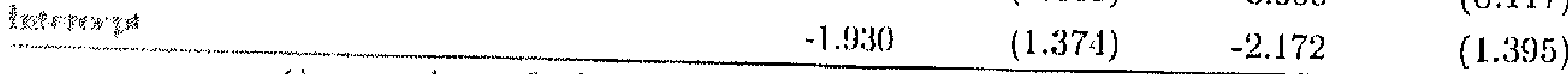

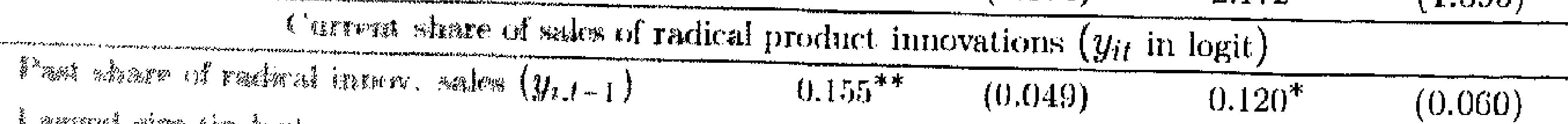

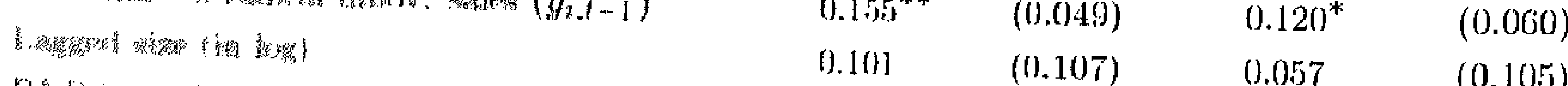

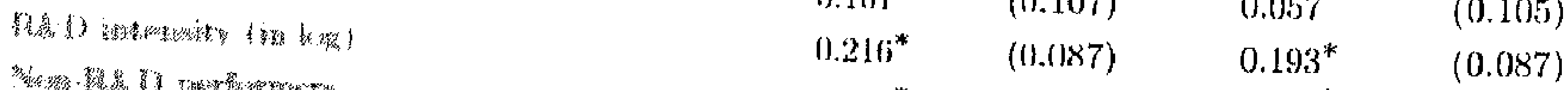

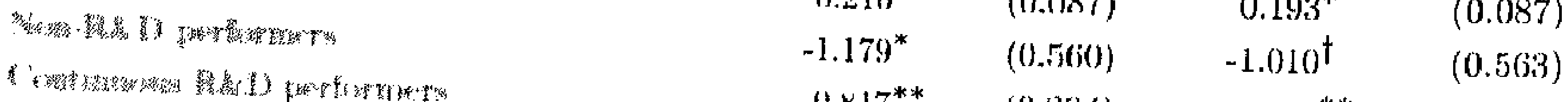

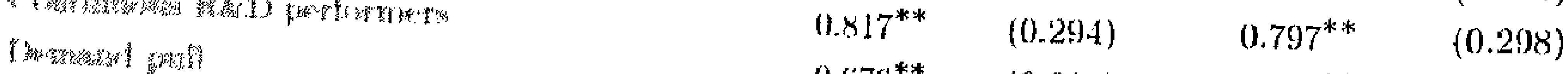

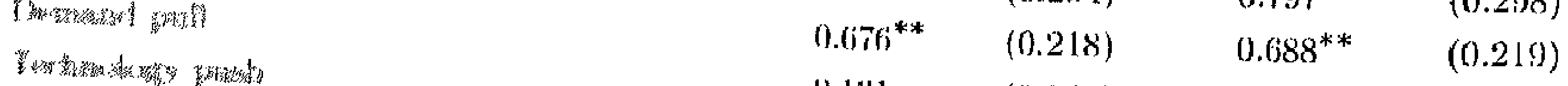

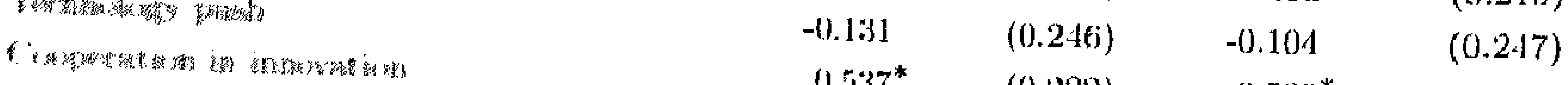

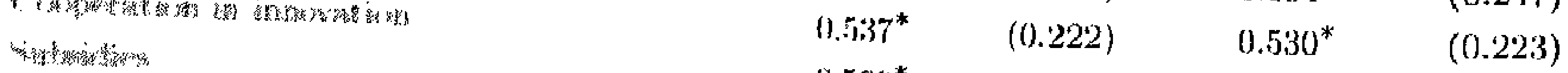

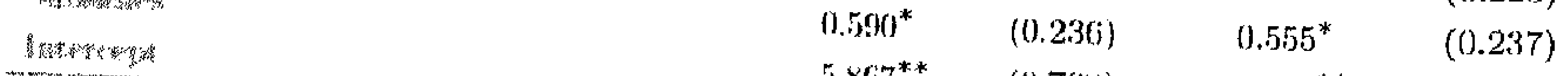

\begin{tabular}{rrrr}
$-5.867^{* *}$ & $(0.768)$ & $-5.165^{* *}$ & $(0.726)$ \\
\hline Extra paranneters &
\end{tabular}

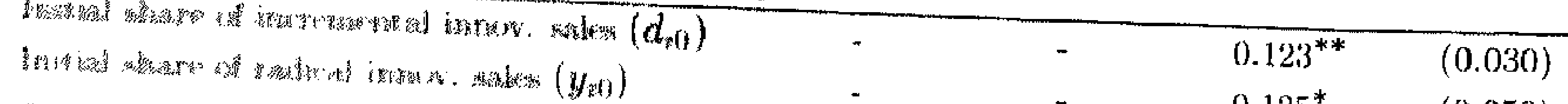

$y_{3}, y_{2}$

$0.310^{* *} \quad(0.075) \quad 0.125^{*} \quad(0.050)$

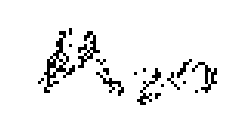

$0.392^{* *} \quad(0.072)$

$w_{0,2}$

tis

- $\quad 1.102^{* *} \quad(0.243)$

$r_{i,}$

$\beta_{i !}$

$\pi_{* j}$

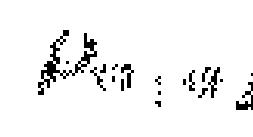

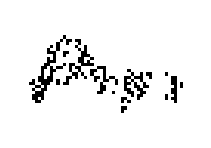

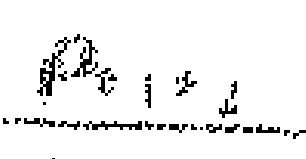

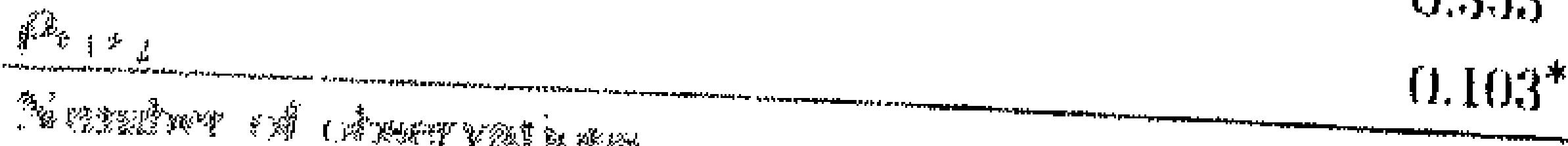

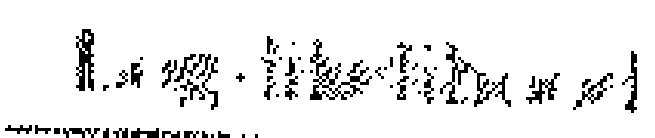

$983^{* *} \quad(0.253) \quad 0.597 \quad(0.681)$

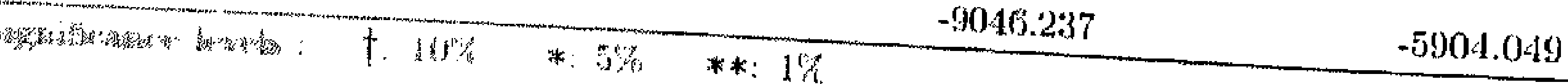

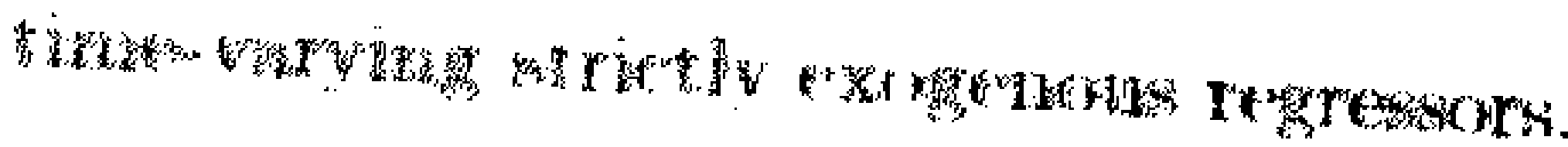

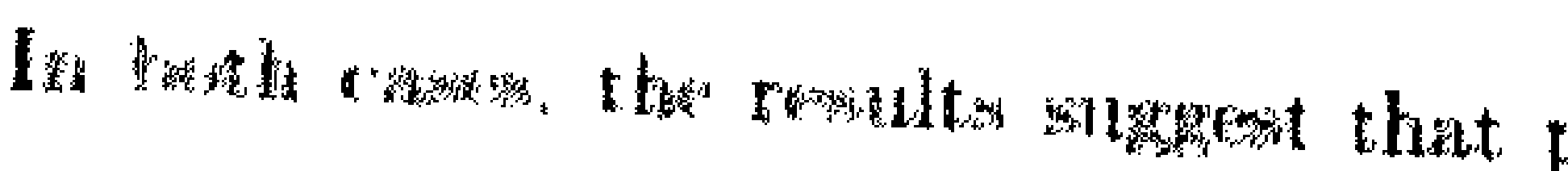

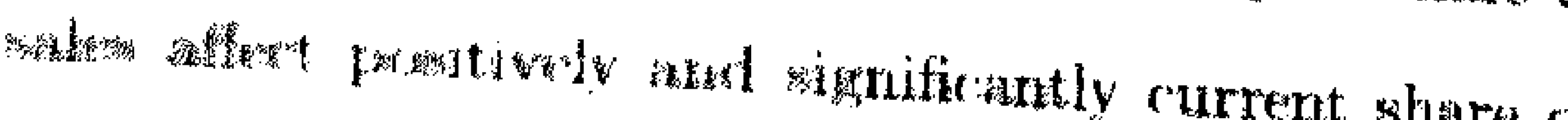
wart: of incrementul and radical innovative

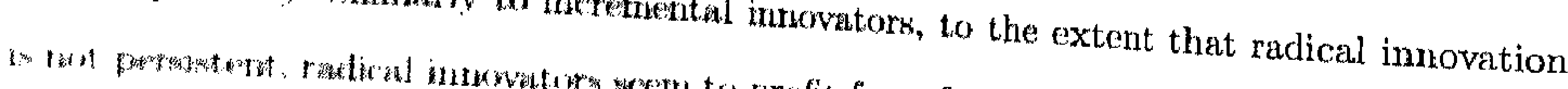
(4) 
radical innovations. The estimated coefficients associated with the lagged dependent variables in both the selection equation and the equation of interest are larger when using the Heckman approach (around 0.160) than when using the Wooldridge approach (around 0.120). Lagged size affects positively and significantly the current share of sales of incremental innovations. The current share of sales of radical innovations is positively and significantly affected by $R \& D$ intensity, performing $R \& D$ continuously, demand pull, innovation cooperation, subsidies while, ceteris paribus, non- $R \& D$ performers are less successful than $R \& D$ performers in terms of generating innovative sales from radical innovations. Both approaches of handling the initial conditions yield fairly similar estimates of the coefficients of the strictly cxogenous explanatory variables. Accounting for unobserved individual effects matters in the estimation of the model (at least in the selection equation), and the individual effects are found to be correlated with the initial conditions as the coefficients associated with the initial conditions, in the Wooldridge approach, and $\rho_{\varsigma_{1} \eta}$ and $\rho_{\varsigma_{2} \alpha}$, in the Heckman approach, are significantly estimated. Hence, the assumptions of absence of unobserved individual effects and exogenous initial conditions can be rejected using a likelihood ratio at $1 \%$ level of significance. Finally, sample selection is present and operates only through the idiosyncratic errors in the Wooldridge case, and through the individual effects and the idiosyncratic errors in the Heckman case.

\subsection{Conclusion}

We have extended the Heckman approach of treating the initial conditions to dynamic panel data sample selection models. A model similar to the underlying model of the remaining process was specified for the initial conditions given the individual effects and the strictly exogenous explanatory variables. More specifically, the initial conditions were specified as a type 2 tobit when the underlying model of the remaining process is dynamic type 2 tobit, and a type 3 tobit was specified for the initial conditions when the underlying model of the remaining process is dynamic type 3 tobit.

We have investigated the sensitivity of results of Chapter 4 on the persistence of innovation and the dynamics of innovation output to the treatment of the initial conditions. We have contrasted the estimate results of the dynamic type 2 tobit when modeling the initial conditions (the Heckman approach) with those of the same model when conditioning on the 
initial conditions (the Wooldridge approach). Regardless of the (proper) treatment of the initial conditions, there is no evidence of true persistence of innovation in Dutch manufacturing while, for innovators, past share of innovative sales conditions, albeit to a small extent, current share of innovative sales. The latter result is interpreted as a rather lengthy enjoyment by innovators of their old innovations. We have also studied the dynamics of incremental and radical innovations by estimating a dynamic type 3 tobit. The estimation results of the model when using the Heckman approach were contrasted with those of the same model when using the Wooldridge approach. We found that past share of sales of incremental and radical product innovations conditions current share of sales of incremental and radical product innovations respectively. Similarly to incremental innovators, radical innovators seem to have a rather lengthy enjoyment of their old radical innovations. The estimation results of the dynamic type 3 tobit when using both the Heckman and the Wooldridge approach are fairly similar, especially the estimates of the coefficients of the strictly exogenous explanatory variables. One notable difference is the coefficients associated with the lagged dependent variables that are somehow overestimated in the former case with respect to the latter. Furthermore, unobserved individual effects play a significant role in the two equations when using the Heckman approach, while they are significant only in the selection equation when using the Wooldridge approach. Finally, sample selection is present and operates only through the idiosyncratic errors when using the Wooldridge approach, and through the individual effects and the idiosyncratic errors when using the Heckman approach. 
CHAPTER 6

Joint modeling of the dynamics of innovation activities, $R \& D$

investments and innovative sales

\subsection{Introduction}

This chapter studies, at the firm level, the dynamics of the interrelationship between the decision to engage in innovation activities, innovation input investments measured as $R \& D$ expenditures over total sales, and innovation output measured by the share of innovative sales using three waves of the Dutch Community Innovation Survey. We extend the model studied in Chapter 4 by adding a third equation with R\&D intensity as the dependent variable.

Economic theory suggests that technological innovation is a nonlinear complex process. For instance, Kline and Rosenberg (1986) define a chain-link model, as opposed to the linear model, where five levels, from the "central chain of innovation" (first level) to the connection between innovation output and science (fifth level), are identified and where "innovation determines and is determined by the market" and R\&D is essential to building up a knowledge base. Crépon et al. (1998, CDM) define a three-stage model of R\&D activities, innovation output (patent or innovative sales) and productivity. ${ }^{1}$ More specifically, in the first stage, firms decide whether or not to engage in R\&D activities and choose the amount that is invested in $R \& D$. In the second stage, innovation output is related to $R \& D$ and other determinants.

\footnotetext{
${ }^{1}$ The term "stage" is usually used in linear models of innovation where the stages of the innovation processes are assuned isolated from one another. In the CDM model, however, there is interrelationship between t. various stages of the process.
} 
Finally, an augmented Cobb-Douglas production function relates productivity to innovation output and other factors.

Technological imnovation is also a dynamic process for which various explanations are given by cconomic theory. On the input side, the decision to engage in $R \& D$ activities is shown to be persistent because of sunk costs (Máñez Castillejo et al., 2004). Van Leeuwen (2002) derives a dynamic R\&D intensity equation from an adaptation of the knowledge accumulation theory along the lines of Hall and Hayashi (1989) and Klette (1996) and relates it to a dynamic share of innovative sales equation. Further, on the output side, Flaig and Stadler (1994) explain the dynamics of product and process innovation by a "success breeds success" hypothesis (Mansfield, 1968) derived from a stochastic dynamic optimization model of innovation activity. Finally, Stein (1997) develops a theoretical competition model where learning-by-doing explains the dynamics of the innovation process.

A third important aspect of the innovation process is that it involves heterogenous firms in that they face different technological opportunities and appropriability conditions (Blundell et al., 1995, 1999) which, together with "the cumulativeness of technical advances and properties of the knowledge base" form what Malerba and Orsenigo (1996) and Breschi et al. (2000) call a technological regime. Firms' heterogeneity can also be interpreted as their difference in ability to carry out and achieve innovations (Labeaga and Martínez-Ros, 2005).

The contribution of this chapter is that we consider the three aspects of the innovation process in a unified framework. More specifically, we study a three-equation nonlinear dynamic model of innovation accounting for unobserved firm heterogeneity by including individual effects. The model is a dynamic panel data version of the first and second stage of the CDM model where we jointly investigate the dynamics of the decision to engage in innovation activities, that of $R \& D$ intensity and the share of innovative sales. ${ }^{2}$ We estimate the model by maximum likelihood assuming random individual effects that are "integrated out" using "three-step" Gauss-Hermite quadrature and handling the initial conditions using the Wooldridge (2005) approach. The results suggest the presence of dynamics in the innovation process. Furthermore, the decision to engage in innovation activities, R\&D intensity and the share of innovative sales are correlated at least through the individual effects, and firm heterogeneity plays an important role in the innovation process.

\footnotetext{
${ }^{2}$ The relationship between innovation and productivity considered in the CDM model is beyond the scope
of this chapter.
} 
We describe the model in Section 6.2, explain the estimation procedure in Section 6.3. present the data and report descriptive statistics in Section 6.4, discuss the estimation results in Section 6.5 and conclude in Section 6.6. The likelihood function of the three-equation nonlinear dynamic model using "three-step" Gauss-Hermite quadrature is derived in Appendix 6.A.

\subsection{A three-equation nonlinear dynamic model of innovation}

The model explains jointly the probability of engaging in innovation activities, the percentage of total sales invested in $R \& D$ and the share of innovative sales generated by $R \& D$ investments and other inmovation activities. Formally it is written as

$$
y_{1 i t}=1\left[\gamma_{1} y_{1 i, t-1}+\beta_{1}^{\prime} \mathbf{x}_{1 i t}+\alpha_{1 i}+\epsilon_{1 i t}>0\right]
$$

and

$$
\begin{aligned}
& y_{2 i l}= \begin{cases}\gamma_{2} y_{2 i, t-1}+\beta_{2}^{\prime} \mathbf{x}_{2 i l}+\alpha_{2 i}+\epsilon_{2 i l} & \text { if } y_{1 i l}=1, \\
0 & \text { if } y_{1 i l}=0,\end{cases} \\
& y_{3 i l}= \begin{cases}\gamma_{3} y_{3 i, t-1}+\beta_{3}^{\prime} \mathbf{x}_{3 i l}+\alpha_{3 i}+\epsilon_{3 i l} & \text { if } y_{1 i l}=1, \\
0 & \text { if } y_{1 i l}=0,\end{cases}
\end{aligned}
$$

with $t=1, \ldots T ; i=1, \ldots N$.

Equation (6.1) models the current decision of enterprise $i$ to engage in innovation activities as a latent function of its past engagement in innovation activities $\left(y_{1 i, l-1}\right)$, strictly exogenous explanatory variables $\left(\mathbf{x}_{1 i t}\right)$, time-invariant unobserved individual effects $\left(\alpha_{1 i}\right)$ and other time-variant unobserved variables $\left(\epsilon_{1 i l}\right)$ uncorrelated with $\mathbf{x}_{1 i t}$. The latent function can be interpreted as an incentive to engage in current innovation activities with the observed counterpart $y_{1 i l}$ being 1 , in which case enterprise $i$ undertakes innovation activities, if the incentive is sufficiently high, or else $y_{1 i t}$ is observed to be 0 . The scalar $\gamma_{1}$ and the vector $\beta_{1}^{\prime}$ capture respectively the effects of past innovation activities and firm and market characteristics on current innovation activities and are to be estimated. If $\gamma_{1}$ is positively and significantly estimated, there is persistence in engaging in innovation activities. However, the existence of true persistence may be ascertained by verifying that, after accounting for 
individual effects and properly handling the initial conditions problem, $\gamma_{1}$ is positive and statistically significant.

Equations (6.2) and (6.3) model respectively current R\&D intensity $\left(y_{2 i t}\right)$ and the current share of innovative sales $\left(y_{3 i t}\right)$ of an innovative enterprise $i\left(y_{1 i l}=1\right)$ as being determined by its past R\&D intensity $\left(y_{2 i . t-1}\right)$ and its past share of imnovative sales $\left(y_{3 i, t-1}\right)$, strictly exogenous explanatory variables ( $\mathrm{x}_{2 i}$ and $\mathbf{x}_{3 i t}$ ), time-invariant unobserved individual effects $\left(\alpha_{2 i}\right.$ and $\left.\alpha_{33}\right)$ and other time-variant unobserved variables $\left(\epsilon_{2 i t}\right.$ and $\left.\epsilon_{3 i l}\right)$ uncorrelated with $\mathbf{x}_{2 i t}$ and $\mathbf{x}_{3 i t}$. R\&D intensity and the share of innovative sales are zero if enterprise $i$ is not imnovative, and the full set of regressors included into $\mathbf{x}_{2 i t}$ and $\mathbf{x}_{3 i t}$ are only available when enterprise $i$ is innovative. The scalars $\gamma_{2}$ and $\gamma_{3}$ capture respectively the effects of past R\&D intensity and past share of inmovative sales on current R\&D intensity and current share of innovative sales and are to be estimated. The vectors $\beta_{2}^{\prime}$ and $\beta_{3}^{\prime}$ capture the effects of firm and market characteristics on current $R \& D$ intensity and current share of innovative sales and are also to be estimated.

Equations $(6.1),(6.2)$ and (6.3) are jointly estimated so that we allow for a correlation between the processes governing the engagement in innovation activitics and R\&D investments, the processes governing the engagement in innovation activities and the generation of innovative sales, and the processes governing $R \& D$ investments and the generation of innovative sales. We now discuss the estimation technique.

\subsection{Maximum likelihood estimation}

Estimating the three-equation dynamic tobit-type model with panel data is a complicated task to achieve. The individual effects have to be handled and the initial conditions problem has to be solved. The use of the within or first-difference transformation to get rid of the individual effects is not feasible because of the nonlinearity of the model, neither is a fixed-effects conditional likelihood approach as there is no sufficient statistic such that, conditional on it, the likelihood function depends only on the slope parameters (Lancaster, 2000). Furthermore, no GMM-type estimator is known for the three-equation dynamic tobit-type model. Hence we use a random-effects approach and make distributional assumptions on the individual effects. The problem of initial conditions is handled using Wooldridge's (2005) "simple solutions" that consist in writing the individual effects, in each period, as linear functions of 
the strictly exogenous explanatory variables and the initial conditions. Formally,

$$
\begin{aligned}
& \alpha_{1 j}=b_{0}^{r_{1}}+b_{1}^{r_{1}} y_{1 \imath 0}+\mathrm{b}_{2}^{\prime r_{1}} \mathrm{x}_{1 i}+a_{1 i} \\
& \alpha_{2 i}=b_{0}^{r_{2}}+b_{1}^{r_{2}} y_{2 i 0}+\mathrm{b}_{2}^{r_{2} \mathrm{x}_{2 i}}+a_{2 i} \\
& \alpha_{3 i}=b_{0}^{r_{3}}+b_{1}^{r_{3}} y_{3 i 0}+\mathrm{b}_{2}^{r_{3} \mathbf{r}_{3 i}} \mathrm{x}_{3 i}+a_{3 i}
\end{aligned}
$$

where $\mathrm{x}_{j i}^{\prime}=\left(\mathrm{x}_{j i 1}^{\prime}, \ldots, \mathrm{x}_{j i T}^{\prime}\right), b_{0}^{r_{j}}, b_{1}^{r_{\prime}}, \mathrm{b}_{22}^{r^{\prime}{ }_{j}}(j=1,2,3)$ are to be estimated, and $a_{1 i}, a_{2 i}$ and $a_{3 i}$ are independent of $\left(y_{1 i}, \mathbf{x}_{1 i}\right),\left(y_{2 i}, \mathbf{x}_{2 i}\right)$ and $\left(y_{3 i i}, \mathbf{x}_{3 i}\right)$ respectively. ${ }^{3}$ The scalars $b_{1}^{r_{1}}, b_{1}^{r_{2}}$ and $b_{1}^{r_{3}}$ capture the dependence of the individual effects on the initial conditions. The vectors $\left(\epsilon_{1 i t}, \epsilon_{2 i t}, \epsilon_{3 i t}\right)^{\prime}$ and $\left(a_{1 i}, a_{2 i}, a_{3 i}\right)^{\prime}$ arc assumed independent of each other, and indepcndently and identically distributed over time and across individuals following a nomal distribution with mean zoro and covariance matrix

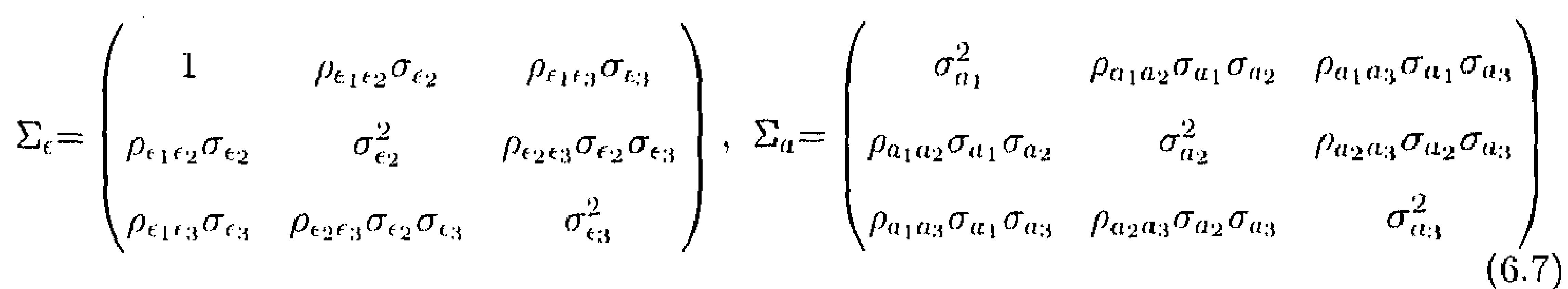

respectively. The parameters of the covariance matrices are also to be estimatcd. Hence, the likelihood function of individual $i$, starting from $t=1$ and conditional on the regressors and the initial conditions, is written as

$$
L_{i}=\int_{-\infty}^{\infty} \int_{-\infty}^{\infty} \int_{-\infty}^{\infty} \prod_{i=1}^{T} L_{i t}\left(\mathbf{y}_{i t} \mid \mathbf{y}_{i 0}, \mathbf{y}_{i, t-1}, \mathbf{x}_{i}, a_{1 i}, a_{2 i}, a_{3 i}\right) g\left(a_{1 i}, a_{2 i}, a_{3 i}\right) d a_{1 i} d a_{2 i} d a_{3 i}
$$

where $\mathrm{y}_{i t}=\left(y_{1 i t}, y_{2 i l}, y_{3 i t}\right), \mathbf{y}_{i 0}=\left(y_{1 i}, y_{2 i 0}, y_{3 i 0}\right), \mathbf{y}_{i, t-1}=\left(y_{1 i, t-1}, y_{2 i, t-1}, y_{i 3 i, 1-1}\right)$ and $\mathbf{x}_{i}=$ $\left(\mathbf{x}_{1 i}, \mathbf{x}_{2 i}, \mathbf{x}_{33 i}\right)$, and $\prod_{l=1}^{T} L_{i l}\left(\mathbf{y}_{i l} \mid \mathbf{y}_{i 0}, \mathbf{y}_{i, l-1}, \mathbf{x}_{i}, a_{1 i}, a_{2 i}, a_{3 i}\right)$ and $g\left(a_{1 i}, a_{2 i}, a_{3 i}\right)$ denote respectively the likelihood function of individual $i$ conditional on the individual effects and the trivariate normal density function of $\left(a_{1 i}, a_{2 i}, a_{3 i}\right)$. Define

$$
\begin{aligned}
& A_{i t}=\gamma_{1} y_{1 i, t-1}+\beta_{1}^{\prime} \mathbf{x}_{1 i t}+b_{0}^{r_{1}}+b_{1}^{r_{1}} y_{1 i 0}+\mathrm{b}_{2}^{\prime r 1} \mathbf{x}_{1 i} \\
& B_{i t}=\gamma_{2} y_{2 i, t-1}+\beta_{2}^{\prime} \mathbf{x}_{2 i t}+b_{0}^{r_{2}}+b_{1}^{r_{2}} y_{2 i 0}+\mathrm{b}_{2}^{\prime r_{2}} \mathbf{x}_{2 i},
\end{aligned}
$$

"The vectors of explanatory variables $x_{1 i}, x_{2 i}$ ind $x_{32}$, in order to be inchuded in equations $(6.4),(6.5)$ and (6.6), must be sufficiently time-variant, otherwise a collinearity problem will arise. 


$$
C_{i t}=\gamma_{33} y_{3 i, t-1}+\beta_{3}^{\prime} \mathrm{x}_{33 t}+b_{11}^{r_{3}}+b_{1}^{r_{3}} y_{330}+\mathrm{b}_{2}^{r_{3}} \mathrm{x}_{3 i}
$$

the individual likelihood function conditional on the individual effects is shown (in subappendix 6.A.1) to be

$$
\begin{aligned}
& \prod_{t=1}^{T} \Phi\left[-\left(A_{i t}+a_{1 i}\right)\right]^{1-y_{1, t}}\left[\frac{1}{\sigma_{t ; 3}} \phi\left(\frac{y_{3 i t}-C_{i t}-a_{33 i}}{\sigma_{\epsilon 3}}\right)\right.
\end{aligned}
$$

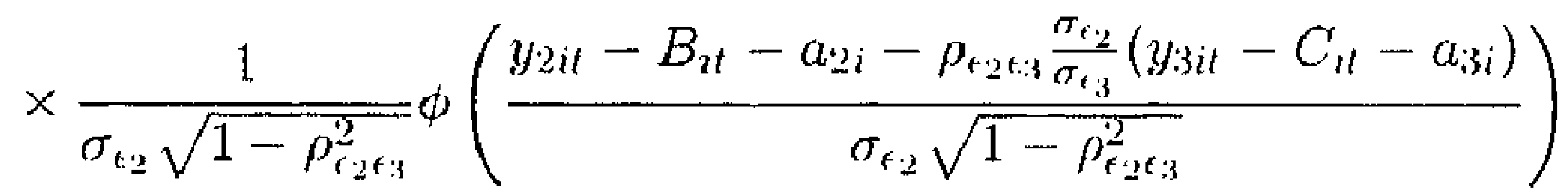

$$
\begin{aligned}
& \left.\times \Phi\left(\frac{A_{i t}+a_{1 i}+\frac{\mu_{12.3}}{\sigma_{t_{2}}}\left(y_{2 i t}-B_{i t}-a_{2 i}\right)+\frac{\rho_{13.2}}{\sigma_{i 3}}\left(y_{3 i t}-C_{i t}-a_{3 i}\right)}{\sqrt{1-R_{1.234}^{2}}}\right)\right]^{y_{1, t}} \text {, }
\end{aligned}
$$

whore $\phi$ and $\Phi$ denote respectivoly the univariate standard normal density and cumulative distribution functions, and the expressions of $R_{1.23}^{2}, \rho_{12.3}$ and $\rho_{13.2}$ arc given in sub-appendix 6.A.1. The triple integral in equation (6.8) can be approximated using "throe-step" GaussHermite quadrature described in sub-appendix 6.A.2 so that the random-effects individual likelihood function of the three-equation dynamic tobit-type model becomes

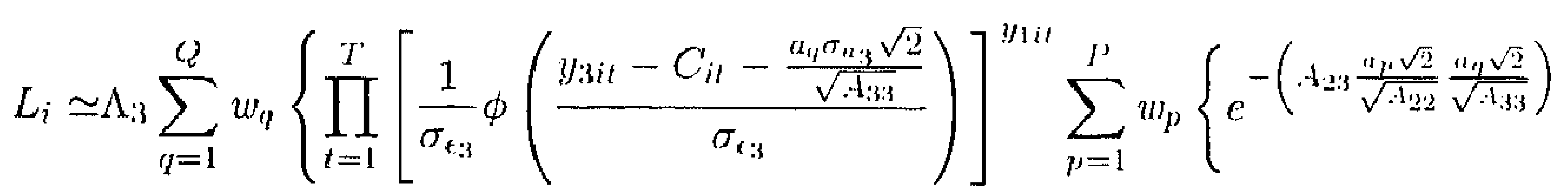

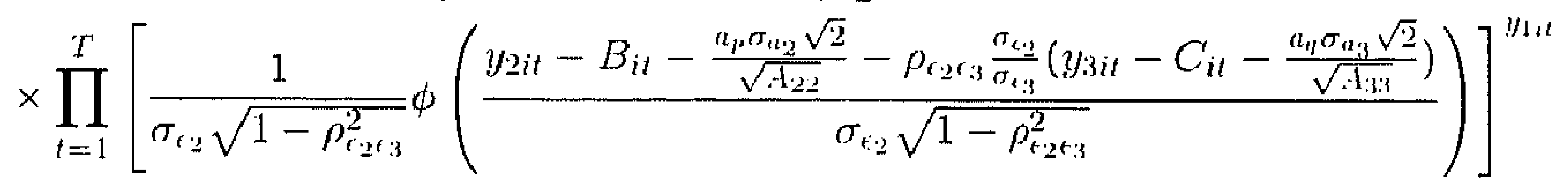

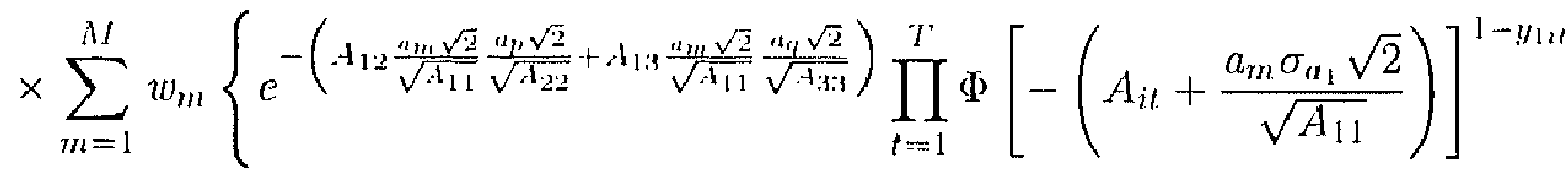

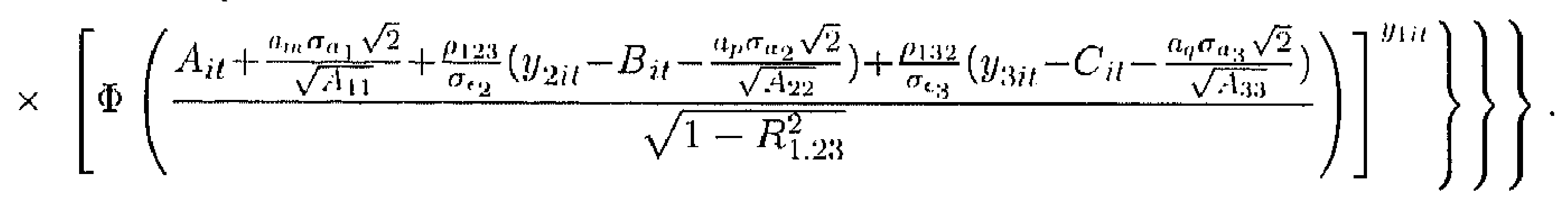

The expressions of $\Lambda_{33}$ and $A_{j k}\left(j, k=1,2,3\right.$ and $\left.A_{j k}=A_{k j}\right)$ are given in sub-appendix 6.A.2; $w_{m}, w_{p}$, and $w_{q}$ are the weights of the first-, second- and third-step Gauss-Hermite quadrature; $a_{m}, a_{p}$ and $a_{q}$ are the corresponding abscissas, and $M, P$ and $Q$ are the first-, second- and third-step total number of integration points. The product over $\mathbf{i}$ of the approximated likelihood function $L_{i}$ can be maximized using standard numerical procedures to obtain estimates of the parameters of the threc-equation dynamic tobit-type model. 


\subsection{Data}

We implement the model using data from three waves of the Dutch Community Innovation Survey (CIS) merged with data from the Production Survey collected at the enterprise level by the Centraal Bureau voor de Statistiek (CBS). More specifically, the data pertain to Dutch manufacturing during the periods 1994-1996 (CIS 2), 1996-1998 (CIS 2.5) and 1998-2000 (CIS 3). The target population consists of enterprises with at least ten employees and positive salcs at the end of the period covered by the innovation survey. ${ }^{-1}$ We estimate a cross-sectional version of the model using cach CIS separately, then we form a balanced panel that is used to estimate a dynamic panel data version of the model ignoring and accounting for individual effects. The panel consists of enterprises that existed in 1994, survived (at least) until 2000 and took part in the three innovation surveys considered in this study. Descriptive statisties of the variables that are included in the estimation of the model are reported in Table 0.1 for the three categories of industries defined in Chapter 2 and each CIS separately, and in Table 6.2 for the balanced panel.

\subsubsection{The cross-sectional model specification}

The dependent variable of equation (6.1) is binary with value 1 if an enterprise engages in innovation activities, i.e. reports positive total imnovation expenditures, and 0 otherwise. An imnovative enterprise may be a product innovator, a process innovator, or may have unsuccessful or incomplete innovation activities. About $70 \%$ of the enterprises are imnovative in the high-tech category, $60 \%$ in the low-tech category and $50 \%$ in the wood industry for CIS 2 and CIS 2.5. The corresponding percentages for CIS 3 are respectively $66 \%, 50 \%$ and $40 \%$. On the grounds of Schumpeter's tradition, we explain the decision to be imnovative by size, as measured by the number of employees (in log), and relative size defined as firms' total sales over sales of industry (in log). For the high-tech and low-tech categories, we also include. sectoral dummies that are assumed to capture technological opportunities and appropriability. The industry of chemical product is the reference sector in the high-tech category and the not elsewhere classified (NEC) industry is the reference sector in the low-tech category. These explanatory variables are available for both innovative and non-innovative cnterprises, unlike those included into vectors $\mathrm{x}_{2}$ and $\mathrm{x}_{3}$.

\footnotetext{
${ }^{1}$ More details about the data cou be found in Seetion 2.3 of Chapter 2.
} 


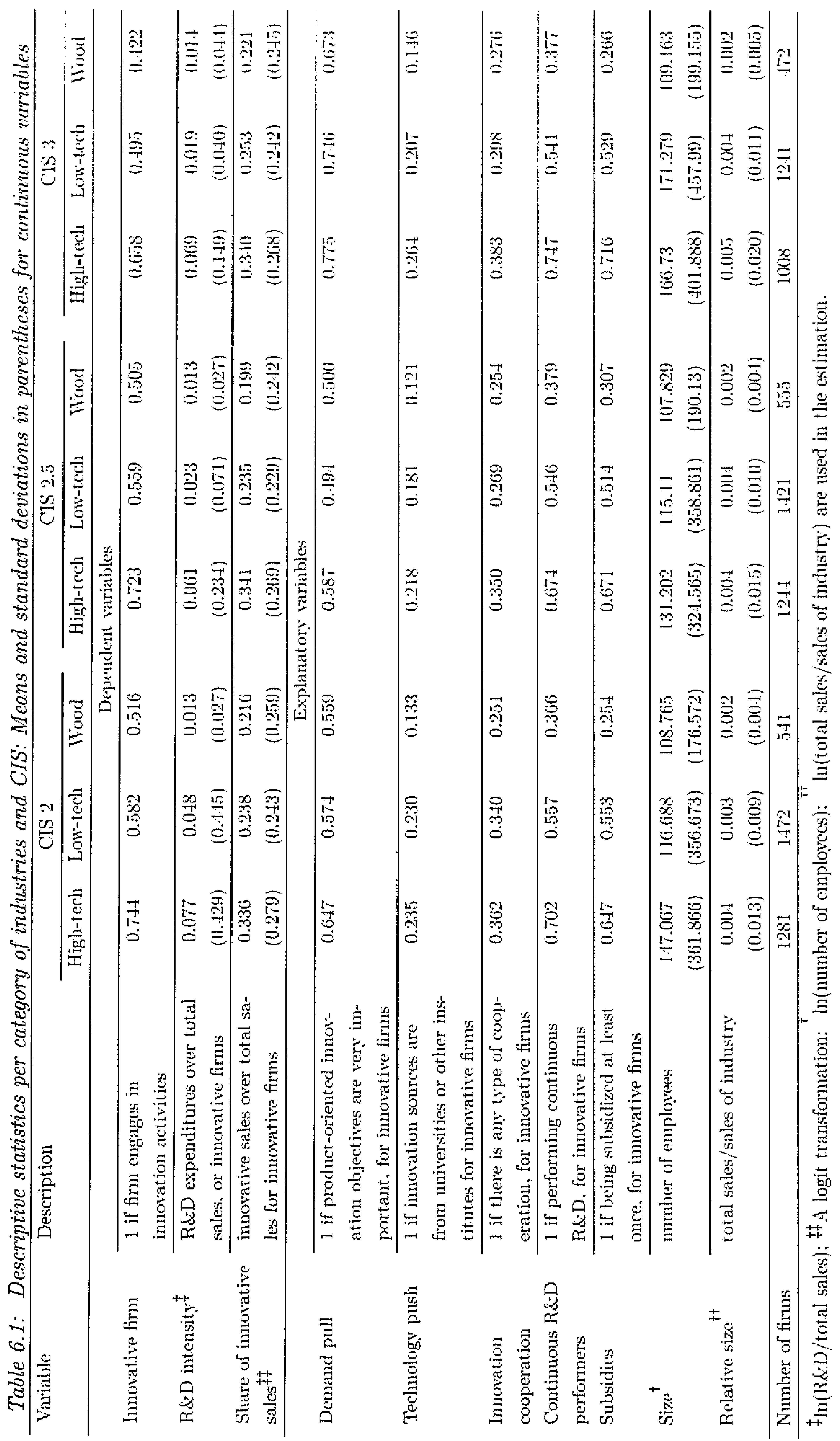


The explained variable of equation (6.2) is R\&D intconsity as measured by total RAD expenditures over total sales. This figure ranges from $6 \%$ (CIS 2.5) to $8 \%$ (CIS 2) in the high-toch category, from $2 \%$ (CIS 2.5 and CIS 3) to $5 \%$ (CIS 2) in the low-tech cattegory and is about $1 \%$ (for the three CIS) in the wood industry. The percentage of total salles invested in R\&D is zero for non-imnovative enterprises. However, some innovative enterprises do not have $R \& D$ investments. There are about $15 \%$ of such firms in the three CIS. Since a natural logarithmic transformation of R\&D intensity is used in the estimation, we replace the zero values for innovative firms by $\varepsilon$ that is taken smaller than the smallest positive observed value of $R \& D$ intensity. Besides size and the sectoral dummies, we explain $R \& D$ intensity by indicators of demand pull, technology push, innovation cooperation and subsidies described in Table 6.1. The decision to engage in innovation activities and the actual percentage of total sales invested in R\&D are allowed to be correlated in the estimation.

Finally, the dependent variable of equation (6.3) is the share of innovative sales measured as the ratio of sales of new or improved products over total sales." This figure is about $34 \%$ and $24 \%$ (for the three CIS) in the high-tech and low-tech category respectively and ranges from $20 \%$ (CIS 2.5) to $22 \%$ (CIS 2 and CIS 3) in the wood industry. We use the same regressors as in equation (6.2) and an indicator of continuous R\&D performers to explain the share of innovative sales which takes on the value zero for non-innovative and some imnovative enterprises, namely the process-only innovators and/or the unsuccessful innovative firms. These last two categories of enterprises represent $14 \%$ of the innovative firms. Furtlermore. in the three CIS about $3 \%$ of the innovative firms, the new established ones, report in value 1 for the share of innovative sales. Since a logit transformation of the share of innovative sales, to make it lie within the set of real numbers, is used in the estimation, we use the same procedure as in Section 4.5 of Chapter 4 to deal with the zero and one values of the imnovative firms. The actual share of innovative sales is allowed to be correlated with the decision to engage in innovation activities and R\&D intensity in the estimation.

\subsubsection{The panel data model specification}

In the panel data specification of the model, we include in each equation the lagged dependent variable as an explanatory variable. More specifically, the current probability of engaging in innovation activities, current $R \& D$ intensity and the current share of imovative sales are

"Like in Chapter 4 , we consider products new to the firm not necessarily new to the natrket. 


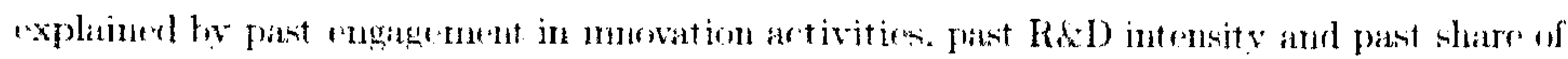

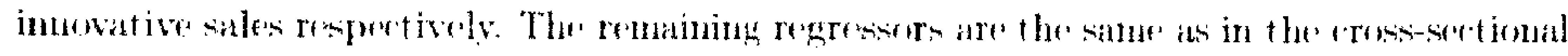

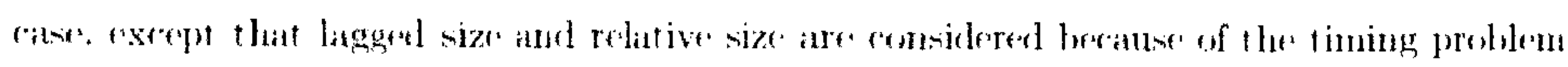

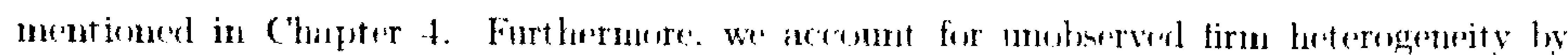
including individual affects in each erquation of the model so that separate estinnation for the thres categories of industries is no honger neesled." Wo still allow for ditferent industry

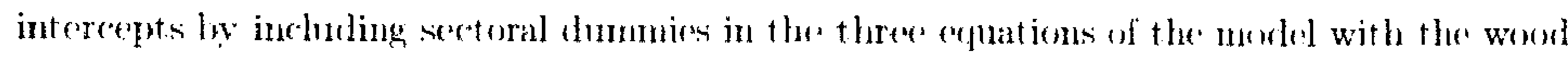
industry heing the referen'ter.

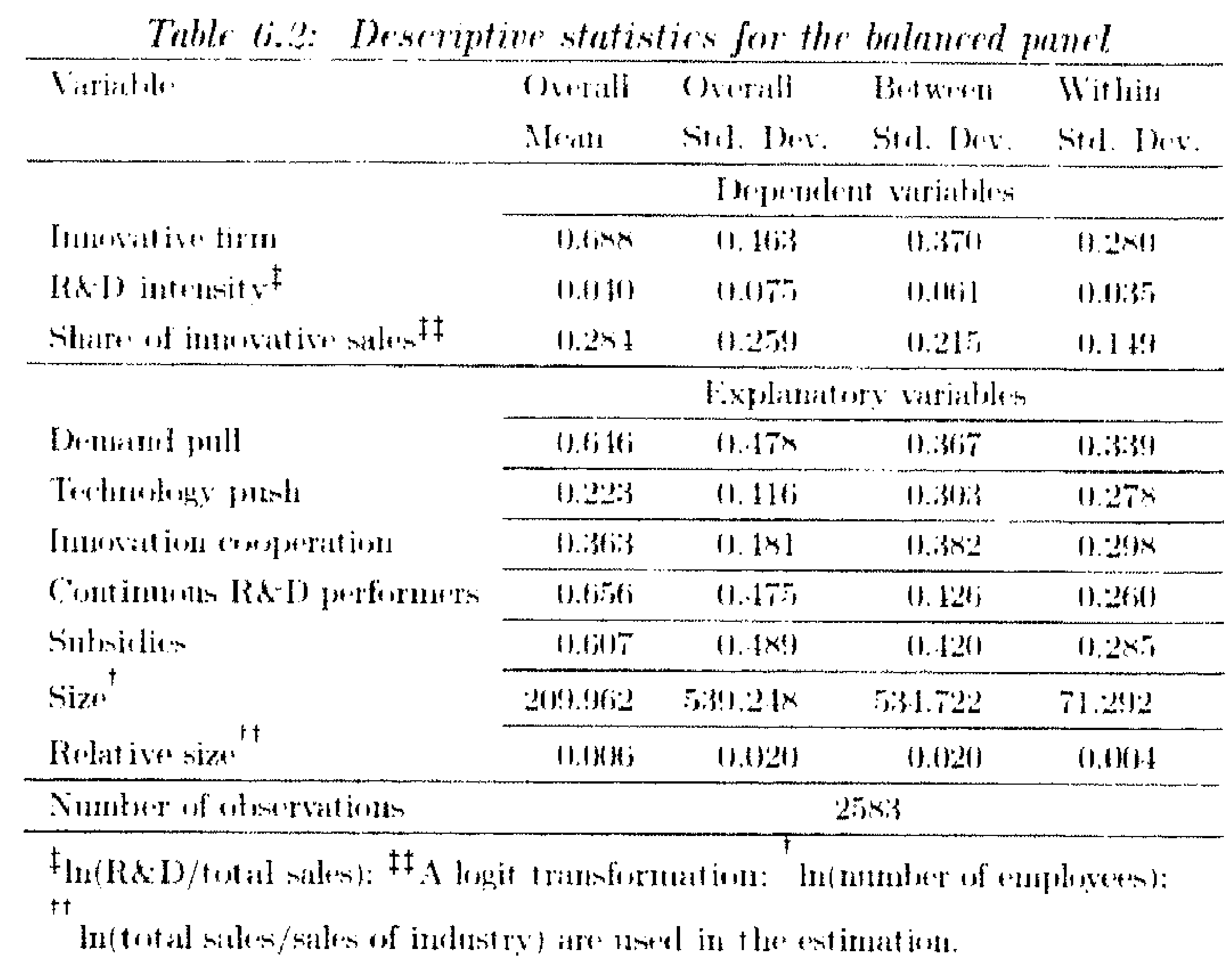

Due to the sumpling design of the Dutch CIS, firms size is larger (on average) in the balanced panel than in each CIS taken separately. Indeed, for each wave of the CIS. a census is used by CBS for the population of enterprises with at least 100 employecs (large enterprises). while a stratified random sampling is used for the popnlation of enterprises with less than 100 mployees (small- and mediun-size cuterprises). The remaining firm chatracteristics in the balanced panel are comparable to those of each single (IS. We now presernt the estimation resilts.

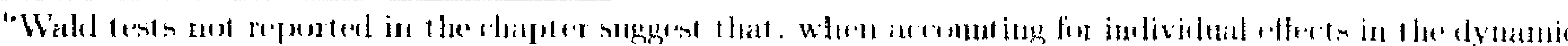

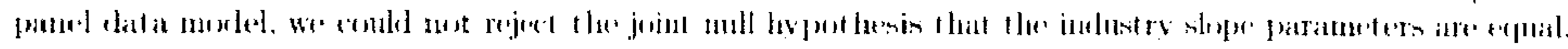




\subsection{Estimation results}

Tables 6.3-6.5 report maximum likelihood (ML) estimation results of the cross-sectional version of the model for the three categories of industries in each CIS taken separatrly. ${ }^{7}$

Table 6.3: ML estimation results of the cross-sectional model: CIS 2 The Netherlands

\begin{tabular}{|c|c|c|c|c|c|c|}
\hline Variable & Coefficientil. & (Strl. Err.) & C'oefficient & (Sidn. Err.) & Cisffiritent & (Stal Erts) \\
\hline & \multicolumn{2}{|c|}{ High-Trech } & \multicolumn{2}{|c|}{ Low-Tech } & \multicolumn{2}{|c|}{ Winod } \\
\hline \multicolumn{7}{|c|}{ Imnovation activities } \\
\hline Size (in log) & $0.396^{* *}$ & $(0.076)$ & $0.210^{* *}$ & $(0.015,8)$ & 0.101 & $(0.112)$ \\
\hline Relative size (in log) & -0.020 & $(0.057)$ & $0.179^{* *}$ & $(0.1) \cdot 10)$ & 0.111 & $(0.0 x x)$ \\
\hline Intercept & $-1.252^{\dagger}$ & $(0.7331)$ & 0.457 & $(0.1355)$ & $0.116 i$ & $(1.06(3))$ \\
\hline \multicolumn{7}{|c|}{ R\&D intensily (in log ) } \\
\hline Size (in log) & -0.0 .41 & $(0.062)$ & 0.06 .1 & $(0.070)$ & $-(1.111$ & $(0.150)$ \\
\hline Demand pull & $0.476^{* * *}$ & $(0.126)$ & $0.138^{* *}$ & $(0.1+2)$ & $0.510 .53^{\dagger}$ & $(0.27 ; 3)$ \\
\hline Innovation cooperation & $0.632^{* * *}$ & $(0.1: 36)$ & 0.202 & $(0.15(i)$ & $0.75,6^{*}$ & $(0.32323\}$ \\
\hline Technology push & $0.3833^{* * *}$ & $(0.1 .17)$ & $0.403^{*}$ & $(0.160)$ & $\left(1.752^{\dagger}\right.$ & $(0.3(m i)$ \\
\hline Subsiclies & $1.461^{* *}$ & $(0.131)$ & $1.3600^{* * *}$ & $(0.1 .17)$ & $1.557^{* *}$ & (11.311) \\
\hline Intercept & $-5.256^{* * *}$ & $(0.3-19)$ & $-5.875 * *$ & (10.117) & $-(0.301)^{* * *}$ & $(0.7(i 2)$ \\
\hline \multicolumn{7}{|c|}{ Share of innovative sales (in logit) } \\
\hline Size (inlog) & $0.600^{* *}$ & $(0.161)$ & $0.991^{* * 4}$ & $(0.18 .1)$ & $0.757^{*}$ & $(0.378)$ \\
\hline Cont innous $R A D$ & $1.961^{* *}$ & $(0.389)$ & $0.944^{* * *}$ & $(0.3500)$ & 0.236 & $(0.6899)$ \\
\hline Demand pull & $0.792^{* *}$ & $(0.297)$ & $1.6013^{* *}$ & $(0.307)$ & $1.770^{* *}$ & $(0.516)$ \\
\hline Inuovation cooperntion & 0.2333 & $(0.321)$ & $0.770^{*}$ & $(0 . .3333)$ & $2.7118^{* *}$ & $(0.669)$ \\
\hline Technology push & -0.028 & $(0.351)$ & -0.123 & $(0.3311)$ & 0.610 & $(0.706)$ \\
\hline Subsidies & $1.186^{* *}$ & $(0.323)$ & $0.920^{* *}$ & $(0.32 .4)$ & $1.380^{*}$ & $(0.619)$ \\
\hline lntercept & $-8.717^{* *}$ & $(0.881)$ & $-10.722^{* *}$ & $(0.91: 3)$ & $-13.1333^{* *}$ & $(1.7(i x)$ \\
\hline \multicolumn{7}{|c|}{ Extra paramelers } \\
\hline$\sigma_{f 2}$ & $1.833^{* *}$ & $(0.0-43)$ & $1.95: 3^{* *}$ & $(0.0+7)$ & $2.2011^{* *}$ & $(0.105)$ \\
\hline$\sigma_{\ell: 3}$ & $5.522^{* *}$ & $(0.151)$ & $5.451^{* *}$ & $(0.1 \times 0)$ & $6.838^{* *}$ & $(0.4 \times 7)$ \\
\hline$\rho_{t_{1} \epsilon_{2}}$ & -0.117 & $(0.08 .1)$ & $0.0: 30$ & $(0.079)$ & $-0.21: 3$ & $(0.14 !)$ \\
\hline$\rho_{\mathrm{i} \mathrm{C}}$ & $0.893^{* *}$ & $(0.016)$ & $0.852^{* *}$ & $(0.022)$ & 0.93()$^{* * *}$ & $(0.0333)$ \\
\hline$\rho_{t, 2} c_{3}$ & -0.044 & $(0.048)$ & 0.1055 & $(0.053)$ & -0.020 & $(0.109)$ \\
\hline Number of firms & \multicolumn{2}{|c|}{1281} & \multicolumn{2}{|c|}{1.172} & \multicolumn{2}{|c|}{541} \\
\hline Log-likelihood & \multicolumn{2}{|c|}{$-5.3339 .998$} & \multicolumn{2}{|c|}{$-5115.7+15$} & \multicolumn{2}{|c|}{-1782.251} \\
\hline
\end{tabular}

The results are different across categorics of industries suggesting different technological opportunities and innovation appropriability, hence the presence of firm heterogencity in the innovation process, and across waves of the CIS. Overall, they are in accordance with most of the cross-sectional empirical studies on the interrelationship between the decision to engage in innovation activities, imnovation input investments and innovation output reported in Table 6.7. A few exceptions are worth noting though. First, the negative and significant effect of

${ }^{7}$ In order to save space, we do not report in Tables $6.3-(3.6$ the codficients of the industry dummies. 


\begin{tabular}{|c|c|c|c|c|c|c|}
\hline bitrinhl. & 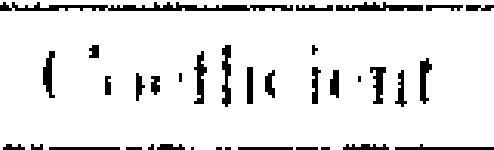 & Mtal. FIt & Cinfficitill & (Sid) Fin & 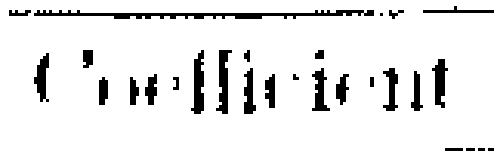 & (Stal Iarr.) \\
\hline & \multicolumn{2}{|c|}{$\mathrm{Hiwh}_{1}-\mathrm{T}_{\mathrm{w}}$} & \multicolumn{2}{|c|}{ I. Mu: Tivlt } & \multicolumn{2}{|c|}{ Minml } \\
\hline \multicolumn{7}{|c|}{ 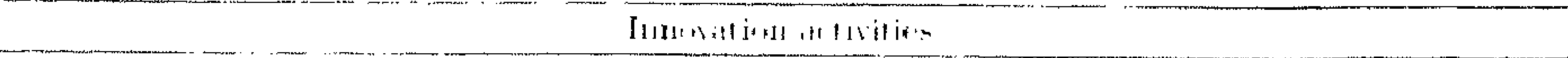 } \\
\hline 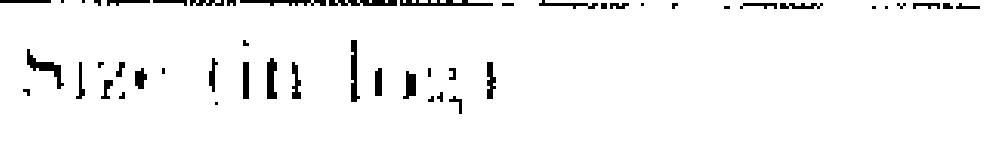 & $19.1: 7^{* *}$ & $(11.617 x)$ & $112 \operatorname{2n} 2 * *$ & $(10 .(1)(x)$ & $11.21 !^{*}$ & $(11.12: 3)$ \\
\hline 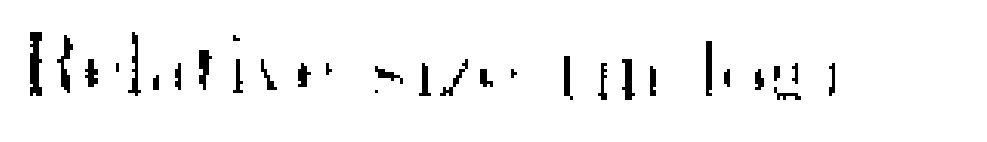 & $13 \mid 2 t i^{*}$ & $(11.115,1)$ & $\left(1,11 i 1^{* *}\right.$ & $(1001 \times)$ & -11.11333 & $(11 .(1+17)$ \\
\hline Intrentght & $01,1,25$ & $(11.9-12)$ & $11.11 \times 5$ & (11.risti) & $-1.231 i$ & $(1.17 x)$ \\
\hline \multicolumn{7}{|c|}{ 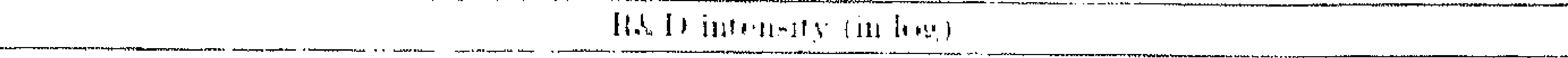 } \\
\hline Sixt lin lons & 11.1112 & $(1) .67911)$ & 11.tum & (mithis & -11.67 .5 & $(0.1110)$ \\
\hline Homami pull & $\|\left.\lim \right|^{-* *}$ & $(11.137)$ & $11.12 x^{* *}$ & (11.1116i & $11.6 t^{2}+1^{*}$ & $(0.270)$ \\
\hline 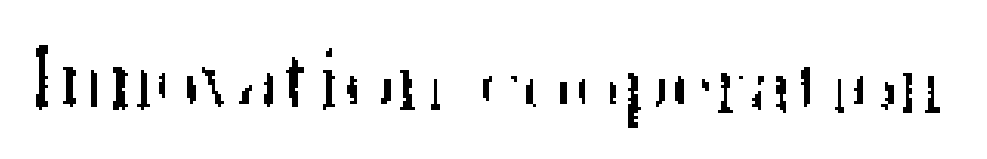 & 0.216 & $(11.117)$ & 1). Itin & $(0.170)$ & $11.6111^{\dagger}$ & $(0.3212)$ \\
\hline 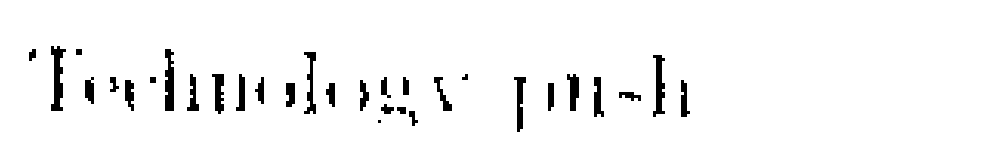 & $\left\{1 \times 17^{* *}\right.$ & $(11.11,3)$ & $11.24: 3$ & $(16 . \mid x: 1)$ & $1 . \ln : !^{* *}$ & (1). 1:30) \\
\hline subilitim & $1,6 x 2^{* *}$ & $(11.1501)$ & $1.0 \% .1^{* *}$ & $(1+15.5)$ & $11 . \sin 1^{*}$ & $(0.312)$ \\
\hline Intranth & $+\left(+2: 21^{* *}\right.$ & $(11.3 \times: 3\}$ & $\therefore$-ラ1N** & $(13.533)$ & $-4 i .7016 i^{* *}$ & (0).x(17) \\
\hline \multicolumn{7}{|c|}{ Shate of immontiw mals (in logit) } \\
\hline Sla $($ in $l, n)$ & $11.6111^{* *+}$ & (11. 1111$)$ & $11 . x+33^{* * *}$ & $(11.17 x)$ & $\left(1.192^{* *}\right.$ & $(11.3322)$ \\
\hline 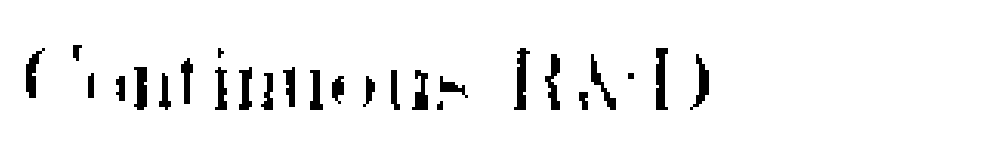 & $1.12)^{* *}$ & $(11.312)$ & $2.11311^{* *}$ & $(11.317)$ & 11.724 & $(11.711)$ \\
\hline 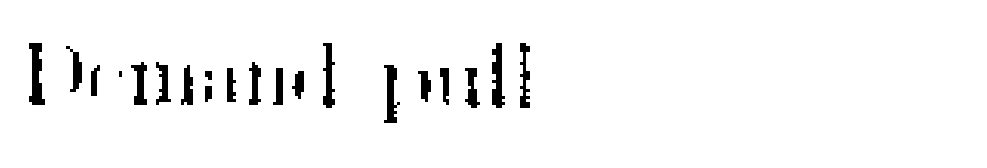 & $11 . x 1 i x^{* *}$ & $(1,2(1,5)$ & $11.95 !^{* * *}$ & $(11.275)$ & $1.733 f^{* *}$ & $(0.72: 3)$ \\
\hline 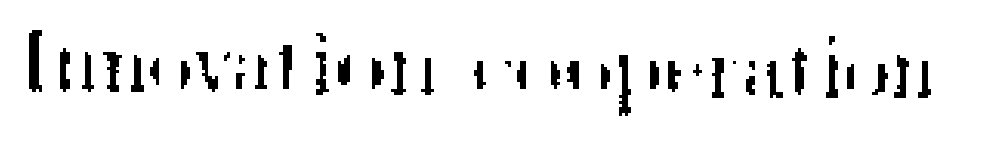 & 11. UIK & $(11.2 \times 3)$ & 11.122 & $(0.3: 32(1))$ & 11.125 & $\left(11.1 i_{2}^{2} 1\right)$ \\
\hline 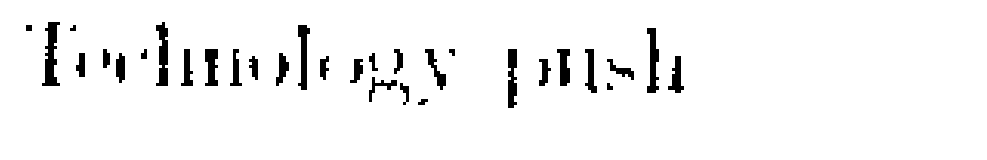 & $-11.2(1.1$ & $(0.316 i j$ & $11.1111^{*}$ & $(11.3 \%)$ & $1.71 k^{*}$ & $(11 . \times 1 !)$ \\
\hline Sintuintit: & $1.112^{* *}$ & $(11.32201)$ & $11.7311^{*}$ & $(11.3(13)$ & $1.117^{*}$ & $(0.1,2 \cdot 2)$ \\
\hline Intagent & $-x \cdot 1 \times 1^{* *}$ & $(11.727)$ & $-*+201^{* *}$ & $(11.927)$ & $-13.721^{* *}$ & $(1 .(6), 1 !)$ \\
\hline \multicolumn{7}{|c|}{ Fxtrat patrimuters } \\
\hline$\sigma_{f}$ & $1.961^{* *}$ & $(10.017)$ & $2.11111^{* *}$ & $(1) .05010)$ & $2.2 \times x^{* *}$ & $(0.116)$ \\
\hline$\sigma_{t, 3}$ & $1.5 \times 1^{* *}$ & (11.1:13i) & $1.131^{* * *}$ & $(1) .|x| 1)$ & $6.26+12^{* *}$ & $(0.5417)$ \\
\hline$\rho_{1+2}$ & 0.120 & $(11 .(1) 9.5)$ & -11.011 & $(6.11 x)$ & $-11.2: 34 ;$ & $(11.171)$ \\
\hline$p_{1+3}$ & $0 . \times 15^{* *}$ & $(11 .(1) \geq 6)$ & $11.711 i^{* *}$ & $(0.0): 3)$ & $(1.291)^{* *}$ & $(0.61919)$ \\
\hline$\rho_{+2+3}$ & 11.01 .4 & $(0.05,50)$ & -11.01311 & $(0,0) ; 2)$ & $-11.19 \%$ & $(10.120)$ \\
\hline Number of timus & \multicolumn{2}{|c|}{1214} & \multicolumn{2}{|c|}{1.121} & \multicolumn{2}{|c|}{ ins } \\
\hline Lom-likelihount & \multicolumn{2}{|c|}{ נוים-1) } & \multicolumn{2}{|c|}{$-171 \times .722$} & \multicolumn{2}{|c|}{$-1 \times 13,2)(i t i$} \\
\hline
\end{tabular}

size on $R \& D$ (or innovation input) intensity of innovative firms fomd in the literature is not supported by our cross-sectional results. Secondly, mulike the empirical lit crature, we do find evidene of peritive and significant effect of reoperation on R\&D intensity of imovative firms especially in the high-tech category (except for CIS 2.5) and the wool industry. There is also) some evidence of positive and significant effere of couperation on the share of inmovative sales of innovalive firms. Finally. size afferets positively and signiticantly the share of innovative sales of innovative firms, while no significant effect of the former on the lat ter is fomd in the literature.

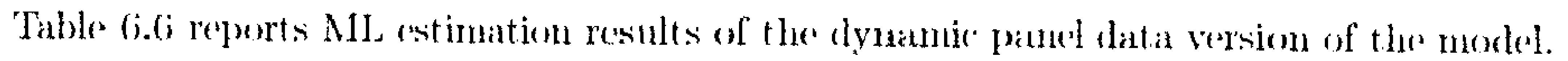

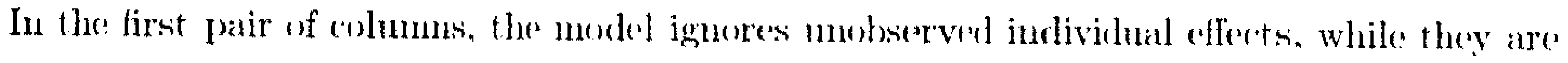
ancounted for as well ats cologenums initial conditions in the second pair of columns. In the 
Table 6.5: ML estimation results of the cross-sectional model: CIS 3 The Netherlands

\begin{tabular}{|c|c|c|c|c|c|c|}
\hline Variable & Coefficionent & (Stct. Err.) & Coetficiante & (Strl. Err.) & Cindfitin'sul & (Stol. Enr.) \\
\hline & \multicolumn{2}{|c|}{ Iligh-'Tech } & \multicolumn{2}{|c|}{ Lown-'Prech } & \multicolumn{2}{|c|}{ Wined } \\
\hline \multicolumn{7}{|c|}{ Innovation ate tivition } \\
\hline Size (in log) & $0.327^{* *}$ & $(0.0106)$ & 11.1170 & $(0.0114)$ & $0.222^{*}$ & $(0,010) 4)$ \\
\hline Relative size (in log) & 0.012 & $(0.01 \cdot 48)$ & $(0.25 .9)^{1 * *}$ & $(0.037)$ & -0.0038 & $(10.1170)$ \\
\hline Intercept & -0.81 .5 & $(0.575)$ & $1.281^{* * *}$ & $(0.412)$ & $-1.39: 5^{\dagger}$ & $(0.8334)$ \\
\hline \multicolumn{7}{|c|}{ RdD intensity (in log) } \\
\hline Size $($ inl $\log )$ & -0.062 & $(0.070)$ & -0.109 & $(0 .(1 \times 3)$ & 0.119 & $(11.177)$ \\
\hline Demand pull & -0.005 & $(0.181)$ & $0.5 .45^{* *}$ & $(0,18 x)$ & 0.197 & $(0.3330)$ \\
\hline Innovalion cooperation & $0.570^{* *}$ & $(0.1677)$ & $0.638^{* *}$ & $(0.1 \times 2)$ & $1.02 \tau^{* *}$ & (0..365i) \\
\hline Technolugy push & $0.573^{* *}$ & $(0.175)$ & $0.3633^{\dagger}$ & $(0.199)$ & $0 . \times 26 i^{\dagger}$ & (0..411) \\
\hline Subsidies & $1.513^{* * *}$ & $(0.172)$ & $1.288^{* *}$ & $(0.16(x)$ & $0.8 \cdot 10^{*}$ & (11..37.1) \\
\hline Intercept & $-5.083^{* *}$ & $(0.42(j)$ & $-6.05 .4^{* *}$ & $(0.5(i 3)$ & $-7 . \times 5.94^{* *}$ & $(1.0 .60)$ \\
\hline \multicolumn{7}{|c|}{ Share of innovative sales (in logit) } \\
\hline Sizo (in log) & $0.8330^{* * 4}$ & $(0.173)$ & $10.881^{* *}$ & $(0.1 \times 1)$ & $0.9135^{*}$ & $(0 .+1.15)$ \\
\hline Contimous Rs:D & $0.808^{\dagger}$ & $(0.158)$ & $0.7(4)^{*}$ & $(0.382)$ & 0.60105 & $(01.819)$ \\
\hline Demand pull & $3.705^{* *}$ & $(0.392)$ & $4.1331^{* *}$ & $(0.370)$ & $1.316^{* *}$ & (0.tifil) \\
\hline Innovation cooperation & $0.738^{*}$ & $(0.351)$ & $0.776^{*}$ & $(0.310 ; 3)$ & 0.225 & $(0.773)$ \\
\hline Technolegy push & $-(0.17 .4$ & $(0.377)$ & 0.275 & $(0.3900)$ & $1.16 i 9^{\dagger}$ & $(0 . x+x)$ \\
\hline Sulssidies & 0.5 .51 & $(0.38: 3)$ & $0.707^{*}$ & $(0.341)$ & 0.975 & $(0.787)$ \\
\hline Intercept & $-11.40 .4^{* * *}$ & $(0.0866)$ & $-13.612^{* *}$ & $(1.04+1)$ & $-16.2225^{* * *}$ & $(2.159)$ \\
\hline \multicolumn{7}{|c|}{ Extral paramelers } \\
\hline$\sigma_{r_{2}}$ & $1.881^{* * *}$ & $(0.053)$ & $1.962^{* *}$ & $(0.060)$ & $2.19 \mathrm{~s}^{* *}$ & $(0.12 \cdot 1)$ \\
\hline$\sigma_{\epsilon: 3}$ & $5.5599^{* *}$ & $(0.189))$ & $5.6855^{* *}$ & $(0.21 \times)$ & $7.421^{* *}$ & $(0.5338)$ \\
\hline$\rho_{+1+2}$ & $-0.1 .44^{\dagger}$ & $(0.088)$ & $-0.17 .1^{\dagger}$ & $(0.10+4)$ & 0.19 .4 & $(0.190)$ \\
\hline$\rho_{\epsilon_{1} \epsilon_{3}}$ & $0.918^{* *}$ & $(0.014)$ & $0.9004^{* *}$ & $(0.016)$ & $0.9339^{* *}$ & $(0.020)$ \\
\hline$\rho_{t 23}$ & -0.0441 & $(0.060)$ & -0.068 & $(0.072)$ & 0.162 & $(0.14 .1)$ \\
\hline Number of firms & \multicolumn{2}{|c|}{1008} & \multicolumn{2}{|c|}{12.11} & \multicolumn{2}{|c|}{172} \\
\hline Log-likeliliood & \multicolumn{2}{|c|}{-3816.298} & \multicolumn{2}{|c|}{-3770.194} & \multicolumn{2}{|c|}{$-1.3: 31.220$} \\
\hline
\end{tabular}

latter case, the likelihood function was maximized using 6-point Gauss-Hermite quadrature in each step of the procedure as described in sub-appendix 6.A.2. We discuss the results in detail for the full dynamic panel data model.

\section{Dynamic effect}

We find evidence of presence of dynamics in the imnovation process. Indeed, in each equation, the lagged dependent variable affects significantly the current dependent variable. There is persistence in engaging in innovation activities and, for innovative firms, past R\&D investments affect negatively and significantly current $R \& D$ investments and past share of innovative sales affect positively and significantly the current share of innovative sales. The first result supports the hypothesis of existence of sunk costs in imnovation activities. This 
Table titi: ML festimation resialls of the dynamio panel data model

\begin{tabular}{|c|c|c|c|c|}
\hline Virialise. & Cindficient & (Stcl. Frr.) & Cisthicitult & (Std. Err.) \\
\hline 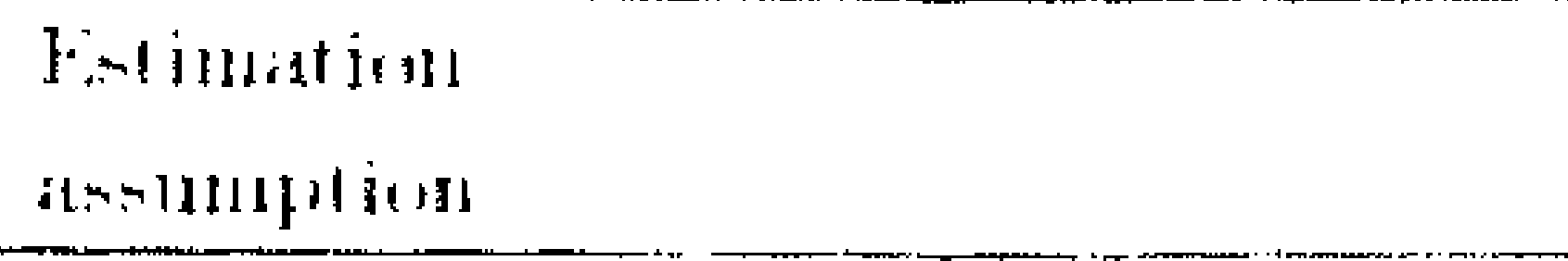 & \multicolumn{2}{|c|}{ No individelual efferets } & \multicolumn{2}{|c|}{ 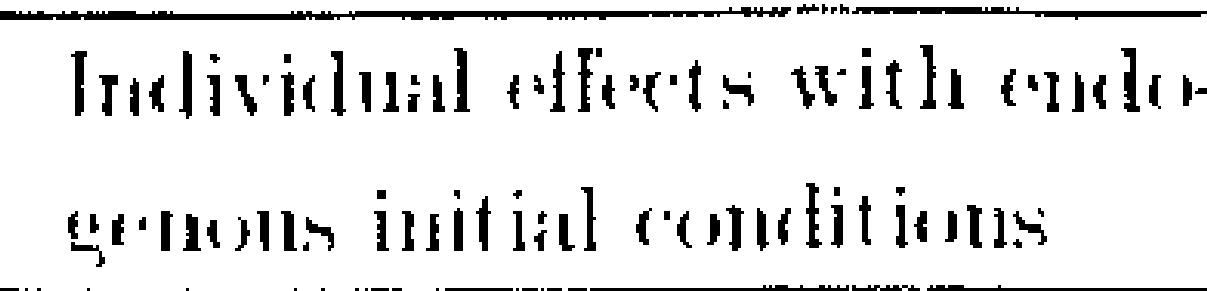 } \\
\hline \multicolumn{5}{|c|}{ ('month inturation antivities $\left(y_{111}\right)$} \\
\hline 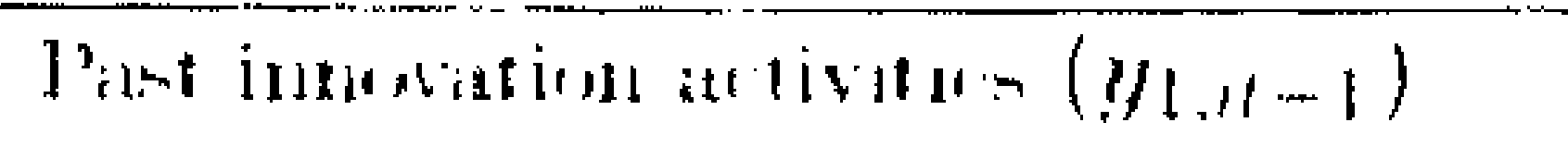 & $2.11 .50^{* *}$ & $(0.121)$ & $11.1122^{* *}$ & $(0.1912)$ \\
\hline 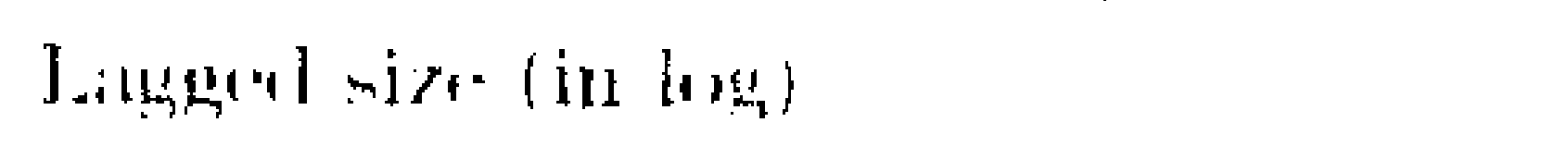 & $0.17 .3^{\dagger}$ & $(01.09011)$ & $01.2366^{\dagger}$ & $(0.12 !)$ \\
\hline 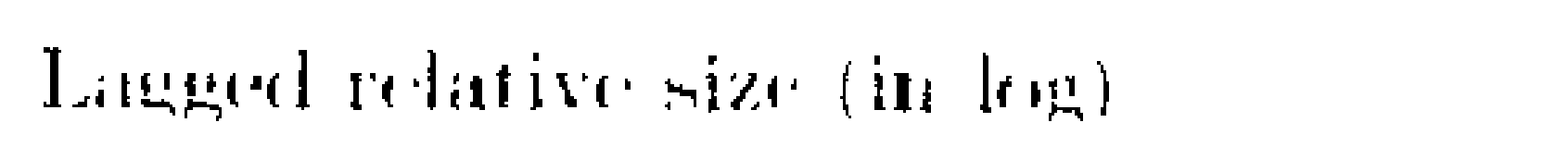 & $11.130^{\dagger}$ & $(11.06 \mathrm{~T})$ & 0.156 & $(0.0,0 ! 16)$ \\
\hline Jiterentent & $-1.61 .1^{\dagger}$ & $(0 . x: 30)$ & $2.70 \pi^{*}$ & $(1.206 i)$ \\
\hline \multicolumn{5}{|c|}{ 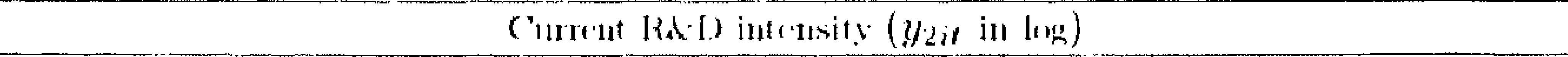 } \\
\hline 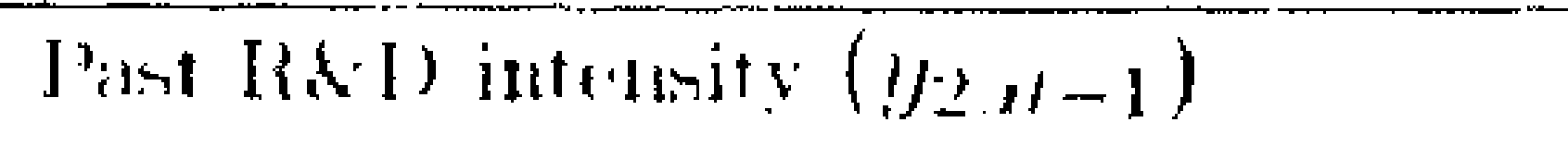 & $0.1: 30^{* *}$ & $(0.027)$ & $-0.107^{*}$ & $(0.047)$ \\
\hline 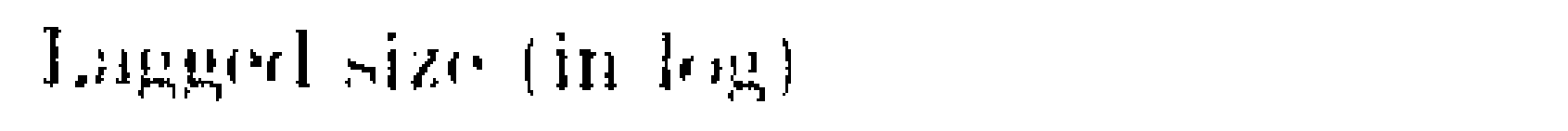 & 0.0111 & $(1.0151)$ & $0.012 x$ & $(0.06 j 2)$ \\
\hline Detmand pull & $0.3 x 5^{* * *}$ & $(11.1099)$ & $0.21 x^{*}$ & $(0.0(1)(3)$ \\
\hline 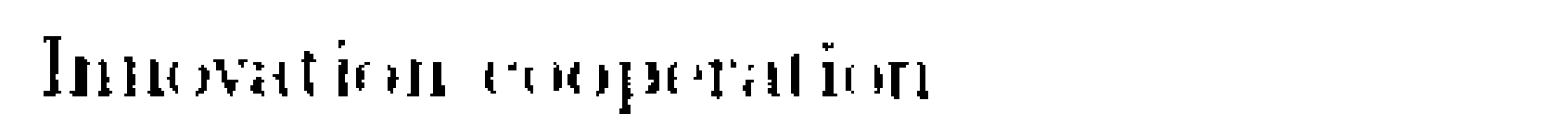 & 0.076 & $(0.114)$ & n.olix & $(0.107)$ \\
\hline Tedhunder push & $0.3 \times 1^{* *}$ & $(0.123)$ & $0.333 ! 3^{* * *}$ & $(0.116)$ \\
\hline Subsidicm & $0 .\left(6 \times 5^{* *}\right.$ & $(11.119)$ & $11.47 .1^{* *}$ & $(0.118)$ \\
\hline Intrercets & $-1.15 x^{* *}$ & $(0.36 i 1)$ & $-1 .|\times|^{* *}$ & $(0.426)$ \\
\hline \multicolumn{5}{|c|}{ (incrent share of inmowative sales (y/sit in logit) } \\
\hline 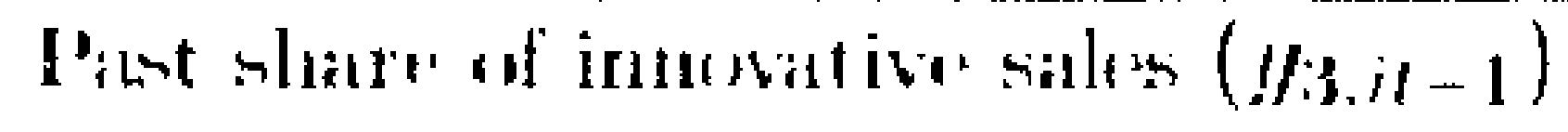 & $0.20 .15^{* *}$ & $(0 .(12) 0)$ & $0.117^{* *}$ & $(10 .(15: 2)$ \\
\hline Lingend sizo(in logs) & 0.17 .1 & $(11.133)$ & 0.16 .1 & $(0.1 .12)$ \\
\hline ('ontinunus Ravl) & $1.1157^{* *}$ & $(0.315)$ & $1.15 x^{k *}$ & $(0.32(6)$ \\
\hline Detmintul pull & $1 . \times 21^{* *}$ & $(0.259)$ & $1.65 .51^{\mathrm{k}}$ & $(0.2(i 1)$ \\
\hline 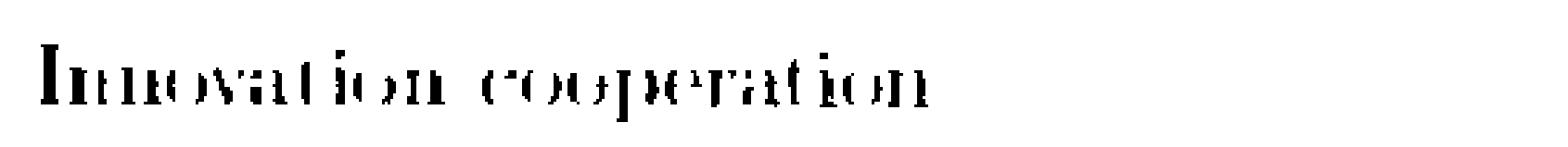 & $0.5 .12^{*}$ & $(0.26(6)$ & $0.5,2.3^{\dagger}$ & $(0,269)$ \\
\hline Techondeng push & $0.65,1^{*}$ & $(0.2 \times T)$ & $0.69 x^{*}$ & $(0.292)$ \\
\hline Sutsidlest & $(1.5) 11^{\dagger}$ & $(0,2 \times-4)$ & 0.417 & $(0.28 x)$ \\
\hline Intererept & $-(i .2) 11^{* *}$ & $(0 . \times 10)$ & $-5.9)\left(60^{* *}\right.$ & $(0.8 \pi, 1)$ \\
\hline \multicolumn{5}{|c|}{ Extra parameders } \\
\hline Intial innuvit ion andivit ifs $\left(y_{1, i 0}\right)$ & - & - & $2.266^{* * *}$ & $(0.327)$ \\
\hline Initial R\&D intentisity $(y / 2.60)$ & - & - & $0.45 ! !^{* *}$ & $(0.0 \cdot 17)$ \\
\hline Initial shate of innowat ive silles $(y / 3 . i 0)$ & - & - & $0.1 .13^{* *}$ & $(0.0 \cdot 17)$ \\
\hline$\sigma_{a_{1}}$ & - & - & $0.814^{* *}$ & $(0.1 .45)$ \\
\hline$\sigma_{a_{2}}$ & - & - & $1.33: 3^{* *}$ & $(0.09(6)$ \\
\hline$\sigma_{1 ; 3}$ & - & - & $1.65: 3^{* *}$ & $(0.301)$ \\
\hline$\rho_{a_{1} a_{2}}$ & - & - & $0.3336^{* *}$ & $(0.0995)$ \\
\hline$\rho_{a_{1} a_{3}}$ & - & - & $0.34 .12^{*}$ & $(0.1099)$ \\
\hline$\rho_{a z a_{3}}$ & - & - & $01.2 \pi 1^{* *}$ & $(0.108)$ \\
\hline$\sigma_{t_{2}}$ & $1.507^{* *}$ & $(0.038)$ & $1.07 t^{* *}$ & $(0.050)$ \\
\hline$\sigma_{1,3}$ & $3.9 \times 55^{* *}$ & (11.112) & $3.6 i 27^{* *}$ & $(0.1 .11)$ \\
\hline$P_{t+1}$ & $0.2 .12^{* *}$ & $(0.072)$ & $-(1.1) 19$ & $(11.134)$ \\
\hline$\rho_{f_{1} f: 3}$ & $0.6506^{* *}$ & $(0.1167)$ & $0.715^{* *}$ & $(0.106 i)$ \\
\hline$\rho_{t+2+3}$ & $0.1190)^{*}$ & $(0.03 \times)$ & -0.0332 & $(0.05 ; 3)$ \\
\hline Number of observations & \multicolumn{4}{|c|}{$15 \pi(i)$} \\
\hline Lom-likulifood & \multicolumn{2}{|c|}{$-5211.7 .16$} & \multicolumn{2}{|c|}{-5116.6772} \\
\hline
\end{tabular}

finding is in accordance with Máñez Castillejo et al. (2004) and Peters (20)5) who estimate a dynanic probit and find evidence of persistence by Spanish manufacturing firms in cngaging in R\&D activities, and by German manufacturing and services lirms in engaging in imnovation 
activities respectively. The second result is somewhat surprising as we would expect past R\&D investments of innovative firms to affect positively current R\&D investments. The positive effect identified in the dynamic: panel data model without individual effects seems to be taken over by the initial R\&D investments.. Hence, a negative effect arises when we estimate the full dynamic panel data model accounting for unobserved individual effects and endogenous initial conditions. We are unable to identify a positive effect of both past and the initial (through its correlation with the individual effects) R\&D investments on current $R \& D$ investments. This phenomenon might be due to the shortness of the panel in which case past and the initial R\&D investments are highly correlated. Finally, the third result corroborates the finding of Chapter 4 and is also in accordance with van Leeuwen (2002). The coefficient of the lagged share of innovative sales in the dynamic model without individual effects is very similar to that of van Leouwen's study which does not account for individual effects.

\section{Size and relative size}

Lagged size affects positively and significantly the probability to engage in innovation activities, although its significance lessens when technological opportunities and appropriability, through scctoral dummies, are controlled for (Crépon et al., 1996). This finding is in accordance with the cmpirical literature (see Table 6.7) and in particular with Cohen and Klepper's (1996) stylized fact 1. ${ }^{10}$ Like Crépon ct al. (1998), we find no correlation between R\&D intensity and firm size. This finding is at variance with the empirical literature which iclentifies a negative relationship between R\&D intensity and firm size. Our results also suggest that firm size does not significantly affect the share of imnovative sales, which is in accordance with the empirical literature and at variance with Cohen and Klepper's stylized fact $4 .^{11}$ The positive and significant effect of size on the share of innovative sales found in the cross-sectional version of the model vanishes when dynamics is allowed for.

\footnotetext{
${ }^{*}$ The coefficient of the lagged R\&D intensity of the molel without individual effects is very similar to that of the study by van Leenwen $(2002)$.

"At firs the "three-step" (Gauss-Hermite quadrature was thought to be the main reason why patsl R\&D investments affect negatively current. R\&D invest ments because of inaceuracy that might result from the? use of too few integration points. We later increased the number of integration points, in each step of the? fore negative effect is confirmed when estimat ing a dynamic linear regression model of R\&D investments, accounting for individual effects and endogenous intial

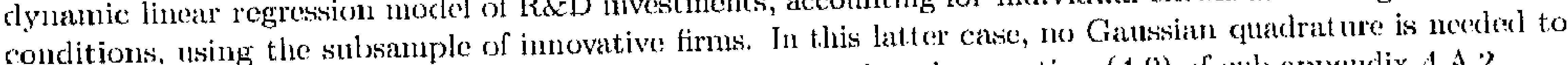

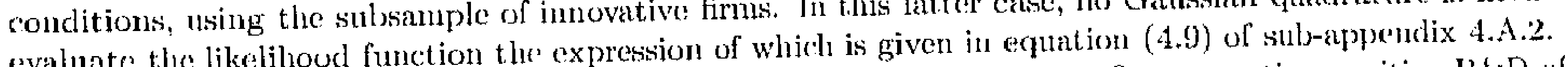

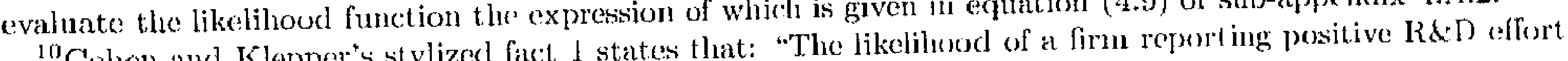
rises with firm size and approaches one for firms in the largest size ranges.

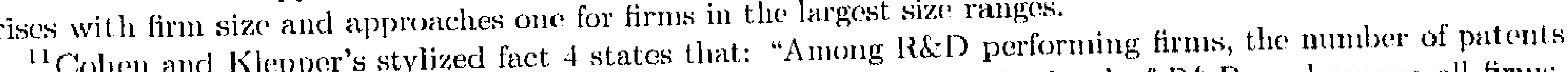

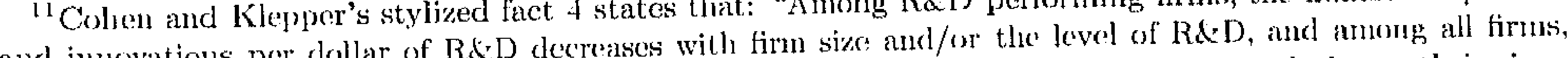
smaller firms account for a disproportionalely large number of patents and innovations relative to their size.
} 
As for rolative size. there is mixed evidence in the literature with regard to its role in the probability to engage in innovation activities. Like Janz and Peters (2002) and van Leenwen (2002) we find no significant effect of relative size on the probability to ongage in imnovation activitics.

\section{Demand pull and technology push}

The results suggest that demand pull and technology push affect positively and significantly both R\&D investments and the share of innovative sales. In line with Cohen and Levinthal's (1989) "absorptive caparity", the coefficient of technology push is larger and more significant than that of demand pull in the R\&D intensity equation. Conversely, demand pull affocts more significantly the share of immovative sales than technology push. This finding is in accordance with the literature which shows a larger and more significant impact of techmology push on R\&D investments than demand pull, while demand pull is shown to have a larger and more significant impact on the share of innovative sales than technology push.

\section{Innovation cooperation}

The positive and significant effect of innovation cooperation on $R \& D$ intensity found in the cross-sectional version of the model vanishes in the dynamic specification of the model with pancl data. Other things being equal cooperative enterprises do not seem to invest more in R\&D than non-cooperative enterprises, which is in accordance with the empirical literature. However, unlike the empirical literature, we find evidence of positive correlation between cooperation and the share of imnovative sales.

\section{Continuous R\&D}

Like Klomp and van Leeuwen (2001) and van Leeuwen (2002) we find that, ceteris paribus, continuous R\&D performers are more successful in terms of share of innovative sales than temporary R\&D performers. This finding is in accordance with the empirical literature which identifies a positive and highly significant impact of doing R\&D continuously on the share of innovative sales (see also Brouwer and Kleinknecht, 1996; Mairesse and Mohnen, 2001; Mohnen and Dagenais, 2001).

\section{Subsidy}


The empirical litcrature identifies two types of relationship, at the firm level, between subsidies and R\&D investments. More specifically, subsidized and private R\&D investments are complements if $\mathrm{R} \& \mathrm{D}$ investments increase with subsidies, otherwise subsidized and private R\&D investments are substitutes in which case the formor "crowd out" the latter (Lach. 2002; Almus and Czarnitzki, 2003). Our results suggest that subsidized firms have on average larger R\&D investments than non-subsidized counterparts. Since we only observe whether or not an enterprise receives $R \& D$ subsidies, we can conclude that the hypothesis of complete "crowding out" effects is not supported by our results although some substitution between subsidized and private R\&D investments may still exist (Czarnitzki and Ficr, 2002). As for the share of innovative sales, the positive and significant effect of subsidy found in the cross-sectional specification of the model vanishes in the dynamic version of the model.

\section{Firm heterogeneity and interrelationship}

Firm heterogeneity is shown in the literature to be an important feature of the innovation process and ignoring it results in misleading inference about the process (see for instance Blundell ot al., 1995, 1999). We account for observed heterogeneity in the crosis-sectional specification by separately estimating the model for the three categories of industrics. Furthermore, the industries of the high- and low-tech categories are allowed to have different intercepts by inchuding sectoral dummies. Tables 6.3-6.5 suggest that the three categories of industries differ in their innovation behavior, hence the presence of heterogeneity in the innovation process. The dynanic panel data specification models both observed and unobserved heterogeneity including sectoral dummies and individual effects respectively. Table 6.6 suggests that the model assuming the absence of individual effects (see the first pair of columns) is rejected using a likelihood ratio test at $1 \%$ level of significance, hence the presence of unobserved firm hetcrogeneity in the imnovation process. Indeed, in each equation of the model the standard deviation of the individual effects is significantly (at $1 \%$ level) estimated. Furthermore, the engagement in innovation activities, R\&D intensity and the share of innovative sales at the initial period affect positively and significantly, through their correlation with the individual offects, the current engagement in innovation activities, current R\&D intensity and the current share of innovative sales respectively.

Table 6.6 also shows that the decision to engage in immovation activities, the amount of $R \& D$ investments and the share of innovative sales are correlated through the idiosyncratic 


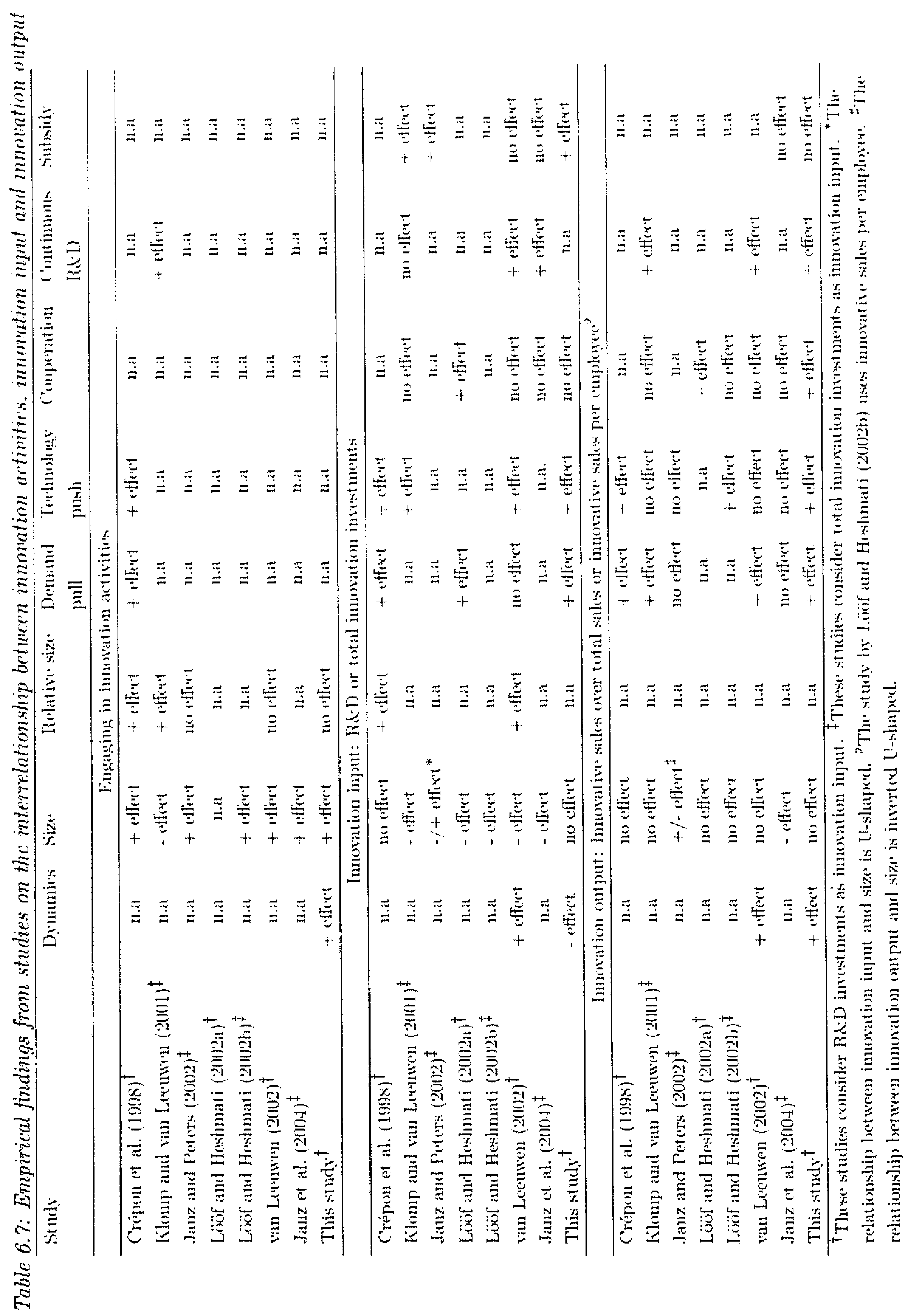


errors, when the model ignores the individual effects, and mostly through the individual effects when they are accounted for by the model. This finding rejects the hypothesis of linearity of the innovation process where the various stages of the process are assumed isolated from one another, and is in accordance with the empirical studies of Table 6.7.

\subsection{Conclusion}

We have studied the innovation process by modeling three important features of the process, namely it is nonlinear, dynamic and involves heterogenous firms. More specifically, we considered a three-equation dynamic tobit-type model, accounting for individual effects in each equation, where the clymamics of the decision to engage in, that of R\&D intensity and the share of innovative sales wore jointly investigated. The model was estimated by maximum likelihood and "three-step" Ganss-Hermite quadrature was used to evaluate the likelihood function. The resultis are summarized as follows.

The nonlinearity of the immovation process as well as the presence of dynamics and firm heterogeneity are confirmed by the estimation results of the model. Firstly, the decision to engage in innovation activities, R\&D intensity and the share of innovative sales are correlated, mostly through the individual effects. Secondly, enganging in innovation activities is persistent and, for innovative firms, past R\&D investments affect negatively and significantly current $R \& D$ investments and past share of innovative sales affect positively and significantly the current share of innovative sales. Thirdly, the individual effects play a significant role in the decision to ongage in imnovation activities, R.\&D investments and the share of innovative sales. The results also suggest that size affects positively and significantly the probability to engage in imnovative activities and plays no role in either the amount of $R \& D$ investments or the share of innovative sales. Demand pull and technology push affect positively and significantly both R\&D investments and the share of immovative sales. Cooperative enterprises do not seem to invest more in $R \& D$ than non-cooperative counterparts, while there is evidence of positive correlation between cooperation and the share of innovative sales. Other things being equal, contimous R\&D performers are more successful in terms of share of innovative sales than tcmporary R\&D performers. Finally, subsidized firms invest more in R\&D but are not more successful than non-subsidized counterparts.

The main caveat of this study is the shortness of the panel, which may explain why we 
were unable to identify a positive effect of past $R \& D$ investments on current $R \& D$ investments when we accounted for individual effects and endogenous initial conditions. The fact that the same phenomenon does not take place in the other two equations indicates that the negative effect found camnot be attributed only to the shortness of the panel. This issue remains a topic: of future researcl. Furthermore, the equations of $R \& D$ and the share of innovative sales were assumed to be correlated only throngh the individual effects and the idiosyncratic errors. A natural extension is to include $R \& D$ intensity in the set of explanatory variables of the equation of the share of imnovative sales and vice versa, hence allowing for a direct effect of R\&D investments on innovation output and a feedback effect of innovation ontput on R\&D investments. Finally, the model ignored the relationship between innovation and firms' economic performance (e.g. productivity). This relationship can be studied by including, in the spirit of Crépon et al. (1998), a fourth equation of economic performance. However, estimating the resulting model allowing for dynamics and mobserved individual effects is a formidable task to achieve. 


\section{Appendix 6.A The random-effects likelihood function of the three-equation tobit-type model}

\section{A.1 The likelihood function conditional on the individual effects}

Consider the three-equation dynamic tobit-type model defined in equations (6.1-(6.3) with individual effects defined in equations (6.4-6.6), and expressions (6.9-6.11). Assume that the vectors $\left(\epsilon_{1 i l}, \epsilon_{2 i l}, \epsilon_{3 i l}\right)^{\prime}$ and $\left(a_{1 i}, a_{2 i}, a_{3 i}\right)^{\prime}$ are independent of each other, and independently and identically distributed over time and across individuals following a normal distribution with mean zero and covariance matrix given in equation (6.7). Denote by $y_{1 i \text { i }}^{*}$ the latent function in square brackets in equation (6.1). The likclihood function of individual $i$ conditional on the individual effects, denoted by $\prod_{l=1}^{T} L_{i l}\left(\mathbf{y}_{i i} \mid \mathbf{y}_{i 0}, \mathbf{y}_{i, l-1}, \mathbf{x}_{i}, a_{1 i}, a_{2 i}, a_{3 i}\right)$, is written as

$$
\begin{aligned}
& \prod_{\ell=1}^{T} L_{i l}\left(\mathbf{y}_{i \ell} \mid \mathbf{y}_{i l\}}, \mathbf{y}_{i, l-1}, \mathbf{x}_{i}, a_{1 i}, a_{2 i}, a_{3 i}\right)=\prod_{t=1}^{T}\left[P\left(y_{1 i l}^{*} \leq 0\right)\right]^{1-y_{1, t}}\left[f\left(y_{2 i l}, y_{3 i l} \mid y_{1 i t}^{*}>0\right) P\left(y_{1, t}^{*}>0\right)\right]^{y_{1, t}} \\
& =\prod_{l=1}^{T}\left[P\left(y_{1 i t}^{*} \leq 0\right)\right]^{1-l / 1 i t}\left[\int_{0}^{\infty} f\left(y_{1 i t}^{*}, y_{2 i t}, y_{3 i i}\right) d y_{1 i l}^{*}\right]^{y_{1, t}}
\end{aligned}
$$

where $\mathbf{y}_{i l}=\left(y_{1 i l}, y_{2 i t}, y_{3 i t}\right), \mathbf{y}_{i 0}=\left(y_{1 i}, y_{2 i 1}, y_{3 i(0)}\right), \mathbf{y}_{i, t-1}=\left(y_{1 i, t-1}, y_{2 i . t-1}, y_{3 i, I-1}\right), \mathbf{x}_{i}=$ $\left(\mathbf{x}_{1 i}, \mathbf{x}_{2 i}, \mathbf{x}_{3 i}\right)$ and $f\left(y_{1 i l}^{*}, y_{2 i t}, y_{3 i l}\right)$ is the density function of the trivariate normal distribution of $\left(y_{1 i t}^{*}, y_{2 i l}, y_{3 i l}\right)$. The trivariate density function can be written as the product of three univariate normal density functions $f\left(y_{1 i t}^{*} \mid y_{2 i t}, y_{3 i t}\right), f\left(y_{2 i l} \mid y_{3 i t}\right)$ and $f\left(y_{3 i t}\right)$ the expressions of which are given respectively by

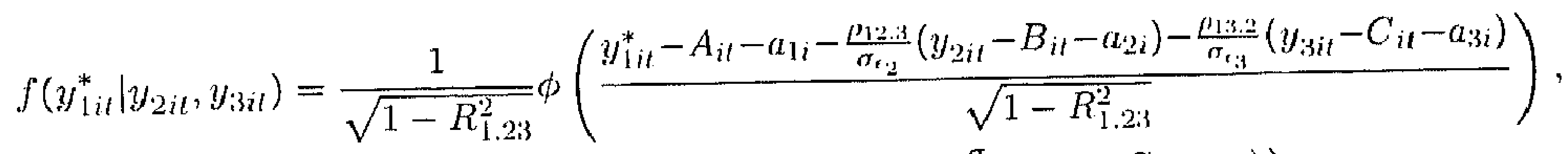

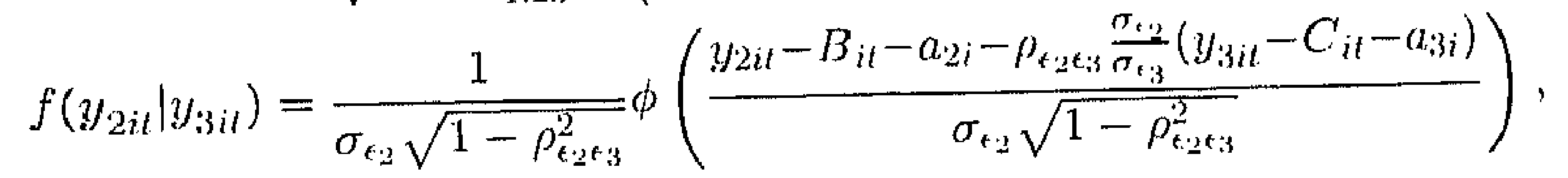

$$
\begin{aligned}
& f\left(y_{3 i t}\right)=\frac{1}{\sigma_{\mathrm{t} 3}} \phi\left(\frac{y_{3 i t}-C_{i l}-a_{3 i}}{\sigma_{\mathrm{t} 3}}\right) .
\end{aligned}
$$

$R_{1.23}^{2}$ denotes the multiple correlation of $\epsilon_{1 i l}$ with $\epsilon_{2 i l}$ and $\epsilon_{33 i}, \rho_{12.3}$ is the partial correlation between $\epsilon_{1 i t}$ and $\epsilon_{2 i l}$ given $\epsilon_{3 i l}, \rho_{13.2}$ is the partial correlation between $\epsilon_{1 i t}$ and $\epsilon_{3 i l}$ given $\epsilon_{22 l}$, and $\phi$ is the univariate standard normal density function. The expressions of the multiple 
and partial correlations are given by

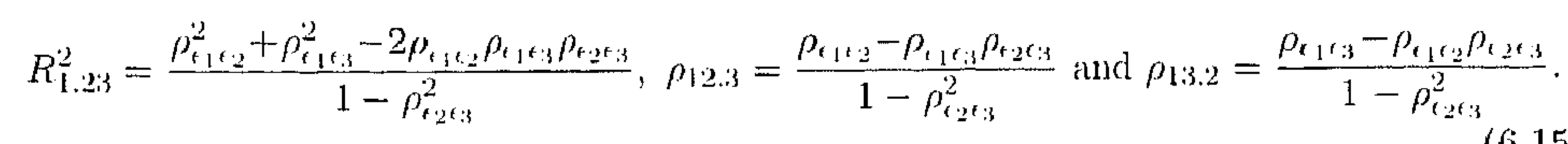

Equation (6.13) then becomes

$$
\begin{aligned}
& \prod_{t=1}^{T} \Phi\left[-\left(A_{i t}+a_{1 i}\right)\right]^{1-y_{1, t}}\left[\frac{1}{\sigma_{t 3}} \phi\left(\frac{y_{3 i t}-C_{i l}-a_{3 i}}{\sigma_{t 3}}\right)\right.
\end{aligned}
$$

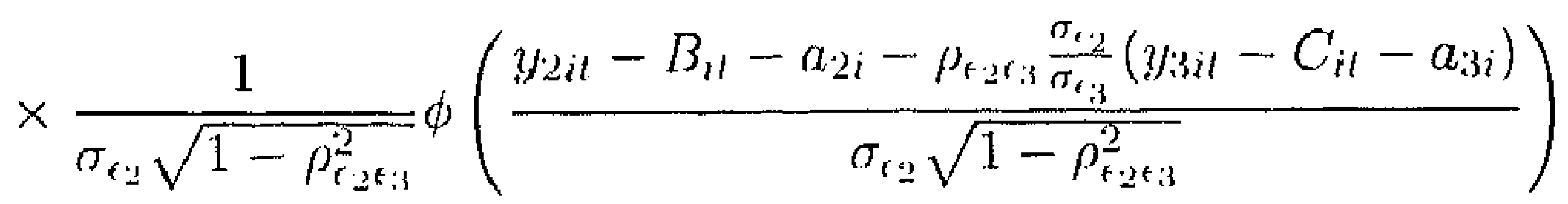

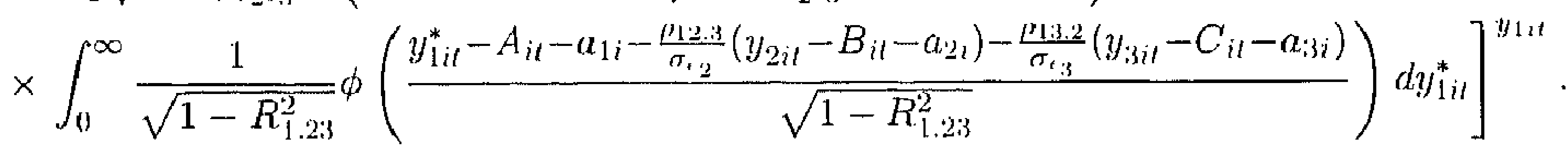

Applying the results of Proposition 1 of Chapter 2 to $\left(y_{1 i l}^{*} \mid y_{2 i t}, y_{3 i t}\right)$ that is normal with mean $A_{i l}+a_{1 i}+\frac{\alpha_{12.33}}{\sigma_{t, 2}}\left(y_{2 i t}-B_{i t}-a_{2 i}\right)+\frac{\rho_{13.2}}{\sigma_{\tau_{3}}}\left(y_{33 i}-C_{i t}-a_{3 i}\right)$ and variance $1-R_{1.23}^{2}$, we obtain

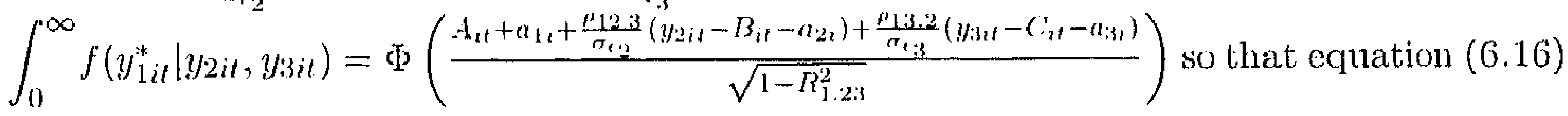
becomes

$$
\begin{aligned}
& \prod_{t=1}^{T} \Phi\left[-\left(A_{i l}+a_{1 i}\right)\right]^{1-y_{1 i t}}\left[\frac{1}{\sigma_{t ; 3}} \phi\left(\frac{y_{3 i i}-C_{i l}-a_{3 i}}{\sigma_{t ; 3}}\right)\right.
\end{aligned}
$$

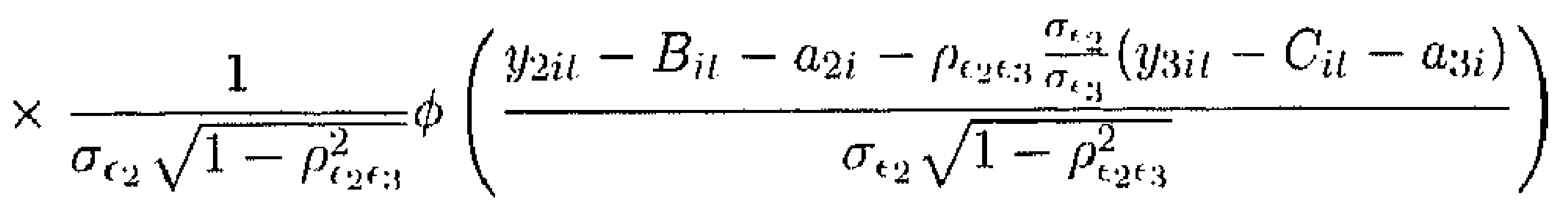

$$
\begin{aligned}
& \left.\times \Phi\left(\frac{A_{i l}+a_{1 i}+\frac{\rho_{12,3}}{\sigma_{\tau_{2}}}\left(y_{2 i t}-B_{i l}-a_{2 i}\right)+\frac{p_{13,2}}{\sigma_{\epsilon_{3}}}\left(y_{33 i}-C_{i l}-a_{3 i}\right)}{\sqrt{1-R_{1.23}^{2}}}\right)\right]^{y_{12 t}} \text {. }
\end{aligned}
$$

The random-effects individual likelihood function of the three-equation dynamic tobittype model is obtained by "integrating out" the individual effects using their trivariate normal density function whose expression is given by

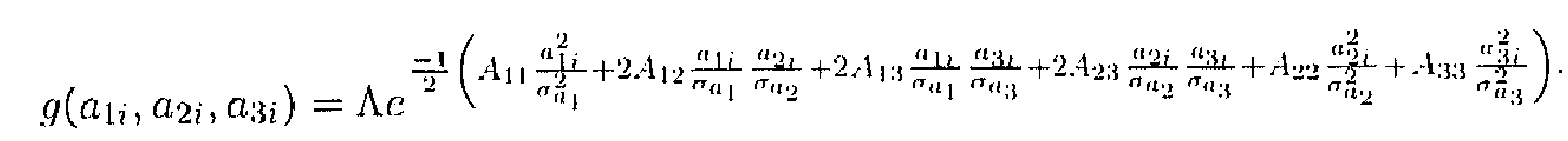

The constant term $\Lambda$ equals $\left(\sigma_{a_{1}} \sigma_{a_{2}} \sigma_{a_{3}}\right)^{-1}(2 \pi)^{\frac{-3}{2}}(\Delta)^{\frac{-1}{2}}$, and the expressions of $\Delta$ and $A_{j k}$ $\left(j, k=1,2,3\right.$ and $\left.A_{j k}=A_{k i j}\right)$ are given by

$$
\Delta=1-\rho_{a_{1} a_{2}}^{2}-\rho_{a_{1} a_{3}}^{2}-\rho_{a_{2} a_{3}}^{2}+2 \rho_{a_{1} a_{2}} \rho_{a_{1} a_{3}} \rho_{a_{2} a_{3} 3}
$$




$$
\begin{aligned}
& A_{11}=\frac{1-\rho_{a_{2} a_{3} 3}^{2}}{\Delta}, A_{22}=\frac{1-\rho_{a_{1} a_{3} 3}^{2}}{\Delta}, A_{333}=\frac{1-\rho_{a_{1} a_{2}}^{2}}{\Delta}, \\
& A_{12}=\frac{\rho_{a_{1} a_{3} \rho_{a_{2} a_{3}}-\rho_{a_{1} a_{2}}}^{2}}{\Delta}, A_{13}=\frac{\rho_{a_{1} a_{2} \rho_{a_{2} a_{3}}-\rho_{a_{1} a_{3}}}}{\Delta}, A_{22_{3}}=\frac{\rho_{a_{1} a_{2}} \rho_{a_{1} a_{3}}-\rho_{a_{2} u_{3}}}{\Delta} .
\end{aligned}
$$

Hence, equation (6.8) can be written as

$$
L_{i}=\int_{-\infty}^{\infty} \exp \left[\frac{-1}{2}\left(A_{333} \frac{a_{3 i}^{2}}{\sigma_{a_{3}}^{2}}\right)\right] \prod_{t=1}^{T}\left[\frac{1}{\sigma_{\mathrm{t} 3}} \phi\left(\frac{y_{3 i 1}-C_{i t}-a_{3 i}}{\sigma_{\mathrm{t} 3}}\right)\right]^{y_{1, t}} H\left(a_{33}\right) d a_{3,3}
$$

where the function $H\left(a_{3 i}\right)$ is written as

$$
\begin{aligned}
& H\left(a_{3 i}\right)=\int_{-\infty}^{\infty} e^{\frac{-1}{2}\left(A_{22} \frac{a_{2 i}^{2}}{\sigma_{a_{2}}^{2}}\right)} e^{-\left(A_{2: 1} \frac{a_{2 i}}{\sigma_{a_{2}}} \frac{a_{33}}{\sigma_{a_{3}}}\right)}
\end{aligned}
$$

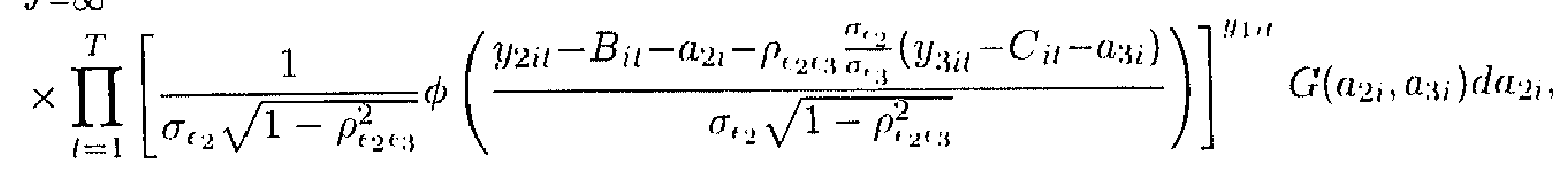

and the function $G\left(a_{2 i}, a_{3 i}\right)$ is written as

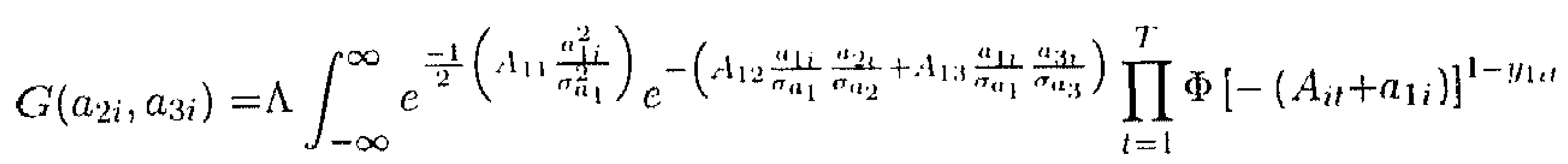

$$
\begin{aligned}
& \times\left[\Phi\left(\frac{A_{i t}+a_{1 i}+\frac{\rho_{1233}}{\sigma_{1,2}}\left(y_{2 i t}-B_{i t}-a_{2 i}\right)+\frac{\rho_{132}}{\sigma_{t 3}}\left(y_{3 i t}-C_{i t}-a_{3 i}\right)}{\sqrt{1-R_{1,233}^{2}}}\right)\right]^{t_{12 t}} d a_{1 i}
\end{aligned}
$$

\section{A.2 "Three-step" Gauss-Hermite quadrature}

In the spirit of Chapter 3, the "threc-step" Gauss-Hermite quadrature consists, in the first step, in approximating equation (6.21) using the Gauss-Hermite quadrature as defined in Butler and Moffitt (1982). In the second step, equation (6.20) is approximated similarly after replacing $G\left(a_{2 i}, a_{3 i}\right)$ by its first-step Gauss-Hermite approximation. In the third step, we apply the same approximation to equation $(6.19)$ where $H\left(a_{3 i}\right)$ is replaced by its second-step Gauss-Hermite approximation.

Consider the variable change $z_{1 i}=\frac{a_{1} \sqrt{A_{11}}}{\sigma_{n_{1}} \sqrt{2}}$ so that $d a_{1 i}=\frac{\sigma_{a_{1}} \sqrt{2}}{\sqrt{A_{11}}} d z_{1 i}$. Equation (6.21) can then be written as

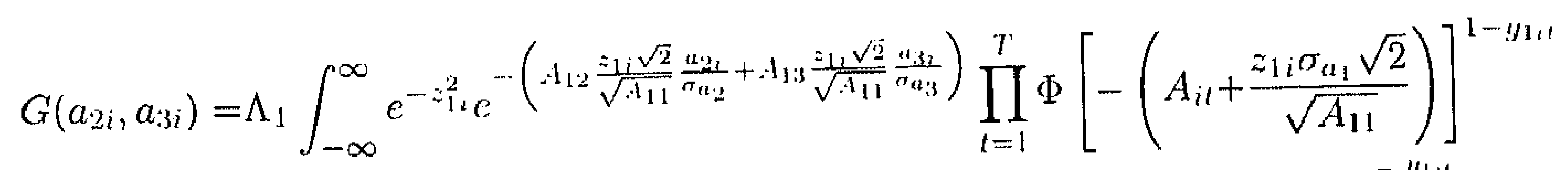

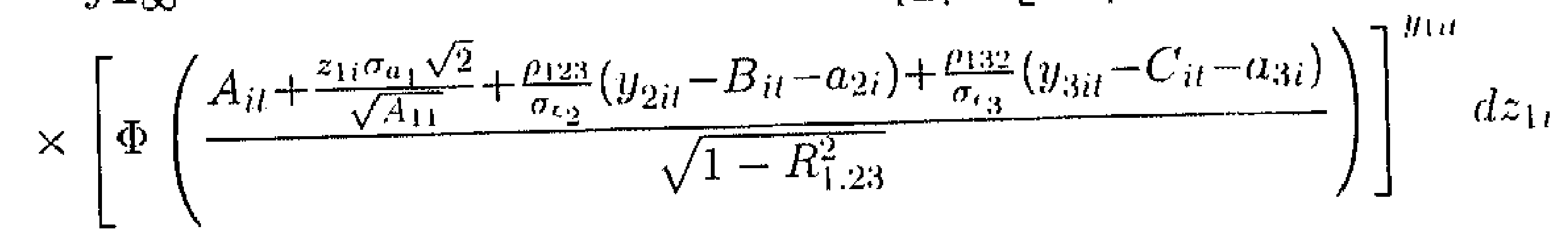


which can be approximated using Ganss-Hermite quadrature by

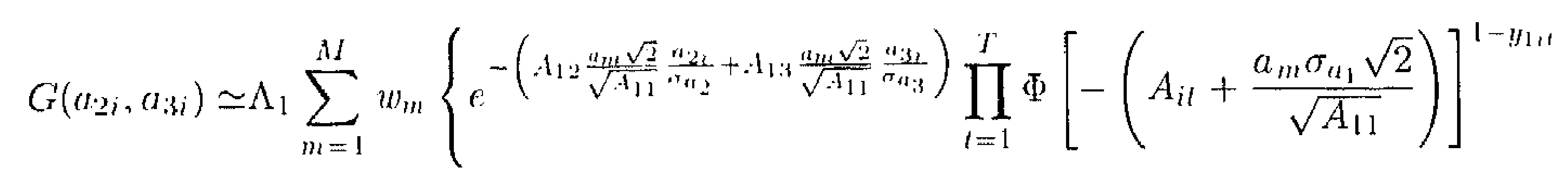

$$
\begin{aligned}
& \left.\times\left[\Phi\left(\frac{A_{i l}+\frac{a_{11} \sigma_{a 1} \sqrt{2}}{\sqrt{A_{11}}}+\frac{\mu_{1233}}{\sigma_{12}}\left(y_{2,1}-B_{i 1}-a_{2 i}\right)+\frac{\rho_{132}}{\sigma_{13}}\left(y_{3 i 1}-C_{i 1}-a_{3 i}\right)}{\sqrt{1-R_{1.23}^{2}}}\right)\right]^{y_{1 i t}}\right\}
\end{aligned}
$$

where $\Lambda_{1}$ equals $\left(2 \sigma_{a_{2},} \sigma_{u_{3}}\right)^{-1}(\pi)^{\frac{-3.3}{2}}\left(1-\rho_{a_{2} a_{3}}^{2}\right)^{\frac{-1}{2}}$, and $w_{m}$ and $a_{m}$ are the weights and abscissas of the first-step Gauss-Hermite quadrature with $M$ being the total number of integration points.

Consider the second variable change $z_{2 i}=\frac{a_{2,} \sqrt{A_{22}}}{\sigma_{a_{2}} \sqrt{2}}$ so that $d a_{2 i}=\frac{\sigma_{a_{2}, 2} \sqrt{2}}{\sqrt{d_{22}}} d z_{2 i}$. Replacing equation (6.22) into equation (6.20) yiclds

$$
\begin{aligned}
& H\left(a_{3 i}\right) \simeq \Lambda_{2} \int_{-\infty}^{\infty} c^{-z_{2,}^{2}} e^{-\left(A_{23} \frac{z_{2}, \sqrt{2}}{\sqrt{\Lambda_{22}}} \frac{u_{32}}{\sigma_{n_{3}}}\right)}
\end{aligned}
$$

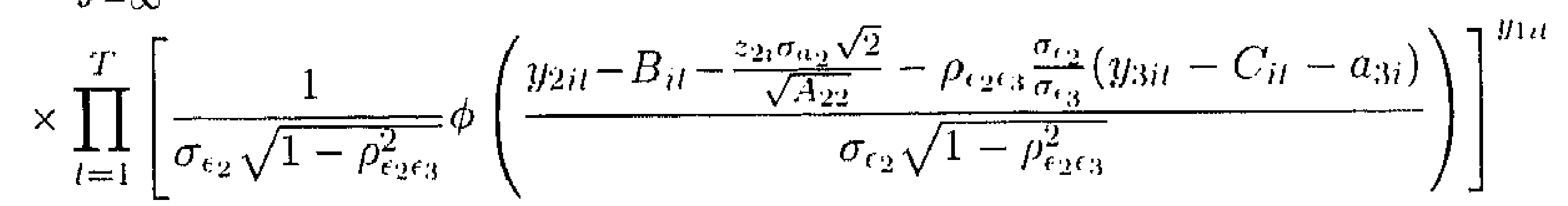

$$
\begin{aligned}
& \sum_{m=1}^{M} w_{m}\left\{e^{-\left(A_{12} \frac{a_{m} \sqrt{2}}{\sqrt{A_{11}}} \frac{\Sigma_{2,} \sqrt{2}}{\sqrt{A_{22}}}+A_{13} \frac{a_{m} \sqrt{2}}{\sqrt{A_{11}}} \frac{a_{3 i}}{a_{a_{3}}}\right)} \prod_{t=1}^{T} \Phi\left[-\left(A_{l l}+\frac{a_{m} \sigma_{a_{1}} \sqrt{2}}{\sqrt{A_{11}}}\right)\right]^{1-y_{12 l}}\right.
\end{aligned}
$$

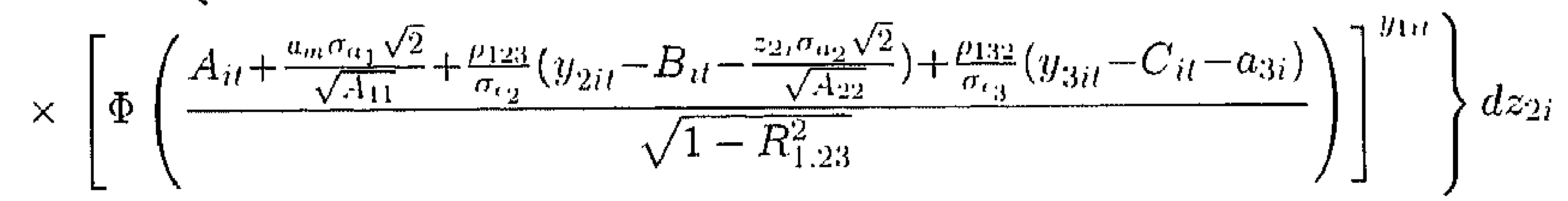

which can be approximated again using Gauss-Hormite quadrature by

$$
\begin{aligned}
& H\left(a_{3 i}\right) \simeq \Lambda_{2} \sum_{p=1}^{P} w_{p}\left\{e^{-\left(A_{2: 3} \frac{a_{p} \sqrt{2}}{\sqrt{A_{22}}} \frac{a_{3, j}}{\sigma_{u_{3}}}\right)}\right.
\end{aligned}
$$

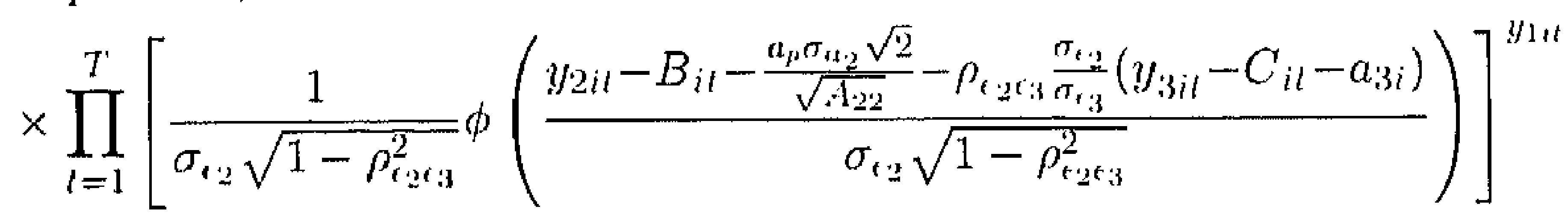

$$
\begin{aligned}
& \sum_{m=1}^{M} w_{m}\left\{e^{-\left(A_{12} \frac{a_{m} \sqrt{2}}{\sqrt{A_{11}}} \frac{a_{l} \sqrt{2}}{\sqrt{A_{22}}}+A_{1: 3} \frac{a_{m} \sqrt{2}}{\sqrt{A_{11}}} \frac{a_{32}}{\sigma_{u_{3}}}\right)} \prod_{l=1}^{T} \Phi\left[-\left(A_{i l}+\frac{a_{m} \sigma_{a_{1}} \sqrt{2}}{\sqrt{A_{11}}}\right)\right]^{1-y_{11 t}}\right.
\end{aligned}
$$

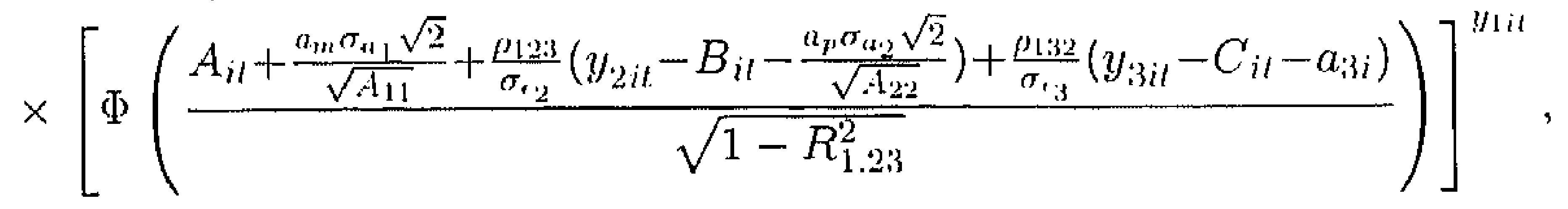


where $\Lambda_{2}$ equals $\left(2 \sigma_{a_{3}, 3}\right)^{-1}(\pi)^{\frac{-33}{2}}\left[\left(1-\rho_{a_{1} n_{3}}^{2}\right)\left(1-\rho_{a_{2} u_{3}}^{2}\right)\right]^{\frac{-1}{2}}(2 \Delta)^{\frac{1}{2}}$, and $w_{p}$ and $a_{p}$ are the weights and abscissas of the second-step Gauss-Hermite quadrature with $P$ boing the tortal number of integration points.

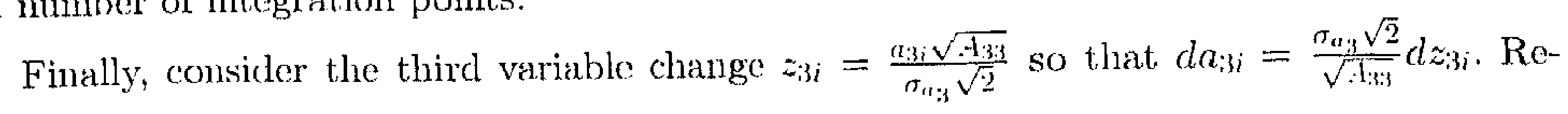
placing equation (6.23) into equation (6.19) yiclds

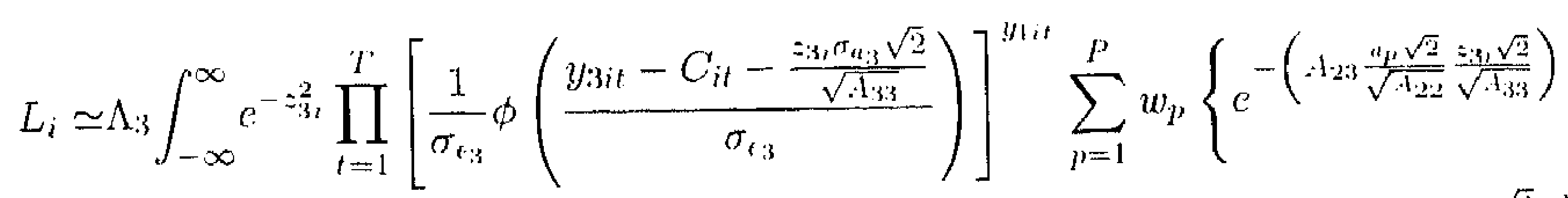

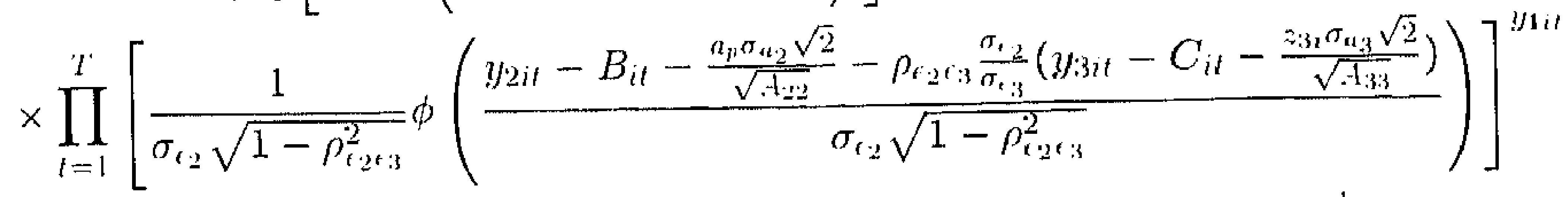

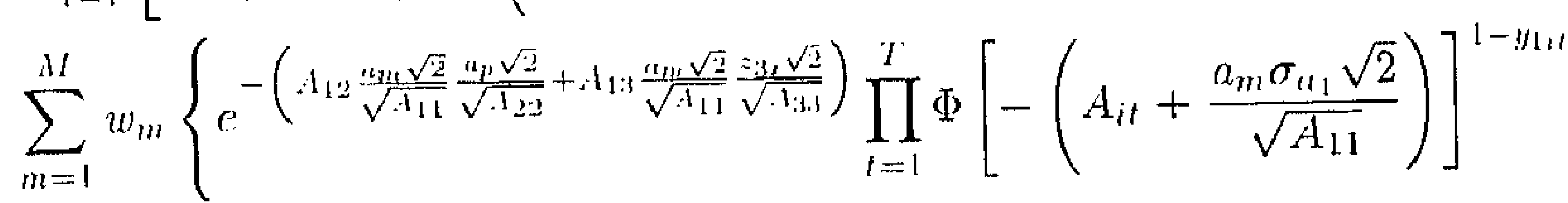

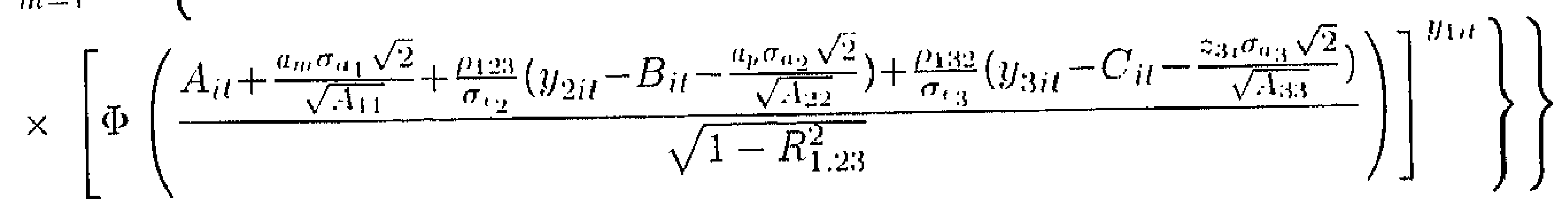

which can be approximated by

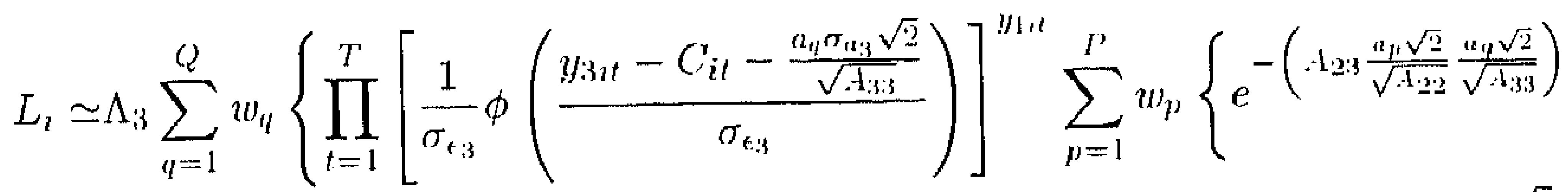

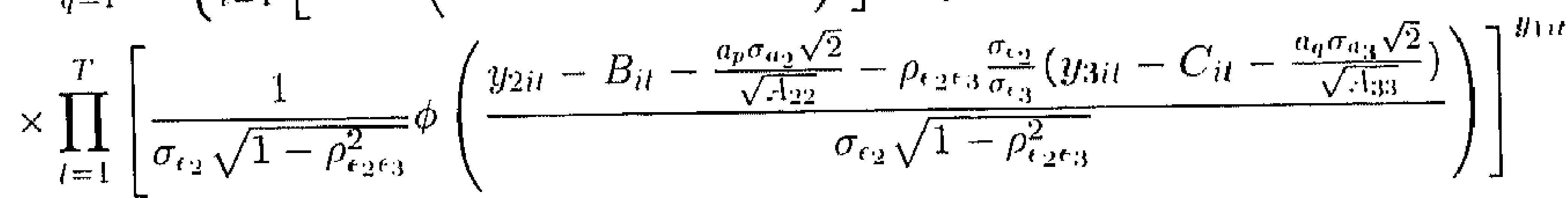

$$
\begin{aligned}
& \times \sum_{m=1}^{M} w_{m}\left\{e^{-\left(A_{12} \frac{a_{m}, \sqrt{2}}{\sqrt{A_{11}}} \frac{u_{p} \sqrt{2}}{\sqrt{A_{22}}}+A_{13} \frac{u_{m n} \sqrt{2}}{\sqrt{A_{11}}} \frac{n_{11} \sqrt{2}}{\sqrt{A_{33}}}\right)} \prod_{t=1}^{T} \Phi\left[-\left(A_{i l}+\frac{a_{m} \sigma_{a_{1}} \sqrt{2}}{\sqrt{A_{11}}}\right)\right]^{1-y_{1}}\right.
\end{aligned}
$$

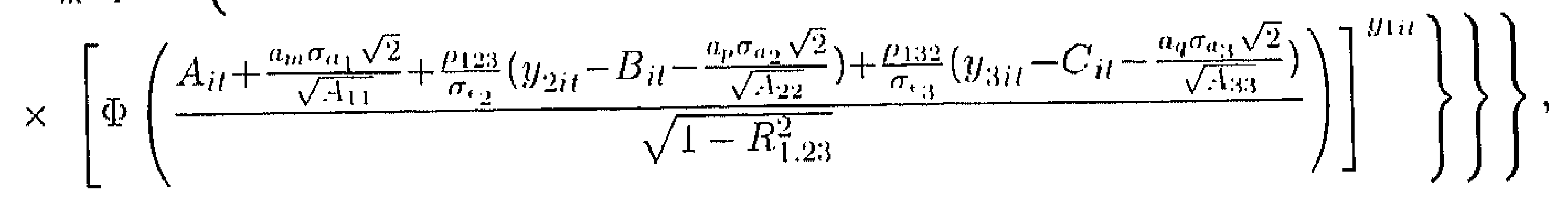

where $\Lambda_{3}$ equals $\Delta(\pi)^{\frac{-33}{2}}\left[\left(1-\rho_{a_{1} a_{2}}^{2}\right)\left(1-\rho_{a_{1} a_{3}}^{2}\right)\left(1-\rho_{a_{2} a_{3}}^{2}\right)\right]^{\frac{--1}{2}}$, and $w_{q}$ and $a_{q}$ are the wcights and abscissas of the third-step Gauss-Hermite cluadrature with $Q$ being the total number of integration points. 


\section{Appendix 6.B The dynamics of R\&D investments of innova- tive firms}

Wi report in Tible $6 . x$ estimation results of a dynamic linear regression model of R\&D investments of innovative firms (er. (6.2)). in which (ase the annoment of R\&D investments is assmmed to be monrelated with the decision to engage in imnovation activities and the share If imnvative sales. Anderson and Hsiao $(1981 ; 1982)$ suggest to estimate the dynamic linear regression by maximmn likelihoed assuming random individual effects and exdogenous initial conditions correlated with the individual effects $\left(\rho_{\left.l l_{1}, n_{2}\right)}\right)$. The initial conditions are assumed normal with mean $\mu_{y_{2, n},}$ and standard deviation $\sigma_{y_{2}+1}$. No Ganss-Hernite quadrature is required to evaluate the: likelihos function and the estimation results suggest that the positive effect of past R\&D intensity on current R\&D intensity becomes negative when individual effects and endogenous initial conditions are accounled for. ${ }^{12}$

Table 6.8: ML estimation results of the dynamic linear regression model of RED

\begin{tabular}{|c|c|c|c|c|}
\hline Viriable & Cinelficiont & (Stul. Etr.) & C'uefficient & (Std. Lrr.) \\
\hline $\begin{array}{l}\text { Iimtimation } \\
\text { itsonmption }\end{array}$ & \multicolumn{2}{|c|}{ So individual efferets } & \multicolumn{2}{|c|}{$\begin{array}{l}\text { Individual affects with ondo- } \\
\text { genoms initial conditions }\end{array}$} \\
\hline \multicolumn{5}{|c|}{ 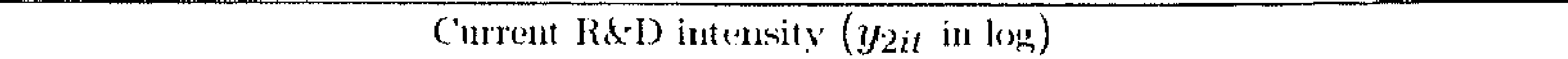 } \\
\hline Past RdD intensity $(y / 2, i t-1)$ & $0.417^{* *}$ & $(0.027)$ & $-11.1172^{f}$ & $(0.043)$ \\
\hline Lagened size (in long) & $-(1.027$ & $(0.053 .3)$ & $-(0.0)(15)$ & $(0.065)$ \\
\hline Drimanal pull & $0.372^{* *}$ & $(0.110)$ & $10.27 .4^{* *}$ & $(0.100)$ \\
\hline Inmsation cooperation & 0.073 & $(0.116)$ & 0.010 .2 & $(0.111)$ \\
\hline Tredinolugy push & $0 . .1111^{* *}$ & $(0.124)$ & $0.35 .52^{* *}$ & $(0.120)$ \\
\hline Subridies & $0.676^{* *}$ & $(0.1 * 21)$ & $0.515 * *$ & $(0.119)$ \\
\hline Intererept & $-3.7 \times 1^{* *}$ & $(0.345)$ & $-6.1017^{* *}$ & $(0.131)$ \\
\hline \multicolumn{5}{|c|}{ Ext rat parameters } \\
\hline$\sigma_{1 x_{2}}$ & - & - & $1.5 .5 \% * *$ & $(0.100)$ \\
\hline$\sigma_{f 2}$ & $1.5 \times 11^{* *}$ & $(0.0336)$ & $1.121 * *$ & $(0.045)$ \\
\hline$\mu_{l_{2,11}}$ & - & - & $-4.533 .1^{* *}$ & $(0.001)$ \\
\hline$\sigma_{y_{i_{1}(1}}$ & - & - & $2.11 .4^{* *}$ & $(0.063)$ \\
\hline$\rho_{y_{2} n_{3} x_{y_{1}}}$ & - & - & $0.1912^{* * *}$ & $(0.0 ; 30)$ \\
\hline Number of observations & \multicolumn{4}{|c|}{942} \\
\hline Log-likelihomel & \multicolumn{2}{|c|}{$-1 \times(i 2.153$} & \multicolumn{2}{|c|}{$-: 3036.110$} \\
\hline
\end{tabular}

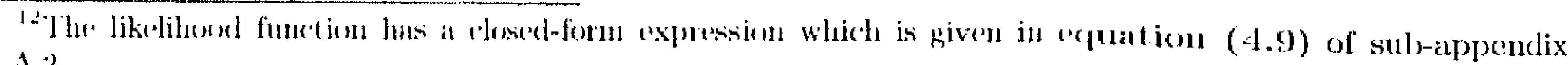
1.1 .2
} 
This chapter summarizes the main findings of the thesis and discusses the limitations and recommondations for future research.

\subsection{Summary}

We have studied the dynamics of inmovation in Dutch manufacturing using three waves of the Community Innovation Survey, and found persistence of innovation when considered on the input side and a lack of persistence when considered on the output side. In other words, firms that have persistent innovation or R\&D activities may not be guaranteed to persistently introduce new or improved products and/or processes into the market. Hence, the hypothesis of cxistence of sunk costs in firms' imnovation or R\&D activities is supported by the results, while Mansficld's (1968) hypothesis of "succcss breeds success" is rejected. Furthermore, while there is strong evidence of dynamics of R\&D investments, the sign of the effect of past $R \& D$ investments on current $R \& D$ investments does not seem to be well-determined. Indeed the positive effect identified in Chapter 4 seems to contradict the negative effect found in Chapter 6. Finally, past share of sales of incremental and radical product innovations conditions current share of sales of incremental and radical product innovations. To the extent that innovation output is not persistent, we interpret this result as a rather lengthy enjoyment by innovators of their old innovations. 
Wo have also studied the role of firm olserved and mobserved heterogeneity in the innovation gronesis. In Chayter 2. we have fonnd that the high-tech and low-tech categories of industries, and the wood industry have different imovative behavior, and that the industries in cach category have the same innovative behavior in the sense that. the parancters of the Inodel for the industries in that category are identical with the exception of the interepts. Unobserved individual effects play a significant role in the probability of introducing new or impreved products and/or processes into the market, and in the share of sales of incremental and radical product innovations (cf. Chapters 4 and 5). In Chapter 6, the individual effects are shown to have a significant role in the decision to engage in innovation activities, in the amount of R\&D investments and in the share of innovative sales of innovative firms.

Finally, we have found evidence of nonlinearity in that the different stages of the process are interrelated. The decision to introduce new or improved products and/or processes into the market and the share of sales of incremental and radical product innovations are interrelated (cf. Chapters 2,4 and 5). There is also interrelationship between the decision to cngage in imnovative activities, the anomnt of $R \& D$ investments and the share of innovative sales (cf. Chapter 6 ). The interrolationship operates mostly through the individual effects.

As for the econometric results, the Monte Carlo investigation with regard to the behavior in finite samples of the method proposed in Chapter 3 shows that using Wooldridge's (2005) solution to deal with the dependence between the initial conditions and the individual effects is successful in recovering the parameters of a process that generates the datat according to a stationary process. It is also shown that incorrectly ignoring the individual effects, or the dependence between the initial conditions and the individual effects results in an overestimation of the coefficients of the lagged dependent variables. This phenomenon was confirmed when studying the persistence of innovation output. When the individual effects were ignored or exogenous initial conditions (assuming no correlation between the individual effects and the initial conditions) were assumed, we found strong persistence of innovation output which then vanished when we accounted for the individual effects and endogenous initial conditions. However, we still found persistence in engaging in R\&D or innovation activities after accounting for the individual effects and endogenous initial conditions. Hence, there is spurious persistence of innovation when considered on the output side and true persistence when considered on the input side. Finally, when estimating the dynamic type 3 tobit model of incremental and radical innovations using both the Hexkman (1981b) and 
the Wooldridge (2005) approach of handling the initial conditions, we found that the two approaches yield similar results in terms of the coefficients of the strictly exogenous variables while some differences arise in the coefficients of the lagged dependent variables and the individual effects.

\subsection{Limitations and further research}

The first limitation of the thesis is that we have little information about non-innovative firms, resulting in a very restricted sct of explanatory variables of the likelihood of engaging in innovative activities or in achieving product and/or process innovations. Secondly, the pancl is rather short $(T=3)$ which may explain in part the lack of true persistence in achieving product and/or process imnovations in Chapter 4, and why we were unable to identify a positive effect of past $R \& D$ investments on current $R \& D$ investincnts when we accounted for individual effects and endogenous initial conditions. Third, there is onc-year overlap between two consecutive waves of the Dutch CIS which was not taken into account. Hence, to the extcnt that respondents answer this survey consistently, the overlap would tend to bias the results towards persistence in being a product and/or process imnovator. As no evidence of persistence is found, it may be concluded that the effect of the overlapping year is not important. Fourth, in the nodel of Chapter 6, R\&D intensity and the share of imnovative sales were assumed to be correlated only through the individual effects and the idiosyncratic errors. A natural extension is to include $R \& D$ intensity in the set of explanatory variables of the equation of the share of immovative sales and vice versa, hence allowing for a direct effect of R\&D investments on inmovation output and a feedback effect of innovation output on R\&D investments. A next step to the three-equation dynamic tobit-type model would be to include $R \& D$ intensity as a regressor in the immovation equation. Finally, the model could be extended so as to link the dynamics of the imnovation process to that of an economic performance (e.g. productivity) along the lines of Crépon et al. (1998). However, estimating the resulting model allowing for dynamics and unobserved individual effects is a formidable task to achieve. 


\section{Bibliography}

Abramovitz, M. AND I. Stegun (1964): Handbook of Mathematical Functions with Formulas, Graphs, and Mathematical Tables, Washington, D.C..: National Bureau of Standards Applied Mathematics, US Govermment Printing Office.

Aghion, P. AND P. HowitT (1992): "A Model of Growth Through Creative Destruction," Econometrica, 60, 323-351.

Ahn, S. C. AND P. SCHMIDT (1995): "Efficient Estimation of Models for Dynamic Panel Data," Journal of Econometrics, 68, 5-27.

AI, C. AND C. CHEN (1992): "Estimation of a Fixed Effects Bivariate Censored Regression Model," Economics Letters, 40, 403-406.

Almus, M. And D. Cznrnitzki (2003): "The Effects of Public R\&D Subsidies on Firms' Imnovation Activities: The Casc of Eastern Germany," Journal of Business and Economic Statistics, 21, 226-236.

Amemrya, T. (1984): "Tobit Models: A Survey," Journal of Econometrics, 24, 3-62.

Anderson, T. W. AND C. Hsino (1981): "Estimation of Dynamic Models with Error Components," Journal of the American Statistical Association, 76, 598-600.

(1982): "Formulation and Estimation of Dynamic Models Using Panel Data," Journal of Econometrics, 18, 47-82. 
Arellano, M., O. Bover, and J. M. I.abenga (1999): "Autoregressive Models with Sanple Selectivtiy for Pand Data," in Analysis of Panels and Limited Dependent Variable Models, ed. by C. Hsiao, K. Lahiri, L.-F. Lee, and M. H. Pesaran, Cambridge: Cambridge University Press.

Arellano, M. ANd B. Honoré (2001): "Panel Data Models: Some Recent Developments," in Handbook of Econometrics, ed. by J. J. Heckman and E. Leamer, Amsterdam: North Holland, vol. 5.

Askildsen, J. E., B. H. Baltagi, And T. H. Holmás (2003): "Wage Policy in the Health Care Sector: A Panel Data Analysis of Nurses' Labour Supply," Health Economics, $12,705-719$.

Baldwin, J. R. and G. Gellatly (2000): "A Firm-Based Approach to Industry Classification: Identifying the Knowledge-Based Economy," in Doing Business in a Knowledge-Based Economy. Facts and Policy Challenges, ed. by L. A. Lefebvre, E. Lefebvre, and P. Mohnen, Boston, Mass: Kluwer Academic Publishers.

Blundell, R., R. Griffith, and J. van Reenen (1995): "Dynamic Count Data Models of Technological Imnovation," The Economic Journal, 105, 333-344.

-...- (1999): "Market Share, Market Valuc and Innovation in a Panel of British Manufacturing Firms," Revieu of Economic. Studies, 66, 529-554.

Breschi, S., F. Malerba, nNd L. Orsenigo (2000): "Technological Regimes and Schumpeterian Patterns of Innovation," The Economic Journal, 110, 388-410.

Brouwer, E. AND A. H. Kleinknecht (1996): "Determinants of Innovation: A Micro Econometric Analysis of Three Alternative Innovative Output Indicators," in Determinants of Innovation: The Message from New Indicators, ed. by A. H. Kleinknecht, London: Macmillan Press.

Butler, J. S. AND R. Mofritt (1982): "A Computationally Efficient Quadrature Procedure for the One-Factor Multinomial Probit Model," Econometrica, 50, $761 \cdot 764$.

Cabngnols, A., C. Gay, and C. Le Bas (1999): "'How Persistently do Firms Immovate?" 
An Evolutionary View. An Empirical Application of Duration Models," CNRS Collection Les Cahiers de l'Innovation no. 00001.

Cefrs, E. (2003a): "Is there Persistence in Innovative Activities?" International Journal of Industrial Organization, 21, 489-515.

(2003b): "Persistence in Innovation and Profitability," Rivista Internazionale di Scienze Sociali, 1, 19-37.

Cefis, E. AND M. Ciccaret.li (2005): "Profit Differentials and Innovation," Economics of Innovation and New Technology, 14, 43-61.

Cefis, E. And O. Marsidi (2005): "A Matter of Life and Death: Innovation and Firm Survival," Industrial and Corporate Change, 14, 1167-1192.

Cefis, E. And L. Orsenigo (2001): "The Persistence of Imnovative Activities A CrossCountries and Cross-Sectors Comparative Analysis," Research Policy, 30, 1139-1158.

Cinamberlain, G. (1980): "Analysis of Covariance with Qualitative Datia," Review of Economic Studies, 47, 225-238.

Charluer, E., B. Melenbera, And A. van Soest (2001): "An Analysis of Housing Expenditure Using Semiparametric Models and Pancl Data," Journal of Econometrics, $101,71-107$.

Cohen, W. M. and S. Klepper (1996): "A Reprise of Size and R\&D," The Economic Journal, 106, 925-951.

Cohen, W. M. And D. A. Levinthal (1989): "Innovation and Learning: The Two Faces of R\&D," The Economic. Journal, 99, 569-596.

Contoyannis, P., A. M. Jones, And N. Rice (2004): "The Dynamics of Health in the British Household Panel Survey," Journal of Applicd Econometrics, 19, 473-503.

Crépon, B. AND E. DUGUet (1997): "Estimating the Immovation Function from Patent Numbers: GMM on Count Panel Data," Journal of Applied Econometrics, 12, 243-263. 
Crépon, B., E. Duguet, and I. Kabla (1996): "Schumpeterian Conjectures: A Moderate Support from Various Innovation Measures." in Determinants of Innovation: The Message? from New Indicators. ed. by A. H. Kleinknecht. London: Macmillan.

Crépon. B.. E. Duguet, anj J. Mairesse (1998): "Research and Development. Innovation and Productivity: An Econometric Analysis at the Firm Level," Economics of Innovation and Neu, Technolog!y, 7, 115158.

Czarnitzki, D. And A. Filer (2002): "Do Inmovation Subsidies Crowd Out Private Investment? Evidence from the German Service Sector," Applied Economics Quarterly (Konjunkturpolitik), $48,1 \cdots 25$.

Duguet. E. And S. Monjon (2002): "Creative Destruction and the Tmovative Core: Is Innovation Persistent at the Firm Level?" UCL Discussion Paper 02-07.

Dustmann. C. and M. E. Rochina-Barrachina (2000): "Selection Correction in Panel Data Models: An Application to Labour Supply and Wages," IZA Discussion Paper No. 162.

Flaic;. G. AND M. StTadrer (1994): "Success Breeds Success. The Dynamics of the Innovation Process," Empirical Economics, 19, 55.68.

Forrest. J. E. (1991): "Models of the Process of Technological Innovation." Technology Analysis and Strategic Management, 3. 439453.

Fotouhı, A. R. (2005): "The Initial Conditions Problem in Longitudinal Binary Process: A Simulation Study," Simulation Modelling Practice and Theory, 13, 566-583.

Gayle, G.-L. And C. Viauroux (2007): "Root-N Consistent Semiparametric Estimators of a Dynamic Pancl-Sample-Selection Model," Journal of Econometrics, forthcoming.

Geroski, P. A. (1989): "Entry, Innovation and Productivity Growth," The Review of Economics and Statistics, 71, 572-578.

Geroski, P. A., J. van Reenen, and C. F. Walters (1997): "How Persistently do Firms Innovate?" Rescarch Policy, 26, 33 -48. 
Greene, W. (2004a): "The Behaviour of the Maximum Likelihood Estimator of Limited Dependent Variable Models in the Presence of Fixed Effects," Econometrics Journal, 7, $98-119$

- (2004b): "Convenient Estimators for the Panel Probit Model: Further Results,"

Empirical Economics, 29, 21-47.

Griliches, Z. (1990): "Patent Statistics as Economic Indicators: A Survey," Journal of Economic Literature, 28, 1661-1707.

Gritiches, Z. And J. Matresse (1984): "Productivity and R\&D at the Firm Level," in RED, Patents and Productivity, ed. by Z. Griliches, Chicago: University of Chicago Press, $339-374$.

Gullkey, D. K. and .J. L. Murphy (1993): "Estimation and Testing in the Random Effects Probit Model," Journal of Econometrics, 59, 301-317.

HAL,L, B. AND F. HAYnshi (1989): "Research and Development as an Investment," NBER Working Paper No. 2973.

Hall, B. H., Z. Griliches, and J. A. Hausman (1986): "Patents and R and D : Is there a Lag?" International Economic Review, 27, 265283.

Hatzichronoglou, T. (1997): "Revision of the High-Technology Sector and Product Classification," Working Paper.

Hausman, J. A. And D. A. Wise (1979): "Attrition Bias in Experimental and Panel Data: Tho Gary Income Maintenance Experiment," Econometrica, 47, 455-474.

Heckman, J. J. (1979): "Sample Selection Bias as a Specification Error," Econometrica, 47, $153 \cdots 162$.

(1981a): "Hetcrogeneity and State Dependence," in Studies in Labor Markets, ed. by S. Rusen, University of Chicago Press, 91-139.

(1981b): "The Incidental Parameters Problem and the Problem of Initial Conditions in Estimating a Discrete Time-Discretc Data Stochastic Proccss," in Structural Analysis of Discrete Data with Econometric Applications, ed. by C. F. Manski and D. McFadden, Cambridge, MA: MIT Press, 179195. 
_.___. (1981c): "Statistical Models for Discrete Panel Data," in Structural Analysis of Discrete Data with Econometric Applications, ed. by C. F. Manski and D. McFadden, Cambriclge, MA: MIT Press, 114-178.

HeCKMAN, J. J. AND T. E. MACURDY (1980): "A Life Cycle Model of Fcmale Labour Supply," Review of Economic Studies, 47, $47-74$.

Hollenstein, H. (1996): "A Composite Indicator of a Firm's Innovativeness. An Empirical Analysis Based on Survey Data for Swiss Manufacturing," Research Policy, 25, 633 -645.

Honoré, B. E. AND E. Kyriazidou (2000a): "Estimation of Tobit-Type Models with Individual Specific Effects," Econometric Revicus, 19, 341360.

- ......- (2000b): "Pancl Data Discrete Choice Models with Lagged Dependent Variables," Econometrica, 69, 839-874.

Hsiao, C. (2003): Analysis of Panel Data, Cumbridge University Press, $2^{m l}$ ed.

Janz, N., H. LoÖF, AND B. PETers (2004): "Firm Level Innovation and Productivity: Is there a Common Story Across Countries," Problems and Perspectives in Management, \#2.

JANZ, N. AND B. PETERs (2002): "Innovation and Innovation Success in the German Manufacturing Sector: Econometric Evidence at Firm Level," ZEW Working Paper.

Kaiser, U. AND H. C. Kongsted (2004): "True Versus Spurious State Dependence in Firm Performance: The Case of West German Exports," ZEW Discussion Paper, No. 04-81.

Kleinknecht, A., K. VAN Montfort, And E. Brouwer (2002): "The Non-Trivial Choice between Innovation Indicators," Economics of Innovation and New Technology, 11, 109121.

KLETTE, T. J. (1996): "R\&D, Scope Economies, and Plant Performance," RAND Journal of Economics, 27, 502-522.

Kline, S. J. And N. Rosenberg (1986): "An Overview of Innovation," in The Positive Sum Strategy. Harnessing Technology for Economic Growth, ed. by R. Landau and N. Rosenberg, Washington DC: The National Acadeny Press. 
Klomp, L. AND G. VAN LeeUWen (2001): "Linking Innovation and Firm Purformmance: A New Approach," International Journal of the Economics of Business, 8, 343304.

KyRInzidou, E. (1997): "Estimation of a Panel Data Sample Selection Model," Econometrica, 65, 1335-1364.

- - (2001): "Estimation of Dynamic Panel Data Sample Selection Mlodels," Review of Economic Studics, 68, 543-572.

LabeagA, J. M. AND E. MArTŕnez-Ros (2005): "Persistence and Ability in the Innovation Decisions," FEDEA Working Paper No. 16.

LAcH, S. (2002): "Do R\&D Subsiclies Stimulate or Displace Private R\&D," Journal of Industrial Economics, 50, 369-390.

LANCASTER, T. (2000): "The Incidental Parameter Problem Since 1948," Journal of Econometrics, 95, 391-413.

LeE, M.-J. (2001): "First-Difference Estimator for Panel Censored-Selection Models," Economics Letters, 70, 43-49.

Lööf, H. AND A. Heshmati (2002a): "Knowledge Capital and Performance Heterogcneity: A Firm-Level Innovation Study," International Journal of Production Economics, 76, 6185.

(2002b): "On the Relationship betwecn Innovation and Performance: A Sensitivity Analysis," SSE/EFI Working Paper Series in Economics and Finance no. 446.

Máñez Castillejo, J. A., M. E. Rochina-Barrachina, A. Sanchis Llopis, and J. A. SANCHIS LlOPIS (2004): "A Dynamic Approach to the Decision to Invest in R\&D: The Role of Sunk Costs," Mimeo.

MAdDAla, G. S. (1983): Limiled-Dependent and Qualitative Variables in Econometrics, Cambridge: Cambridge University Press.

MagnaC, T. (2004): "Panel Binary Variables and Sufficiency: Generalizing Conditional Logit," Economelrica, 72, 1859-1876. 
Matresse, J. And P. Mohnen (2001): "To Be or Not To Be Innovative: An Exercise in Measirement," STI Revicu Special Issue on New Science and Technology Indicators, 27, $103-129$.

Marresse. .J. And M. Sassenou (1991): "R\&D and Productivity: A Survey of Econometric Studies at the Firm Level," STI Review, OECD, 8, 9-46.

Malerba, F. And L. Orsenigo (1996): "Schumpeterian Patterns of Innovation are Technology-Specific," Research Policy, 25, 451-478.

- - (1999): "Technological Entry, Exit and Survival: An Empirical Analysis of Patent Data," Research Policy, 28, 643-660.

MANSField, E. (1968): Industrial Research and Technological Innovation: An Econometric. Analysis, New York.

Mohnen, P. And M. Dagennis (2001): "Towards an Innovation Intensity Index. The Case of Cis 1 in Denmark and Ireland," in Innovation and Firm Performance: Econometric Explorations of Survey Data, ed. by A. Kleinknecht and P. Mohnen, London: Palgrave.

Neyman, J. AND E. L. Scott (1948): "Consistent. Estimates Based on Partially Consistent Observations," Econometrica, 16, 1-32.

Nijman, T. And M. Verbeek (1992): "Nonresponse in Panel Data: The Impact on Esti1nates of a Life Cycle Consumption Function," Journal of Applied Econometrics, 7, 243257.

OECD (1997): OECD Proposed Guidelines for Collecting and Interpreting Technological Innovation Data, Oslo Manual, Paris: OECD, $2^{\text {nd }}$ ed.

-_. (1998): Technology, Productivity and Job Creation: Best Policy Practices, Paris: OECD.

(1999): Science, Technology and Industry Scoreboard. Benchmarking KnowledgeBased Economies, Paris: OECD.

Pakes, A. And Z. Griliches (1984): "Patents and R\&D at the Firm Level: A First Look," in RED, Patents, and Productivity, ed. by Z. Griliches, University of Chicago Press, 73-88. 
PavitT, K. (1984): "Sectoral Patterns of Technical Change: Towards a Taxonomy and a

Theory," Rescarch Policy, 13,343*373.

Peters, B. (2005): "Persistence of Innovation: Stylised Facts and Panel Data Evidence," ZEW Discussion Paper, No. 05-81.

Pianta, M. (2004): "Tnnovation and Employment," in The Oxford Handbook of Innovation, ed. by J. Fagerberg, D. C. Mowery, and R. R. Nelson, Oxford University Press, chap. 21.

Pickles, A. R. AND R. B. Dnvies (1991): "The Empirical Analysis of Housing Careers: A Revicw and a General Statistical Modelling Framework," Environment and Planning A, $23,465-484$.

Rabe-Hesketh, S., A. Skrondal, and A. Pickles (2005): "Maximum Likelihood Estimation of Limited and Discrete Dependent Variable Models with Nested Random Effects," Journal of Econometrics, 128, 301-323.

Raymond, W., P. Mohnen, F. Palm, and S. Schim van der LoefF (2004): "An Empirically-Based Taxonomy of Dutch Manufacturing: Imnovation Policy Implications," CESifo Working Paper, No. 1230.

Ridder, G. (1990): "Attrition in Multi-Wave Panel Data," in Panel Data and Labor Market Studics, ed. by J. Hartog, G. Ridder, and J. Theeuwes, North-Holland, Amsterdam.

Roberts, P. W. (2001): "Innovation and Firm-Level Persistent Profitability: A Schumpeterian Framework," Managerial and Decision Economics, 22, 239-250.

Rochina-Barrachina, M. E. (1999): "A New Estimator for Panel Data Sample Selection Models," Annales d'Economic et de Statistiques, 55-56, 153 182.

Romer, P. M. (1990): "Endogenous Technical Change," The Journal of Political Economy, $98, \mathrm{~S} 71-\mathrm{S} 102$.

Rosett, R. N. (1959): "A Statistical Model of Friction in Economics," Econometrica, 27, 141-146.

SCHERER, F, M. (1967): "Research and Development Resource Allocation under Rivalry," Quarterly Journal of Economics, 81, 359-394. 
Semykina, A. And J. M. Wooldridge (2005): "Estimating Pand Data Models in the Presence of Endogeneity and Solection: Theory and Application," Unpublished working papor, Michigan State University.

Stein, J. C. (1997): "Waves of Creative Destruction: Firm-Specific Learning-by-Doing and the Dynamics of Innovation," Review of Economic Studies, 64, 265-288.

Trromas, A. (2000): Econométrie des Variables Qualitatives, Paris: Dunod.

Utterback, J. M. (1971): "The Process of Technological Innovation within the Firm," Academy of Management Journal, 14, 75-88.

(1994): Mastering the Dynamics of Innovation: How Companies Can Seize Opportunities in the. Face of Technological Change, Boston: Harvard Busincss School Press.

Utterback, J. M. and W. J. Abernathy (1975): "A Dynamic Modol of Process and Product Innovation," Omega, 3, 639-656.

VAN Leeuwen, G. (2002): "Linking Imnovation to Productivity Growth Using two Waves of the Community Innovation Survey," OECD Science, Techology and Industry Working Papers, 2002/8, OECD Publishing.

VelLA, F. (1998): "Estimating Models with Sample Selection Bias: A Survey," The Journal of Human Resources, 33, 127-169.

VetuA, F. AND M. Verbeek (1998): "Whose Wages do Unions Ratise? A Dynamic Model of Unionism and Wage Rate Determination for Young Men," Journal of Applied Econometrics, 13, 163-183.

_.._ (1999): "Two-Step Estimation of Panel Data Models with Censored Endogenous Variables and Selection bias," Journal of Econometrics, 90, 239-203.

Verbeek, M. (1990): "On the Estimation of a Fixed Effects Model with Selectivity Bias," Economic Letter's, 34, 267-270.

Wooldridge, J. M. (1995): "Selection Corrections for Panel Data Models Under Conditional Mean Independence Assumptions," Journal of Econometrics, 68, 115-132. 
- (2005): "Simple Solutions to the Initial Conditions Problem in Dymamic Nonlinear Panel Data Nodels with Unobserved Heterogeneity." Journal of Applicd Econometrics, 20. 3954.

Zabec, J. E. (1992): "Estimating Fixed and Random Effects Models with Selectivity," Economics Letters, 40, 269-272. 
Abernathy, 3

Abramovitz, 58

Aghion, 63

Alnı, 70

Ai, 36, 37

Alnuls, 113

Amomiya, 6, 33, 39, 42, 67

Anderson, 77, 79-81, 85, 122

Arellano, 37-39

Askildsen, 36, 37

Baldwin, 10, 28

Blundell, 98, 113

Breschi, 98

Brouwer, 4, 24-26, 67, 112

Butler, 43, 119

Cabagnols, 68

Cefis, 1, 65, 67, 68, 73

Chamberlain, 40

Charlier, 37,38

Chen, 36,37

Ciccarelli, 65, 67
Cohen, 111, 112

Contoyannis, 80

Crépon, 4, 23-25, 28, 64, 66, 68, 97, 111, 114, 116,125

Czarnitzki, 113

Dagenais, 25, 112

Davies, 86

Duguet, $5,66-68,76,78$

Dustmamn, 36, 37

Fier, 113

Flaig, 4, 67, 68, 78, 98

Forrest, 3, 5

Fotouhi, 87

Gayle, 37, 38

Gellatly, 10, 28

Geroski, 63, 68

Greene, 34, 40

Griliches, 1, 2, 66

Guilkey, 34

Hall, 1, 4, 98 
Hatzichronoglou, 9

Hausman, 35, 37

Hayashi, 1, 4, 98 $79,86,87,91,9396,124$

Heshmati, 4, 64, 114

Hollenstein, 10

Honoré, 35 37, 39, 70

Howitt, 63

Hsia. , 40, 77, 79 $81,85,122$

$\operatorname{Janz}, 4,24,25,64,112,114$

Kaiser, 86

Kleinknecht, 2, 4, 24-26, 67, 112

Klepper, 111

Klette, 4, 98

Kline, 3, 5, 97

Klomp, 5, 12, 13, 64, 112, 114

Kongsted, 86

Kyriazidou, 35-38, 70

Lööf, 4, 64, 114

Labeaga, 98

Lach, 27, 113

Lancaster, 40, 100

Lec, 36,37

Leeuwen, 12, 13, 64

Levinthal, 112

Máñez Castillojo, 67, 68, 78, 98, 110

MaCurdy, 36, 37, 40

Maddala, 12

Magnac, 40
Mairesse, 1, 4, 5, 12-14, 25, 67, 112

Malerba, $68,73,98$

Mansfield, 2, 1, 64, 98, 123

Marsili, 1

Martínez-Ros, 98

Moffitt, 43, 119

Mohnen, 4, 5, 12 14, 25, 67, 112

Monjon, 5, 66-68, 76, 78

Murphy, 34

Neyman, 40

Nijman, 35, 37, 85

OECD, $2,9,10,13,27$

Orsenigo, $68,73,98$

Pakes, 1

Pavitt, 10

Peters, $4,5,25,67,68,78,86,110,112,114$

Pianta, 64

Pickles, 86

Rabe-Hesketh, 46, 48

Raymond, 13

Ridder, 35,37

Roberts, 63

Rochina-Barrachina, 36, 37

Romer, 63

Rosenberg, 3, 5, 97

Rosett, 12

sample selection model, 34, 38

panel data, 30

Sassenou, 1 
Scherer, 4

Schmidt, 70

Scott, 40

Semykina, 36,37

Stadler, 4, 67, 68, 78, 98

Stegun, 58

Stein, 4, 98

subsidies, 25

Thomas, 12

Utterback, 1, 3

van Leeuwen, $5,28,67,98,111,112,114$

Vella, $34,36,37,86$

Verbeck, $35 \cdot 37,85,86$

Viauroux, 37, 38

Wise, 35,37

Wooldridge, 6, 7, 33-37, 40, 41, 56, 65, 68, 70, $71,86,87,91,9396,98,100,124$,

125

Zabel, 35, 37 


\section{Samenvatting}

Techmologische imnovatie wordt erkend als ecn factor zeer belangrijke in de groei van ondernemingen, zowel als creatieve kracht voor de groei en als vernietigende kracht die diezelfde ondernemingen aan de concurrentio blootstelt. In de kenniseconomie, innovatie speelt ook een positieve rol in de overleving van bedrijven. Nieuwe producten en nieuwe processen worden voortdurend op de markt gebracht en dwingen bedrijven om zich aan te passen als zij in het spel willen blijven. On de economische groei te bevorderen, werkgelegenheid en milieuduurzaamheid, de overheden zijn meer en meer bezorgd over het bevorderen van de imovatie van firma's maar hebben niet altijd liet juiste recept om hun doel te berciken. Het is vandaar zeer belangrijk om te begrijpen wat bedrijven innovatief maakt, hoe lang het duurt voordat innovatiestimulans hun vruchten afwerpen, hoe lang het duurt voor $O \& O$, proef productie en eerste lancering van nieuwe producten om succesvol te worden, en ten slotte hoe lang het duurt tussen eerste verschijning van producten op de markt en de verbeteringen van economische prestaties in de ondernemingen. En van de moeilijkheden die door beleidsvormers in het verleden werden ondervonden is de meting van innovatie. In de jaren ' 80 voelden de geleerden en de statistici in innovatic een groeiende ontevredenheid met het zuivere bestaan van O\&Oof octrooigegevens om imnovatie te analyseren. Het gebruik van de van O\&O of van het octrooi gegevens alleen laat immers belangrijke aspecten van het innovatieproces weg omdat O\&O slechts cén van diverse imnovatie-inputs is en sommige soorten technologie niet patentecrbaar zijn. Vandaar, onder bescherming van OESO, werd het handboek van Oslo geschreven om een nieuw soort onderzoek te leiden, het imovaticonderzoek dat in Europa bekend staat als CIS. In dit onderzoek, de ondervraagden worden gevraagd om informatio te geven over de 
input. de ontput en de gedrags- en organiwatorische climensies van hum innovaties. Voor de inputhant, gregevens over de nitgaven van O\&O en over andere inmovatienitgaven naast O\&O (zoals productontwerp. profef productie. opleiding van werknemers. en de marktanalyse) worden verzamold. Voor de output lant. diverse marktinnovatieindicatoren (in tegenstelling tot octrooien) zijn beschikbatr, namelijk de verklaring of een onderneming een nieuw product of een proces heeft geintroduceerd, het percentage verkoop toe te schrijven anm stapsgewijs of beduidend betere of nienwe producten of het andeel van de opbrengsten van innovatieve producten die nienw zijn voor de onderneming of zelfs voor de industrie. Op de andere dimensies van innovatie hobben wij binaire gegevens op of $R \& D$ ononderbroken en in samenwerking met anderen is gedatan an categorische gegevens op de bromen van kemnis, de redenen tot het vernienwen. de watargenomen belemmeringen naar innovatic on de walargenomen kracht van verschillende mechanismen on zich de voordelen van innovatie toe te oigenen.

Verscheidene golven van de CIS werden gelanceerd sinds cle eerste uitgave die van het handboek van Oslo in 1992 en maken het gebruik van paneclgegevens mogelijk bij het antalyseren van het innovatieproces. Het doel van deze thesis is de dynamica van innovatie in Nederlandse bewerkingsbedrijven te bestuderen met bedrijfsgegevens van dric golven van de CIS betreffende de periodes 1994-1996, 1996-1998. cn 1998-2000. Neer specifiek, deze thesis heeft tot doel om vragen te beantwoorden met betrekking tot de tot nu toe zelden onderzochte dynamica van innovatie met gebruikmaking van de CIS, zoals de persistentie van innovatie die aan zowel de input als de outputkant wordt bekeken, het cffect van de afgelopen investeringen van $O \& O$ op de huidige investeringen van $O \& O$, het effect van afgelopen aandeel in totale verkoop van innovatieve verkoop op huidig aandeel in totale verkoop van innovatieve verkoop, en de rol van bedrijvenheterogeniteit in het innovatieproces. Vandaar, de hypothesen van "succes kweckt succes", de "dynamische schaalvoordelen" en het bestaan van "sunk-costs" in de innovatioactiviteiten van firma's kumnen worden getest. Do thesis heeft ook tot doel om empirische modellen te ontwikkelen die op andere types van economische paneelgegevens kumen worden toegepast die gelijkaardige kenmerken als de CIS- gegevens hebben, vandaar bijdragen tot de grociende econometrische literatuur over (dynamische) paneelgegevens.

Hoofflstuk 2 bestudeort de graad van homogeniteit van imovatief gerlrag om empirisch de industrie- categorisatie van Nederlandse bewerkingsbedrijven te bepalen die voor beleidsdoeleinden kan worden gebruikt. Voor elk van de olf Nederlandse verwerkende industrie dic op niveau met tweo cijfers wordt bepaald, wij schatten twee-grens tobit model met steekproef- 
selectic dic het besluit tot innovatie door ondernemingen verklaart on, voor vernieuwers, de intensiteit van innovatic, gemeten door het aandeel innovaticve verkopen. Door het model voor elke industrietak afzonderlijk te schatten, mogelijke verschillen in het innovatiugedrag tussen verschillende bedrijfstakken kumnen worden verklaard. Verder, binnen die bedrijfstakken, verklaren wij onopgemerkte heterogeniteit door "niet-vernieuwers", "proces-alleen vernieuwers", productvernieuwers en "grote" productvernicuwers anders te behandelen. En de hypothese van homogeniteit van vernieuwend gedrag over industrieën is getest met cen waarschijnlijkheid verhouding test die drie soorten categorieën van industrieën in Nedcrlandse productiebedrijven aan hot licht brengt, namelijk high-tech, laag-technologie on de hout industrie die schijnen verschillend te zijn van de overige inclustrieën.

Hoofdstuk 3 onderzoekt door middel van een Monte Carlo simulatic het gedrag van de maximale waarschijnlijkheid schatter van dynamische panelen gegevensuithreidingen van het type 2 en type 3 tobit modellen met ongemerkte individuele effecten (misschien gecorreleerde met de verklarende variabelen) in elk vergelijking. De individucle resultaten worden aangenomen willekeurig te zijn en een normale distributic te volgen, zijn " uit gen̈ntegreerd" van de gezamenlijke dichtheidsfunctie voor de gegevens en individuele effecten. En het beginvoorwaarden probleem is opgelost met gebruik van recente "eenvondige oplossingen" die erin bestaat de individuele effecten van elk periode te schrijven als een lineaire functie van de strikt exogene verklarende variabelen en de beginvoorwaarden. De resulterende waarschijnlijkheidsfunctie bevat een twee-dimensionale onbepaalde integraal die geëvalueerd kan worden met gebruik van twee opeenvolgende Gauss-Hermite benaderingen. In de Monte Carlo experimenten, de "twee-stappen" Gauss-Hermite kwadratuur werkt goed voor een aantal integratiepunten zo klein als twee. Daarom de maximale waarschijnlijkhcid schatting van de parameters in een willekeurige-effecten dynamische steekproef model is mogelijk en zou denkbaar geïntegreerd kumnen worden als cen commando in een algemeen gebruikt softwarepakket zoals Stata.

In Hoofdstuk 4 passen wij het dynamische type toe dat 2 tobit van Hoofdstuk 3 op een model van innovatic dat de persistent van innovatie en de dynamica van het aandeel van innovatievee verkopen in Nederlandse productiobedrijven onderzoekt. Wij vinden dat de persistentie van imnovatie onecht is in de zin dat, wannecr ongemerkte individuele effecten en de beginvoorwaarden op de juiste manier behandeld zijn, de persistente van innovatie verdwijnt. Meer bepaald, succesvol zijn in voorgaande innovaticactiviteiten heeft geen verhogende invloed op de waarschijnlijkheid van de succes in buidige innovatieactiviteiten. Nochtans, voor- 
gaand aandeel van innovatieve verkoop beïnvloedt huidig aandeel van imovatieve verkoop, loewol maar in beperkte mate.

Hoofdstuk 5 beschouwt een altcrnatieve weg van behandeling van het van de beginvoorwaarden, die in het specificcren een model voor de eerste voorwaarde bestaat, met gegeven individuele voorwaarden en de strikt exogene verklarende variabelen. Dit model wordt dikwijls aangenomen als gelijkwaardig met het onderliggende model van het blijvende proces te zijn. Wij passen dan de benadering toe om het dynamische type 2 tobit model te schatten dat als in Hoofdstuk 4 wordt gespecificeerd. Vandaar studeren we claarom de gevoeligheid van de persistentie vall imovatie naar de behandeling van de beginvoorwaarden. Wij vinden dat het ontbreken van persistentie robuust is op het (gepast) behandeling van de beginvoorwaarde.

In Hoofdstuk 6 verlengen wij het model van Hoofdstuk 4 door het toevoegen van een dercle vergelijking van $O \& O$ investeringen. Meer bepaald onderzoeken wij gezamenlijk de dynamica van de boslissing om te investeren in innovatieactiviteiten, dat van O\&O intensiteit en het aandeel van innovatieve verkopon. Wij gebruiken dezelfde schattingsmethode als in Hoofdstuk 3 uitgebreid tot een steelproef selectie model met twee regressie vergelijkingen en een selectie vergelijking. De"drie-stapppen" Gauss-Hermite kwadratuur wordt nu vereist om de waarschijnhijkheid functic te evaluercn. De resultaten wijzen op de aanwezigheid van een dynamiek in het innovatieproces. Verder zijn de beslissing om zich bezig te houden inet imnovatieactiviteiten, R\&D intensiteit on het aandeel van innovatieve verkopen gecorreleerd, op zijn minst door de individuele effecten. Ten slotte, ongemerkte bedrijfsheterogeniteit speelt een belangrijke rol in het vernieuwing proccs. 


\section{Curriculum vitae}

Wladimir Raymond was born on May the $20^{\text {th }} 1978$ in Jacmel, Haiti. He attended secondary education at Centro Culturel Alcibiade Ponmayrac, one of the two French high schools of the country. In 1997, he obtained a scholarship and went to Strasbourg, France, where he studied mathematics and economics. In 2002, he obtained his MSc in Economic Analysis, and later that year, joined the Quantitative Economics Department of Maastricht University where he started bis PhD. Whadimir is currently employed as post-doc at the Department of Quantitative Economics, Maastricht. 